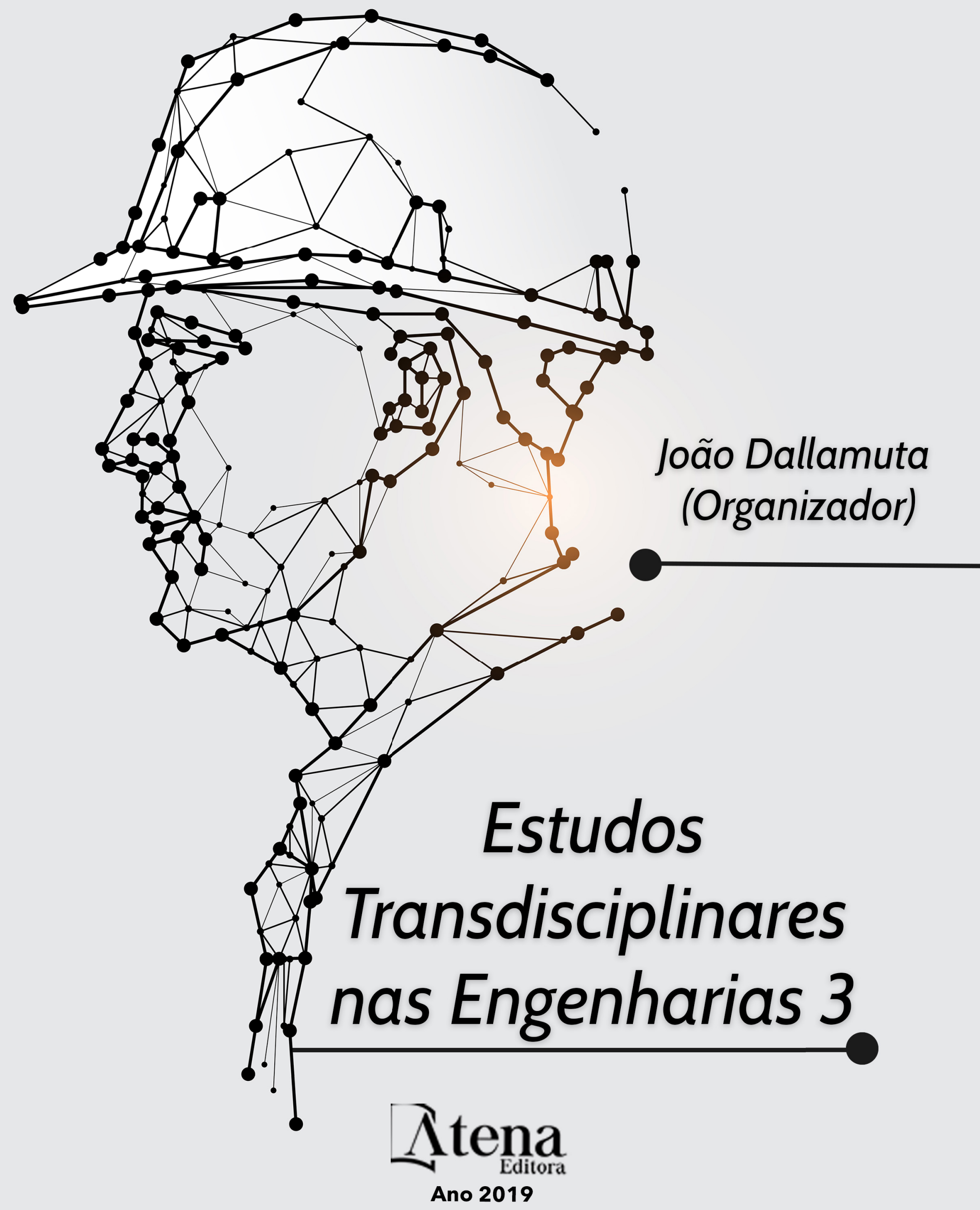


João Dallamuta

(Organizador)

\title{
Estudos Transdisciplinares nas Engenharias 3
}

\author{
Atena Editora
}




\author{
2019 by Atena Editora \\ Copyright $($ ) Atena Editora \\ Copyright do Texto @ 2019 Os Autores \\ Copyright da Edição (c) 2019 Atena Editora \\ Editora Chefe: Prof ${ }^{\mathrm{a}} \mathrm{Dr}^{\mathrm{a}}$ Antonella Carvalho de Oliveira \\ Diagramação: Rafael Sandrini Filho \\ Edição de Arte: Lorena Prestes \\ Revisão: Os Autores
}

Todo o conteúdo deste livro está licenciado sob uma Licença de Atribuição Creative Commons. Atribuição 4.0 Internacional (CC BY 4.0).

O conteúdo dos artigos e seus dados em sua forma, correção e confiabilidade são de responsabilidade exclusiva dos autores. Permitido o download da obra e o compartilhamento desde que sejam atribuídos créditos aos autores, mas sem a possibilidade de alterá-la de nenhuma forma ou utilizá-la para fins comerciais.

\title{
Conselho Editorial
}

\section{Ciências Humanas e Sociais Aplicadas}

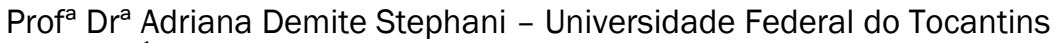

Prof. Dr. Álvaro Augusto de Borba Barreto - Universidade Federal de Pelotas

Prof. Dr. Alexandre Jose Schumacher - Instituto Federal de Educação, Ciência e Tecnologia de Mato Grosso

Prof. Dr. Antonio Carlos Frasson - Universidade Tecnológica Federal do Paraná

Prof. Dr. Antonio Isidro-Filho - Universidade de Brasília

Prof. Dr. Constantino Ribeiro de Oliveira Junior - Universidade Estadual de Ponta Grossa

Prof $^{\text {a }}$ Dr $^{\text {a }}$ Cristina Gaio - Universidade de Lisboa

Prof. Dr. Deyvison de Lima Oliveira - Universidade Federal de Rondônia

Prof. Dr. Edvaldo Antunes de Faria - Universidade Estácio de Sá

Prof. Dr. Eloi Martins Senhora - Universidade Federal de Roraima

Prof. Dr. Fabiano Tadeu Grazioli - Universidade Regional Integrada do Alto Uruguai e das Missões

Prof. Dr. Gilmei Fleck - Universidade Estadual do Oeste do Paraná

Prof $^{a} \mathrm{Dr}^{\mathrm{a}}$ Ivone Goulart Lopes - Istituto Internazionele delle Figlie de Maria Ausiliatrice

Prof. Dr. Julio Candido de Meirelles Junior - Universidade Federal Fluminense

Prof $^{a}$ Dr $^{a}$ Keyla Christina Almeida Portela - Instituto Federal de Educação, Ciência e Tecnologia de Mato Grosso

Prof $^{a}$ Dr $^{a}$ Lina Maria Gonçalves - Universidade Federal do Tocantins

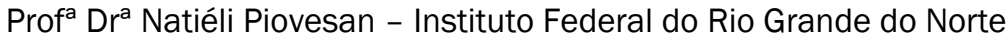

Prof. Dr. Marcelo Pereira da Silva - Universidade Federal do Maranhão

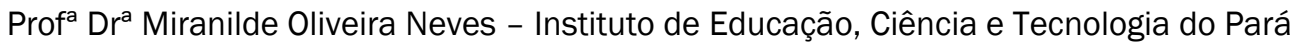

Prof $^{a}$ Dr $^{a}$ Paola Andressa Scortegagna - Universidade Estadual de Ponta Grossa

Prof $^{a}$ Dr $^{\text {a }}$ Rita de Cássia da Silva Oliveira - Universidade Estadual de Ponta Grossa

Prof $^{a}$ Dr $^{\text {a }}$ Sandra Regina Gardacho Pietrobon - Universidade Estadual do Centro-Oeste

Profa ${ }^{\text {Dra }}$ Sheila Marta Carregosa Rocha - Universidade do Estado da Bahia

Prof. Dr. Rui Maia Diamantino - Universidade Salvador

Prof. Dr. Urandi João Rodrigues Junior - Universidade Federal do Oeste do Pará

Prof $^{a}$ Dr $^{\mathrm{a}}$ Vanessa Bordin Viera - Universidade Federal de Campina Grande

Prof. Dr. Willian Douglas Guilherme - Universidade Federal do Tocantins

\section{Ciências Agrárias e Multidisciplinar}

Prof. Dr. Alan Mario Zuffo - Universidade Federal de Mato Grosso do Sul

Prof. Dr. Alexandre Igor Azevedo Pereira - Instituto Federal Goiano

Prof $^{a}$ Dr $^{a}$ Daiane Garabeli Trojan - Universidade Norte do Paraná

Prof. Dr. Darllan Collins da Cunha e Silva - Universidade Estadual Paulista

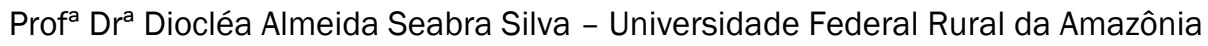

Prof. Dr. Fábio Steiner - Universidade Estadual de Mato Grosso do Sul

Prof $^{a}$ Dr $^{\text {a }}$ Girlene Santos de Souza - Universidade Federal do Recôncavo da Bahia

Prof. Dr. Jorge González Aguilera - Universidade Federal de Mato Grosso do Sul

Prof. Dr. Júlio César Ribeiro - Universidade Federal Rural do Rio de Janeiro

Prof ${ }^{a}$ Dr $^{a}$ Raissa Rachel Salustriano da Silva Matos - Universidade Federal do Maranhão

Prof. Dr. Ronilson Freitas de Souza - Universidade do Estado do Pará

Prof. Dr. Valdemar Antonio Paffaro Junior - Universidade Federal de Alfenas 


\section{Ciências Biológicas e da Saúde}

Prof. Dr. Benedito Rodrigues da Silva Neto - Universidade Federal de Goiás

Prof. Dr. Edson da Silva - Universidade Federal dos Vales do Jequitinhonha e Mucuri

Prof $^{a}$ Dr $^{a}$ Elane Schwinden Prudêncio - Universidade Federal de Santa Catarina

Prof. Dr. Gianfábio Pimentel Franco - Universidade Federal de Santa Maria

Prof. Dr. José Max Barbosa de Oliveira Junior - Universidade Federal do Oeste do Pará

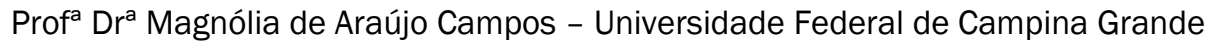

Prof $^{a}$ Dr $^{a}$ Natiéli Piovesan - Instituto Federacl do Rio Grande do Norte

Profa ${ }^{a}{ }^{a}$ Vanessa Lima Gonçalves - Universidade Estadual de Ponta Grossa

Prof $^{a}$ Dr $^{a}$ Vanessa Bordin Viera - Universidade Federal de Campina Grande

\section{Ciências Exatas e da Terra e Engenharias}

Prof. Dr. Adélio Alcino Sampaio Castro Machado - Universidade do Porto

Prof. Dr. Alexandre Leite dos Santos Silva - Universidade Federal do Piauí

Prof ${ }^{a}$ Dr $^{a}$ Carmen Lúcia Voigt - Universidade Norte do Paraná

Prof. Dr. Eloi Rufato Junior - Universidade Tecnológica Federal do Paraná

Prof. Dr. Fabrício Menezes Ramos - Instituto Federal do Pará

Prof. Dr. Juliano Carlo Rufino de Freitas - Universidade Federal de Campina Grande

Prof $^{a}$ Dr $^{a}$ Neiva Maria de Almeida - Universidade Federal da Paraíba

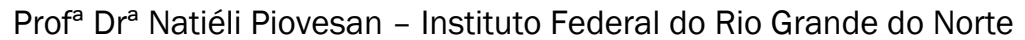

Prof. Dr. Takeshy Tachizawa - Faculdade de Campo Limpo Paulista

\begin{tabular}{|c|c|}
\hline & $\begin{array}{c}\text { Dados Internacionais de Catalogação na Publicação (CIP) } \\
\text { (eDOC BRASIL, Belo Horizonte/MG) }\end{array}$ \\
\hline \multirow[t]{2}{*}{ E82 } & $\begin{array}{l}\text { Estudos transdisciplinares nas engenharias } 3 \text { [recurso eletrônico] / } \\
\text { Organizador João Dallamuta. - Ponta Grossa, PR: Atena Editora, } \\
\text { 2019. - (Estudos Transdisciplinares nas Engenharias; v. 3) } \\
\text { Formato: PDF } \\
\text { Requisitos de sistema: Adobe Acrobat Reader } \\
\text { Modo de acesso: World Wide Web } \\
\text { Inclui bibliografia } \\
\text { ISBN 978-85-7247-682-9 } \\
\text { DOI 10.22533/at.ed.829190710 } \\
\text { 1. Engenharia - Pesquisa - Brasil. 2. Transdisciplinaridade. } \\
\text { I.Dallamuta, João. II. Série. } \\
\text { CDD } 620\end{array}$ \\
\hline & Elaborado por Maurício Amormino Júnior - CRB6/2422 \\
\hline
\end{tabular}

Atena Editora

Ponta Grossa - Paraná - Brasil

www.atenaeditora.com.br

contato@atenaeditora.com.br 


\section{APRESENTAÇÃO}

Se o Senhor Leonardo di Ser Piero da Vinci, por uma hipótese, fosse realizar concurso público para lecionar em uma universidade brasileira, teria enorme dificuldade para se adequar às regras do certame. Ele era cientista, matemático, inventor, engenheiro, médico anatomista, escultor, desenhista, arquiteto, artista plástico pintor poeta e músico. Dificilmente iria conseguir comprovar títulos ou se adequar as exigências.

Em termos mais modernos da Vinci teria conhecimentos transdisciplinares, um conceito para conhecimento de forma plural. Disciplinas e carreiras são divisões artificiais para facilitar a organização de cursos, currículos, regulamentações profissionais e facilitar a prática do ensino. Em tempos onde isto não existia, como na Grécia antiga ou na renascença havia o conhecimento plural na qual Leonardo da Vinci talvez seja o maior expoente.

Não se sugere que todo conhecimento transdisciplinar prove de um gênio, tão pouco que a organização por áreas do conhecimento não tenha seu valor. Apenas que a boa engenharia, em função da sua crescente complexidade trás necessidades de conhecimentos e competências transdisciplinares.

Neste livro são apresentados artigos abordando problemas de fornecimento de energia, agua potável, urbanismo, gestão de varejo, técnicas de projeto e fabricação, uma combinação de áreas e temas que possuem um ponto em comum; são aplicações de ciência e tecnologia que buscam soluções efetivas para problemas técnicos, como deve ser em tese a boa engenharia.

Aos pesquisadores, editores e aos leitores para quem em última análise todo o trabalho é realizado, agradecemos imensamente pela oportunidade de organizar tal obra.

Boa leitura!

João Dallamuta 


\section{SUMÁRIO}

CAPÍTULO 1

DEMANDA ENERGÉTICA E PROPOSTAS DE SOLUÇÕES NO ESTADO DE RORAIMA

Laura Vieira Maia de Sousa

Talyta Viana Cabral

Josiane do Socorro Aguiar de Souza de Oliveira Campos

Luciano Gonçalves Noleto

Maria Vitória Duarte Ferrari

Túlio Costa de Oliveira

DOI 10.22533/at.ed.8291907101

CAPÍTULO 2

15

ANÁLISE DO POTENCIAL DE CONSERVAÇÃO DE ENERGIA ELÉTRICA NA SANTA CASA DE AREALVA: SISTEMAS DE ILUMINAÇÃO E AR CONDICIONADO

José Rodrigo de Oliveira

Matheus Henrique Gonçalves

DOI 10.22533/at.ed.8291907102

CAPÍTULO 3

TRATAMENTO DA ÁGUA DE DRENAGEM PLUVIAL: UM MAL NECESSÁRIO?

Carlos Augusto Furtado de Oliveira Novaes

DOI 10.22533/at.ed.8291907103

CAPÍTULO 4

DIAGNÓSTICO DA GESTÃO DE ÁGUAS URBANAS DA CIDADE DE CARAÚBAS/RN

Larisa Janyele Cunha Miranda

Leonete Cristina de Araújo Ferreira Medeiros Silva

Rokátia Lorrany Nogueira Marinho

Guilherme Lopes da Rocha

Clélio Rodrigo Paiva Rafael

DOI 10.22533/at.ed.8291907104

CAPÍTULO 5

CALIBRAÇÃO DO FATOR DE ATRITO EM REDES DE ABASTECIMENTO DE ÁGUA

Alessandro de Araújo Bezerra

Renata Shirley de Andrade Araújo

Marco Aurélio Holanda de Castro

DOI 10.22533/at.ed.8291907105

CAPÍTULO 6 55

AVALIAÇÃO QUANTITATIVA DE ALTERNATIVAS DE USO E OCUPAÇÃO DO SOLO, SOB ASPECTOS DE RESILIÊNCIA A INUNDAÇÕES E REQUALIFICAÇÃO AMBIENTAL

Bruna Peres Battemarco

Lilian Marie Tenório Yamamoto

Aline Pires Veról

Marcelo Gomes Miguez

DOI 10.22533/at.ed.8291907106

CAPÍTULO 7 67

MANIFESTAÇÕES PATOLÓGICAS EM EDIFICAÇÕES PÚBLICAS: ESTUDO DE CASO EM ALGUNS 
TEATROS NA CIDADE DO RECIFE/PE

Carlos Fernando Gomes do Nascimento

Eduardo José Melo Lins

Eliana Cristina Barreto Monteiro

Amanda de Morais Alves Figueira

Cynthia Jordão de Oliveira Santos

Débora Cristina Pereira Valões

Edenia Nascimento Barros

George da Mota Passos Neto

Gilmar Ilário da Silva

Lucas Rodrigues Cavalcanti

Marcionillo de Carvalho Pedrosa Junior

Maria Angélica Veiga da Silva

Mariana Santos de Siqueira Bentzen

Paula Gabriele Vieira Pedrosa

DOI 10.22533/at.ed.8291907107

CAPÍTULO 8

80

CARACTERIZAÇÃO E ANÁLISE COMPARATIVA DE PÓS NANOMÉTRICOS OBTIDOS POR MOAGEM DE ALTA ENERGIA COM E SEM LIXÍVIA ÁCIDA PARA APLICAÇÃO EM FOTOCATÁLISE

Lucca Monteiro Silva Semensato

Luis Fernando Baldo Estorari

Maisa Helena Mancini

Veridiana Magalhães Costa Moreira

Ana Gabriela Storion

Eliria Maria de Jesus Agnolon Pallone

Tânia Regina Giraldi

Sylma Carvalho Maestrelli

DOI 10.22533/at.ed.8291907108

CAPÍTULO 9 93

CONTRIBUIÇÕES DA ANÁLISE DE REDES SOCIAIS A UM CLUSTER COMERCIAL PLANEJADO DE VAREJO DE AUTOMÓVEIS

Marco Aurélio Sanches Fittipaldi

Denis Donaire

DOI 10.22533/at.ed.8291907109

CAPÍTULO 10 106

IMPLEMENTAÇÃO DE UMA MESA DE VARREDURA XY E APRIMORAMENTO DO SISTEMA FOCAL DE UM APARELHO DE LITOGRAFIA

Raul de Queiroz Mendes

Arlindo Neto Montagnoli

DOI 10.22533/at.ed.82919071010

CAPÍTULO 11 120

ANÁLISE DO IMPACTO DO ROTEAMENTO FIXO EM REDES ÓPTICAS ELÁSTICAS TRANSLÚCIDAS CONSIDERANDO DIFERENTES CENÁRIOS DE DEGRADAÇÃO DA QUALIDADE DE TRANSMISSÃO

Arthur Hendricks Mendes de Oliveira

Helder Alves Pereira

DOI 10.22533/at.ed.82919071011

CAPÍTULO 12 128

ANÁLISE DO IMPACTO DO CASCATEAMENTO DE FILTROS ÓPTICOS CONSIDERANDO 
DIFERENTES ARQUITETURAS DE REDES ÓPTICAS ELÁSTICAS

Eloisa Bento Sarmento

Helder Alves Pereira

DOI 10.22533/at.ed.82919071012

CAPÍTULO 13 138

MODELAGEM DO EQUILÍBRIO SÓLIDO-LÍQUIDO NA SOLUBILIDADE DE ÁCIDOS GRAXOS EM SOLVENTES ORGÂNICOS

Bruno Rossetti de Souza

Vanessa Vilela Lemos

Jessica Cristina Silva Resende

Karolina Soares Costa

Marlus Pinheiro Rolemberg

Rodrigo Corrêa Basso

DOI 10.22533/at.ed.82919071013

CAPÍTULO 14 149

AVALIAÇÃO DE NANOPARTÍCULAS DE TIO 2 OBTIDAS POR MOAGEM DE ALTA ENERGIA COM E SEM LIXIVIAÇÃO
Lucca Monteiro Silva Semensato
Vanessa Vilela Lemos
Gabriel de Paiva
Luis Fernando Baldo Estorari
Maisa Helena Mancini
Ana Gabriela Storion
Eliria Maria de Jesus Agnolon Pallone
Tânia Regina Giraldi
Sylma Carvalho Maestrelli

DOI 10.22533/at.ed.82919071014

CAPÍTULO 15 161

ANÁLISE DA INTERFERÊNCIA DO PRÉ-AQUECIMENTO DO ÓLEO E DA TEMPERATURA DE TRANSESTERIFICAÇÃO NAS CARACTERÍSTICAS FÍSICO-QUIIMICAS DO BIODIESEL

Gerd Brantes Angelkorte

Ivenio Moreira da Silva

DOI 10.22533/at.ed.82919071015

CAPÍTULO 16 170

ASPECTOS BOTÂNICOS DOS ÓLEOS ESSENCIAIS

Sebastião Gomes Silva

Jorddy Neves da Cruz

Pablo Luis Baia Figueiredo

Wanessa Almeida da Costa

Mozaniel Santana de Oliveira

Rafael Henrique Holanda Pinto

Renan Campos e Silva

Fernanda Wariss Figueiredo Bezerra

Raul Nunes de Carvalho Junior

Eloisa Helena de Aguiar Andrade

DOI 10.22533/at.ed.82919071016

CAPÍTULO 17 182

ESTUDO DOS EFEITOS DAS VARIÁVEIS DE IMPRESSÃO 3D POR EXTRUSÃO SOBRE AS PROPRIEDADES MECÂNICAS DO ÁCIDO POLILÁTICO (PLA) OBTIDAS POR INTERMÉDIO DE 
ENSAIO DE TRAÇÃO

Camila Colombari Bomfim

Antônio Carlos Marangoni

Rafael Junqueira Marangoni

DOI 10.22533/at.ed.82919071017

CAPÍTULO 18 194

ESTUDO DO ASPECTO GEOMÉTRICO DOS CORDÕES DE SOLDA COMO ORIENTAÇÃO OPERACIONAL PARA O USO NA SOLDAGEM MAG ROBOTIZADA

Everaldo Vitor

Paulo Eduardo Alves Fernandes

DOI 10.22533/at.ed.82919071018

SOBRE O ORGANIZADOR .............................................................................. 206

ÍNDICE REMISSIVO .................................................................................... 207 


\section{DEMANDA ENERGÉTICA E PROPOSTAS DE SOLUÇÕES NO ESTADO DE RORAIMA}

Laura Vieira Maia de Sousa

Universidade de Brasília, Faculdade de

Engenharia Brasília - DF

Talyta Viana Cabral

Universidade de Brasília, Faculdade de

Engenharia Brasília - DF

\section{Josiane do Socorro Aguiar de Souza de} Oliveira Campos

Universidade de Brasília, Faculdade de

Engenharia Brasília - DF

Luciano Gonçalves Noleto Universidade de Brasília, Faculdade de

Engenharia Brasília - DF

Maria Vitória Duarte Ferrari

Universidade de Brasília, Faculdade de

Engenharia Brasília - DF

Túlio Costa de Oliveira

Universidade de Brasília, Faculdade de

Engenharia Brasília - DF

RESUMO: O estado de Roraima, localizado na região Norte do país, possui cerca de 576.568 habitantes e uma área total de $224.273,831 \mathrm{~km}^{2}$ e é, ainda, o único estado não interligado ao Sistema Interligado Nacional (SIN). Osuprimento energético da região é fornecido pelo complexo hidrelétrico de Guri/Macaguá, proveniente da Venezuela e que tem gerado conflitos quanto aos reincidentes apagões e à necessidade de acionamento das termoelétricas. As diretrizes para o Leilão 01/2019 foram determinadas pela Portaria do MME $n^{\circ} 131$, com objetivo de suprimento energético para Roraima. Nesse trabalho o objetivo principal foi identificar e avaliar as principais zonas de demanda energética do estado por meio da ferramenta QGIS e também apresentar as alternativas do Governo Federal para fornecimento do serviço de energia.

PALAVRAS-CHAVE: Demanda energética Roraima - Comunidades Rbemotas.

\section{ENERGY DEMAND IN THE STATE OF}

\section{RORAIMA}

ABSTRACT: The state of Roraima, located in the north of the country, has about 576,568 inhabitants and a total area of $224,273,831 \mathrm{~km}^{2}$ and is also the only state to be interconnected to the National Interconnected System. Since then, the region's energy supply is being hydrated by hydrocarbons from Guri / Macaguá, the country of Venezuela and its country has been the target of recidivists and the production needs of the thearmal industries. By Ordinance of the MME $n^{\circ} 131$, were defined as guideline for the Auction 01/2019 with the objective of energetic supply to Roraima.

KEYWORDS: Solar Energy. Wind power. Biomass. Renewable Energy. 


\section{I INTRODUÇÃO}

O estado de Roraima, localizado na região Norte do país, possui uma população estimada de 576.568 habitantes e uma área de 224.273, $831 \mathrm{~km}^{2}$. O Índice de Desenvolvimento Humano (IDH) é de 0,707 , sendo o $13^{\circ}$ do país (IBGE, 2018).

Em 26 de abril de 2002, foi estabelecida no Brasil a garantia de universalização de suprimento energético fornecidos pelo Estado pelo art. 14 da Lei n¹0.438 . Essa Lei dispôs sobre a expansão de fornecimento energético, criação do Programa de Incentivo às Fontes Alternativas de Energia Elétrica (Proinfa) e a Conta de Desenvolvimento Energético (CDE) e sobre a universalização do uso de energia elétrica a partir do serviço público (BRASIL, 2002).

Em 11 de novembro de 2003, um novo decreto possibilitaria o acesso à energia elétrica pelas comunidades rurais. Esse foi um dos maiores programas nacionais de fornecimento de energia elétrica às comunidades isoladas, o Programa "Luz Para Todos" (LPT) (Lei $n^{0}$ 4.783). Desde então, cerca de 206.081 famílias, identificadas no Censo de 2010, tiveram acesso ao benefício do LPT. Em 2017, de acordo com dados fornecidos pela Pesquisa Nacional por Amostra de Domicílios (PNAD), de 69,4 milhões de residências, cerca de 99,8\% foram atendidas com fornecimento de energia elétrica (MORAIS, 2019).

O estado de Roraima ainda não possui conexão ao Sistema Interligado Nacional (SIN). Desde o ano de 2001 mantém contrato com o país vizinho, a Venezuela, para fornecimento da demanda energética do estado. Sofrendo apagões desde 2016 e tendo que acionar termelétricas a custos fora do negociado, é necessário que se apresentem maneiras alternativas para garantia da segurança energética do estado (ANEEL, 2019).

O papel da Empresa de Pesquisa Energética - EPE também é promover estudos de atendimento as demandas energéticas, analisar as propostas de fornecimento e encaminhar para a aprovação do MME. As principais soluções propostas pela EPE estão apresentadas no Quadro 1.

1) Fornecimento de energia por termoeletricas com diesel importado pela Venezuela - desde 2001 esse arranjo funcionou, no entanto, as interrupções constantes devido aos problemas políticos da Venezuela tornaram inviável essa opção.

2) Interligação ao Sistema Interligado Nacional - devido as dificuldades associadas à travessia da Terra Indígena Waimiri Atroari, provocaram a suspensão da Licença Prévia em 2016 e o atraso no licenciamento, de forma que até o momento não há previsão para conclusão desse empreendimento;

3) Construção da UHE Bem Querer - Estudo de Inventário Hidrelétrico da Bacia do rio Branco, elaborado pela Empresa de Pesquisa Energética (EPE) entre 2007 e 2010. Ela atinge comunidades indigenas. A previsão de entrega do EIA/RIMA ao Ibama é 2021. 
4) ANEEL lançou a Consulta Pública ANEEL nº 007/2018, "Leilão de Eficiência Energética em Roraima", o objetivo de discutir o conceito do leilão de eficiência energética e o conjunto de metodologias e premissas utilizado na Análise de Impacto Regulatório de projeto piloto a ser realizado em Roraima. As diretrizes para realização do Leilão de Boa Vista foram estabelecidas pelo Ministério de Minas e Energia - MME com a publicação da Portaria MME n 512/2018, de 24 de dezembro de 2018, e da Portaria MME $n^{\circ}$ 134, de 13 de fevereiro de 2019. Entre 2018 a 2019 foi realizado o cadastramento das empresas. O número total de empresas cadastradas foram 156, de diversas capacidades, fontes energéticas e tecnologias. As propostas totalizam uma oferta de aproximadamente $6 \mathrm{GW}$. Dentre as diversas fontes participantes, destacaramse: fotovoltaica, eólica, gás natural, óleo combustível, óleo diesel, biomassa, biodiesel, biogás, além de soluções com armazenamento em baterias.

5) O primeiro estudo pela EPE visou a identificação de alternativas de atendimento de médio e longo prazo. Foram mapeadas as possíveis soluções de geração de energia elétrica para Roraima, tendo sido consideradas as fontes eólica, solar fotovoltaica, biomassa, biodiesel, PCH e UHE.

Em maio de 2019, foi realizado o leilão 01/2019 para suprimento da capital de Roraima, Boa Vista, e demais localidades. Os projetos para fornecimento de energia englobam usinas fotovoltaicas, de biomassa e biocombustíveis (ANEEI, 2019).

No entanto, a segurança em suprimento de energia elétrica do estado só poderá ser alcançada quando o estado for interligado ao sistema nacional. Dos cerca de 270 Sistemas Isolados existentes no Brasil, Boa Vista representa o maior de todos, com uma demanda máxima anual da ordem de $200 \mathrm{MW}$ atualmente.

Diante o exposto, é importante destacar que, o acesso à energia torna-se fator sine qua non para que objetivos econômicos, sociais e ambientais sejam atingidos a fim de que se obtenha um desenvolvimento sustentável (GOLDEMBERG, 2000).

Nesse contexto o presente trabalho propõe-se a avaliar e caracterizar as áreas urbanas das regiões do estado de Roraima, os potenciais energéticos associados às regiões apontadas, especificamente de biomassa, eólica, solar e hídrica utilizando a ferramenta de geoprocessamento QGIS, e propor discussões acerca da viabilidade dessas tecnologias a serem empregadas, visando a segurança energética da região.

\section{I REFERENCIAL TEÓRICO}

O referencial teórico apresenta, de maneira objetiva, caracterização populacional do estado de Roraima, bem como a sua situação energética atual. Por conseguinte, discorre sobre a proposição da Portaria do MME no 131, que determina as diretrizes do Leilão 01/2019 da ANEEL para suprimento do estado de Roraima com energias renováveis. 


\subsection{Caracterização Populacional}

Roraima é o estado com menor população do país, com um valor estimado de 576.568 habitantes. A densidade demográfica é de aproximadamente dois habitantes por quilômetro quadrado. Cerca de 76,6 \% da população reside em áreas urbanas e o restante em áreas rurais. Cerca de 50\% mora em Boa Vista (IBGE, 2010).

A população tem em sua composição brancos, negros, pardos e um número bastante considerável de indígenas, se comparado a outros estados brasileiros. Essa população indígena é formada por aproximadamente 46.106 pessoas, de origem nos seguintes povos: Yanomamis, Ingaricó, Macuxi, Patamona, Taurepang, WaimiriAtroari, Wai-Wai e Wapixana (FUNAI, 2019).

Devido ao intenso de fluxo de imigrantes venezuelanos nos últimos anos, o Estado possui atualmente a maior taxa de crescimento populacional do país, segundo a pesquisa de estimativa da população realizada pelo IBGE, somando entre 2017 e julho de 2018 aproximadamente 54 mil pessoas. As regiões que tiveram maior impacto com a imigração para o estado foi o município de Pacaraima e Boa Vista (IBGE, 2018).

\subsection{Caracterização Energética}

O Estado de Roraima é, ainda, a única unidade federativa do País não ligada ao Sistema Interligado Nacional. Desde 2001, o fornecimento energético do estado é realizado pela importação de energia elétrica do complexo hidrelétrico de Guri/ Macaguá, na Venezuela, e por termelétricas brasileiras.

Em 2001 o linhão de Guri foi construído Linhão e permite a transmissão de até 200 megawatts (MW) (Eletronorte, 2019), do país vizinho até a cidade de Boa Vista, capital do estado. De lá, essa carga pode ser distribuída por toda a extensão de Roraima. O estado também é abastecido, em casos de emergência, pela Usina Termelétrica Floresta, que possui 62 MW de potência instalada (Eletronorte, 2019).

No período de janeiro de 2016 a abril de 2018 ocorreram 82 desligamentos de, aproximadamente, cinquenta minutos cada, pelo fornecimento de energia do complexo hidroelétrico venezuelano. Esse fato ocasionou, então, o acionamento das termelétricas e custos não planejados.

Afora os apagões, a não interligação ao SIN também inviabiliza o fornecimento de energia elétrica às comunidades isoladas da região, dadas as dificuldades quanto à travessia da Terra Indígena Waimiri Atroari. Dispostos pela Lei $\mathrm{n}^{\circ}{ }^{12.111}$, de 9 de dezembro de 2009, os sistemas isolados, também, não são conectados. No ano de 2008, comunidades do Maranhão e da Bahia, foram conectadas ao SIN e, posteriormente, em 2009, os estados do Acre e Rondônia também foram interligados ao sistema (Lima, 2009).

O contrato com o complexo de Guri/Macaguá encerra em 2021 (EPE, 2019), contudo, diante a atual conjuntura, serão necessárias alternativas para que a população seja atendida, bem como as comunidades isoladas da região. Em junho de 
2016, de acordo com estudo realizado pela EPE (2017), estava sendo considerado o início das operações de um linhão de 500 kV, que ligará Manaus- AM a Boa Vista $\mathrm{RR}$, conectando o estado ao SIN. No entanto, empasses burocráticos com a empresa Transnorte Energia a fizeram desistir do contrato e, consequentemente, manter o estado isolado.

\subsubsection{Leilão 01/2019 Aneel - Suprimento a Boa Vista-Rr}

Diante dos problemas no suprimento energético de Roraima, e dos recorrentes blecautes (ANEEL, 2019), foi estabelecido um Grupo de Trabalho, deliberado pelo Ministério de Minas e Energia, e com participação da Agência Nacional de Energia Elétrica (ANEEL), da Empresa de Pesquisa Energética (EPE), do Operador Nacional do Sistema Elétrico (ONS) e da Câmara de Comercialização de Energia Elétrica (CCEE) a fim de que se pudesse avaliar os potenciais energéticos de Roraima, estudar e propor alternativas para suprimento da região (EPE;ONS, 2019).

Os estudos realizados pelos Grupo de trabalho apontam para um crescimento de $8 \%$ no mercado no estado, uma demanda de $230 \mathrm{MW}$ e cerca de $\mathrm{R} \$ 749$ milhões gastos na Conta de Desenvolvimento Energético (CDE) (ANEEL, 2019). No ano de 2018, a Conta de Consumo de Combustíveis (CCC) reembolsou R $\$ 211$ milhões dos $\mathrm{R} \$ 386$ milhões gastos (ANEEL, 2019).

Em maio de 2017 foi, então, elaborado um estudo de potencialidades energéticas para Roraima para que, no mês seguinte, pudesse ser avaliada a ocorrência de um leilão de energia elétrica (EPE; ONS, 2019). Em 13 de fevereiro de 2019, o MME estabelece as diretrizes para o leilão a partir da portaria MME $n^{\circ} 131$, cujo objetivo é a garantia de suprimento por até quinze anos.

\subsection{Uso e Ocupação do Solo Limitantes}

As leis 9.985/2000 e 1175/96 regulam a exploração de recursos ambientais para geração de energia em Unidades de Conservação e Terras Indigenas. É necessário a observância de alguns critérios quanto se trata dessas áreas.

\subsubsection{Unidades de Conservação}

As Unidades de Conservação (UC's) são administradas pelo ICMbio, bem como o resguardado pela Lei $n^{\circ}$ 9.985, de 18 de julho de 2000. Essa lei instituiu o Sistema Nacional de Unidades de Conservação da Natureza (SNUC) e determina critérios e normas para gestão e implementação destas UC's. Portanto, de acordo com a Lei ${ }^{\circ}$ 9.985, Art. 2º, inciso I, entende-se por Unidade de Conservação:

"[...]o espaço territorial e seus recursos ambientais, incluindo as águas jurisdicionais, com características naturais relevantes, legalmente instituído pelo Poder Público, com objetivos de conservação e limites definidos, sob regime 
A Lei n 9.985 caracteriza, também, os tipos de unidade de conservação, que são dois: Unidades de Proteção Integral e Unidades de Uso Sustentável.

A principal diferença entre as duas categorias de unidade de conservação é que, para as unidades de proteção integral, é permitida apenas a utilização indireta dos seus recursos naturais. E nas unidades de uso sustentável é permitida a utilização de parte dos seus recursos de maneira sustentável, concomitante à conservação da área e de sua natureza.

As principais classes de UC's são de proteção integral e uso sustentável. As unidades de proteção integral são subdivididas em cinco categorias que se seguem: Estação ecológica; Reserva biológica; Parque nacional; Monumento natural; Refúgio de vida silvestre.

Estas áreas de proteção integral têm em comum a impossibilidade de instalação de empreendimentos de qualquer natureza, como determina a Lei $n^{\circ}$ 9.985. Ou seja, são áreas cujo acesso permitido é apenas para pesquisa científica e manutenção do ecossistema local. Quanto às unidades de uso sustentável, tem-se: Área de Proteção Ambiental; Área de Relevante Interesse Ecológico; Floresta Nacional; Reserva Extrativista; Reserva de Fauna; Reserva de Desenvolvimento Sustentável; Reserva Particular do Patrimônio Natural.

O Decreto $n^{\circ} 4.340$, de 22 de agosto de 2002, que regulamenta os artigos 15, 17, 18 e 20 , da Lei $n^{\circ} 9.985$, referentes à área de proteção ambiental, floresta nacional, reserva extrativista e reserva de desenvolvimento sustentável determina que estas áreas são passíveis de autorização para exploração de produtos, subprodutos e serviços. Dessa forma, são áreas cujos potenciais deverão ser avaliados e possíveis empreendimentos poderão ser implementados.

A ocupação de área de florestas em Roraima representa $67 \%$ do estado, conforme dados do Instituto Nacional de Pesquisas Espaciais (Inpe) coletados por meio do sistema Prodes (Programa de Cálculo do Desflorestamento da Amazônia). Os resultados são referentes ao ano de 2012. O Estado possui grande parte do seu território demarcado como área indígena ou de preservação ambiental.

Atualmente, no estado de Roraima é possível localizar oito UC's, sendo três parques nacionais, três estações ecológicas e duas florestas nacionais. São elas: Parque Nacional do Monte Roraima, localizado no município de Uiramutã; Parque Nacional do Viruá, localizado no município de Caracaraí; Parque Nacional Serra da Mocidade, localizado no município de Caracaraí; Estação Ecológica de Maracá, localizada no município de Amajari; Estação Ecológica de Cacararaí, localizada no município de Caracaraí; Estação Ecológica do Niquiá, localizada no município de Caracaraí; Floresta Nacional de Roraima, localizada nos municípios de Mucajaí e Alto Alegre e Floresta Nacional do Anauá, localizada no município de Rorainópolis (ICMBio, 2019). 
Em 19 de dezembro de 1973 foi sancionada a Lei $n^{\circ} 6.001$ que dispõe do Estatuto do Índio. Seu propósito está em integrar e preservar as culturas e povos indígenas, bem como caracterizá-los quanto a sua interação com outras culturas. A lei, portanto, dispõe das seguintes caracterizações quanto aos índios: 1) Isolados - comunidades cujas informações são pouco conhecidas coletadas a partir de encontros eventuais; 2) Em vias de integração - mantém algum contato com outros grupos e acabam aceitando práticas diferentes das do seu convívio e englobando ao seu modo de vida; 3) Integrados - incorporados à comunhão nacional, mesmo que conservando seus costumes;

No capítulo III, quanto às áreas reservadas, essas também podem ser classificadas em: 1) Reserva indígena - área onde o grupo indígena tem como habitat, com todos os recursos para a sua subsistência; 2) Parque indígena - área cuja integração já permite assistência do estado sendo elas econômica, sanitária e educacional; 3) Colônia Agrícola Indígena - áreas que permitam a exploração agrícola.

Da área total do Estado de Roraima, que soma $225.116 \mathrm{Km} \mathrm{2,} \mathrm{101.710,15} \mathrm{km2}$ $(45,18 \%)$ estão distribuídos em trinta e duas Terras Indígenas, que ocupam quase a metade do Estado. Quatro destas áreas são contínuas e as demais demarcadas em ilhas. São ao redor de 38.000 indígenas pertencentes a oito etnias. Dos quinze municípios que formam o Estado todos apresentam presença de terras indígenas formando parte de seu território. Os municípios de Normandia, Uiramutã, Alto Alegre, Pacaraíma e Iracema apresentam mais de $70 \%$ de sua área composta por terras indígenas (IBGE, 2005).

\section{I METODOLOGIA}

Os passos metodológicos desse trabalho foram: pesquisa bibliográfica; levantamento, organização, armazenamento, tratamento dos dados e informações segundárias. Em seguida, foram elaboradas as cartas de demanda utilizando a ferramenta QGIS.

\subsection{Carta de Caracterização de Unidades de Conservação e Terras Indígenas}

Foi elaborada primeiramente uma carta a fim de, identificar e caracterizar as Unidades de Conservação em relação a suas categorias, Terras Indígenas e a disposição dos empreendimentos que suprem atual demanda energética do estado.

Para produção dessa carta foram utilizados dados do site i3Geo, plataforma de downloads de mapas do Ministério de Meio Ambiente - MMA, dados do IBGE, SIGEL - ANEEL que disponibiliza a localização de empreendimentos de geração de energia elétrica, ANA, FUNAI e DNIT. 
Para edição das camadas selecionadas, foi utilizada a ferramenta de interseção de geoprocessamento, na aba vetor do software QGis. Para melhor visualização de cada item na carta, as cores foram editadas utilizando convenção para cada tipo de camada de acordo com o gênero.

Nas Unidades de Conservação e Terras indígenas, foi realizado tratamento de gradiente de cores a fim de identificar a classificação de cada área quanto a sua disponibilidade de uso territorial. Além das camadas já citadas, também foram utilizadas as seguintes camadas mostradas no quadro abaixo:

- Principais Rodovias e Estradas - Identificar as vias de acesso aos principais centros e também as comunidades mais isoladas;

- Geração de energia - Conhecer os empreendimentos de geração de energia elétrica que abastece as regiões do estado;

- Linha de Transmissão - Identificar a localização da Linha de Transmissão vinda da Venezuela para suprimento de Boa Vista;

- Principais Rios e Massa de água - Caracterizar com um pouco mais de detalhes a disposição de rios, riachos e lagos do estado, para reconhecer geograficamente onde os possíveis empreendimentos poderão ser alocados.

\subsection{Carta de Demanda}

A Carta de Demanda Energética do estado de Roraima foi elaborada com dados fornecidos pelo IBGE (2016). Com a tabela de Domicílios Particulares Permanentes (DPP`s) sem energia elétrica, pela variável VAR046, disponibilizado pelo IBGE (2011), foi possível elaborar um gradiente de áreas sem energia elétrica no estado de Roraima por meio da união de dados na tabela de atributos da camada de microrregiões. Obtendo os dados de gradiente, foram adicionadas as seguintes camadas apresentadas no quadro a seguir:

- Principais rios - É necessário reconhecer o território a fim de que se saiba onde será possível alocar os empreendimentos propostos;

- Rodovias - É necessária para que se possa avaliar as regiões ótimas para transporte de combustível e empreendimentos, como de biomassa e biocombustíveis;

- TIS e UC's - Como avaliado anteriormente, as TI's e UC's possuem sua classificação quanto à possibilidade ou não de alocar empreendimentos nas regiões. Dessa forma, é preciso avaliar os locais possíveis de instalações de empreendimentos;

- Divisão estadual - Necessária para delimitar o estado;

- Localização de aglomerados rurais isolados - Necessária para melhor alocação de empreendimentos energéticos;

- Divisão do estado por microrregiões- A divisão estadual por microrregiões foi utilizada para que se pudesse avaliar as regiões sem energia elétrica. 
As microrregiões foram identificadas na tabela Domicílios.csv e, pela união de dados na tabela de DPP`s sem energia elétrica, foi possível graduá-las por percentuais e definir a quantidade de DPP`s sem energia elétrica.

Posteriormente, para que se pudesse atender às comunidades de áreas isoladas, foi necessário definir uma carga mínima de energia elétrica a ser fornecida em kWh/mês, pela definição de materiais eletrodomésticos definidos neste trabalho como essenciais para estas unidades consumidoras. Os requisitos listados para esta definição foram: Possibilidade de acesso à informação; Possibilidade de conservação de alimentos e vacinas; e Conforto do ambiente.

Dessa forma, foi calculada a demanda energética de cada uma destas microrregiões, possibilitando o dimensionamento dos possíveis empreendimentos próximos a essas regiões.

Depois foram criadas zonas de demanda de energia segundo as coindições dos consumidores.

\section{I RESULTADOS E DISCUSSÕES}

A partir do uso do software QGIS, e de extenso banco de dados, foi possível relacionar as principais áreas de análise do trabalho. A caracterização energética do local, bem como a localização das UC's e TI’s foi feita a partir de mapas cartográficos. Em seguida, o mapa de demanda da região, levando em consideração as áreas isoladas sem energia elétrica.

\subsection{Caracterização Energética Local de Uc's e Ti’s}

Por meio da carta produzida (Figura 1) foi possível identificar a disposição das Unidades de Conservação do Estado, sendo elas de Uso Integral e Uso Sustentável, e suas respectivas classificações quanto ao nível de proteção. 


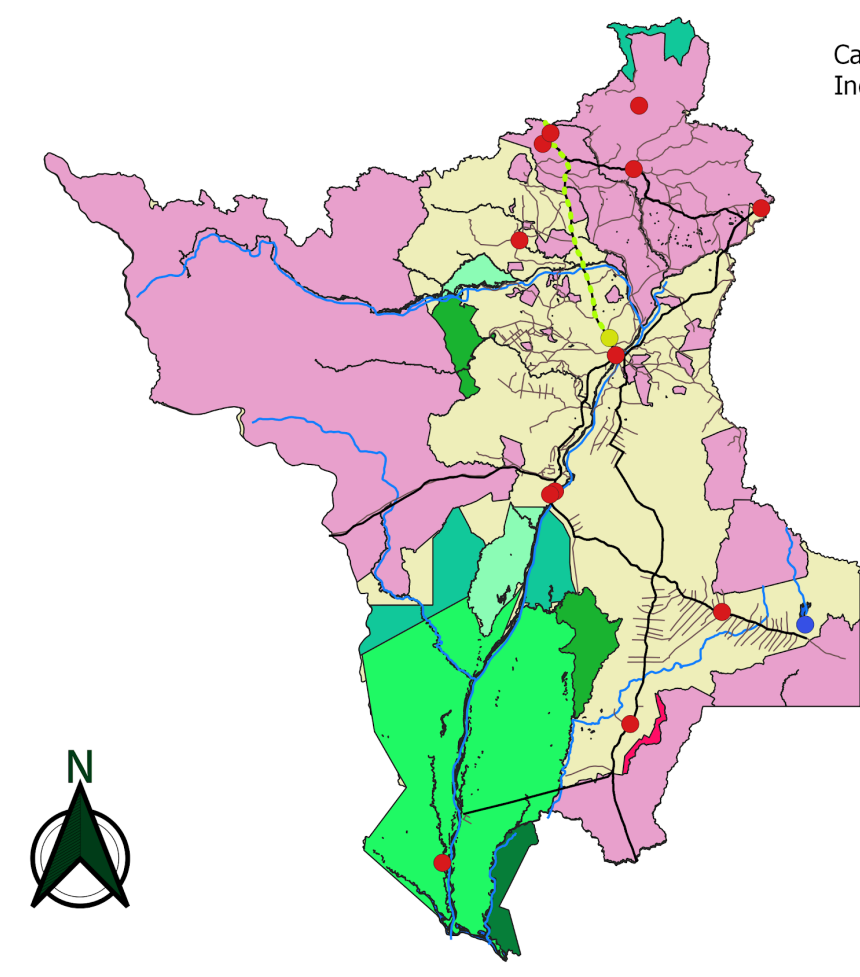

Carta de Unidades de Conservação, Terras

Indígenas e Caracterização Energética

- Termelétricas Combustíveis Fósseis

- Pequena Central Hidrelétrica

Subestação

- - Linha de Transmissão

- Principais Rodovias

- Estradas

- Principais Rios

$\square$ Massa de água

Unidade de Conservação de Proteção Integral

$\square$ Estação Ecológica

$\square$ Parque

Unidade de Conservação de Uso Sustentável

$\square$ Área de Proteção Ambiental

$\square$ Floresta

Reserva Extrativista

Reserva Particular do Patrimônio Natural

Territórios Indígenas

$\square$ Terras Isoladas

$\square$ Reservas Indígenas

$\square$ Roraima

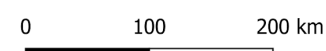

Figura 1. Carta de Unidades de Conservação, Terras Indígenas e Caracterização Energética.

Fonte: Do autor, 2019.

Com a camada de TI's dispostos na carta, foi constatado como eles ocupam grande área de terra do estado e como isso afeta e deixa mais sensível o estudo de potenciais energéticos para regiões sem acesso á energia elétrica dentro do estado. No levantamento de dados específicos, utilizando a tabela de atributos das camadas, foi identificado um território isolado de indígenas mais ao Sul e próximo de uma Área de Proteção Ambiental.

No que diz respeito á geração de energia elétrica, foram mapeadas usinas termelétricas a combustíveis fósseis, que como podemos ver, tem uma grande participação na matriz energética de Roraima e uma PCH no município de Caroebe. Boa Vista e algumas regiões próximas são abastecidas pela linha de transmissão vinda da Venezuela, como mostrado na figura do item de demanda energética que e a energia que vem pela linha é distribuída pela Subestação também localizada na região. Não foram identificados outros empreendimentos de geração, além dos já citados.

\subsection{Demanda Energética de Áreas Isoladas}

A Carta de Demanda do estado de Roraima foi elaborada no software QGIS a partir de camadas de microrregiões, UC's, TI's e dados de união quanto às DPP's sem energia elétrica (figura 2). 


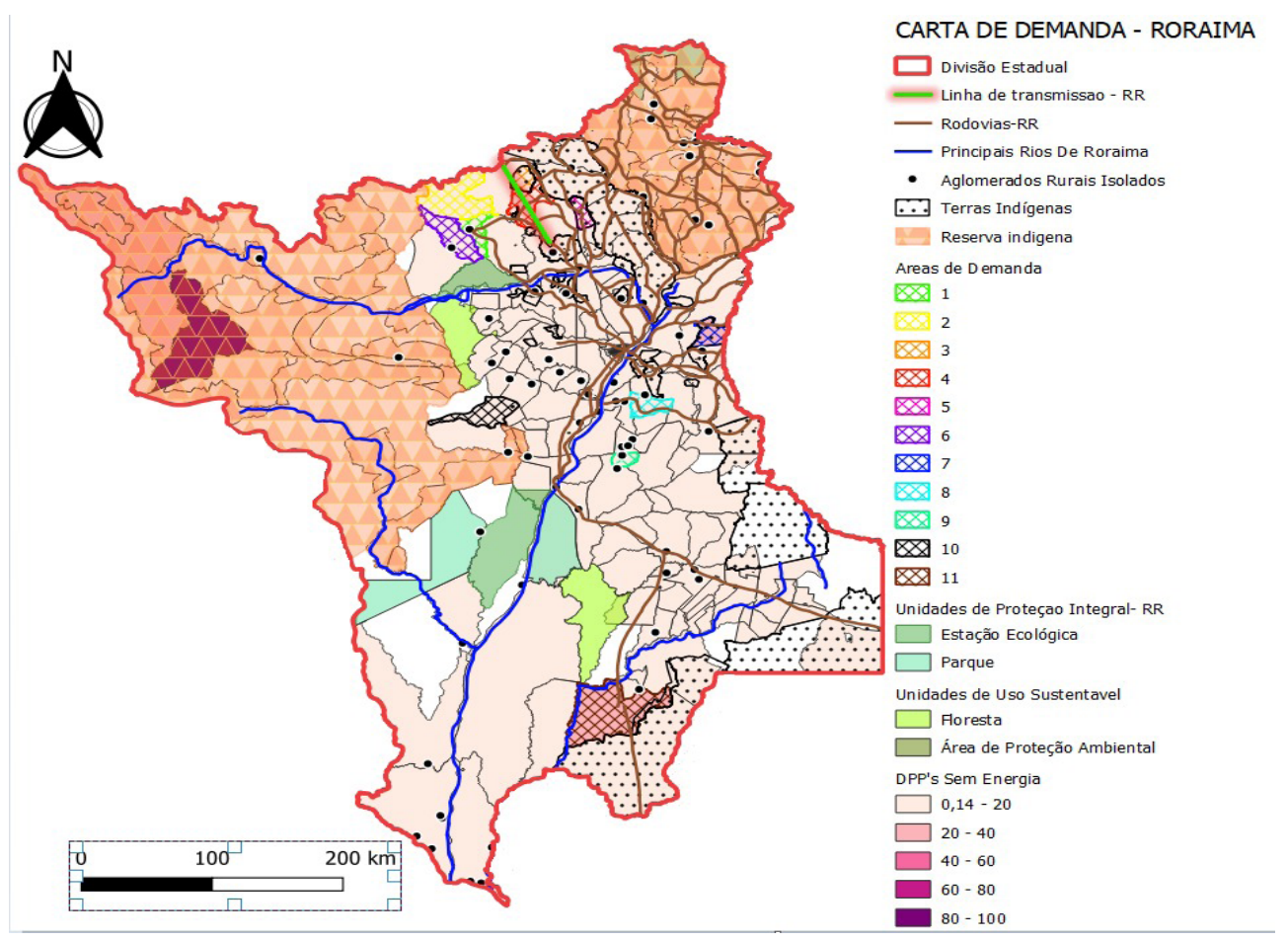

Figura 2. Carta de demanda - Roraima.

Fonte: Do autor (2019).

Os dados da Tabela 2 apresentam a graduação feita quanto à quantidade de DPP`s sem energia elétrica nas microrregiões do estado de Roraima.

\begin{tabular}{|c|c|c|c|}
\hline \multicolumn{5}{|c|}{ DPP's sem energia elétrica } \\
\hline Graduação & 1 a 20 [\%] & 20 a $40[\%]$ & 80 a $100[\%]$ \\
\hline Quantidade de domicílios & 1048 & 125 & 680 \\
\hline
\end{tabular}

Tabela 2. DPP`s sem energia elétrica.

Fonte: IBGE, 2011.

O desafio, contudo, é o de alcançar comunidades isoladas e sem energia elétrica, mas que estejam em áreas de possível acesso para alocação dos empreendimentos. Na Figura 2 as regiões com percentuais de $100 \%$ e de 20 a 40\% estão localizadas em regiões de reserva indígena, que estão localizadas na Reserva lanomâmi e Reserva Raposa Serra do Sol. Isso significa que é inviável alocar empreendimentos nestes locais, como já exposto anteriormente, por restrições legais.

Portanto, foram selecionadas zonas de demanda nas microrregiões localizadas em áreas fora das regiões de Reserva Indígena e de Áreas de Proteção Integral. Levando em consideração, num cenário hipotético, de que cada unidade consumidora seria composta por cinco integrantes, foi feito um levantamento dos eletrodomésticos necessários para subsistência (Tabela 3). 


\begin{tabular}{c|c|c|c|c}
\hline Aparelho & Potência (W) & Horas de uso por dia & Quantidade & Consumo [kWh/mês] \\
\hline Refrigerador RDE33 & - & - & 1 & 37,7 \\
\hline TV de 20' LG & 20 & 5 & 1 & 3 \\
\hline Ventilador Mondial & 70 & 8 & 1 & 16,8 \\
\hline Lâmpada Led Lightex & 5 & 8 & 5 & 6 \\
\hline & & & TOTAL: & 63,5 \\
\hline
\end{tabular}

Tabela 3. Carga por unidade consumidora.

Fonte: Do autor, 2019.

A carga necessária para suprir essas unidades consumidoras foi estimada em $63,5 \mathrm{kWh} / \mathrm{mês}$. O somatório dessas cargas por unidade consumidora nas microrregiões selecionada a demanda energética, é disposta na tabela 4 a seguir.

\begin{tabular}{|c|c|c|c|c|c|c|}
\hline Zona & $\begin{array}{c}\text { Código } \\
\text { Microrregião }\end{array}$ & Microrregião & Mesorregião & Município & $\begin{array}{l}\text { DPP's sem } \\
\text { energia }\end{array}$ & $\begin{array}{l}\text { Demanda } \\
\text { [kWh/mês] }\end{array}$ \\
\hline 1 & 140002705000007 & Boa Vista & \multirow{6}{*}{$\begin{array}{l}\text { Nordeste de } \\
\text { Roraima }\end{array}$} & Amajari & 25 & 1587,5 \\
\hline 2 & 140002705000009 & Boa Vista & & Amajari & 9 & 571,5 \\
\hline 3 & 140002705000011 & Boa Vista & & Amajari & 25 & 1587,5 \\
\hline 4 & 140002705000013 & Boa Vista & & Amajari & 9 & 571,5 \\
\hline 5 & 140002705000015 & Boa Vista & & Amajari & 5 & 317,5 \\
\hline 6 & 140002705000021 & Boa Vista & & Amajari & 95 & $6.032,5$ \\
\hline 7 & 140015905000009 & \multirow{3}{*}{$\begin{array}{l}\text { Nordeste de } \\
\text { Roraima }\end{array}$} & $\begin{array}{l}\text { Norte de } \\
\text { Roraima }\end{array}$ & Bonfim & 139 & $8.826,5$ \\
\hline 8 & 140017505000011 & & \multirow{2}{*}{$\begin{array}{l}\text { Norte de } \\
\text { Roraima }\end{array}$} & Cantá & 90 & 5.715 \\
\hline 9 & 140017505000015 & & & Cantá & 90 & 5.715 \\
\hline 10 & 140028205000016 & Caracaraí & \multirow{2}{*}{$\begin{array}{l}\text { Sul de } \\
\text { Roraima }\end{array}$} & Iracema & 84 & 5.334 \\
\hline 11 & 140047205000020 & $\begin{array}{l}\text { Sudeste de } \\
\text { Roraima }\end{array}$ & & Rorainópolis & 155 & $9.842,5$ \\
\hline & & & & & & \\
\hline
\end{tabular}

Tabela 4. Demanda das zonas selecionadas.

Fonte: Do autor, 2019.

\section{CONCLUSÃO}

O objetivo principal foi identificar e avaliar as principais zonas de demanda energética do estado por meio da ferramenta QGIS e também apresentar as alternativas do Governo Federal para fornecimento do serviço de energia. Esse objetivo atingindo por meio da elaboração de cartas.

Acredita-se que no decorrer do tempo a demanda energética de Roraima será atendida. No entanto, devido as suas dinâmicas territoriais a certeza de que se a sustentabilidade será considerada ainda é uma icógnita. 
Os potenciais de fontes eólica, solar fotovoltaica, biomassa, biodiesel, $\mathrm{PCH}$ e UHE deverão ser objetos de futuros estudos que podem ir um pouco além dos estudos da EPE.

\section{REFERÊNCIAS}

ANEEL. Leilão 01/2019. Suprimento a Boa Vista. Disponível em: <http://www2.aneel.gov.br/ aplicacoes/editais_geracao/documentos_editais.cfm? IdProgramaEdital=178>. Acessado em: junho de 2019.

Aneel. Leilão de Energia para Roraima contrata nove projetos, totalizando $R \$ 1,6$ bi de investimentos. 2019. Disponível em: <http://www.aneel.gov.br/sala-de-imprensa-exibicao-2// asset_publisher/zXQREz8EVIZ6/content/leilaodeenergiapararoraimacontratanoveprojetostotalizando r16bideinvestimentos/656877? inheritRedirect=falseredirect=http\%3A\%2F\%2Fwww.aneel. ov.br\%2Fsaladeimprensaexibicao2\%3Fp_p_id\%3D101_INSTANCE_zXQREz8EVIZ6\%26p_p_ lifecycle\%3D0\%26p_p_state3Dnormal\%26p_p_mode\%3Dview\%26p_p_col_id\%3Dcolumn2\%26p_p_ col_pos\%3D2\%26p_p_col_count\%3D3>. Acessado em: junho de 2019.

BRASIL, LEI No. DECRETO № 4.340, de 22 de agosto de 2002. Regulamentação dos artigos da Lei, n. 9.985, 2002.

BRASIL, Leis. Lei 6001 de 15 de janeiro de 1973. Dispõe sobre o Estatuto do Índio, 2014. CIVIL, Casa. Lei n 10.438 de 2002. Abril 26. 2002.

CIVIL, Casa. Lei n 4.873 de 2003. Novembro 11. 2003.

DE PESQUISA ENERGÉTICA, EPE-Empresa. Nota Técnica DEA 15/14-Inventário Energético de Resíduos Rurais. Rio de Janeiro, 2014.

Eletronorte. Geração: Roraima, 2019. Disponível em: <http://www.eletronorte.gov.br/opencms/ opencms/pilares/geracao/estados/roraima/>. Acessado em: junho de 2019.

EPE. Sistemas Isolados: Identificação de Alternativas de Atendimento - Médio e Longo Prazo, 2019. Disponível em: <http://www.epe.gov.br/pt/publicacoes-dados-abertos/publicacoes/roraimaplanejamento-energetico\#PARTE02>. Acessado em: junho de 2019.

EPE;ONS. Definição das características Elétricas para o Leilão de Suprimento a Roraima: Margens de escoamento, correntes de curto-circuito, requisitos elétricos mínimos. Março, 2019. Disponível em: <http://www2.aneel.gov.br/aplicacoes/editais_geracao/documentos_editais. cfm?ldProgramaEdital=178>. Acessado em: junho de 2019.

FUNAI. Modalidades de Terras Indígenas, 2019. Disponível em: <www.funai.gov.br/index.php/indiosno-brasil/terras-indigenas>. Acessado em junho de 2019.

GOLDEMBERG, José et al. (Ed.). World Energy Assessment: Energy and the challenge of sustainability. New York^ eNY NY: United Nations Development Programme, 2000.

ICMBIO. Unidades de Conservação - Amazônia. Disponível em: <www.icmbio.gov.br/portal/ unidadesdeconservacao/biomas-brasileiros/amazonia/unidades-de-conservacao-amazonia>. Acessado em: junho de 2019,

IBGE. Produção Agrícola Municipal - PAM. 2017. Disponível em: <https://www.ibge.gov.br/ estatisticas/economicas/agricultura-epecuaria/9117-producao-agricola-municipal-culturas-temporariase-permanentes.html?t=resultados> Acessado em: julho de 2019. 
IBGE. Estimativas de população, 2010. Disponível em: <https://www.ibge.gov.br/estatisticas/sociais/ populacao/9103-estimativas-de-populacao.html?edicao $=16985 \& \mathrm{t}=$ resultados $>$. Acessado em: junho de 2019.

IBGE. Panorama Cidades: Roraima, 2018. Disponível em: < https://cidades.ibge.gov.br/brasil/rr/ panorama>. Acessado em: junho de 2019.

IBGE. Projeto Levantamento e Classificação da Cobertura e do Uso da Terra. Rio de Janeiro, 2005. Disponível em: <https://biblioteca.ibge.gov.br/visualizacao/livros/liv95890.pdf>. Acessado em: junho de 2019.

INSTITUTO BRASILEIRO DE GEOGRAFIA E ESTATÍSTICA. Base de informações do Censo Demográfico 2010: resultados do universo por setor censitário. 2011.

INSTITUTO BRASILEIRO DE GEOGRAFIA E ESTATÍSTICA - IBGE. Panorama: Roraima, 2018. Disponível em:<https://cidades.ibge.gov.br/brasil/rr/panorama>. Acessado em: junho de 2019.

LIMA, Rogério Lúcio. Geração, Transmissão e Distribuição de Energia Elétrica. 2009.

Luz Para Todos. Secretaria de Governo, 2019. Disponível em: < http://www.secretariadegoverno. gov.br/iniciativas/internacional/fsm/eixos/inclusaosocial/luzparatodos?TSPD_101_R $0=e$ ec 11 a 24 c 9 b 833079 b 0 e 229 e 190 a e c 80 IU 800000000000000 $009 \mathrm{~d} 603 \mathrm{dbdffff00000000000000000000000000005cf48876}$ 00 d 742404 b 08282 a 9212 a b 200078 d a b fa a 8 a 5a5a2 a65ce9 6aa93 848c1f f7c7284c c5bec4 4a494 $0 \quad 822464$ 21df01083 02ad7c40a 2800cc2e2bb7 acaa93 5179c38a318d0d8be51a415ed47f6043fc5bb866cfd4a81338b0bc33ddad733988>. Acessado em: junho de 2019.

MORAIS, José Mauro de. Cadernos ODS: ODS 7: assegurar o acesso confiável, sustentável, moderno e a preço acessível à energia para todos: o que mostra o retrato do Brasil?. 2019.

SZKLAROWSKY, Leon Frejda. Lei 9985, de 2000-SNUC-Sistema Nacional de Unidades de Conservação da Natureza. Âmbito Jurídico. Rio Grande, II, n. 5, 2001 


\section{CAPÍTULO 2}

\section{ANÁLISE DO POTENCIAL DE CONSERVAÇÃO DE ENERGIA ELÉTRICA NA SANTA CASA DE AREALVA: SISTEMAS DE ILUMINAÇÃO E AR CONDICIONADO}

José Rodrigo de Oliveira

Faculdade de Tecnologia de Bauru

Bauru - São Paulo

Matheus Henrique Gonçalves

Faculdade de Tecnologia de Bauru

Bauru - São Paulo

RESUMO: A iluminação e a climatização em uma unidade de saúde são fatores importantes para o desenvolvimento das atividades em um ambiente hospitalar, desta maneira há necessidade de se buscar sistemas mais eficientes que possam proporcionar economia de energia elétrica tanto nos sistemas luminosos como nos de climatização. Em cada sistema analisado, buscou-se sempre a redução de consumo energético, proporcionando a melhoria significativa dos ambientes do prédio. O objetivo desta pesquisa foi a análise do potencial de conservação de energia elétrica na Santa Casa de Arealva, através de uma proposta de substituição dos sistemas de iluminação e climatização existentes, por sistemas mais eficientes. Percebe-se uma redução no consumo de energia elétrica de $25,84 \%$ nos sistemas de iluminação e $8,78 \%$ nos sistemas de climatização.

PALAVRAS-CHAVE: Conservação de Energia Elétrica; Eficiência Luminosa; Economia de energia.
ANALYSIS OF THE POTENTIAL OF

CONSERVATION OF ELECTRIC ENERGY IN

SANTA CASA DE AREALVA: LIGHTING AND

\section{AIR CONDITIONING SYSTEMS}

ABSTRACT: Lighting and air conditioning in a health unit are important factors for the development of activities in a hospital environment, so there is a need to look for more efficient systems that can provide electric energy savings in both light and air conditioning systems. In each system analyzed, we always sought to reduce energy consumption, providing a significant improvement of the building's environments. The objective of this research was the analysis of the potential of electric energy conservation in Santa Casa de Arealva, through a proposal to replace existing lighting and air conditioning systems, by more efficient systems. There is a reduction in electricity consumption of $25.84 \%$ in lighting systems and $8.78 \%$ in air conditioning systems.

KEYWORDS: Electric Power Conservation, Illumination, Energy Saving.

\section{I INTRODUÇÃO}

Nós prédios públicos, como em outras unidades, existem grandes oportunidades de redução de consumo de energia elétrica, 
principalmente através da utilização de equipamentos elétricos eficientes (OLIVEIRA, 2013).

Segundo Polo (2016), a iluminação em uma unidade hospitalar é responsável por cerca de $44 \%$ do consumo. As instituições de saúde podem reduzir os seus custos entre $30 \%$ e $50 \%$ realizando a substituição do seu sistema de iluminação por um sistema mais eficiente.

Quanto aos sistemas de refrigeração, estes também possuem um impacto bastante significativo de consumo de energia elétrica no ambiente hospitalar. Segundo o Programa Nacional de Conservação de Energia Elétrica - PROCEL (2010), o aparelho de ar condicionado do tipo janela possui um elevado consumo de energia elétrica, em comparação ao aparelho de ar condicionado do tipo Split.

Este trabalho tem como objetivo apresentar potencial de conservação de energia elétrica, em unidade de saúde, através de uma proposta de substituição dos sistemas de iluminação e climatização existentes na Santa Casa de Arealva, por sistemas eficientes, visando a redução do consumo de energia elétrica nesta unidade de saúde.

\section{I REFERENCIAL TEÓRICO}

\subsection{Iluminação}

Segundo Hélio Creder (2007), as lâmpadas elétricas, utilizadas nos sistemas de iluminação, podem ser pertencentes a três famílias:

a) Incandescentes;

b) Descargas (fluorescentes, luz mista, vapor mercúrio, vapor de sódio e vapor metálico);

c) Estado sólido - LED (Light Emitting Diode - Diodo Emissor de Luz).

O aspecto mais importante na hora da escolha de uma lâmpada é a sua eficiência luminosa, que é o quanto uma fonte de luz é capaz de converter energia elétrica em energia luminosa. A eficiência luminosa é medida em lumens por watt ( $\mathrm{Im} / \mathrm{W})$. Quanto maior for o rendimento luminoso, maior será a eficiência da lâmpada (PROCEL, 2010).

A tabela 1 apresenta o rendimento luminoso médio das fontes de luz.

\begin{tabular}{cc}
\hline Tipo de Lâmpada & Eficiência Luminosa (Im/W) \\
\hline Incandescente & 10 a 15 \\
Halógena & 15 a 25 \\
Luz Mista & 20 a 35 \\
Vapor de mercúrio & 45 a 35 \\
Fluorescentes compactas & 50 a 80 \\
Fluorescentes tubulares (comum) & 55 a 75 \\
Fluorescentes tubulares (especiais) & 75 a 90 \\
Vapor de sódio & 80 a 140
\end{tabular}


Tabela 1- Eficiência luminosa das fontes de luz Fonte: Sória e Filipini (2010).

As lâmpadas incandescentes, conforme tabela 1, apresentam baixa eficiência luminosa e baixa vida útil (PROCEL, 2010).

As lâmpadas halógenas são lâmpadas incandescentes, porém internamente o bulbo possui elementos como iodo ou bromo, considerados elementos halógenos, sua eficácia fica entre $15 \mathrm{Im} / \mathrm{W}$ a $25 \mathrm{Im} / \mathrm{W}$, para uma vida útil aproximada de 2.000 horas (CAPELLI, 2013).

A figura 1 apresenta tipos de lâmpadas incandescentes e halógenas.

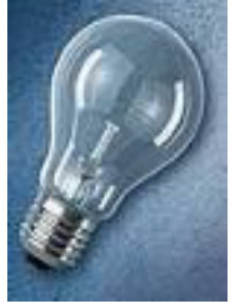

Incandescente Comum

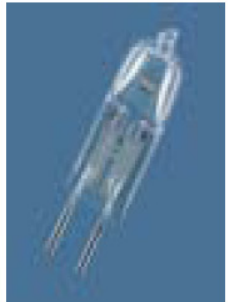

Halógena Compacta

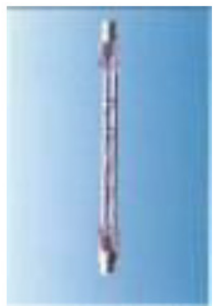

Halógena Palito

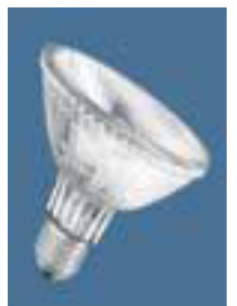

Halógena Dicróica

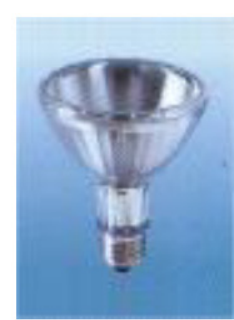

Halógena Par

Figura 1- Lâmpadas incandescentes e halógenas Fonte: Adaptado de CEPEL (2015).

As lâmpadas fluorescentes compactas (LFC) são lâmpadas que possuem baixa potência, aplicadas na substituição das lâmpadas incandescentes. Possuem equipamento auxiliar chamado de starter incorporado à sua base. Sua vida útil é bem superior as lâmpadas incandescentes (PROCEL, 2010).

A figura 2 destaca alguns modelos de lâmpadas fluorescentes compactas.
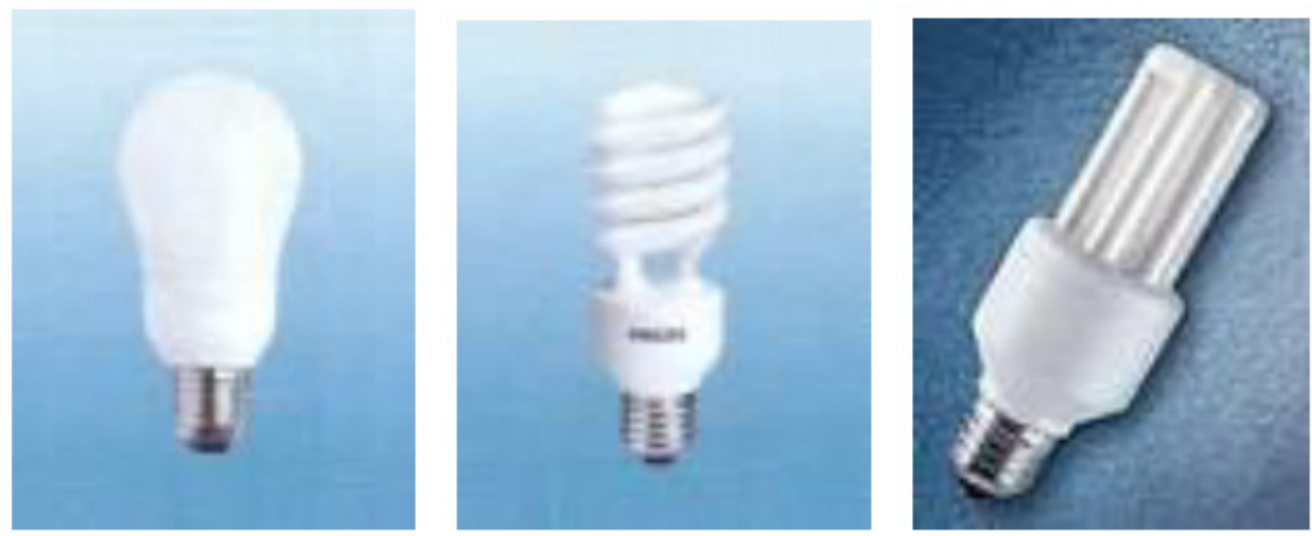

Figura 2- Lâmpadas fluorescentes compactas Fonte: CEPEL (2015).

As lâmpadas fluorescentes tubulares (figura 3) também apresentam maior 
eficiência luminosa e maior vida útil em comparação as lâmpadas incandescentes. Essas lâmpadas exigem reatores para seu funcionamento (PROCEL, 2010).

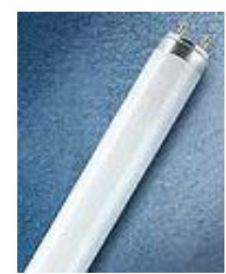

Fluorescente Tubular - T $20 w-40 w$

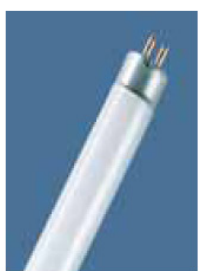

$20 w-40 W$

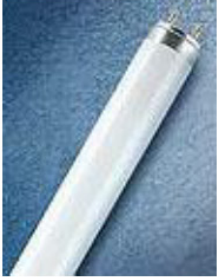

$16 \mathrm{~W}-32 \mathrm{~W}$

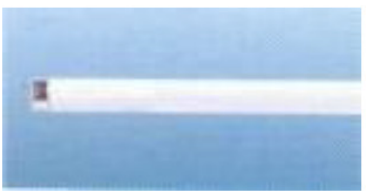

Fluorescente Tubular - T5 $14 \mathrm{~W}-28 \mathrm{~W}$

Figura 3 - Lâmpadas fluorescentes tubulares Fonte: Adaptado de CEPEL (2015).

A lâmpada a LED (figura 4) é um tipo de lâmpada que utiliza Diodo Emissor de Luz (LED). O LED é um componente semicondutor que quando energizado emite uma radiação sob a forma de luz visível. Pinto et al (2008) cita que o desenvolvimento dos LEDs mais potentes e com maior eficiência luminosa tornou possível sua utilização em iluminação de ambientes. A vantagem da utilização de LEDs em sistemas de iluminação é sua alta eficiência luminosa (100 Im/W, conforme tabela 1) e longa vida útil.
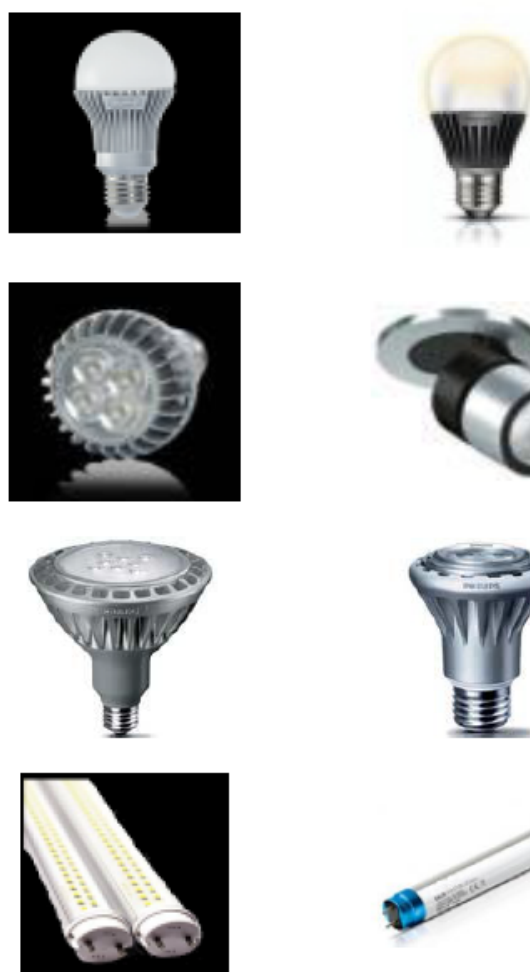
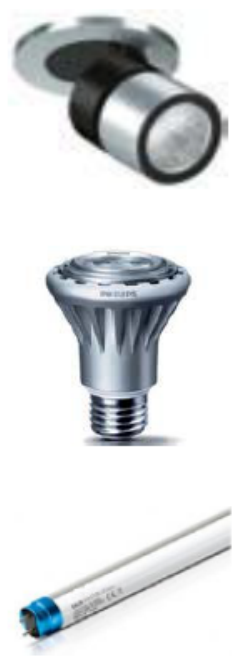

Lâmpadas Led tubular:

- Substitui lâmpada fluorescente tubular ;

Figura 4 - Lâmpadas LED

Fonte: CEPEL (2015).

\subsection{Sistemas de Climatização}

Os sistemas de climatização (ar condicionado) são responsáveis por um grande consumo de energia elétrica em uma unidade hospitalar, sendo seu uso final 
responsável por cerca de $49 \%$ do consumo total da energia (LEME FILHO; CARLOS; GEDRA, 2008).

Pirani et al. (2006) cita que a grande maioria dos prédios públicos é dotados de sistemas climatização com aparelhos de ar condicionado do tipo janela e/ou do tipo Split.

Os condicionadores de ar de janela (figura 5) são equipamentos compactos, de instalação simples, possuem pequena capacidade, devido a sua característica construtiva e ainda possuem elevado nível de ruído; são menos eficientes, apenas distribuem ar no ambiente em um único ponto e podem provocar alterações na fachada da edificação (PIRANI et al, 2006).

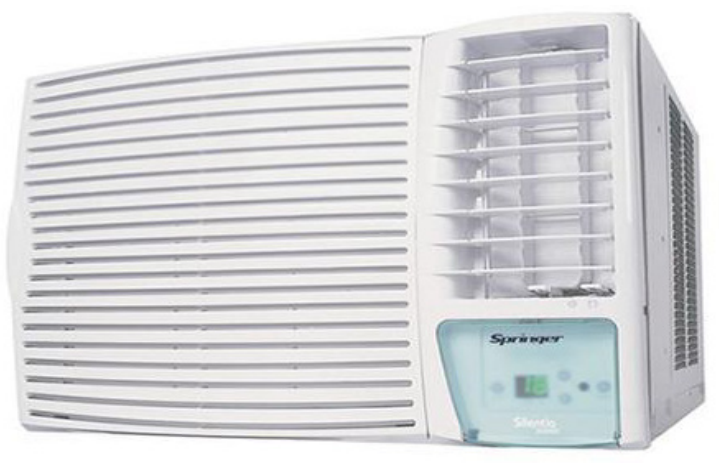

Figura 5 - Condicionador de ar do tipo janela Fonte: Oliveira (2013).

Os condicionadores de ar do tipo Split (figura 6) são equipamentos que surgiram após os condicionadores de ar do tipo janela, são constituídos de duas partes, sendo uma unidade evaporadora e outra condensadora, conectadas através de tubulações de cobre, por onde circulará o fluído refrigerante. Seu custo de aquisição é superior aos modelos do tipo janela, porém são equipamentos versáteis, de fácil manutenção, não interferem nas fachadas e são mais eficientes em comparação aos modelos do tipo janela (PIRANI et al, 2006).

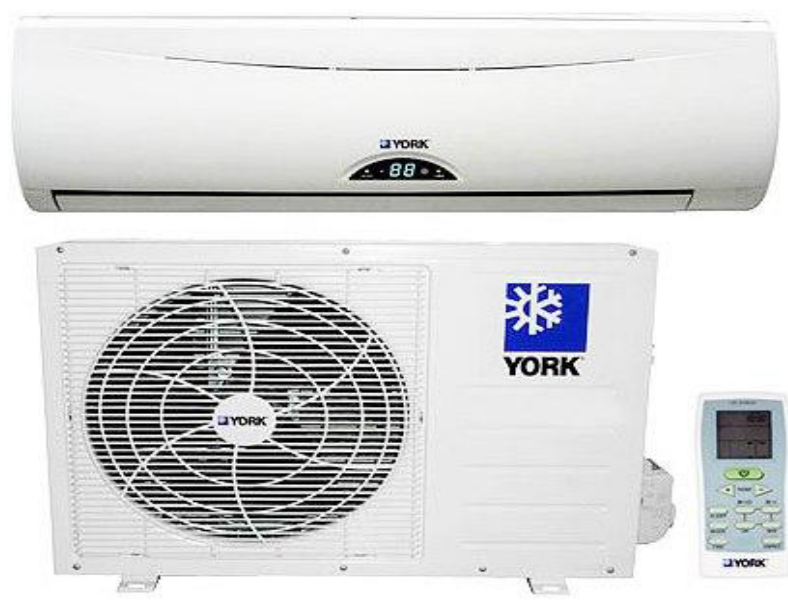

Figura 6 - Condicionador de ar do tipo split Fonte: Oliveira (2013). 


\section{3। MÉTODOS}

Para a análise do potencial de conservação de energia elétrica da Santa Casa de Arealva, foi realizado um levantamento do parque de iluminação e climatização existentes, com o objetivo de propor análise quantitativa de cargas elétricas existentes bem como a substituição por equipamentos eficientes.

O desenvolvimento deste trabalho foi feito em 2 etapas:

a) Levantamento das cargas do sistema de iluminação e climatização existentes na Santa Casa de Arealva, quantificando os tipos de lâmpadas e aparelhos de ar condicionado, destacando a potência total instalada, em quilowatts $(\mathrm{kW})$ e consumo anual de energia elétrica, em megawatts hora (MWh) em cada sistema;

b) Proposta de eficientização do parque de iluminação e climatização, através da substituição das lâmpadas convencionais por lâmpadas a LED e da substituição dos aparelhos de ar condicionado do tipo janela, por aparelhos de ar condicionado do tipo Split, apresentando a nova potência instalada e a perspectiva consumo anual de energia elétrica, com os novos sistemas.

\subsection{Sistema de iluminação existente na Santa Casa de Arealva}

O sistema de iluminação atualmente instalado na Santa Casa de Arealva é constituído de lâmpadas fluorescentes tubulares de 20 e 40 Watts (W), lâmpadas fluorescentes compactas (LFC) de 23, 25 e 30 W e lâmpadas incandescentes de 60 e $100 \mathrm{~W}$.

A Santa Casa de Arealva conta com dois focos cirúrgicos de 6 bulbos dotadas de lâmpadas halógenas de $25 \mathrm{~W}$, totalizando o consumo total em plena operação de $150 \mathrm{~W}$.

A tabela 2, apresenta o parque de iluminação da Santa de Casa de Arealva, detalhando quantitativamente, os tipos de equipamentos existentes, permitindo o cálculo da potência total instalada do sistema de iluminação da unidade. A tabela também indica a estimativa do total de horas de uso, ou seja, estimamos o tempo de funcionamento de cada equipamento (lâmpada) durante o ano.

Para este trabalho, foi adotado o seguinte critério quanto as horas de utilização das lâmpadas:

- Lâmpadas fluorescentes tubulares de 20 e 40 W: estimou-se um total de 24 horas diárias, pois são lâmpadas pertencentes ao Pronto Socorro, cujo atendimento é ininterrupto;

- Lâmpadas fluorescentes compactas de 25 e 30 W, consideramos o período de utilização do prédio que ocorre entre 07:00 as 18:00 horas, durante os dias da semana (horário comercial);

- Lâmpadas incandescentes de 60 e 100 W e lâmpadas fluorescentes compactas de $23 \mathrm{~W}$ utilizadas nos banheiros: consideramos um total de 3 horas diárias, pois existe um consenso de somente ligar a luz quando for utilizar o 
banheiro, a lâmpada é desligada após esse uso;

- Foco cirúrgico: foi considerado um tempo de utilização máximo de 3 horas diárias, pois o Centro Cirúrgico atende apenas cirurgias ambulatoriais de pequena complexidade.

\begin{tabular}{|c|c|c|c|c|c|c|c|c|}
\hline $\begin{array}{c}\text { Tipo de } \\
\text { Equipamento }\end{array}$ & $20 \mathrm{~W}$ & $23 \mathrm{~W}$ & $25 \mathrm{~W}$ & $30 \mathrm{~W}$ & $40 \mathrm{~W}$ & $60 \mathrm{~W}$ & $100 \mathrm{~W}$ & $\begin{array}{c}\text { Foco Cirúrgico } \\
150 \mathrm{~W}\end{array}$ \\
\hline Quantidade & 28 & 6 & 27 & 54 & 84 & 2 & 2 & 2 \\
\hline Horas de uso & 8760 & 720 & 2640 & 2640 & 8760 & 720 & 720 & 720 \\
\hline $\begin{array}{c}\text { Potência } \\
\text { Instalada (kW) }\end{array}$ & 0,560 & 0,138 & 0,675 & 1,620 & 3,360 & 0,120 & 0,200 & 0,300 \\
\hline $\begin{array}{l}\text { Energia } \\
\text { Consumida } \\
\text { (MWh/ano) }\end{array}$ & 4,906 & 0,099 & 1,782 & 4,277 & 29,434 & 0,086 & 0,144 & 0,216 \\
\hline \multicolumn{8}{|c|}{ Potência total instalada (kW) } & 6,413 \\
\hline \multicolumn{8}{|c|}{ Energia consumida total (MWh/ano) } & 36,038 \\
\hline
\end{tabular}

Tabela 2 - Sistema de iluminação e consumo anual da Santa Casa de Arealva

\subsection{Eficientização do parque de iluminação da Santa Casa de Arealva}

A eficientização do sistema de iluminação da Santa Casa de Arealva visa a substituição do parque de iluminação atual, por um sistema mais eficiente, pela simples substituição de equipamentos, visando uma redução do consumo de energia elétrica, sem perdas de luminosidade nos ambientes.

- Substituição de lâmpadas fluorescentes tubulares de 20 W por lâmpadas tubulares à LED de $18 \mathrm{~W}$;

- Substituição de lâmpadas fluorescentes tubulares de 40 W por lâmpadas tubulares à LED de $30 \mathrm{~W}$;

- Lâmpadas fluorescentes compactas de 23, 25 e $30 \mathrm{~W}$ a proposta visa a substituição por lâmpadas compactas a LED de $15 \mathrm{~W}$;

- Lâmpadas incandescentes de 60 e 100 W: substituição por lâmpadas compactas a LED de $15 \mathrm{~W}$;

- Substituição dos focos cirúrgicos de 6 bulbos, dotados de lâmpadas halógenas de $25 \mathrm{~W}$, por focos cirúrgicos de 19 bulbos a LED, totalizando consumo de $19 \mathrm{~W}$.

A tabela 3, apresenta o parque de iluminação proposto para a Santa de Cada de Arealva, detalhando as novas lâmpadas, a nova potência total instalada e a perspectiva de consumo de energia elétrica anual. 


\begin{tabular}{ccccccc}
\hline $\begin{array}{c}\text { Tipo de } \\
\text { Equipamento }\end{array}$ & $\mathbf{1 8} \mathbf{~ W}$ & $\mathbf{3 0 ~ W}$ & $\mathbf{1 5} \mathbf{~ W}$ & $\begin{array}{c}\mathbf{1 5} \mathbf{~ W} \\
\text { Banheiro }\end{array}$ & $\begin{array}{c}\text { Foco Cirúrgico } \\
\mathbf{1 9} \mathbf{~ W}\end{array}$ & TOTAL \\
\hline Quantidade & 28 & 84 & 1 & 10 & 2 & \\
Horas de uso & 8790 & 8790 & 640 & 720 & 720 & \\
$\begin{array}{c}\text { Potência } \\
\text { Instalada (kW) }\end{array}$ & 0,504 & 2,52 & 0,015 & 0,15 & 0,038 & $\mathbf{3 , 2 2 7}$ \\
$\begin{array}{c}\text { Energia } \\
\begin{array}{c}\text { Consumida } \\
\text { (MWh/ano) }\end{array}\end{array}$ & 4,430 & 22,151 & 3,208 & 0,108 & 0,027 & $\mathbf{2 6 , 7 2 6}$ \\
\hline
\end{tabular}

Tabela 3 - Sistema de iluminação proposto para a Santa Casa de Arealva.

\subsection{Sistema de climatização existente na Santa Casa de Arealva}

Quanto ao sistema de climatização, observou-se que o prédio da Santa Casa é dotado de aparelhos de ar condicionado do tipo janela e Split, distribuídos pelos setores da Santa Casa. A tabela 4, apresenta o parque de climatização da Unidade, que é composta aparelhos de ar condicionado do tipo janela, sendo possível estimar a potência total instalada, como também, a energia total consumida pelo sistema de climatização da unidade.

Os aparelhos de ar condicionado do tipo Split não foram citados na tabela 4, por se tratar de equipamentos eficientes e, desta maneira, não se faz necessária a substituição.

\begin{tabular}{ccccccc}
\hline $\begin{array}{c}\text { Tipo de } \\
\text { Equipamento }\end{array}$ & Quantidade & $\begin{array}{c}\text { Capacidade } \\
\text { (Btu/h) }\end{array}$ & $\begin{array}{c}\text { Horas } \\
\text { de uso }\end{array}$ & $\begin{array}{c}\text { Potência } \\
\text { (W) }\end{array}$ & $\begin{array}{c}\text { Potência } \\
\text { Instalada } \\
\text { (kW) }\end{array}$ & $\begin{array}{c}\text { Energia Total } \\
\text { Consumida } \\
\text { (MWh/ano) }\end{array}$ \\
\hline JANELA & 2 & 7500 & 2640 & 740 & 1,48 & 3,907 \\
\hline
\end{tabular}

Tabela 4 - Levantamento do sistema climatização instalado na Santa Casa de Arealva

\subsection{Eficientização do sistema de climatização da Santa Casa de Arealva}

O sistema proposto visa à substituição dos aparelhos de ar condicionado do tipo janela por aparelhos do tipo Split de mesma capacidade, sem estudo de cálculo de carga térmica.

As potências elétricas dos aparelhos de ar condicionado do tipo Split utilizados nos cálculos obedecem aos critérios do Selo Procel de economia de energia. Os aparelhos de ar condicionado de janela de 7500 BTU/h, possuem potência elétrica média de $740 \mathrm{~W}$, já os aparelhos de ar condicionado do tipo Split de 7500 BTU/h, possuem potência elétrica nominal de $675 \mathrm{~W}$, como pode ser observado na tabela 5 . 


\begin{tabular}{ccccccc}
\hline $\begin{array}{c}\text { Tipo de } \\
\text { Equipamento }\end{array}$ & Quantidade & $\begin{array}{c}\text { Capacidade } \\
\text { (Btu/h) }\end{array}$ & $\begin{array}{c}\text { Horas } \\
\text { de uso }\end{array}$ & Potência(W) & $\begin{array}{c}\text { Potência } \\
\text { Instalada } \\
\text { (kW) }\end{array}$ & $\begin{array}{c}\text { Energia Total } \\
\text { Consumida } \\
\text { (MWh/ano) }\end{array}$ \\
\hline SPLIT & 2 & 7500 & 2640 & 675 & 1,35 & $\mathbf{3 , 5 6 4}$ \\
\hline
\end{tabular}

Tabela 5 - Sistema climatização proposto para Santa Casa de Arealva

\section{I RESULTADOS E DISCUSSÃO}

De posse dos quantitativos apresentados nas tabelas anteriores, verificamos a redução de potência, o total de energia elétrica conservada e a economia proporcionada pelos sistemas em porcentagem, conforme pode ser visto na tabela 6 .

\begin{tabular}{cccc}
\hline \multicolumn{2}{c}{ SISTEMA DE ILUMINAÇÃO } & \multicolumn{2}{c}{ SISTEMA DE CLIMATIZAÇÃO } \\
\hline Redução de Potência (kW) & 3,186 & Redução de Potência (kW) & 0,130 \\
Energia Conservada (MWh/ano) & 9,312 & Energia Conservada (MWh/ano) & 0,343 \\
Economia \% & 25,84 & Economia \% & 8,78 \\
\hline
\end{tabular}

Tabela 6 - Resultados esperados

Observa-se, na tabela 6, o sistema proposto, que em comparação com o modelo existente, apresenta uma redução significativa do consumo de energia elétrica, para ambos os sistemas analisados. Na situação proposta há uma economia de 25,84\%, para o sistema de iluminação e $8,78 \%$ para o sistema de climatização.

\section{I CONSIDERAÇÕES FINAIS}

De acordo com os dados apresentados neste trabalho, pode-se observar que existe um grande potencial de conservação de energia elétrica na Santa Casa de Arealva, através da proposta de substituição dos sistemas de climatização e iluminação existentes pelos sistemas apresentados.

Do estudo apresentado, destacam-se os seguintes resultados: economia de $25,84 \%$ do consumo de energia elétrica no sistema de iluminação e $8,78 \%$ de economia de consumo de energia elétrica no sistema de climatização da Unidade.

O conteúdo apresentado neste trabalho serve como referência de plano de eficiência energética em uma unidade de saúde. Este trabalho pode ser aplicado em outras instituições de saúde, visando a otimização dos recursos públicos, sem perda da operacionalidade e conforto dos ambientes.

\section{REFERÊNCIAS}

CAPELLI, A. Energia Elétrica: Qualidade e Eficiência para Aplicações Industriais. São Paulo: Érica, 2013. 272 p. 
Centro de Pesquisas de Energia Elétrica - CEPEL (Org.). GUIA PARA EFICIÊNCIA ENERGÉTICA NAS EDIFICAÇÕES PÚBLICAS. Rio de Janeiro: Ministério de Minas e Energia, 2015. 229 p.

CREDER, H. Instalações elétricas. 15. ed. Rio de Janeiro: LTC Editora. 2007. 427 p.

LEME FILHO, R.; CARLOS, Marcio Visini; GEDRA, Ricardo. Uso Eficiente de Energia no Setor Hospitalar - Hospitais Públicos. In: SEMINÁRIO NACIONAL DE DISTRIBUIÇÃO DE ENERGIA ELÉTRICA, 18., 2008, Olinda. Anais.... Olinda: Sendi, 2008. v. 1, p. 1 - 9.

OLIVEIRA, J. R. Estudo do potencial de conservação de energia elétrica no prédio do centro administrativo da Prefeitura Municipal de Bauru, através da análise dos sistemas de iluminação e climatização existentes. In: SIMPEP, XX, 2013. SIMPÓSIO. Bauru: Simpósio de Engenharia de Produção, 2013. v. 1, p. 11 - 23.

PINTO, R. A. et al. Lâmpada compacta empregando LEDs de alto-brilho. In: CONGRESSO BRASILEIRO DE AUTOMÁTICA, 17, 2008, Juiz de Fora. Anais.... Juiz de Fora: Cba, 2008. p. 1 - 6.

PIRANI, M. J. et al. Conservação de energia elétrica: eficiência energética de equipamentos e instalações. 3. Ed. Itajubá: Fupai, 2006. 621 p.

POLO, P. Iluminação em hospitais: a parceria perfeita. Disponível em: <http://www. jornaldainstalacao.com.br/img/artigos/Lutron_2.pdf>. Acesso em: 10 ago. 2016.

PROCEL. Manual do pré-diagnóstico energético: autodiagnóstico na área de prédios públicos. Rio de Janeiro, 2010. 53 p.

SORIA, A. F. S.; FILIPINI, F. A. Eficiência Energética. Curitiba: Base Editorial, 2010. 272 p. 


\section{CAPÍTULO 3}

\section{TRATAMENTO DA ÁGUA DE DRENAGEM PLUVIAL: UM MAL NECESSÁRIO?}

Carlos Augusto Furtado de Oliveira Novaes Universidade de Brasília, Faculdade de Ciência e

Tecnologia

Brasília, Distrito Federal

RESUMO: Com altas cargas de contaminação, por vezes superiores as de efluentes de águas residuárias com pouco tratamento, os efluentes de águas pluviais urbanas, no Brasil, não têm recebido atenção à altura dos desafios que a questão apresenta. Existem, no entanto, diversas técnicas disponíveis para este tratamento, que não as ETE’s - Estações de Tratamento de Esgotos, de forma a evitar ou reduzir o comprometimento de Mananciais.

PALAVRAS-CHAVE: drenagem urbana; águas pluviais; tratamento de efluentes; remoção de contaminantes; escoamentos.

STORMWATER TREATMENT: A NECESSARY EVIL?

ABSTRACT: Although the great stormwater contaminant loads, sometimes higher than primary treated wastewater, in Brazil there is no attention to stormwater pollution control and so the challenges are enormous. Besides that, there are many other disponible options than ETE's to treat stormwater in way to avoid or reduce the water supply sources damages.

KEYWORDS: urban drainage; stormwater; wastewater treatment; contaminants removal; outflows.

\section{I INTRODUÇÃO}

O principal foco das atenções no Brasil, quando se trata de drenagem urbana ou de águas pluviais, recai quase sempre nas questões de quantidades ou volumes, por serem mais evidentes as consequências da falta de espaço disponível nas cidades para acomodá-las. Assim, os grandes volumes de precipitações, quando ocorrem, provocam inundações pontuais e chamam a atenção de todos ocupando espaço na mídia e passando a ser de conhecimento geral.

Nesse contexto os responsáveis pelas gestões municipais têm se dedicado ao assunto e procurado soluções que, via de regra, recaem sobre o armazenamento temporário por meio de reservatórios de detenção (curto período de tempo) ou de retenção (tempo mais longo) propiciando em algumas soluções a infiltração de parte do volume armazenado.

Tal tem sido a frequência de utilização dessa solução "única", que se tornou conhecida pela população como "piscinões".

Construídas de diversas formas e podendo 
se localizar de forma distribuída, ao longo das bacias, ou concentrada, próxima de seus exutórios, acumulando maiores volumes, são posicionadas de acordo com o espaço disponível e as características de cada bacia.

No entanto, deve-se perceber que além da questão de quantidade existem outras, nem sempre ressaltadas, mas não menos importantes, que se referem aos aspectos de qualidade das águas pluviais.

Há problemas decorrentes não só do espaço para armazenamento de volumes significativos de água pluvial em meio urbano, como também da possibilidade de proliferação de larvas de mosquitos e outras espécies além de odores desagradáveis e concentração da poluição de fontes difusas, arrastada pelos fluxos pluviais até os reservatórios.

Por outro lado, em muitas situações, o destino final dos efluentes pluviais, sem tratamento algum, são os mananciais de abastecimento como é o caso, por exemplo, do Lago Paranoá em Brasília - DF.

Dessa maneira coloca-se a questão do presente artigo: deve-se tratar o efluente pluvial em meio urbano? Seria esse tratamento um mal necessário? Quais as alternativas disponíveis para a efetivação deste tratamento?

\section{I REVISÃO BIBLIOGRÁFICA}

\subsection{Tratamento do Efluente Pluvial}

Quando se pensa em tratamento de efluentes a primeira ideia que surge é a das ETE's - Estações de Tratamento de Esgotos, forma mais convencional, com seus componentes complementares, as redes de coleta e transporte e seus acessórios como os sistemas de bombeamento e demais.

Outro conceito importante é o de sistema separador absoluto que individualiza as redes de coleta e transporte para cada um dos dois sistemas de efluentes, o de águas residuárias, ou esgotos, e o de águas pluviais, ou de chuva.

Apenas estes dois aspectos citados, estações e redes, são suficientes para indicar que esse caminho, o das ETE's, para o tratamento dos efluentes pluviais, seria bastante oneroso, para não dizer inviável, técnica, operacional e financeiramente.

Em temos de efluentes pluviais, os longos períodos secos, acentuados em função das mudanças climáticas, produzem altas cargas de poluentes momentâneas e extensos períodos sem carga, refletindo-se na forma de operação e manutenção das instalações de tratamento, e nas soluções adotadas.

Existem, no entanto, diversas outras opções chamadas de Ecotecnologias de tratamento ou de BMP's - "Best Management Practices", melhores práticas de gestão, que oferecem alternativas não só quantitativas, mas também relativas à qualidade dos efluentes, possibilitando diversos graus de tratamento das águas pluviais. 


\subsection{Sistemas e Processos}

Os sistemas de tratamento de águas pluviais podem reduzir os volumes de escoamento, as concentrações de poluentes e as massas totais de contaminantes que afluem aos corpos hídricos. As lagoas e bacias de detenção e retenção, as wetlands, naturais ou construídas, as valas de infiltração, os pavimentos permeáveis são alguns desses sistemas.

Os processos de tratamento, em função de seus princípios de funcionamento, classificam-se em físicos, como, por exemplo, a sedimentação, filtração ou infiltração; térmicos; biológicos; químicos ou combinados entre estas diversas formas, devendose ressaltar que um sistema pode conter diversos processos.

\subsubsection{Bacias, Lagoas de Detenção e Wetlands Construídas}

As bacias e lagoas de detenção surgiram a partir dos anos sessenta como soluções de tratamento ao final da rede ou "end of the pipe", geralmente para grandes volumes de escoamentos e, a partir dos anos noventa, surgem as Wetlands Construídas projetadas para tratamento de fluxos variáveis, associadas a filtros vegetais, os denominados filtros de bioretenção (TONDERA, 2013), baseados no princípio de filtração por gravidade e inspiradas nas Wetlands naturais, chamadas em português de banhados. Estes dispositivos têm sua eficiência diretamente ligada a parâmetros hidráulicos como volume, velocidade do fluxo, turbulência e outros, de forma a propiciar o funcionamento de acordo com os princípios de sedimentação. A construção de uma pré-bacia de entrada, mostrada na figura 1, onde as partículas maiores se sedimentam pode favorecer o processo sendo também relevantes longos tempos de residência hidráulica.

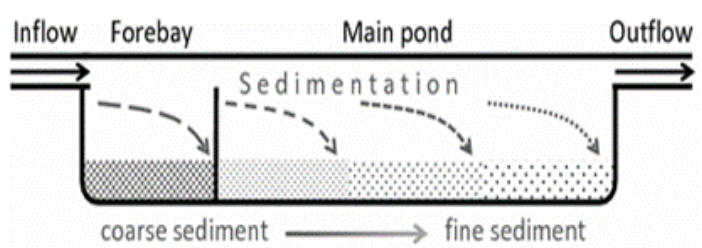

Figura 1 - Corte esquemático de bacia de retenção com bacia de acesso, ou "Forebay", e bacia principal, mostrando gradiente de sedimentos da esquerda para a direita (BLECKEN et al., 2011).

Após a análise de 98 Wetlands urbanas, diversos autores australianos (DAVID et al., 2017) concluíram que o tipo de uso do solo na bacia é determinante do perfil de poluentes nos sedimentos, sendo a presença de indústria na bacia um fator de risco elevado para a contaminação. Bacias industrializadas apresentaram maior risco em relação às demais. Fatores como a idade da Wetland e a geologia da bacia também influenciam a qualidade dos sedimentos. Houve a verificação da presença 
de metais pesados em todas as bacias (13 tipos de metais em 100\% das bacias) e hidrocarbonetos de petróleo ( $94 \%$ das bacias) além da presença de pesticidas comuns, nos sedimentos. Deve-se notar que alguns poluentes se encontram aderidos aos sedimentos e são removidos no processo de sedimentação. Poluentes dissolvidos são removidos por processos biológicos associados à vegetação existente nas regiões de pouca profundidade, mas essa remoção tem, em geral, pouca eficiência (TONDERA, 2013), à exceção de casos aonde há abundância de vegetação.

\subsubsection{Valetas de Infiltração}

Valetas de infiltração são dispositivos baseados em sedimentação, filtração, infiltração e interações químicas e biológicas com o solo (WINSTON et al., 2012). Em sua maioria são revestidas por grama, conforme mostra a figura 2 e, de acordo com diversos autores, apresentam eficiências médias na remoção de poluentes da ordem de: $72 \%$ para sólidos em suspensão totais, $52 \%$ para fósforo e $45 \%$ para nitrogênio (DELETIC; FLECHTER, 2006).

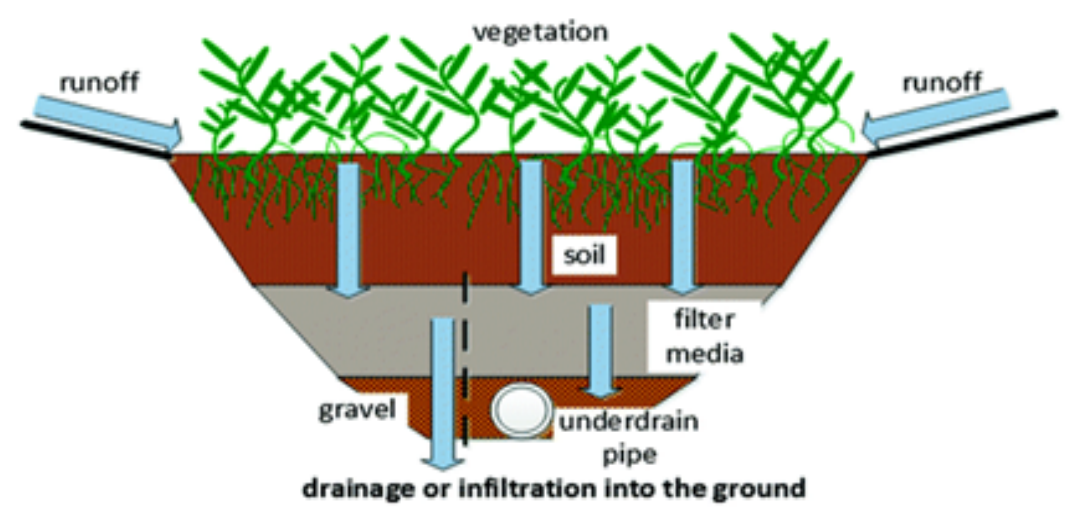

Figura 2 - Corte esquemático da seção transversal de valeta de infiltração típica com as setas azuis demonstrando os fluxos de efluentes pluviais (MANGANGKA; GOONETILLECKE; EGODAWATTA, 2016).

Constituem-se, em sua maioria, de canais vegetalizados com declividades longitudinais usualmente menores do que 1,5\% e inclinações laterais em torno de $1 \mathrm{~V}: 13 \mathrm{H}$ (KACHCHU et al., 2014) ou mais. Ao longo de estradas são muito utilizadas em conjunto com pequenas sarjetas, posicionadas de forma a conduzirem os fluxos da estrada para as valetas. As valetas de infiltração não devem ser propostas como dispositivos únicos para tratamento de águas pluviais, mas como complementares ou complementados por outros sistemas (KACHCHU et al., 2014). Diversos fatores como o percentual de vegetalização de sua superfície, seu comprimento e até mesmo a sua eventual adubação, contribuem para dar maior ou menor eficiência ao dispositivo. As partículas maiores, afluentes na corrente líquida, tendem a sedimentar-se nos primeiros metros enquanto os de menor tamanho tendem a seguir adiante por um 
maior percurso criando um gradiente de sedimentação a partir das entradas das valetas. A utilização de valetas em experimentos (KACHCHU et al., 2014), no intuito de verificar a sua efetividade como pré-tratamento para a utilização de pavimentos permeáveis, demonstrou bons resultados para a remoção de sólidos em suspensão totais, mas pouca eficiência na remoção de nutrientes. Foram removidos de 50 a 75\% dos sólidos em suspensão totais nos primeiros 10 metros de valetas. Dessa forma concluíram que não há necessidade de longas valetas para efeito de remoção de sólidos em suspensão. Da mesma maneira consideraram, após os experimentos, que valetas podem ser utilizadas como dispositivos para tratamento prévio a outros sistemas possibilitando assim a estes últimos o prolongamento de sua vida útil. Estas valetas devem ser dimensionadas de acordo com as características locais, como as condições hidrológicas e tipos de poluentes presentes, de forma a terem eficiência (HAIYAN et al., 2016), sem deixar de levar em conta as características dos solos para que se possa projetá-las considerando a infiltração, especialmente para o caso de pequenos fluxos.

\subsection{Remoção de Nutrientes}

\subsubsection{Nitrogênio e Fósforo}

Nutrientes causam a depleção do oxigênio dissolvido nos corpos hídricos e a eutrofização de suas superfícies com o excessivo crescimento de plantas e algas. Por essas razões a remoção de nutrientes, especialmente de Nitrogênio e Fósforo, deve ser realizada. Deve-se, no entanto, levar em conta que, enquanto partículas de nutrientes aderentes a sedimentos podem ser removidas por processos físicos, como filtração e sedimentação, compostos de nitrogênio e fósforo dissolvidos requerem outros processos de remoção, pois tem processo de degradação bioquímica diferente. De forma geral, em sistemas separadores urbanos, com exceção de situações onde ocorrem ligações ilícitas (PANASIUK et al., 2015), a concentração de nutrientes nos escoamentos pluviais é pequena e não chama a atenção dos pesquisadores. A pequena presença de fósforo $(P)$ em escoamentos de estradas comprova este fato já que, inexistem contaminações cruzadas em decorrência de ligações irregulares e, nesses casos, há pouca presença de detritos. Ainda que apresentem boa remoção de fósforo $(P)$, com 60 a 70\% de eficiência (MARSALECK; URBONAS e LAWRENCE, 2005), lagoas e bacias não são recomendadas para a remoção de Nitrogênio (N), a não ser quando associadas a uma zona de desnitrificação, constituindo-se de um segundo estágio, ou tenham sua capacidade de detenção aumentada. Para valetas de infiltração existem resultados variados, dependentes de maiores verificações, sendo sugerida sua utilização combinada a outros dispositivos. 


\subsection{Cargas Microbianas}

A avaliação da presença de microrganismos patogênicos em efluentes é complexa e dispendiosa e, por essas razões, usualmente utiliza-se de indicadores da presença de organismos fecais (e. coli, organismos termotolerantes, e enterococci, assim como bacteriófagos como F-RNA). Os bacteriófagos são considerados melhores indicadores de vírus por representarem mais adequadamente as características dos vírus intestinais humanos (HAVELAAR et al.1993).A presença nos efluentes pluviais de micro-organismos fecais e bacteriófagos é muitas vezes significativa, ocorrendo não só em razão da poluição difusa de origem humana e animal, como de cargas pontuais, com origem em extravasamentos das redes de águas residuárias (MERTENS et al., 2017) e de ligações irregulares destas, nos sistemas de efluentes pluviais. A forma mais comum de remoção desses micro-organismos é sua sedimentação, quando estão aderentes a partículas maiores sedimentáveis ou quando seu tamanho o permite como, por exemplo, no caso de parasitas. Cerca de 30\% a 55\% das bactérias fecais (E. coli, enterococos intestinais e coliformes) encontram-se associadas a sólidos sedimentáveis (CHARACKLIS, et al., 2005). E. coli tem predominância em escoamentos urbanos (90\%) podendo aparecer associada às partículas finas de diâmetro menor que $3 \mu \mathrm{m}$ ou na forma livre, em suspensão (CHANDRASENA et al., 2012). Esses resultados foram obtidos para sistemas separadores e, indicam que a remoção de partículas finas é importante para eliminação desta contaminação microbiana. Ressalta-se que a sobrevivência microbiana pode ser maior quando esses organismos se encontram ligados a sólidos (DAVIES; BAVOR, 2000). Microrganismos ligados a sólidos e micróbios maiores que $5 \mu$ m podem ser removidos por filtração. A figura 3 apresenta o tamanho de patógenos encontrados em águas residuárias (GARGIULO et al., 2007).

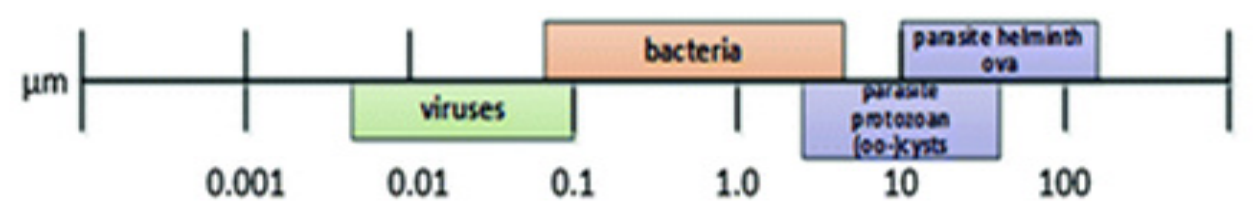

Figura 3 - Tamanho dos patógenos encontrados em águas residuárias.

Partículas em suspensão podem ser removidas por adsorção ou por processos físico-químicos de filtração se o seu diâmetro for menor que o do material do filtro. O processo predominante de retenção de vírus em meios porosos é a adsorção (CORAPCIOGLIU; HARIDAS, 1984) sendo maior quanto maior for o crescimento da massa de biofilme no meio filtrante (WALDHOFF, 2008, apud TONDERA et al., 2017). Por outro lado, micro-organismos removidos por processos físicos como sedimentação, filtração e adsorção tem potencial para serem reintroduzidos nos sistemas sendo aconselhável a utilização de outros processos que permitam sua inativação ou remoção 
permanente. A radiação UV - ultravioleta - presente em áreas abertas, onde exista a presença de luz penetrante, pode ser um destes processos de inativação, como é o caso de lagoas e de Wetlands com fluxo superficial (NGUYEN et al. 2015). Outros mecanismos são a predação (STOTT et al., 2003), aderência à biofilmes (STOTT; TANNER, 2005) e inibição (STEVIK et al., 2004). Os escoamentos de águas pluviais de sistemas separadores, em geral, podem apresentar altas contaminações por microorganismos fecais, similares àquelas encontradas em sistemas de tratamento parcial de águas residuárias. Indicadores de níveis de bactérias em efluentes pluviais têm demonstrado, quando comparados aos padrões microbiológicos de qualidade da água, que essas águas representam um perigo potencial quando o manancial que as recebe tem como uso a recreação ou a extração de água bruta para abastecimento (GALFI et al., 2016).

A variabilidade é uma característica marcante dos fluxos em sistemas de drenagem de efluentes pluviais, marcadamente o chamado fluxo inicial, ou "first flux", que carrega alta carga de poluentes, e ocorre após um prolongado período sem chuvas. Assim, a escolha dentre as opções disponíveis de sistemas de tratamento deve considerar os fluxos de escoamentos variáveis no tempo e a variação das cargas poluidoras. Em termos espaciais, as cargas de áreas densamente habitadas e áreas urbanizadas centralizadas nas bacias de contribuição tendem a apresentar maior concentração de carga bacteriana, sugerindo correlação entre as cargas e uso do solo (GALFI et al., 2016), além de outras características como sazonalidades, períodos secos e intensidades de precipitações. Diversos estudos mostram variações nas concentrações de poluentes para diversos usos do solo e sistemas (separadores, únicos ou combinados).

Em termos de sistemas de tratamento tanto lagoas como bacias apresentam bom potencial de tratamento já que existe um percentual significativo de bactérias associado a partículas sedimentáveis (CHARACKLIS et al., 2005).

Wetlands construídas de fluxo superficial também tem apresentado eficiência na remoção para determinadas faixas de fluxos, podendo atingir $75 \%$ de taxa de remoção (DAVIES; BAVOR, 2000). São mais eficientes que as lagoas devido à presença da vegetação, que reduz a velocidade do fluxo, facilitando a sedimentação de partículas mais finas $(<2 \mu \mathrm{m})$ e, permite o crescimento de biofilme favorecendo a adesão de micróbios (DAVIES; BAVOR, 2000). Existem ainda diversos estudos, com dados variados, visando à utilização de Wetlands de fluxo vertical e biofiltros, cujos resultados (WALDHOFF, 2008) merecem análise por demonstrarem potencialidade na remoção de micro-organismos.

\subsection{Remoção de Metais}

Os metais são poluentes de grande preocupação e sua presença nos efluentes pluviais acontece sob duas formas: substâncias aderentes às partículas mais finas 
dos sedimentos e de forma dissolvida, chamada biodisponível. Essa segunda parte, dissolvida, subdivide-se em duas frações, uma coloidal e outra dita verdadeiramente dissolvida. A superfície dos colóides tem geralmente carga negativa atraindo outros íons positivos. Já a parte restante, encontrando-se livre, pode ser absorvida por todo tipo de organismos convertendo-se em fonte de alta toxicidade. Dois fatores têm importância na solubilização dos metais: o PH e a matéria orgânica dissolvida, sendo maior a solubilidade quanto menor for o PH (INGRI, 2012). Estudos (BOOGAARD et al., 2014) revelaram que a maior parte das partículas metálicas se encontra aderida a outras de tamanho inferior a $90 \mu \mathrm{m}$, ou até de $60 \mu \mathrm{m}$, e assim os dispositivos de tratamento devem ser capazes de remoção de partículas finas. Uma das fontes mais importantes de metais é o tráfego veicular, mas os telhados, equipamentos de iluminação e outras superfícies das edificações como, por exemplo, as fachadas, contribuem para a presença desses poluentes nas correntes de efluentes pluviais urbanos. Telhados metálicos geralmente contribuem com $\mathrm{Zn}$ e $\mathrm{Cu}$ e rodovias com $\mathrm{Pb}, \mathrm{Cd}, \mathrm{Cr}$ e $\mathrm{Ni}$. Em áreas conectadas a pistas de tráfego de veículos há grande concentração destes poluentes (CZEMIEL, 2014). Estudos recentes, realizados na Suécia (KARLSON et al., 2016), demonstraram que em lagoas de sedimentação e tanques, em se tratando de sedimentos pluviais, a maior parte dos poluentes metálicos ( $\mathrm{Cu}, \mathrm{Cd}, \mathrm{Pb}, \mathrm{Zn}$ e $\mathrm{Ni}$ ) encontravam-se sob a forma não aderida, ou seja, potencialmente móvel. A análise de sistema constituído por lagoas-Wetlands (AL-RUBAEl et al. 2016) demonstrou uma eficiência de remoção de metais variando entre 55\% e 80\%, atribuindo-se à presença de Wetlands um grande incremento na remoção de metais dissolvidos quando se compara a sistemas contendo apenas lagoas. Para valetas a eficiência na remoção de metais mostrou-se pequena (BACKSTROM et al., 2006).

\subsection{Contaminantes Emergentes}

Contaminantes emergentes são substâncias que, apesar de detectadas no meio ambiente, ainda não tem seus comportamentos e efeitos toxicológicos conhecidos, e por essa razão não fazem parte das rotinas de monitoramento.

São produtos com diversas origens como remédios para seres humanos e animais, produtos de cuidados pessoais, nanomateriais, pinturas e acabamentos. Podem ser subdivididos em inorgânicos e orgânicos como, por exemplo, metais, pesticidas e fenóis. Os mecanismos de remoção dependem das suas composições químicas e envolvem desde processos físicos (sedimentação e filtração), biológicos, como a retirada pelas plantas e micro-organismos, até processos químicos, como precipitação, oxidação e hidrólise, dentre outros (ZHANG et al. 2012). Devido ao grande número de compostos produzidos industrialmente todos os dias, indicadores de fonte e de processo têm sido sugeridos como caminho para a identificação desses poluentes. Tais indicadores devem facilitar o monitoramento de poluentes, tendo características que possibilitem isso como, por exemplo, serem facilmente detectáveis com relativamente baixo esforço 
e por meio de vários métodos (JEKEL et al., 2015). Para escoamentos agrícolas de fontes não pontuais foram propostos pesticidas como substâncias indicadoras (PASSEPORT et al., 2011) e para escoamentos urbanos diversos herbicidas (JEKEL et al., 2015). Existem diversos estudos analisando a remoção de pesticidas em bacias, wetlands construídas, biofiltros e valetas. Sabe-se que, além do processo de sedimentação, agem na remoção processos de transferência (por meio de absorção) e de transformação que, produzem outras moléculas (metabólitos e produtos de degradação) a partir da molécula de pesticida, cujo processo apresenta-se de forma esquemática na figura 4.

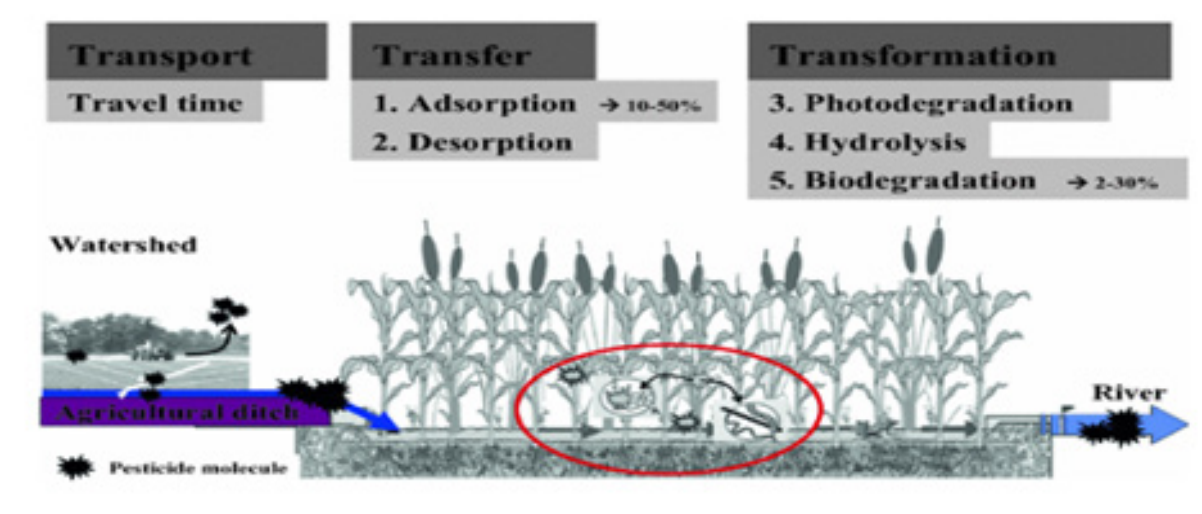

Figura 4 - Processos envolvidos na remoção de pesticidas em uma Wetland artificial (PASSEPORT et al., 2011).

Existem números representativos de resultados obtidos a partir de experimentos com S-metolachlor e expoxiconazole (HOYOS-HERNANDEZ, 2010). A biodegradação das moléculas é um processo lento que se beneficia da existência de tempos de detenção longos. A vegetação tem diversos efeitos sobre a remoção de pesticidas: por efeito de aeração dos sedimentos permite aumentar a atividade microbiana e, por aumento da rugosidade, provoca maiores tempos de detenção, favorecendo a sedimentação. Por adsorção superficial retira parte dos pesticidas, e ainda pela decomposição dessa vegetação, se constitui em fonte de carbono orgânico para os microrganismos. Os filtros de bioretenção, por sua vez, apresentam diversos processos de remoção de contaminantes como: filtração, processos físicos, químicos e bioquímicos (RANDELOVIC et al. 2016).

\section{I CONCLUSÕES}

Existem alternativas para o tratamento de efluentes de águas pluviais que não o seu simples encaminhamento às ETE's. A opção por não os tratar, além de se mostrar inadequada, por desprezar um importante contribuinte da poluição de mananciais, não encontra justificativa sob o ponto de vista das soluções técnicas disponíveis. Dessa forma seu tratamento é um BEM necessário, a ser buscado o mais breve possível. 


\section{REFERÊNCIAS}

Al-Rubaei, A. M. et al. Long-term hydraulic and treatment performance of a 19-year old constructed stormwater wetland finally maturated or in need of maintenance? Ecol Eng, 95, 2016. p. 73-82.

Babut, M. et al. Pesticide risk assessment and management in a globally changing world-report from a European interdisciplinary workshop. Environ Sci Poll Research. 20 (11), 2013. p. 82988312.

Backstrom, M. et al. Transport of stormwater pollutants through a roadside grassed swale. Urban Water J, 3 (2), 2006. p. 55-67.

Blecken, G.T. et al. Laboratory study on stormwater biofiltration in cold temperatures: metal removal and fates. Water Air Soil Pollut, 219, 2011. p. 303-317.

Boogaard, F. C. et al. Stormwater quality characteristics in (Dutch) urban areas and performance of settlement basins. Challenges, 5, 2014. p. 112-122.

Chandrasena, G. I. et al. Evaluation Escherichia coli removal performance in stormwater biofilters: a laboratory scale study. Water Sci Technol, 66 (5), 2012. p. 1132-1138.

Characklis, G. W. et al. Microbial partitioning to settleable solids in stormwater. Water Res., 39 (9), 2005. p. 1773-1782.

Corapciogliu, Y.; Haridas, A. Transport and fate of microorganisms in porous media: a theoretical investigation. J. Hidrol, 72, 1984. p. 149-169.

Czemiel, B. J. Storm water quality of first flush urban runoff in relation to different traffic characteristics. Urban Water, 11 (4), 2014. p. 284-296.

David, J. S. et al. Linking urban land use to pollutants in constructed wetlands: Implications for stormwater and urban planning. Landscape and Urban Planning, 162, 2017. p. 80-91.

Davies, C. M.; Bavor, H. J. The fate of stormwater-associated bacteria in constructed wetland and water pollution control pond systems. J. Appl Microbiol, 89, 2000. p. 349-360.

Deletic, A.; Flechter T. D. Performance of grass filters used for stormwater treatment $-\mathbf{a}$ field and modelling study. Hydrol, 317 (3/4):2, 2006. p. 261-275.

Galfi, H. et al. Inter-event and intra-event variations of indicator bacteria concentrations in the storm weser system of the city of Östersund, Sweden.

J Environ Eng., 142, 7, 2016. p. 601-603.

Gargiulo, G. et al. Bacteria transport and deposition under unsaturated conditions: the role of the matrix grain size and the bacteria surface protein. J. Contam. Hydrol., 92 (3-4), 2007. p. 255273.

Haiyan, L. et al. Performance evaluation of Grassed swales for stormwater pollution control. Procedia Engineering, 154, 2016. p. 898 - 910.

Havelaar, A. H. et al. F-specific RNA bacteriophages are adequate model organisms for enteric viruses in fresh-water. Appl. Envir. Microbiol., 59, 1993. p. 2956-2962.

Hoyos-Hernandez C. Degradation du S-metolachlor dans une zone tampon humide artificielle en fonction de l'activité microbienne, des conditions d'oxydoréduction et des différentes sources de carbone. Master Thesis in French, Vol. Master II, Ingénierie Biologique de l'environment, Univ. Paris Est, Créteil, France, 2010. p.62. 
Jekel, M. et al. Selection of organic process and source indicator substances for the anthropogenically influenced water cycle. Chemosphere, 125, 2015. p. 155-167.

Kachchu, M. M. A. et al. Preliminary investigation into the pollution reduction performance of swales used in a stormwater treatment train. J. Water Sci Technol ,69(5), 2014. p. 1014-1020.

Karlson, K. et al. Environmental risk assessment of sediments deposited in stormwater treatment facilities: trace metal fractionation and its implication for sediment management. J. Environ Eng., 142 (11), 2016.

Mangangka, I. R. et al. Enhancing the storm water treatment performance of constructed wetlands and bioretention basins. Springer Briefs in Water Science and Technology, Singapore, 2016. ISBN 978-981-10-1659-2.

Marsaleck, J; Urbonas, E., Lawrence I. "Stormwater Management Ponds", in Shilton A. (ed.) Pond Treatment Technology. IWA Publishing, London, UK. 2005.

Mertens, F. M. et al. Micropollutants in discharged water from a separate sewer rain basin within the catchment area of river Swist. Korrespondenz Wasserwirtschaft, 10 (3), 2017. p. 145-150.

Nguyen, M. T. et al. Sunlight inactivation of fecal indicator bacteria in open-water unit process treatment wetlands: Modeling endogenous and exogenous inactivation rates. Water Res, 83, 2015. p. 282-292.

Panasiuk, O. et al. Contamination of stormwater by wastewater: a review of detection methods. J Environ Manage, 152, 2015. p. 241-250.

Passeport E. et al. Selected pesticides adsorption and desorption in substrates from artificial wetland and forest buffer. Environ Tox Chem, 30 (7), 2011. p. 1669-1676.

Randelovic, A. et al. Stormwater biofilter treatment model (MPiRe) for selected micro-pollutants. Water Res, 89, 2016. p. 180-191.

Stevik, T. K. et al. Retention and removal of pathogenic bacteria in wastewater percolating through porous media: a review. Water Res, 38, 2004. p. 1355-1367.

Stott, R. et al. Predation of Cryptosporidium oocysts by protozoa and rotifers: implications for water quality and public health. Water Sci Tech, 47, 2003. p. 77- 83.

Stott, R.; Tanner, C. C. Influence of biofilm on removal of surrogate faecal microbes in a constructed wetland and saturation pond. Water Sci Tech, 51, 2005. p. 315-322.

Tondera, K. et al. Combined sewer overflow treatment: removal of oxygen depleting parameters via retention soil filters. In: 8th NOVATECH, June 2013, Lyons, France. p. 23-26.

Tondera, K. et al. Ecotechnologies for the treatment of variable stormwater and wastewater flows. SpringerBriefs in Water Science and Technology. Springer International Publishing, Nov 23, 2017. 127p.

Winston, R. J. et al. Field evaluation of stormwater control measures for highway runoff treatment. J Environ Eng., 138 (1), 2012. p. 101-111.

Zhang, Z. et al. Removal mechanisms of heavy metal pollution from urban runoff in wetlands. Front Earth Sci, 6 (4), 2012. p. 433-444. 


\section{CAPÍTULO 4}

\section{DIAGNÓSTICO DA GESTÃO DE ÁGUAS URBANAS DA CIDADE DE CARAÚBAS/RN}

Larisa Janyele Cunha Miranda Universidade Federal Rural do Semi-Árido

(UFERSA)

Jaguaribe-CE

Leonete Cristina de Araújo Ferreira Medeiros Silva

Universidade Federal Rural do Semi-Árido

(UFERSA)

Natal-RN

Rokátia Lorrany Nogueira Marinho

Universidade Federal Rural do Semi-Árido

(UFERSA)

Apodi-RN

Guilherme Lopes da Rocha

Universidade Federal Rural do Semi-Árido

(UFERSA)

Fortaleza-CE

Clélio Rodrigo Paiva Rafael Universidade Federal Rural do Semi-Árido

(UFERSA)

Mossoró-RN

RESUMO: Medidas de saneamento básico são adotadas desde as mais antigas civilizações e apresentam-se crescentes com o passar dos séculos, devido comprovação da importância que têm para a saúde. No Brasil, o saneamento é direito de toda a população, assegurado pela Constituição Federal e, em 2007, pela Política Nacional de Saneamento Básico. A gestão de águas urbanas apresenta grande relevância na área de saneamento, porém atualmente são os serviços que se encontram com piores índices, agravando-se ainda mais nos interiores das Regiões Norte e Nordeste. O objetivo desse trabalho é diagnosticar a cobertura dos serviços relacionados à gestão de águas urbanas da cidade de Caraúbas/RN, por meio de mapas construídos baseando-se em documentos fornecidos pela Companhia de Água e Esgoto do Rio Grande do Norte (CAERN), pesquisas bibliográficas e levantamentos em campo. Contatou-se que a cidade não foge da realidade crítica dos interiores brasileiros no quesito de saneamento, apresentando falhas na continuidade de distribuição de água no seu sistema de abastecimento, beirando a inexistência dos serviços de esgotamento e drenagem, e não apresentando qualquer tipo de tratamento ou coleta adequada dos resíduos líquidos, que em sua quase totalidade são transportados a céu aberto pelas ruas da cidade.

PALAVRAS-CHAVE: Saneamento básico, Caraúbas, Gestão de Águas Urbanas.

\section{DIAGNOSIS OF THE URBAN WATERS MANAGEMENT OF THE CITY OF}


ABSTRACT: Basic sanitation measures have been adopted since the earliest civilizations and have been increasing over the centuries, as evidence of their importance to health. In Brazil, sanitation is the right of the entire population, guaranteed by the Federal Constitution and, in 2007, by the National Policy of Basic Sanitation. The management of urban waters has great relevance in the area of sanitation, but nowadays they are the services that are with worse indexes, aggravating even more in the interiors of the North and Northeast Regions. The objective of this work is to diagnose the coverage of services related to urban water management in the city of Caraúbas/RN, using maps constructed based on documents provided by the Rio Grande do Norte Water and Sewer Company (CAERN), surveys bibliographies and surveys in the field. It was contacted that the city does not escape the critical reality of the Brazilian interiors in the area of sanitation, presenting failures in the continuity of water distribution in its supply system, bordering the lack of exhaustion and drainage services, and not presenting any type of treatment or adequate collection of liquid waste, which is almost entirely transported in open air through the streets of the city.

KEYWORDS: Basic sanitation. Caraúbas. Urban Water Management.

\section{I INTRODUÇÃO}

O saneamento básico é um dos fatores de fundamental importância para o bem-estar da população, à medida que extingue os fatores de perigos à saúde, melhora a qualidade de vida dos habitantes da cidade. De acordo com Rosen (1994), a associação do saneamento com a saúde do homem vem desde as mais antigas civilizações, existindo evidências de hábitos sanitários há cerca de 4.000 anos atrás.

No Brasil, o cidadão tem o direito de saneamento básico assegurado pela Constituição Federal e fixado pela Lei $n^{\circ}$. 11.445/2007, conhecida também como Lei do Saneamento, que trata do acesso e dos ajustes devidos neste campo, visando assim garantir a saúde pública. Segundo essa legislação, os municípios são responsáveis por prestar direta, ou via concessão a empresas privadas, os serviços de saneamento básico. Cada município teria então por obrigação elaborar o Plano Municipal de Saneamento Básico até o ano de 2014, condição obrigatória para o acesso aos recursos orçamentários da união.

Assim como em várias cidades do Brasil quando o assunto é saneamento básico, a cidade de Caraúbas/RN apresenta falhas no acesso aos serviços de saneamento. Neste trabalho, foram abordados em específico os serviços de águas urbanas que, segundo Tucci (2008), compreende o sistema de abastecimento de água, esgotamento sanitário e drenagem urbana, tendo como metas a saúde e a conservação ambiental.

De acordo com a FUNASA (2006), o sistema de abastecimento público de água é constituído por obras, instalações e serviços para produção e distribuição de água 
em qualidade e quantidade necessária para atender as necessidades da população, e são formados pelas seguintes unidades: manancial, captação, adução, tratamento, reservatório, reservação, rede de distribuição, estações elevatórias e ramal predial.

O esgoto sanitário segundo a NBR 9648 (ABNT, 1986) é o: "despejo líquido constituído de esgotos doméstico e industrial, água de infiltração e a contribuição pluvial parasitária". Os sistemas públicos convencionais de esgotamento sanitário são constituídos de ramal predial, coletor de esgoto, coletor tronco, interceptor, emissário, poços de visita, elevatória, estação de tratamento e disposição final (FUNASA,2006).

Tucci (2013) define que a drenagem urbana é um conjunto precauções que tenham como objetivo extinguir inundações, minimizando os riscos que a população estar sujeita com tais acontecimentos.

De acordo com Tucci e Bertoni (2003), os sistemas de drenagem podem ser de microdrenagem para atender precipitações de risco moderados e de macrodrenagem para acomodar precipitações de maior porte.

Segundo Righetto (2009), algumas medidas podem ser adotadas para a drenagem urbana, dentre elas as medidas estruturais, que relacionam às obras de captação, armazenamento e transporte das águas pluviais, e as medidas não estruturais, ações de outra natureza que exige esforços de conscientização popular, legislação apropriada, manutenção regular dos elementos estruturais e etc.

$\mathrm{Na}$ cidade em estudo, quando se trata do abastecimento de água, por mais que toda a população da zona urbana tenha acesso a esse serviço, o mesmo é realizado em escalas nos bairros.

O esgotamento sanitário, segundo informações do Instituto Brasileiro de Geografia e Estatística (IBGE) em 2010 é disponibilizado para apenas 12,7\% da população, porém nas pesquisas realizadas na cidade não foram encontrados sistemas de esgotamento ou de tratamento dos resíduos líquidos

A drenagem urbana na cidade é quase inexistente, sendo presente em poucas ruas e encontra- se em péssimas condições. A água que é coletada pelos bueiros é direcionada para o canal da cidade, onde se mistura com o esgoto, e tem como destino o um dos açudes do munícipio.

A precariedade da gestão das águas urbanas expõe a população a possíveis doenças e também afeta negativamente o meio ambiente, o estudo do sistema atual é grande importância para que possa ser diagnosticar a atual situação da cidade e apresentando pontos que deveriam ser melhorados na cidade para a disponibilização de uma melhor qualidade de vida para a população.

\section{I OBJETIVO}

Diagnosticar o estado atual da gestão de águas urbanas da cidade de Caraúbas/ $\mathrm{RN}$, realizando a construção de um mapa com caracterização dos serviços de 
saneamento e a observação da potencialidade e vulnerabilidade do sistema.

\section{I METODOLOGIA}

A princípio foram realizadas pesquisas bibliográficas, a fim de realizar um levantamento geográfico sobre a cidade de Caraúbas/RN, obtendo uma caracterização adequada, para que se fosse possível realizar uma melhor análise dos resultados. Posteriormente foram elaborados os mapas referentes à atual situação da gestão de águas da cidade.

\section{Mapa atual do abastecimento de água}

O mapa atual de abastecimento da cidade foi elaborado utilizando a estrutura e as informações contidas no mapa de abastecimento fornecido pela CAERN, foram retiradas as alterações futuras sugeridas pela companhia e alguns dados técnicos que somente são de interesse para distribuição de água na cidade, dessa maneira permanecendo apenas as áreas atuais que recebem o abastecimento.

Foi realizada também uma pesquisa junto com o responsável técnico da CAERN na cidade de Caraúbas, com o propósito de identificar os reservatórios que estão operando no momento, a vazão diária fornecida para o município e os critérios de fornecimento de água para cada bairro, podendo dessa forma realizar o diagnóstico do abastecimento de água atual na cidade.

\section{Mapa de esgotamento sanitário}

A princípio realizou-se uma consulta junto à $\mathrm{PMC}$ a fim de obter dados sobre o esgotamento sanitário da cidade, devido à ausência de informações mais detalhadas tornou-se necessário à realização de uma pesquisa de campo com o propósito de fazer um levantamento dos pontos da cidade que contém esgoto a céu aberto e pontos com rede coletora pública, como também observar a trajetória e o destino final dos resíduos líquidos e em alguns casos dos dejetos provenientes dos domicílios.

Os pontos foram primeiramente destacados em um mapa impresso da cidade ao decorrer da visita de cada bairro. Após a obtenção dos dados necessários começou a ser construído o mapa de esgotamento sanitário da cidade com o auxilio do software AutoCAD. Utilizando a base do mapa fornecido pela CAERN, foram destacados os pontos com rede de esgoto a céu aberto em áreas calçadas, os pontos que contem esgoto a céu aberto, porém que não contam com calçamento, como também o seu destino final. Desse modo possibilitou realizar o diagnóstico da situação atual da cidade na área de esgotamento sanitário.

\section{Mapa de drenagem de águas pluviais}

Juntamente com a consulta realizada para a obtenção de dados sobre o 
esgotamento sanitário junto à PMC foi realizada a consulta sobre a drenagem de águas pluviais da cidade e, devido ao mesmo motivo de falta de informações, foi necessária a realização de uma pesquisa de campo, a fim de identificar os pontos que continham algum tipo de sistema de drenagem e qual o destino da água coletada pelo mesmo.

Os pontos foram primeiramente destacados em um mapa impresso da cidade ao decorrer da visita de cada bairro. Após a obtenção de todos os dados necessários o mapa referente à drenagem de águas da cidade começou a ser construído no software AutoCAD, também utilizando o mapa fornecido pela CAERN foram destacados os pontos que continham alguma forma de drenagem como também o destino final da água coleta. Viabilizando a realização de uma análise mais precisa sobre a drenagem urbana da cidade.

\section{I RESULTADOS}

O município de Caraúbas situado no Estado Rio Grande do Norte pertence geograficamente à mesorregião Oeste Potiguar, inserida na microrregião Chapada do Apodi. De acordo com o censo de 2010, realizado pelo IBGE, esse município possuía uma população total de 19.576 habitantes com um total de 13.704 residindo na área urbana e 5.872 na área rural. Esse trabalho foi realizado apenas na área urbana.

\section{Abastecimento de água}

O abastecimento de água da cidade de Caraúbas é realizado pela CAERN, toda a água que é fornecida é proveniente de poços tubulares, pertencentes à Bacia Hidrográfica Apodi/Mossoró. A figura 1 ilustra a atual situação da rede de abastecimento da cidade.

Atualmente o sistema de abastecimento da cidade conta com um reservatório em funcionamento, com vazão estimada de $100 \mathrm{~m}^{3}$ de água por hora, e dois que estão inoperantes, devido a falhas na sua construção.

Segundo dados do censo de 2010 realizado pelo IBGE, somente 81,62\% da população total de Caraúbas contam com o abastecimento de água, porém 100\% da população urbana da cidade é beneficiada com esse sistema, deixando o déficit presente nas áreas rurais. 


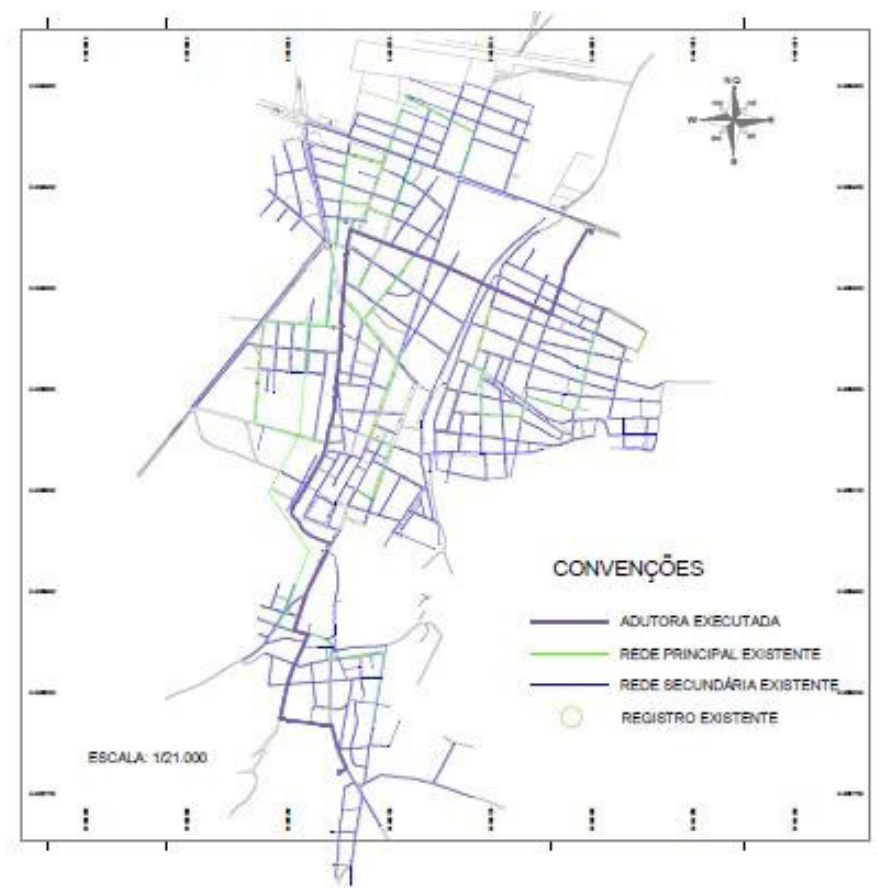

Figura 1 - Distribuição Espacial do Atual Abastecimento da Cidade de Caraúbas/RN

Segundo dados do censo de 2010 realizado pelo IBGE, somente $81,62 \%$ da população total de Caraúbas contam com o abastecimento de água, porém 100\% da população urbana da cidade é beneficiada com esse sistema, deixando o déficit presente nas áreas rurais.

Apesar de todos os habitantes que residem no perímetro urbano do município terem acesso a água potável em sua residência, a rede de abastecimento ainda apresenta déficits, que acabam por prejudicar a população, falhas no planejamento de distribuição, como também a existência de apenas um reservatório operante, deixam muitas vezes os habitantes sem acesso a água em suas residências.

\section{Esgotamento Sanitário}

Após as pesquisas junto a PMC e de campo, foi possível analisar que a cidade conta com um único canal, o qual recebe todos os resíduos líquidos dos domicílios e dejetos de algumas residências, em sua maioria os esgotos correm a céu aberto até chegarem ao canal ou a corpos d'água, não sendo identificado nenhum ponto com rede publica de esgoto. A figura 2 representa o mapa com a atual situação do esgotamento sanitário da cidade.

Os trechos calçados apresentam sarjetas que conduzem os resíduos até o canal, nos pontos em que a cidade não é calçada os esgotos são direcionados para as ruas, onde acabam por ocasionar erosão no solo e expor a população a possíveis doenças. Todos os resíduos e dejetos direcionados para o canal são transportados para um corpo d'água denominado de açude de Deusdeti, o esgoto é laçado no açude sem passar por nenhum tipo de tratamento. As figuras 3, 4, 5 e 6 representam alguns dos pontos do esgotamento sanitário da cidade. 


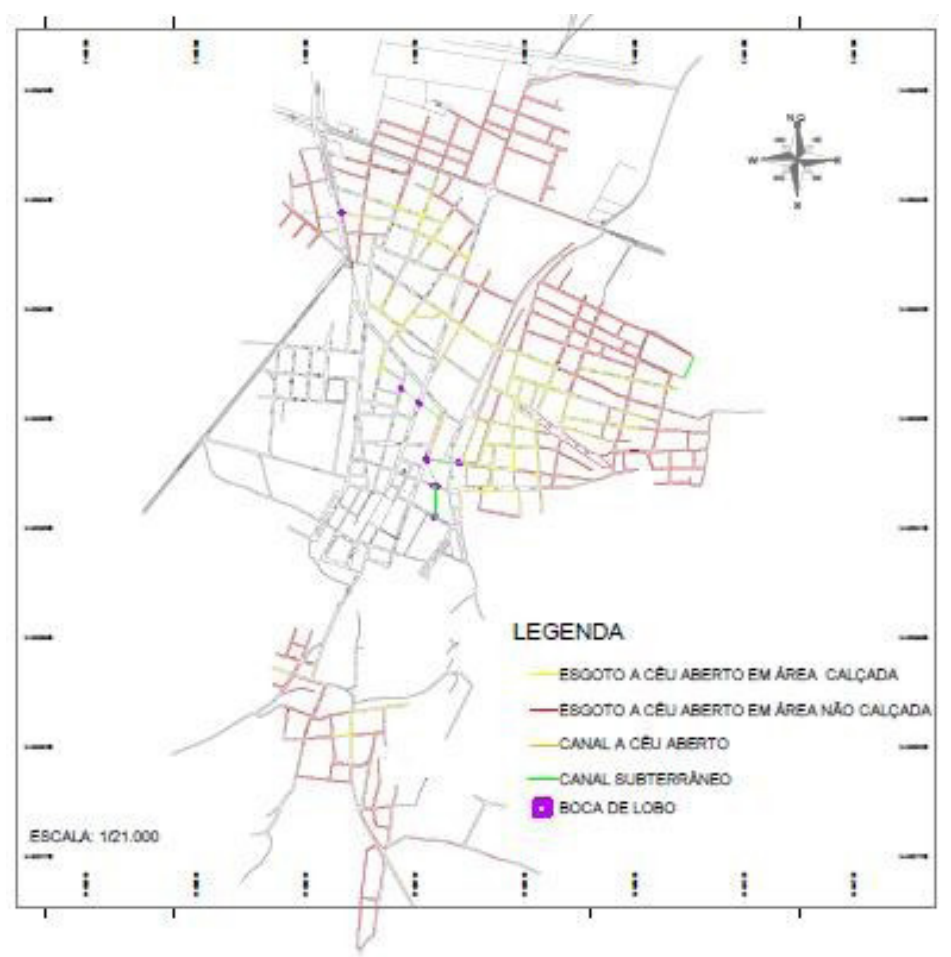

Figura 2 - Distribuição Espacial do Esgoto Sanitário na Zona Urbana

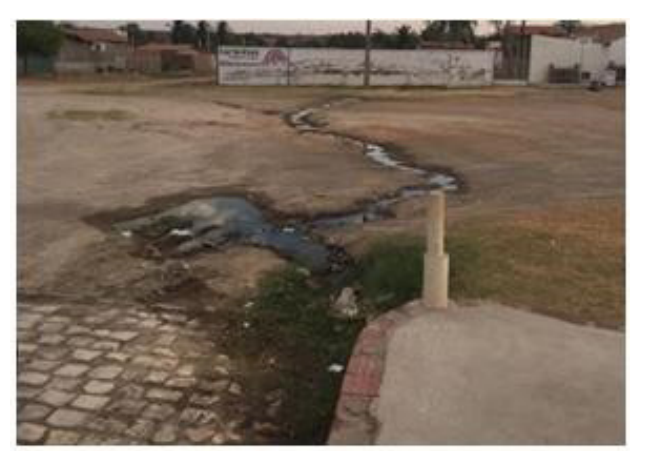

Figura 3 - Área com esgoto a céu aberto em ruas não calçada no bairro Leandro Bezerra

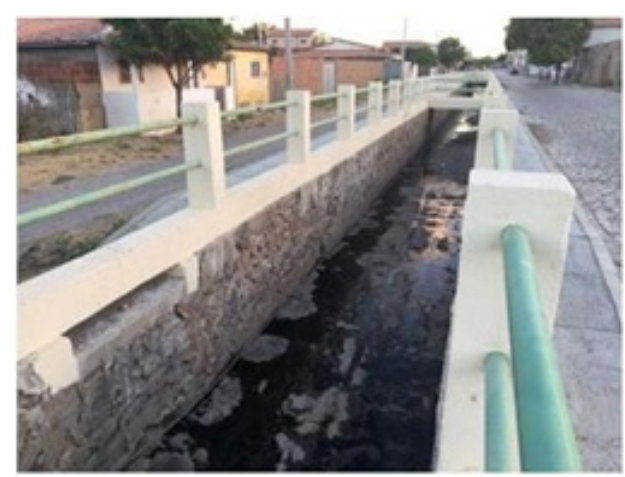

Figura 5 - Canal de Esgoto (Centro)

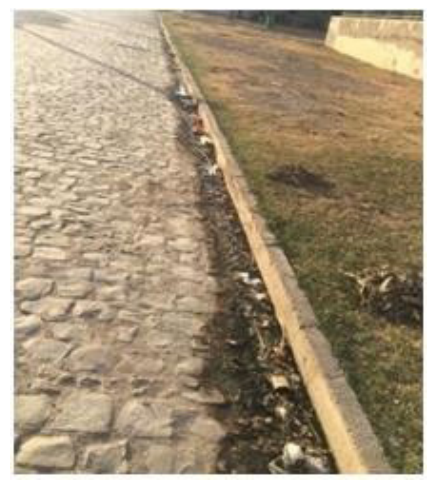

Figura 4 - Área com esgoto a céu aberto em rua calçada no bairro Sebastião Maltez

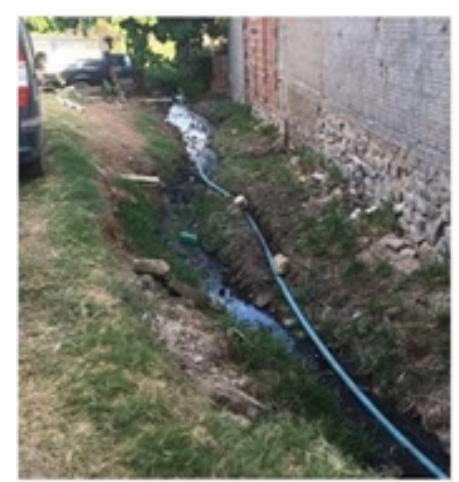

Figura 6 - Corpo d'água direcionado para o canal principal (Bairro Centro)

De acordo com o censo de 2010 realizado pelo IBGE na cidade de Caraúbas, somente $12,7 \%$ dos domicílios são beneficiados com uma rede de esgotamento sanitário, porém no estudo realizado não foram encontradas residências com tal rede, 
foram encontradas apenas residências que continham ligações precárias a corpos de água ou ao canal.

É possível notar nitidamente a precariedade do sistema de esgotamento do município, a forma como o esgoto é disposto nas ruas expõe a população a riscos de saúde e agride gravemente o ambiente, o sistema de esgotamento sanitário é de essencial importância para o saneamento básico, o qual é direito assegura pela Lei do Saneamento para toda a população brasileira.

\section{Drenagem de águas pluviais}

A figura 7 mostra a atual situação da drenagem urbana da cidade de Caraúbas/ $\mathrm{RN}$, que atualmente é concentrada apenas no ponto mostrado.

Após a conclusão do mapa de drenagem de Caraúbas/RN e comparação com a literatura, foi possível analisar que o município dispõe de um sistema de microdrenagem, foram analisados também as medidas de drenagem aplicadas na cidade, onde foi possível notar que a cidade não conta com qualquer medida estrutural, sendo presente apenas duas medias não estruturais, que são elas a varrição das ruas e a coleta de resíduos sólidos.

Foram contabilizadas na cidade um total de 20 bocas de lobo visíveis, que são ligadas diretamente com o sistema de esgotamento, as águas pluviais captadas tem como destino o mesmo local que os resíduos do esgotamento sanitário.

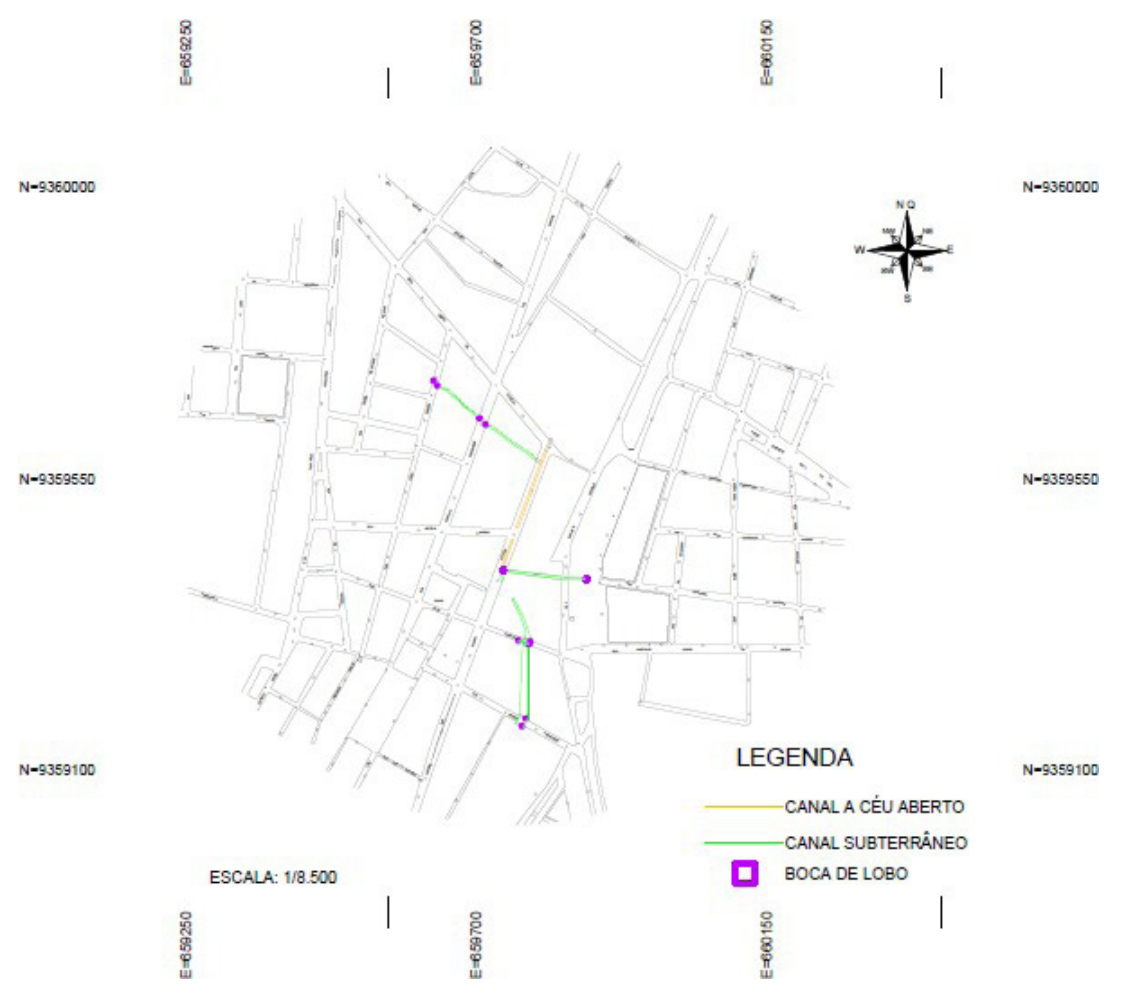

Figura 7 - Distribuição Espacial da Drenagem - Ampliada

É perceptível que o atual sistema de drenagem do município é precário e quase inexistente, é nítida a ausência de quase todas as medidas tomadas para a drenagem, os poucos meios de escoamento de água presentes na cidade encontra- se em péssimo estado e sem qualquer manutenção. 


\section{I CONCLUSÃo}

Como discutido no decorrer deste trabalho é inegável a importância dos serviços de saneamento básico para a saúde da população e preservação do meio ambiente, a gestão de águas urbanas abrange parte essencial desses serviços, visto que engloba o abastecimento de água, esgotamento sanitário e drenagem urbana.

A falta de saneamento afeta grande parte da população brasileira, em especial as Regiões Norte e Nordeste, agravando-se mais ainda quando se trata de cidades com população inferior a 50.000 habitantes. Com base nos resultados apresentados no decorrer do trabalho pode-se afirmar que o município de Caraúbas/RN não foge desse padrão. A gestão de água urbanas no munícipio apresenta sérios déficits.

Apesar do abastecimento de água na zona urbana do município poder ser considerado satisfatório por alcançar $100 \%$ da população, o mesmo ainda apresenta falhas que acabam por prejudicar os habitantes. Logo, atende qualidade, porém em quantidade deixa a desejar.

No que diz respeito ao esgotamento sanitário, mais uma vez observa-se precariedade dos sistemas, sem cobertura de rede coletora e tratamento das águas residuárias geradas na região.

Quanto à drenagem urbana, das medidas indicadas na literatura, percebeu-se que existe uma disponibilidade mínima, oferecendo apenas medidas não estruturais.

De modo geral pode-se ser observado neste trabalho que o cenário da gestão de águas urbanas no município de Caraúbas/RN de acordo com as leis em vigor encontrase em uma situação precária tanto municipal quanto populacional, negligenciando dessa forma serviços que são direitos da população.

O presente trabalho pode ser de grande relevância na elaboração do Plano Municipal de Saneamento da cidade de Caraúbas/RN que ainda se encontra em fazer inicial e sem a presença de qualquer diagnostico da atual situação da cidade, os resultados obtidos nesta pesquisa poderiam agilizar a finalização do referente plano.

\section{REFERÊNCIAS}

ASSOCIAÇÃO BRASILEIRA DE NORMAS TÉCNICAS. NBR 9648: Estudo de concepção de sistemas de esgoto sanitário. 1 ed. Rio de Janeiro, 1986.

BRASIL. Lei $n^{\circ}$. 11.445, de 05 de janeiro de 2007. Estabelece diretrizes nacionais para o saneamento básico; altera as Leis nos 6.766, de 19 de dezembro de 1979, 8.036, de 11 de maio de 1990, 8.666, de 21 de junho de 1993, 8.987, de 13 de fevereiro de 1995; revoga a Lei no 6.528, de 11 de maio de 1978; e dá outras providências. Disponível em: <www.planalto.gov.br/ccivil_03/_ato2007-2010/2007/ lei/l11445.htm>

FUNDAÇÃO NACIONAL DA SAÚDE - FUNASA. Manual de Saneamento. 3. Ed. rev. - Brasília: Ministério da Saúde, 2006.

IBGE, Instituto Brasileiro de Geografia e Estatística. CONHEÇA CIDADES E ESTADOS DO BRASIL. 
2017. Disponível em: <https://cidades.ibge.gov.br/>. Acesso em: 01 nov. 2017.

RIGHETTO, Antônio Marozzi. Manejo de Águas Pluviais Urbanas. 5. ed. Rio de Janeiro: Abes, 2009.

ROSEN, George. Uma história da saúde pública. Rio de Janeiro: Hucitec, 1994. TUCCI, Carlos. E. M. Águas urbanas. Estudos Avançados, v.22, n.63, p.97-112, 2008.

TUCCI, Carlos E. M.; BERTONI, Juan Carlos. INUNDAÇÕES URBANAS NA AMÉRICA DO

SUL. Porto Alegre: Associação Brasileira de Recursos Hídricos, 2003.

TUCCI, Carlos E. M.. Hidrologia: Ciência e Aplicação. 3. ed. Porto Alegre: Ufrgs, 2013., 


\section{CAPÍTULO 5}

\section{CALIBRAÇÃO DO FATOR DE ATRITO EM REDES DE ABASTECIMENTO DE ÁGUA}

Alessandro de Araújo Bezerra Universidade Federal do Piauí, Departamento de Recursos Hídricos, Geotecnia e Saneamento Ambiental, Teresina - PI

Renata Shirley de Andrade Araújo Universidade Federal do Piauí, Departamento de Recursos Hídricos, Geotecnia e Saneamento Ambiental, Teresina - PI

Marco Aurélio Holanda de Castro Universidade Federal do Ceará, Departamento de Engenharia Hidráulica e Ambiental, Fortaleza -

CE

RESUMO: Este capítulo tem como objetivo a apresentação de uma aplicação da nova equação para calibração do fator de atrito de Darcy-Weisbach através do uso do Método Iterativo do Gradiente Hidráulico Alternativo (MIGHA), em redes de distribuição de água. A equação é baseada na proporcionalidade entre o elemento calibrado, o fator de atrito, e o gradiente hidráulico. Após calibrado o fator de atrito de todos os trechos da rede, a rugosidade absoluta é calculada. $\mathrm{O}$ método foi aplicado através de um software desenvolvido com o auxílio da biblioteca Epanet2.dll como simulador hidráulico da rede. Arede considerada é uma rede fictícia que já apresenta resultados de calibração através da aplicação de outro método. Por fim, os resultados encontrados através da calibração com o MIGHA foram comparados com os resultados encontrados em um trabalho científico que utilizou o renomado método dos algoritmos genéticos. Através da comparação pôde-se perceber que o MIGHA não apresentou os melhores resultados, no entanto, os resultados podem ser considerados tão bons quanto os encontrados com uso dos algoritmos genéticos e com segundos como tempo de processamento.

PALAVRAS-CHAVE: Fator de atrito; Calibração; MIGHA.

\section{CALIBRATION OF THE FRICTION FACTOR}

\section{IN WATER DISTRIBUTION NETWORKS}

ABSTRACT: This chapter aims to present an application of a new equation for calibration of the Darcy-Weisbach friction factor through the use of the Alternative Hydraulic Gradient Iterative Method in water distribution networks. The equation is based on the proportionality between the calibrated element, the friction factor, and the hydraulic gradient. After calibrating the friction factor of all sections of the net, absolute roughness is calculated. The method was applied through a software developed with the aid of the Epanet2.dll library as a hydraulic simulator of the network. The network considered is a fictitious network that 
already presents calibration results through the application of another method. Finally, the results obtained through the calibration with the proposed method were compared with the results found in a scientific paper that used the renowned method of genetic algorithms. Through the comparison it was possible to see that the proposed method did not present the best results, however, the results can be considered as good as those found using genetic algorithms and with seconds as processing time.

KEYWORDS: Friction factor; Calibration; MIGHA.

\section{I INTRODUÇÃO}

A água é e sempre foi extremamente importante para a vida humana. Para Wolkmer e Pimmel (2013), a água é um patrimônio estratégico, sendo mais do que um recurso imprescindível ao desenvolvimento econômico e social, é um elemento vital para a conservação dos ecossistemas e da vida de todos os seres em nosso planeta. Dessa forma, as populações antigas buscavam viver o mais próximo possível desse tão importante recurso. Desprovidos de tecnologia avançada, este elemento precisava ser buscado em rios, córregos ou riachos para satisfazer as necessidades dos habitantes.

Já nos tempos atuais, dispõe-se de redes de distribuição de água. Estes elementos de um sistema de abastecimento tornam possível a distribuição de água em todas as residências onde vivem os consumidores deste recurso. As redes de distribuição de água são compostas de tubulações, conexões e outras peças acessórias com a finalidade de distribuir água ao consumidor final. Para Gomes e Formiga (2001), as redes de distribuição são os componentes responsáveis por levar a água ao usuário final, nos sistemas de abastecimento de água, de comunidades urbanas e rurais. Uma definição similar, porém mais antiga, foi proposta por Dacach (1967), para ele, uma rede de distribuição é um elemento que se constitui de tubulações que distribuem água, atendendo aos diversos pontos de consumo. Uma forma mais completa pode ser vista em Tsutiya (2006) e Heller e Pádua (2010), que definem rede de distribuição de água como a parte do sistema de abastecimento formada por tubulações e órgãos acessórios instalados em logradouros públicos com o objetivo de fornecer água potável em quantidade, qualidade, pressões adequadas e de forma contínua aos consumidores, sejam esses residenciais, comerciais, industriais ou de serviço.

Rao e Salomons (2007) explicam que cada rede de distribuição de água compreende uma configuração única de tubos interconectados, tanques de armazenamento, estações de bombeamento e câmaras de válvulas, que está sujeita a exigências muito variáveis que não podem ser previstas com grande grau de certeza. Ainda, as redes de distribuição são compostas por tubos e conexões que podem ser de vários materiais em que alguns destes materiais são muito lisos e apresentam rugosidades absolutas extremamente pequenas. Assim, na fabricação destes tubos, essas rugosidades não se apresentam de forma constante ao longo do tubo, além 
disso, cada tubo fabricado apresenta rugosidades diferentes, uma vez que a perfeita reprodução das rugosidades das tubulações é muito difícil. Isso explica o motivo de as pressões de funcionamento da rede não coincidir com as pressões previstas no simulador hidráulico.

Ao iniciar o funcionamento da rede, o atrito entre a água e as tubulações danifica os condutos, por este motivo existem limites máximos de velocidade. Com o limite máximo de velocidade atendido, o desgaste do conduto ocorre de forma lenta, no entanto, com o passar dos anos, esse desgaste se torna grande o suficiente para alterar de forma considerável a rugosidade das paredes das tubulações e, consequentemente, gerar variações nas pressões e vazões. Isso pode ocasionar o não atendimento adequado ao usuário do sistema pela rede de distribuição, atendimento este, previsto na simulação hidráulica da rede.

Assim, para que se possa simular, computacionalmente, de forma adequada uma rede de distribuição, seja esta uma rede recém implantada ou uma rede antiga, é necessário que haja a calibração dos coeficientes da rede de distribuição. Cheng e He (2011), afirmam que sem uma estimativa apropriada dos parâmetros, um modelo numérico não pode simular adequadamente a realidade, havendo, na prática, diferenças entre os comportamentos de modelos previstos e de sistemas reais em campo. A calibração de uma rede de distribuição visa à adequação de um modelo computacional para que este possa simular a rede estudada com base em dados observados da rede real.

Solomatine et al. (1999) consideram que o objetivo da calibração de qualquer modelo físico é encontrar parâmetros, em um modelo, os quais não são conhecidos a priori. Segundo Soares et al. (2004), a calibração visa ao ajuste dos parâmetros do sistema de tal forma que os desvios entre os dados simulados e observados em campo sejam minimizados. Cheng e He (2011) explicam que a calibração de modelos computacionais é definida como o processo de ajuste de dados descrevendo o modelo matemático do sistema até que os desempenhos observados, tipicamente pressões e taxas de fluxo, estejam razoavelmente de acordo com os desempenhos calculados por computador em uma ampla gama de condições operacionais.

Para Walski (1983), uma definição mais precisa para calibração de um modelo de distribuição de água consiste em um processo de dois passos, no qual, o primeiro, consiste na comparação de pressões e vazões calculadas com as observadas em condições de operação do sistema e, o segundo, no ajuste dos dados de entrada do modelo para que haja concordância entre o modelo calculado e o sistema observado.

Os métodos implícitos ou de otimização, que buscam a minimização de uma função objetivo, são muito utilizados nos processos de calibração. Entre estes métodos está o Método Iterativo do Gradiente Hidráulico Alternativo (MIGHA) que foi desenvolvido para calibração da transmissividade no escoamento subterrâneo por Schuster e Araújo (2004) e, posteriormente, adaptado para redes de distribuição de água, primeiramente por Rocha et al. (2009), para a calibração do coeficiente C de 
Hazen-Williams.

Rocha et al. (2009) consideram o uso de redes de distribuição as quais foram chamadas de Rede Calculada e Rede Observada. No caso do uso de uma rede fictícia, os autores definiram, ainda, uma rede denominada Rede Gabarito.

Rede Calculada é a rede a qual serão realizados os cálculos hidráulicos e obtidos os resultados calculados. Parâmetros iniciais estimados são usados e, a cada iteração, com base no valor dos gradientes hidráulicos calculados obtidos nessa rede, esses parâmetros são alterados, gerando novos resultados, cada vez mais próximos dos medidos em campo.

Rede Observada é a rede que apresenta os mesmos parâmetros iniciais da rede calculada, no entanto, possui pressões fixadas de acordo com os dados conhecidos. Além disso, são obtidos valores de gradientes hidráulicos observados para cada trecho e, esses valores, podem ser diferentes a cada iteração, dependendo da forma de calibração do MIGHA utilizada;

Rede Gabarito é uma rede fictícia na qual todos os parâmetros de entrada e resultados hidráulicos são conhecidos. Pode ser utilizada como base para conferir os resultados encontrados com o uso do método.

Assim, o principal objetivo deste trabalho é a apresentação de uma aplicação da nova equação para calibração do fator de atrito de Darcy-Weisbach através do uso do Método Iterativo do Gradiente Hidráulico Alternativo (MIGHA), apresentada em Bezerra et al. (2017), na rede de distribuição fictícia conhecida como Walski (1983) Gambale (2000) e a comparação dos resultados com os resultados obtidos através de algoritmos genéticos no trabalho de Silva (2006).

\section{I METODOLOGIA}

\subsection{Equação MIGHA utilizada para a calibração do fator de atrito}

Como o fator de atrito $f$ da fórmula universal da perda de carga é diretamente proporcional ao gradiente hidráulico, a adaptação MIGHA para a calibração do fator de atrito da equação de Darcy-Weisbach em redes de distribuição de água ocorre de acordo com a Equação 1.

$$
\mathrm{f}_{\mathrm{j}}^{\mathrm{i}+1}=\mathrm{f}_{\mathrm{j}}^{\mathrm{i}}\left(\frac{\left|\nabla \mathrm{H}_{\mathrm{C}_{\mathrm{j}}}^{\mathrm{i}}\right|}{\left|\nabla \mathrm{H}_{\mathrm{O}_{\mathrm{j}}}^{\mathrm{i}}\right|}\right)^{-1}
$$

Em que f é o fator de atrito, i é o número da iteração, j é a identificação do trecho, $\nabla \mathrm{H}_{\mathrm{C}}$ é o gradiente hidráulico calculado e $\nabla \mathrm{H}_{\mathrm{O}}$ é o gradiente hidráulico observado.

Para o cálculo da rugosidade absoluta, esta foi isolada na fórmula de SwameeJain e apresentada na Equação 2, uma vez que o simulador hidráulico utilizado, o 
Epanet, utiliza esta equação para o cálculo do fator de atrito.

$$
\varepsilon=\frac{3,7 \mathrm{D} \times\left(\operatorname{Rey}^{0,9}-5,74 \times 10^{0,5 / \sqrt{\mathrm{f}}}\right)}{\operatorname{Rey}^{0,9} \times 10^{0,5 / \sqrt{\mathrm{f}}}}
$$

O software desenvolvido realiza a calibração através do fluxograma apresentado na Figura 1.

Simulações através do Epanet2.dll para obtenção dos gradientes hidráulicos calculados e observados iniciais

$$
\begin{aligned}
& \mathrm{f}_{\mathrm{j}}^{\mathrm{i}+1}=\mathrm{f}_{\mathrm{j}}^{\mathrm{i}}\left(\frac{\left|\nabla \mathrm{H}_{\mathrm{C}_{\mathrm{j}}}^{\mathrm{i}}\right|}{\left|\nabla \mathrm{H}_{\mathrm{O}_{\mathrm{j}}}^{\mathrm{i}}\right|}\right)^{-1} \text { e } \quad \cos \theta_{\mathrm{j}}=\frac{\nabla \mathrm{H}_{\mathrm{O}_{\mathrm{j}}} \nabla \mathrm{H}_{\mathrm{C}_{\mathrm{j}}}}{\left|\nabla \mathrm{H}_{\mathrm{O}_{\mathrm{j}}}\right|\left|\nabla \mathrm{H}_{\mathrm{C}_{\mathrm{j}}}\right|} \\
& \varepsilon_{j}^{i+1}=\frac{3,7 \mathrm{D} \times\left(\operatorname{Rey}^{0,9}-5,74 \times 10^{0,5 / \sqrt{\mathrm{f}}}\right)}{\operatorname{Rey}^{0,9} \times 10^{0,5 / \sqrt{\mathrm{f}}}} \\
& 0<\varepsilon_{j}^{i+1}<12 \mathrm{~mm} \stackrel{\text { Não }}{\longleftarrow} \varepsilon_{j}^{i+1}=\varepsilon_{j}^{i} \\
& \theta_{\mathrm{j}}>60^{\circ} \stackrel{\operatorname{Sim}}{\longleftarrow} \varepsilon_{\mathrm{j}}^{\mathrm{i}+1}=\varepsilon_{\mathrm{j}}^{\mathrm{i}}
\end{aligned}
$$

Simulações através do Epanet2.dll para obtenção dos gradientes hidráulicos calculados e observados

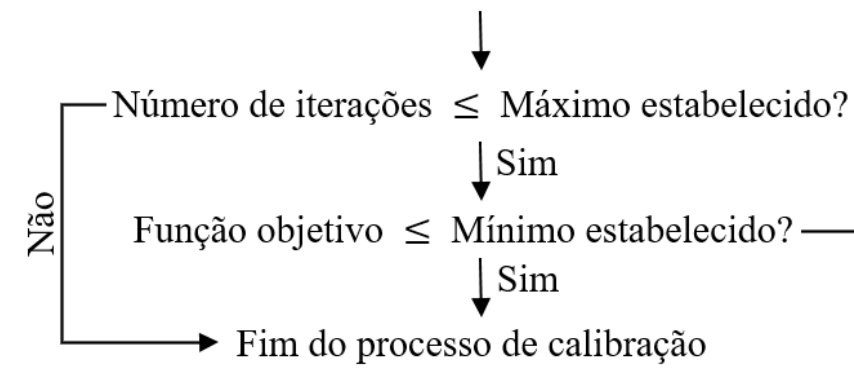

Figura 1 - Fluxograma do processo MIGHA para a calibração do fator de atrito e cálculo da rugosidade absoluta de Darcy-Weisbach

\subsection{Rede de distribuição utilizada}

A rede de distribuição utilizada, apresentada na Figura 2, é do tipo malhada e foi proposta por Walski (1983) e modificada por Gambale (2000). A rede apresenta 10 trechos e 7 nós. Os gabaritos referentes aos trechos e nós desta rede são apresentados nas Tabelas 1 e 2. As simulações realizadas para obtenção do gabarito tinham como cota do nível d’água do reservatório o valor 60,0 m. 


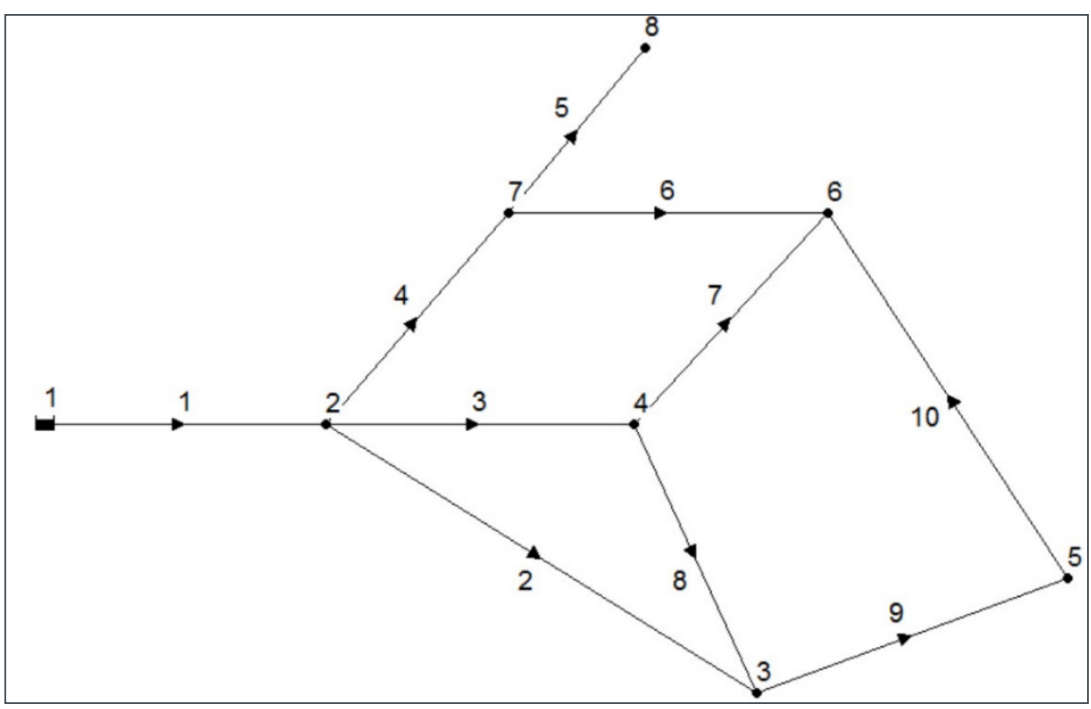

Figura 2 - Rede Walski (1983) - Gambale (2000)

\begin{tabular}{ccccccccc}
\hline Nome & $\begin{array}{c}\mathbf{1}^{\circ} \\
\mathbf{N}^{\mathbf{2}}\end{array}$ & $\begin{array}{c}\mathbf{2}^{\circ} \\
\mathbf{N o ́}\end{array}$ & $\begin{array}{c}\text { Comp. } \\
(\mathbf{m})\end{array}$ & $\begin{array}{c}\text { Diâmetro } \\
(\mathbf{m m})\end{array}$ & $\begin{array}{c}\text { Rug. } \\
\mathbf{a b s .} \\
(\mathbf{m m})\end{array}$ & $\begin{array}{c}\text { Vazão } \\
(\mathbf{L} / \mathbf{s})\end{array}$ & $\begin{array}{c}\text { Velocidade } \\
(\mathbf{m} / \mathbf{s})\end{array}$ & $\begin{array}{c}\text { Gradiente } \\
\text { Hidráulico }\end{array}$ \\
\hline 1 & 1 & 2 & 700 & 500 & 0,09 & 363,5 & 1,85 & 0,00511 \\
\hline 2 & 2 & 3 & 1800 & 250 & 1,2 & 41,9 & 0,85 & 0,00455 \\
\hline 3 & 2 & 4 & 1520 & 400 & 0,2 & 188,68 & 1,5 & 0,00507 \\
\hline 4 & 2 & 7 & 1220 & 300 & 0,12 & 132,92 & 1,88 & 0,01022 \\
\hline 5 & 7 & 8 & 600 & 300 & 4,8 & 37,5 & 0,53 & 0,00216 \\
\hline 6 & 7 & 6 & 1220 & 200 & 1,2 & 15,42 & 0,49 & 0,00204 \\
\hline 7 & 4 & 6 & 920 & 250 & 0,5 & 62,15 & 1,27 & 0,00789 \\
\hline 8 & 4 & 3 & 300 & 150 & 1 & 6,53 & 0,37 & 0,00162 \\
\hline 9 & 5 & 3 & 600 & 200 & 6,5 & $-12,43$ & 0,4 & 0,00238 \\
\hline 10 & 6 & 5 & 1220 & 100 & 7,8 & $-2,43$ & 0,31 & 0,00438 \\
\hline
\end{tabular}

Tabela 1 - Gabarito referente aos trechos: Rede Walski (1983) - Gambale (2000)

\begin{tabular}{cccc} 
Nó & Consumo (L/s) & Carga Hidráulica $(\mathbf{m})$ & Pressão (m) \\
\hline 2 & 0 & 56,44 & 56,42 \\
\hline 3 & 36 & 48,37 & 48,24 \\
\hline 4 & 120 & 48,72 & 48,72 \\
\hline 5 & 10 & 47,03 & 46,81 \\
\hline 6 & 80 & 41,8 & 41,46 \\
\hline 7 & 80 & 44,12 & 43,95 \\
\hline 8 & 37,5 & 42,88 & 42,66 \\
\hline
\end{tabular}

Tabela 2 - Gabarito referente aos nós: Rede Walski (1983) - Gambale (2000)

\subsection{Comparação entre o MIGHA e algoritmos genéticos}

Utilizando o MIGHA, os fatores de atrito dos trechos da rede de distribuição foram calibrados e suas rugosidades absolutas foram calculadas através da fórmula 
de Swamee-Jain. A calibração através do MIGHA se deu com a utilização de uma rugosidade absoluta igual a $0,006 \mathrm{~mm}$ em todos os trechos da rede trabalhada. Foram considerados um número máximo de 100 iterações.

Já em Silva (2006), utilizando algoritmos genéticos, o autor calibrou a rugosidade absoluta de Darcy-Weisbach. Para este elemento da rede calibrado, os parâmetros utilizados pelo autor foram substituição de indivíduos do tipo steady-state, seleção tipo torneio, mutação gaussiana, recombinação aleatória dos operadores a cada geração e uma população de 2.000 indivíduos com 100 gerações.

Nos dois casos foram consideradas pressões conhecidas em todos os nós da rede.

\section{I RESULTADOS}

Para a calibração da rugosidade absoluta através de Algoritmos Genéticos e calibração do fator de atrito com uso do MIGHA, tanto as pressões quanto as rugosidades absolutas encontradas com uso da equação MIGHA utilizada neste trabalho foram piores que as encontradas em Silva (2006), com uso de Algoritmos Genéticos. Na Tabela 3 pode ser vista a comparação entre as pressões encontradas com calibrações realizadas com uso de Algoritmos Genéticos e obtidas através do MIGHA, além de seus erros relativos.

A comparação entre as rugosidades absoltas encontradas, além de seus erros relativos, entre as duas metodologias pode ser vista na Tabela 4.

\begin{tabular}{cccccc}
\hline \multicolumn{5}{c}{ Pressões (m) } \\
\hline Nó & Gabarito & AG & MIGHA & Erro (\%) AG & Erro (\%) MIGHA \\
\hline $\mathbf{2}$ & 56,42 & 56,42 & 56,43 & 0,00 & 0.02 \\
\hline $\mathbf{3}$ & 48,24 & 48,21 & 48,37 & 0,06 & 0.27 \\
\hline $\mathbf{4}$ & 48,72 & 48,73 & 48,72 & 0,02 & 0.00 \\
\hline $\mathbf{5}$ & 46,81 & 46,77 & 47,03 & 0,09 & 0.47 \\
\hline $\mathbf{6}$ & 41,46 & 41,42 & 41,8 & 0,10 & 0.82 \\
\hline $\mathbf{7}$ & 43,95 & 43,95 & 44,12 & 0,00 & 0.39 \\
\hline $\mathbf{8}$ & 42,66 & 42,66 & 42,88 & 0,00 & 0.52 \\
\hline \multicolumn{5}{c}{ Erro (\%) médio: } & $\mathbf{0 , 0 4}$ \\
\hline
\end{tabular}

Tabela 3 - Comparação entre as pressões encontradas com calibrações realizadas com uso de Algoritmos Genéticos e obtidas através do MIGHA

\begin{tabular}{cccccc}
\hline Trecho & Gabarito & AG & MIGHA & Erro (\%) AG & Erro (\%) MIGHA \\
\hline $\mathbf{1}$ & 0,09 & 0,091 & 0,088 & 1,11 & 2,51 \\
\hline $\mathbf{2}$ & 1,2 & 1,092 & 0,483 & 9,00 & 59,74 \\
\hline $\mathbf{3}$ & 0,2 & 0,19 & 0,221 & 5,00 & 10,62 \\
\hline $\mathbf{4}$ & 0,12 & 0,135 & 0,150 & 12,50 & 24,93 \\
\hline $\mathbf{5}$ & 4,8 & 4,759 & 4,253 & 0,85 & 11,39 \\
\hline $\mathbf{6}$ & 1,2 & 2,307 & 4,372 & 92,25 & 264,35 \\
\hline
\end{tabular}




\begin{tabular}{cccccc}
\hline $\mathbf{7}$ & 0,5 & 0,455 & 0,346 & 9,00 & 30,83 \\
\hline $\mathbf{8}$ & 1 & 1,424 & 7,659 & 42,40 & 665,91 \\
\hline $\mathbf{9}$ & 6,5 & 5,614 & 2,228 & 13,63 & 65,72 \\
\hline $\mathbf{1 0}$ & 7,8 & 3,717 & 0,105 & 52,35 & 98,65 \\
\hline \multicolumn{7}{c}{ Erro (\%) médio: } & & $\mathbf{2 3 , 8 1}$ & $\mathbf{1 2 3 , 4 7}$ \\
\hline
\end{tabular}

Tabela 4 - Comparação entre as rugosidades absolutas encontradas com calibrações realizadas com uso de Algoritmos Genéticos e obtidas através do MIGHA

Percebe-se que, apesar de as pressões encontradas com a calibração realizada através do MIGHA possuírem valores mais distantes do gabarito que as encontradas através de Algoritmos Genéticos, exceto para o nó 4, os erros relativos calculados são menores que $1 \%$ em todos os nós, ou seja, apesar de o pior entre os testados, os resultados ainda são bons. Já no caso das rugosidades absolutas encontradas, os resultados calculados através do MIGHA não foram melhores em nenhum trecho da rede e, de forma geral, não foram bons com o uso de nenhum dos dois métodos, sendo, pior, quando calculados através do MIGHA.

Assim, percebe-se que, apesar de gerar excelentes resultados para as pressões, o método proposto não obteve as melhores rugosidades. No entanto, é válido considerar que o método MIGHA foi comparado com os melhores resultados obtidos por Silva (2006). Além disso, já é sabido que há uma necessidade de um elevado tempo de processamento do uso do Método de Algoritmos Genéticos e, para a calibração da rede Walski (1983) - Gambale (2000) com uso do MIGHA, o tempo de processamento foi inferior a 3 segundos, sendo necessário 4 iterações para chegar ao valor de função objetivo igual a 0,0000000001 .

\section{I CONCLUSÕES}

O MIGHA foi comparado com a metodologia de Algoritmos Genéticos e, pôdese perceber que as melhores pressões foram encontradas através de Algoritmos Genéticos, no entanto, as diferenças entre as pressões calculadas através do MIGHA e as pressões observadas/gabarito foram menores que $1 \%$, o que mostra que, apesar de não ser o melhor resultado, este também foi muito bom. Quanto as rugosidades encontradas, os resultados foram inferiores aos de Algoritmos Genéticos, entretanto, com um tempo de processamento bem melhor. Assim, o uso do MIGHA não gera os melhores resultados, mas bons resultados em pouco tempo.

\section{REFERÊNCIAS}

BEZERRA, A. A.; CASTRO, M. A. H.; ARAÚJO, R. S. A. (2017). Absolute roughness calculation by the friction factor calibration using the Alternative Hydraulic Gradient Iterative Method on water distribution networks. Revista Brasileira de Recursos Hídricos. v. 22, e24. 
CHENG, W.; HE, Z. (2011). Calibration of Nodal Demand in Water Distribution Systems. Journal of Water Resources Planning and Management. v. 137, n. 1, pp. 31-40.

DACACH, N. G. (1967). Modalidades de rêdes públicas de água. Revista DAE. v. 27, n. 66, pp. 1016.

GAMBALE, S. R. (2000). Aplicação de algoritmo genético na calibração de rede de água. Dissertação (Mestrado em Recursos Hídricos) - Escola Politécnica, Universidade de São Paulo, São Paulo. 266 p.

GOMES, H. P.; FORMIGA, K. T. M. (2001). PNL2000 - Método Prático de Dimensionamento Econômico de Redes Malhadas de Abastecimento de Água. Revista DAE. v. 6, n. 4, pp. 91-108.

HELLER, L.; PÁDUA, V. L. (2010). Abastecimento de água para consumo humano. v. 2, 2. ed., Belo Horizonte: Editora UFMG.

RAO, Z.; SALOMONS, E. (2007). Development of a real-time, near-optimal control process for water-distribution networks. Journal of Hydroinformatics. v. 9, n. 1, pp. 25-37.

ROCHA, V. A. G. M.; CASTRO, M. A. H.; ARAÚJO, J. K. (2009). Calibração de Rugosidade em Redes de Abastecimento a Partir de Gradientes Hidráulicos Através de Método Iterativo in Anais do XVIII Simpósio Brasileiro de Recursos Hídricos. 2009.

SCHUSTER, H. D. M.; ARAÚJO, H. D. B. (2004). Uma Formulação Alternativa do Método Iterativo de Gradiente Hidráulico no Procedimento de Calibração dos Parâmetros Hidrodinâmicos do Sistema Aqüífero. Revista Brasileira de Recursos Hídricos. v. 9, n 2, pp. 31-37.

SILVA, A. C. A. (2006). Calibração automática de rugosidades de tubulações em sistemas de distribuição de água com aplicação de algoritmos genéticos. Dissertação (Mestrado em Engenharia Civil: área de concentração em Recursos Hídricos) - Universidade Federal do Ceará, Fortaleza. $176 \mathrm{p}$.

SOARES, A. K.; CHEUNG, P. B.; REIS, L. F. R.; SANDIM, M. P. (2004). Avaliação das perdas físicas de um setor da rede de abastecimento de água de Campo Grande-MS via modelo inverso. Engenharia Sanitária e Ambiental. v. 9, n. 4, pp. 312-321.

SOLOMATINE, D. P.; DIBIKE, Y. B.; KUKURIC, N. (1999). Automatic calibration of groundwater models using global optimization techniques. Hydrological Sciences Journal. v. 44, n. 6, pp. 879894.

TSUTIYA, M. T. (2006). Abastecimento de Água. 3. ed., São Paulo: Departamento de Engenharia Hidráulica e Sanitária da Escola Politécnica da Universidade de São Paulo.

WALSKI, T. M. (1983). Technique for Calibrating Network Models. Journal of Water Resources Planning and Management. v. 109, n. 4, pp. 360-372.

WOLKMER, M. F. S.; PIMMEL, N. F. (2013). Política Nacional de Recursos Hídricos: governança da água e cidadania ambiental. Sequência: Estudos Juridicos e Politicos. v. 34, n. 67, pp. 165-198. 


\section{AVALIAÇÃO QUANTITATIVA DE ALTERNATIVAS DE USO E OCUPAÇÃO DO SOLO, SOB ASPECTOS DE RESILIÊNCIA A INUNDAÇÕES E REQUALIFICAÇÃO AMBIENTAL}

\begin{abstract}
Bruna Peres Battemarco
Programa de Engenharia Civil - COPPE/UFRJ
\end{abstract}

Rio de Janeiro - RJ

Lilian Marie Tenório Yamamoto

Escola Politécnica - POLI/UFRJ

Rio de Janeiro - RJ

Aline Pires Veról

Programa de Pós-Graduação em Arquitetura Faculdade de Arquitetura e Urbanismo/UFRJ e Programa de Engenharia Civil - COPPE/UFRJ

Rio de Janeiro - RJ

Marcelo Gomes Miguez

Programa de Engenharia Civil - COPPE/UFRJ e Programa de Engenharia Ambiental, Programa de

Engenharia Urbana - Escola Politécnica - POLI/

UFRJ

Rio de Janeiro - RJ

RESUMO: Ao longo dos anos, a visão tradicional do projeto de drenagem vem sofrendo modificações que visam articular o projeto de drenagem com a paisagem urbana por meio do manejo sustentável de águas pluviais, resgatando características hidrológicas naturais. Assim, este trabalho propõe a utilização de um quadro metodológico para avaliar quantitativamente os impactos, sob o ponto de vista da resiliência a inundações e da requalificação ambiental, de diferentes situações de uso e ocupação do solo em uma bacia hidrográfica, considerando desde uma urbanização irregular até uma alternativa sustentável. Para tal, utiliza-se a modelagem matemática hidrodinâmica como ferramenta de suporte, para obter dados do comportamento das inundações na bacia, em cada cenário. Realiza-se também a aplicação do Índice de Resiliência a Inundações (IRES) e o Índice de Requalificação Fluvial (REFLU) para a avaliação da resiliência a inundações e da requalificação ambiental, respectivamente. Como resultado, obtém-se valores de índices que confirmam as expectativas iniciais, nas quais a alternativa com medidas de desenvolvimento sustentável apresenta maior resiliência a inundações e maior requalificação ambiental, quando comparado a cenários caracterizados por uma ocupação sem controle.

PALAVRAS-CHAVE:

Desenvolvimento

Urbano Sustentável; Resiliência a Inundações; Requalificação Ambiental.

\section{QUANTITATIVE EVALUATION OF LAND \\ USE ALTERNATIVES, UNDER FLOOD \\ RESILIENCE AND ENVIRONMENTAL}

\section{RESTORATION ASPECTS}

ABSTRACT: The classical drainage design has gone through several modifications aiming to articulate the drainage design with the urban landscape by developing a sustainable 
stormwaters management, recovering the natural hydrological characteristic. This project aims to propose a framework to measure the impacts of different alternatives of land use and occupation on a watershed, from the point of view of flood resilience and environmental restoration, considering scenarios varying from an uncontrolled urbanization scenario to a sustainable one. In order to map the watershed flood behavior in each scenario, a hydrodynamic mathematical modelling tool was used to support this task. The Flood Resilience Index (FResl) and the Urban River Restoration Index (URRIx) were also applied for flood resilience and environmental restoration analysis, respectively. As a result, the obtained indexes values confirm the initial expectations, in which the situation with sustainable development measures shows greater flood resilience and also greater environmental restoration results, when compared with scenarios characterized by an occupation without control.

KEYWORDS: Sustainable Urban Development; Flood Resilience; Environmental Restoration.

\section{I INTRODUÇÃO}

Nos últimos anos, a maneira de lidar com as inundações urbanas vem sofrendo uma mudança de paradigma. Essa mudança leva a discussão a migrar da tradicional proteção contra inundações para o conceito de gestão dos riscos de inundação. Com a nova abordagem, torna-se mais clara a necessidade de integração setorial no processo de pensar e planejar as cidades. Destaca-se que a urbanização abre dois caminhos possíveis: um que gera oportunidades para o desenvolvimento sustentável e outro que aumenta o risco de desastres, a partir do momento que aumenta a exposição e a vulnerabilidade às inundações (UNISDR, 2017).

No sentido contrário à materialização do risco, desenvolve-se a atuação da resiliência. Segundo a Estratégia Internacional para a Redução de Desastres - UNISDR (2009) e Jha et al. (2012), resiliência é a capacidade de um sistema, comunidade ou sociedade exposta a um perigo de resistir, absorver, adaptar e recuperar de seus efeitos de maneira rápida e eficaz, incluindo a preservação e restauração de suas estruturas e funções básicas. Como ressaltado por Veról (2013), o aumento da resiliência das cidades pode ser obtido preparando a cidade para um melhor convívio com as cheias, a partir de um zoneamento de inundações, por exemplo, ou ainda diminuindo a geração de escoamentos provocados pela transformação da chuva em vazão e reorganizando os padrões de escoamento das vazões resultantes. Esse caminho de ação incorpora medidas de controle de escoamento na fonte, com a implantação de medidas de armazenamento e infiltração nos espaços públicos, por exemplo, como paisagens multifuncionais e infraestruturas verdes, em nível de loteamento, e ações de requalificação fluvial, na escala da bacia, entre outras possibilidades. A resiliência pode crescer pela adaptação do sistema para gerar menores inundações.

A requalificação fluvial, por sua vez, trata de um conjunto de ações sinérgicas, 
que procuram agregar valor ambiental e ecológico aos rios, abordando quatro elementos principais: risco hidráulico e controle de cheias, qualidade da água, equilíbrio morfológico e recuperação dos ecossistemas fluviais. É uma prática que busca recuperar (algumas) características naturais dos corpos hídricos, procurando satisfazer também objetivos socioeconômicos e proporcionando, assim, benefícios para uso recreativo ou lazer, aspectos que agregam valor para a sociedade (CIRF, 2006). O seu objetivo global é obter um curso d'água com melhor qualidade ambiental.

Nesse contexto, o presente trabalho tem como objetivo avaliar, de forma quantitativa, diferentes alternativas de uso e ocupação do solo em uma bacia hidrográfica ainda em processo de urbanização e com vários desdobramentos possíveis, sob o ponto de vista de aumento da resiliência a inundações e da requalificação ambiental.

\section{I ESTUDO DE CASO: VARGEM GRANDE, RIO DE JANEIRO}

O foco deste trabalho recai em Vargem Grande, Bairro da Zona Oeste da cidade do Rio de Janeiro. Vargem Grande está inserida na região da Baixada de Jacarepaguá e é uma área ambientalmente sensível, que se caracteriza, principalmente, pela existência de vegetação nativa, uma rede hidrográfica densa e a oferta de muitos espaços livres de edificações. Também possui cotas próximas ao nível do mar, o que a torna propensa a sofrer inundações. Apesar disso, essa área também se configura como vetor de expansão urbana da cidade. Para fins de avaliação do impacto de diferentes alternativas de uso e ocupação do solo, optou-se por delimitar uma área, de aproximadamente 500 hectares, situada na sub-bacia da Zona dos Canais (Figura 1).

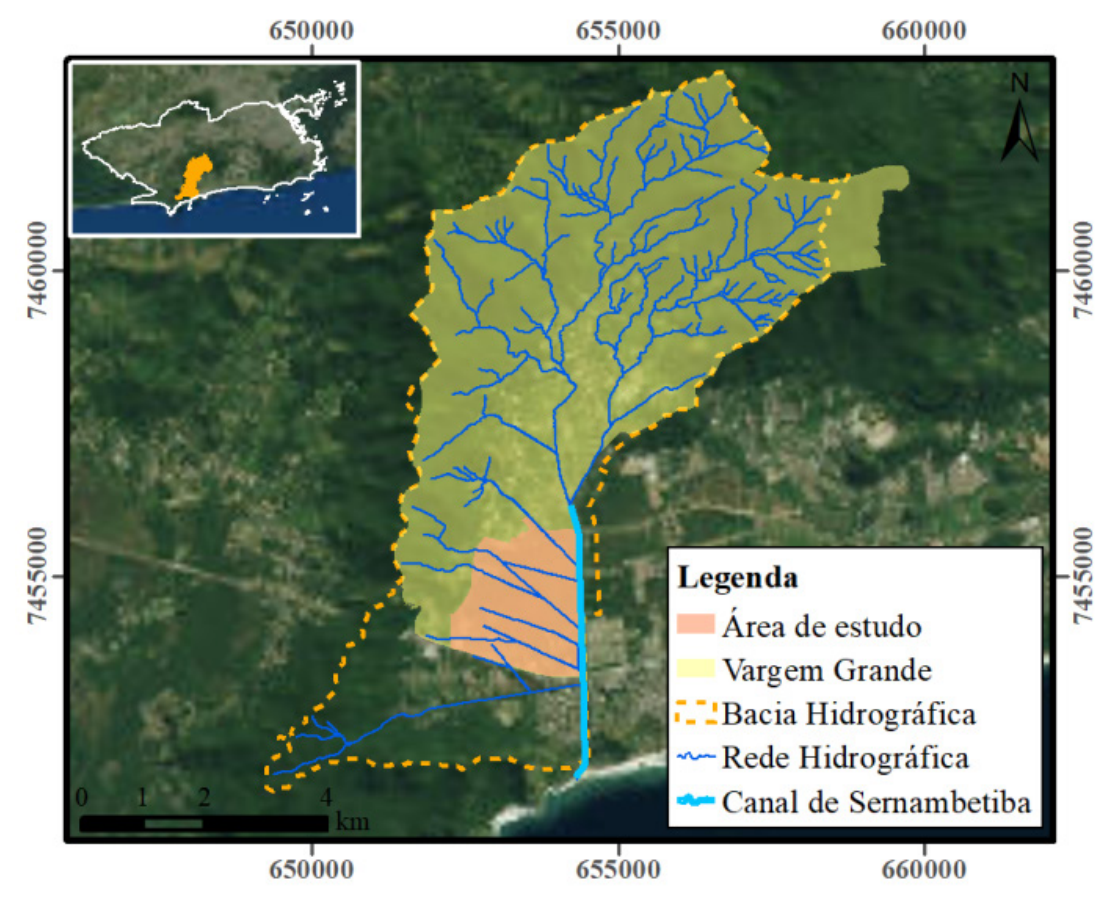

Figura 1 - Localização da área de estudo (BATTEMARCO et al., 2018)

Diferentes alternativas de uso e ocupação do solo foram consideradas para fins 
de avaliação comparativa do comportamento destas formas de ocupação. A Alternativa de Urbanização sem Controle (Figura 2 (a)) é caracterizada por altos índices de impermeabilização do solo, intensificação da ocupação irregular nas margens dos rios e alta densidade habitacional. Já a alternativa de Urbanização Conforme Padrão da Orla Local (Figura 2 (b)), supõe que, em um contexto futuro, poder-se-ia expandir o padrão de urbanização consolidado na parte costeira, no bairro do Recreio dos Bandeirantes, que mesmo respondendo a uma legislação formal pode conter deficiências, no que tange à sustentabilidade e à efetividade da drenagem.

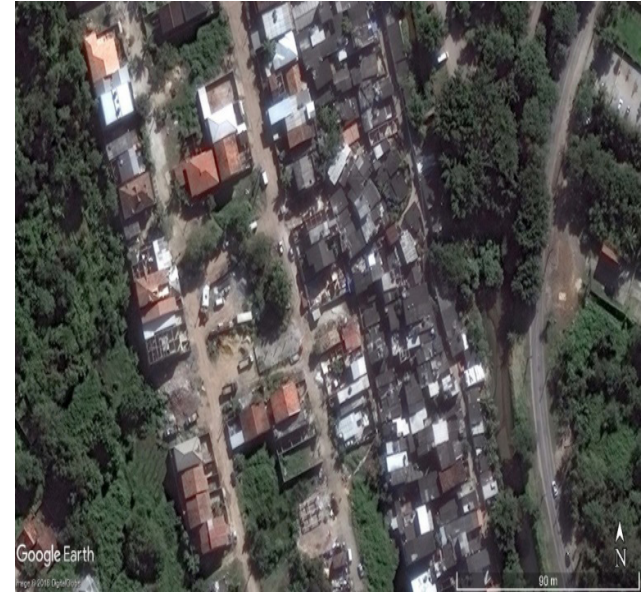

(a) Sem Controle

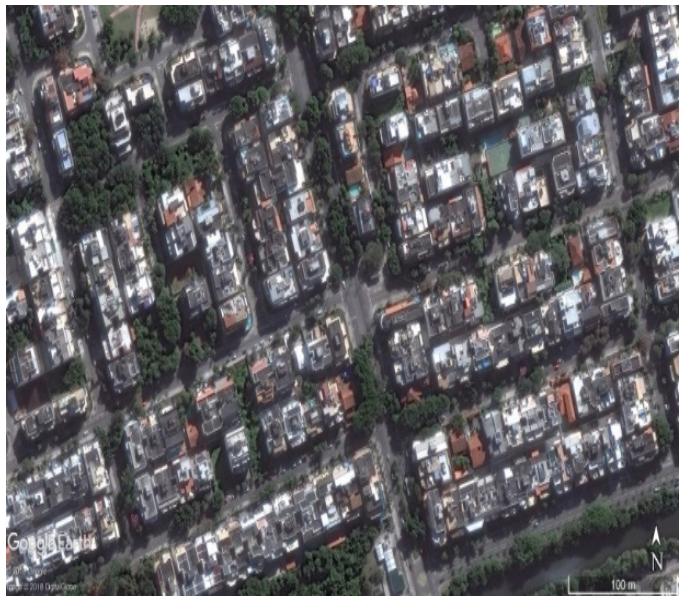

(b) Padrão da Orla Local

Figura 2 - Alternativas de Uso e Ocupação do Solo Consideradas

A Alternativa de Urbanização Sustentável (Figura 3), por sua vez, considera a conservação ou recuperação da Faixa Marginal de Proteção nos canais, quando possível, com a implantação de áreas de lazer e convívio para a população, consolidando parques lineares. Simultaneamente, esses parques reservam espaço para receber eventual extravasamento do rio e, portanto, produzem um amortecimento de cheia. Para garantir sua eficácia, o projeto propõe a realocação da população que atualmente habita dentro da calha secundária do Canal Sernambetiba e sofre prejuízos com eventuais inundações, para uma área do novo loteamento dotada de infraestrutura e capaz de acolher estes habitantes com qualidade. É importante ressaltar que os parques lineares propostos formam verdadeiros corredores verdes urbanos, promovendo a integração do Parque Estadual da Pedra Branca até a Praia da Macumba.

Outra proposta é conectar os espaços recém formalizados por meio de highlines, que são caminhos elevados que promovem o fluxo de pedestres ao longo do parque, atraindo o lazer ecológico. Além disso, foram previstos pequenos corredores verdes entre lotes, a implantação de aterros na cota mínima de segurança $(2 \mathrm{~m})$ e o remanejamento do Museu Casa do Pontal para um ponto nodal do projeto, estabelecendo um centro de referência cultural. 


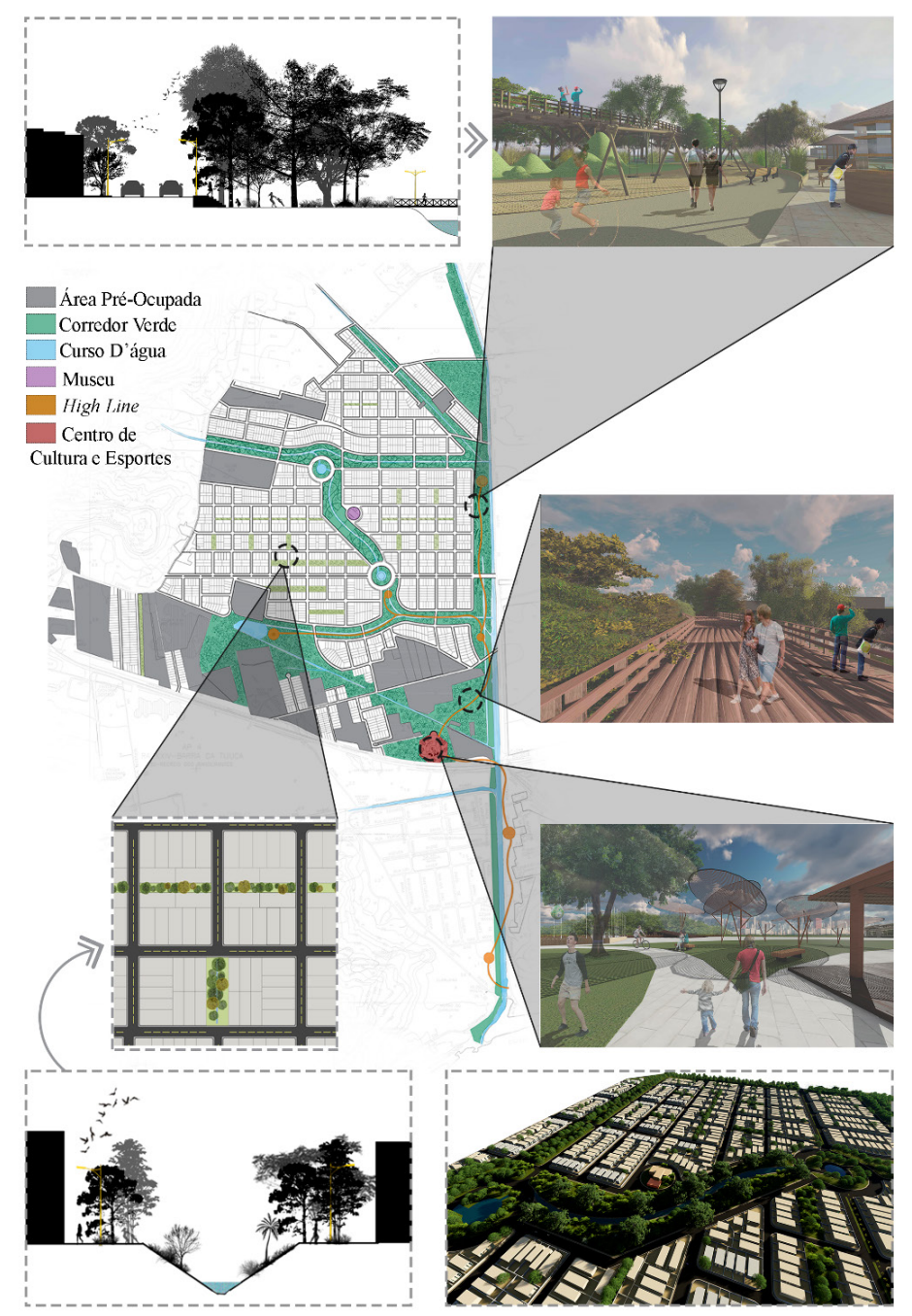

Figura 3 - Alternativa de Urbanização Sustentável (VERÓL et al., 2018a)

\section{I METODOLOGIA}

A ferramenta de modelagem matemática MODCEL (MASCARENHAS E MIGUEZ, 2002; MIGUEZ et al., 2017) foi usada para definir mapas de inundação. A discretização da bacia compreendeu 800 células (Figura 4 (a)) na simulação da situação atual, bem como das alternativas sem controle e conforme padrão da orla local. Já para a alternativa de urbanização sustentável, o número total de células utilizadas para representação da área de estudo foi de 1046 (Figura 4 (b)). As alternativas foram simuladas considerando um tempo de recorrência de 25 anos, referência do Ministério das Cidades para projetos de macrodrenagem, e duração da chuva de projeto igual a 125 minutos, condizente ao tempo de concentração da bacia. Ao todo, foram utilizadas quatro condições de contorno: três de vazão e uma de nível, representativa da maré local. 


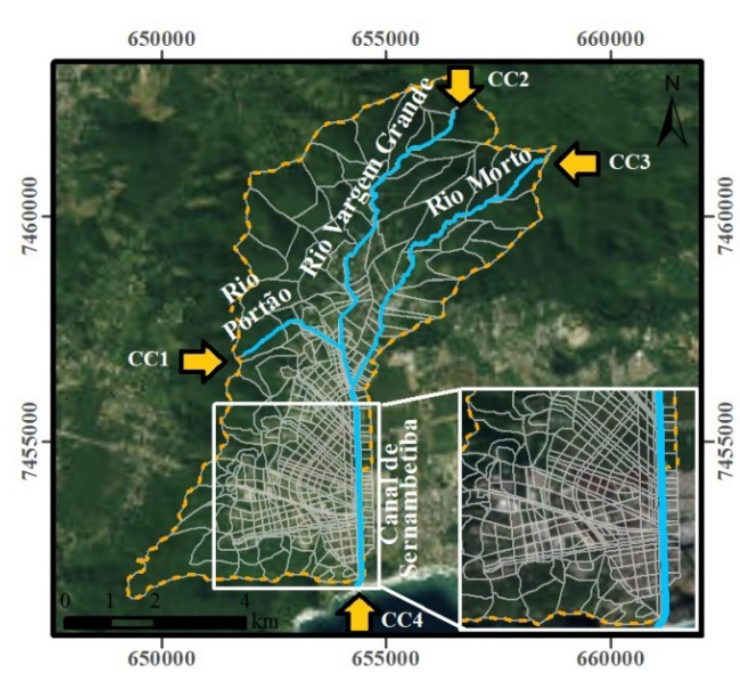

(a)

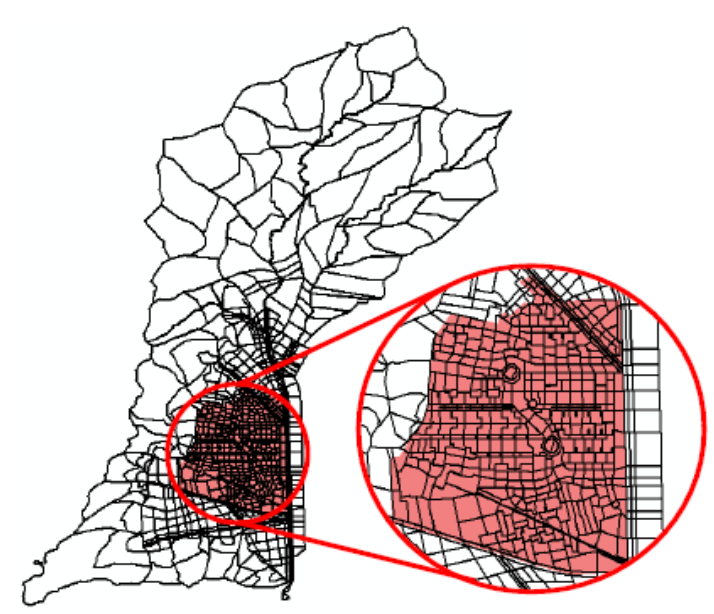

(b)

Figura 4 - Divisão de Células: (a) Situação Atual e Alternativas Sem Controle e Conforme o Padrão da Orla; (b) Alternativa de Urbanização Sustentável

A avaliação quantitativa da resiliência foi feita com o Índice de Resiliência a Inundações - IRES (TEBALDI et al., 2015; BERTILSSON; WIKLUND, 2015). O IRES é um índice quantitativo multicritério com variação de 0 a 1 em uma escala normalizada (quanto mais próximo de 1, mais resiliente). Sua metodologia se baseia no conceito de minimização do Risco, combinando seus componentes básicos de perigo e vulnerabilidade, considerados no sentido contrário de sua efetiva materialização. Com isso, o índice conjuga seis subíndices, referentes às características de inundação, idade da população afetada, vulnerabilidade, valor relativo e exposição, agrupados em um somatório (Equação 1).

IRES $=\left[1-\left(I_{P}^{n_{1}} \cdot I_{E}^{n_{2}} \cdot I_{S}^{n_{3}}\right) \cdot m_{1}\right]+\left(1-I_{V R}\right) \cdot m_{2}+\left(1-I_{F P}\right) \cdot m_{3}+\left(1-I_{I d}\right) \cdot m_{4}$

Onde:

- IRES - Índice de Resiliência a Inundações;

- $I_{p}$ - Subíndice "Perigo", correspondente à lâmina d'água dentro das edificações, em uma dada área, capaz de gerar dados, dependendo da altura atingida;

- $I_{E}$ - Subíndice "Exposição", relativo à densidade de domicílios presente nas áreas inundáveis;

- $I_{s}$ - Subíndice "Susceptibilidade", relativo às edificações efetivamente afetadas pelas cheias (casa e pavimentos térreos de edifícios) nas áreas inundáveis;

- $I_{V R}$ - Subíndice "Valor Relativo", relativo às perdas provocadas pela inundação, sofridas pela população local, divididas pela renda familiar, indicando a importância relativa das perdas provocadas pela inundação, quando comparada a capacidade de reposição da população, indicada pela sua renda; 
- $I_{F P}$ - Subíndice "Fator de Permanência", relativo ao tempo de alagamento mantido acima de determinadas lâminas de referência, associadas a perturbações em residências e na circulação de pedestres e no tráfego;

- $I_{i d}$ - Subíndice "Idade da População", relativo ao percentual de jovens e crianças (menores de 15 anos) e idosos (maiores de 60 anos) na população residente na área analisada;

- $m_{1}, m_{2}, m_{3}, m_{4}$ - Pesos associados a cada uma das parcelas, atribuídos em função de sua importância relativa. O somatório dos pesos " $m$ " deve resultar 1 (adotado: $m_{1}=m_{2}=m_{3}=m_{4}=0,25$ );

- $n_{1}, n_{2}, n_{3}$ - Pesos associados aos subíndices $I_{P}, I_{E}, I_{s}$ atribuídos em função de sua importância relativa. O somatório dos pesos " $n$ " deve resultar $1\left(n_{1}=\right.$ 0,$5 ; n_{2}=n_{3}=0,25$, como sugestão inicial).

Dados socioeconômicos do IBGE (2010), relativos à renda familiar e classe social, e também das edificações, foram utilizados. Também foi necessário realizar um estudo prospectivo em relação à distribuição da população e de domicílios nas alternativas de uso e ocupação do solo considerados.

Para a avaliação quantitativa da requalificação ambiental, foi considerado o Índice de Requalificação Fluvial Urbana (VERÓL, 2013; VERÓL et al., 2018b), proposto com o objetivo de medir a qualidade do sistema fluvial como sistema natural, em bacias urbanas. O REFLU (Equação 2) varia entre 0 e 1, sendo o valor mais próximo de 1 correspondente a uma melhor qualidade ambiental, e é composto por quatro subíndices: Estado Geral da Bacia, Conectividades, Situação das Margens e Mitigação de Cheia, também variáveis entre 0 e 1.

$$
R E F L U=I_{E G B} \cdot p_{E G B}+I_{C} \cdot p_{C}+I_{S M} \cdot p_{S M}+I_{M C} \cdot p_{M C}
$$

Onde:

- REFLU - Índice de Requalificação Fluvial;

- $I_{E G B}$ - Subíndice "Estado Geral da Bacia", relativo aos impactos da ocupação da bacia hidrográfica relacionados ao uso do solo e a gestão de recursos hídricos. Indicadores: "Permeabilidade" e "Saneamento";

- $I_{c}$ - Subíndice "Conectividades", relativo ao nível de conectividade do curso d'água principal. Indicadores: "Conectividade Transversal", "Conectividade Longitudinal" e "Conectividade Vertical";

- $I_{S M}$ - Subíndice "Situação das Margens", relativo às extensões de margem com configuração original e preservação de mata ciliar. Indicadores: "Margens Vegetadas" e "Margens Não Ocupadas por Casas".

- $I_{M c}$ - Subíndice "Mitigação de Cheia", relativo aos alagamentos nas áreas urbanizadas. Relaciona-se o volume de alagamento no pico da cheia ao volume total precipitado.

- $\quad P_{E G B}, P_{C}, P_{S M}, P_{M C}$ - Pesos associado aos subíndices, atribuídos em função

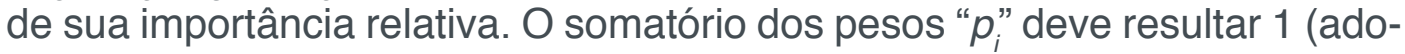
tado: $\left.P_{E G B}=P_{C}=P_{S M}=P_{M C}=0,25\right)$. 


\section{I RESULTADOS E DISCUSSÕES}

As manchas de inundação (Figura 5) confirmam as expectativas iniciais de que quanto mais impermeável a configuração urbana e com saídas mais limitadas para os canais, maiores são as lâminas d'água. Como pode ser observado, as alternativas de Urbanização sem Controle (b) e conforme Padrão da Orla Local (c) apresentam uma inundação generalizada, com concentração das maiores lâminas d'água nas margens dos canais e, principalmente, nas confluências entre rios. Na Alternativa de Urbanização Sustentável, por sua vez, parques cumprem a função de reservatórios de detenção, recebendo boa parte dos escoamentos superficiais. No entanto, ainda é possível observar inundações espraiadas devido ao caráter plano do terreno, com lâminas de até $0,35 \mathrm{~m}$, que podem ser minoradas por meio do funcionamento da rede de microdrenagem, não representada no modelo.

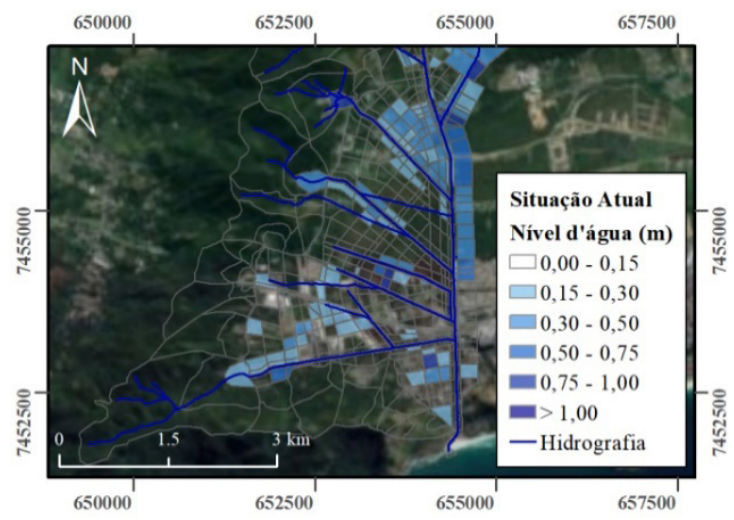

(a)

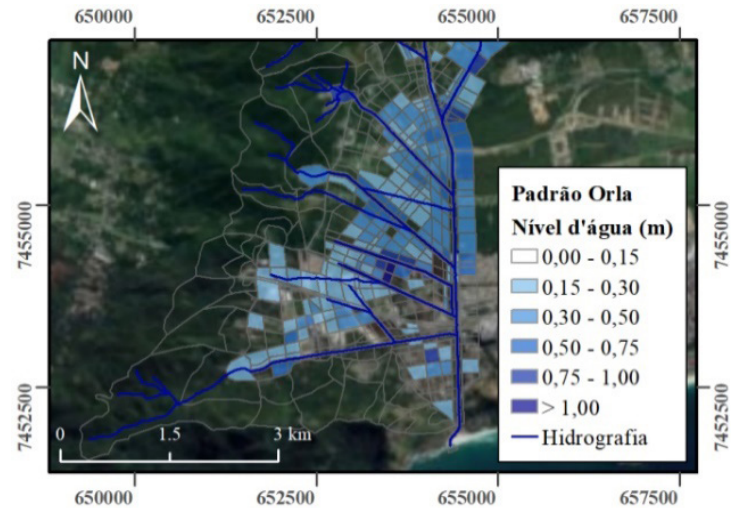

(c)

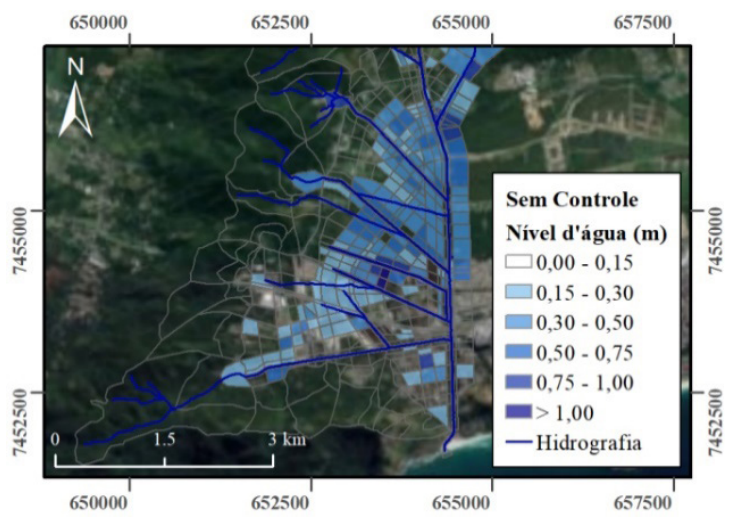

(b)

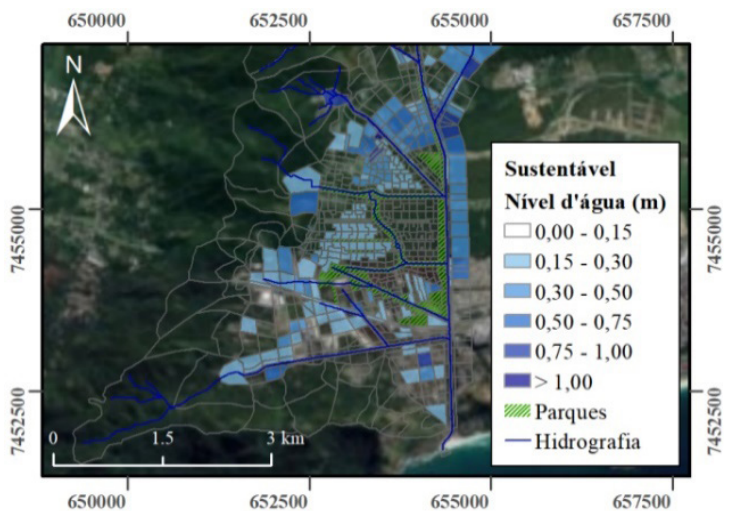

(d)

Figura 5 - Manchas de Inundação: (a) Situação Atual; (b) Alternativa de Urbanização Sem Controle; (c) Alternativa de Urbanização Conforme Padrão da Orla Local; (d) Alternativa de Urbanização Sustentável

Os resultados da aplicação do Índice de Resiliência a Inundações (IRES) são apresentados nos mapas da Figura 6, e de forma numérica, na Tabela 1. É possível observar, através dos mapas, que as alternativas consideradas impactam diretamente a resiliência da bacia. Como esperado, a Alternativa de Urbanização Sem Controle, que representa a pior configuração de expansão, altera significativamente a resiliência 
para uma situação pior, enquanto a que considera a Urbanização Sustentável é capaz de até melhorar a resiliência em alguns lugares.
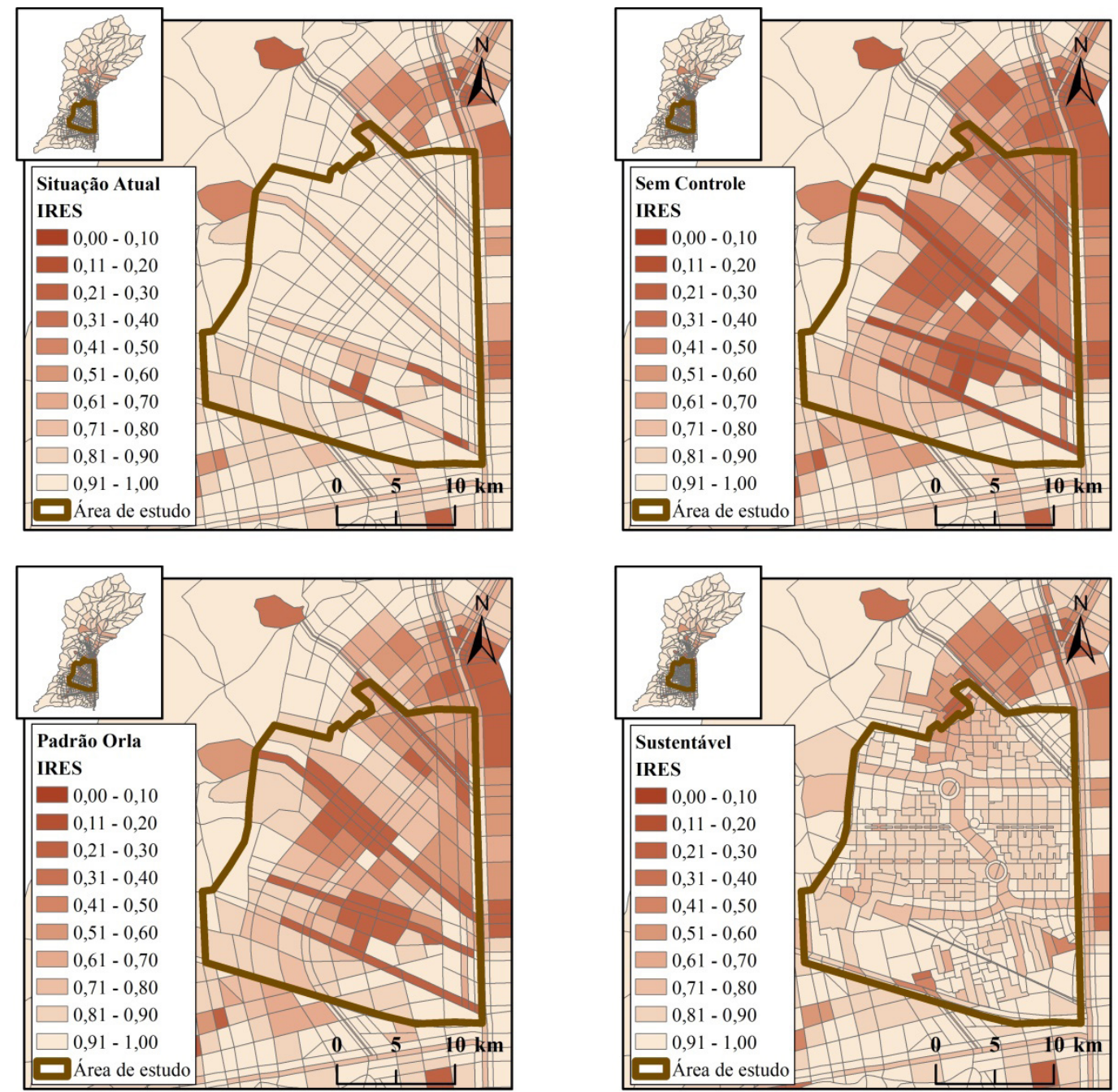

Figura 6 - Resultados da Aplicação do IRES com foco na área de estudo

\begin{tabular}{|l|c|c|}
\hline \multicolumn{1}{|c|}{ Alternativas } & IRES - Bacia & IRES - Recorte \\
\hline Situação Atual & 0,81 & 0,90 \\
\hline Urbanização Sem Controle & 0,79 & 0,66 \\
\hline Urbanização Padrão Orla Local & 0,80 & 0,72 \\
\hline Urbanização Sustentável & 0,81 & 0,87 \\
\hline
\end{tabular}

Tabela 1 - Resultados da Aplicação do IRES - Valores médios para a bacia e para o recorte da área de estudo

Ao se comparar as diferentes alternativas para os valores obtidos somente no recorte da área de estudo, onde foram introduzidas as alterações de cada expansão considerada, pode-se observar, então, que as Alternativas de Urbanização Sem Controle e Conforme Padrão da Orla Local são capazes de diminuir significativamente os valores de resiliência da região, ou seja, a capacidade de recuperação da área frente a um evento de inundação. A Alternativa de Urbanização Sustentável, por sua vez, é capaz de praticamente manter o valor atual (com suas características naturais) 
mesmo com a introdução de um projeto de loteamento e ocupação da área.

Os resultados obtidos com a aplicação do índice REFLU, apresentados na Tabela 2, permitem concluir que as Alternativas de Urbanização sem Controle e Conforme Padrão da Orla Local reduzem bastante as características naturais da bacia, diminuindo assim a sua qualidade ambiental. Por outro lado, a Alternativa de Urbanização Sustentável é capaz de conciliar a expansão urbana com o ganho de qualidade ambiental para a bacia.

\begin{tabular}{|l|c|}
\hline \multicolumn{1}{|c|}{ Alternativas } & REFLU \\
\hline Situação Atual & 0,78 \\
\hline Urbanização Sem Controle & 0,47 \\
\hline Urbanização Padrão Orla Local & 0,47 \\
\hline Urbanização Sustentável & 0,89 \\
\hline
\end{tabular}

Tabela 2 - Resultado da Aplicação do Índice REFLU

A grande diferença entre os valores obtidos pode ser melhor entendida quando se avalia o impacto de alguns subíndices no resultado final. Por exemplo, destacamse os subíndices "Conectividades" e "Situação das Margens". Como na Alternativa de Urbanização Sustentável é previsto o remanejamento de habitações irregulares na calha do rio, promovendo maior liberdade de extravasamento, os valores de conectividade transversal tendem a ser maiores do que na Situação Atual e nas Alternativas de Urbanização sem Controle e Conforme Padrão da Orla Local. Além disso, nestas últimas alternativas, os canais passam a ser concretados, fazendo com que a conectividade vertical se iguale a 0 . No que diz respeito à "Situação das Margens", na Alternativa de Urbanização Sustentável, tende-se ao aumento da extensão de rio com margens vegetadas e não ocupadas por casa, mantendo ou melhorando tais indicadores em relação a conjuntura atual. Destaca-se ainda que, embora haja impacto na permeabilidade pelo processo de urbanização, as alterações foram realizadas em um recorte que representa uma parcela pequena da área da bacia. Desta forma, a presença do Parque Estadual da Pedra Branca em grande parte da bacia mantém o valor do indicador de permeabilidade alto em todas as alternativas.

\section{I CONCLUSÕES}

A transição de um ambiente mais natural - situação atual - para um ambiente urbanizado intensifica as inundações devido às alterações no uso do solo. Além disso, é de se esperar também uma perda na qualidade ambiental dos rios e da bacia nesse processo. Entretanto, os efeitos da urbanização podem ser minorados, por exemplo, por meio das medidas adotadas na alternativa de urbanização sustentável, tais como: a preservação das margens e fundos de vale, a destinação de espaços ao amortecimento de cheia, entre outras. 
Os resultados obtidos com a modelagem matemática e com a aplicação do REFLU e do IRES, permitem constatar, quantitativamente e por meio da comparação entre os diversos cenários, a importância de um planejamento urbano que considera o desenvolvimento sustentável, respeitando o espaço dos rios e permitindo uma maior integração entre o ambiente natural e o ambiente construído. Com a Alternativa de Urbanização Sustentável, observou-se um ganho ambiental e a manutenção da resiliência atual da região, com características ainda bem naturais, mesmo com o projeto de uma ocupação urbana.

\section{AGRADECIMENTOS}

O presente trabalho foi realizado com apoio da Coordenação de Aperfeiçoamento de Pessoal de Nível Superior - Brasil (CAPES) [Código de Financiamento 001; 1681776]; Conselho Nacional de Desenvolvimento Científico e Tecnológico [303240/2017-2].

\section{REFERÊNCIAS}

BATTEMARCO, B. P.; YAMAMOTO, L. M. T.; VERÓL, A. P.; MIGUEZ, M. G. Avaliação Quantitativa de Alternativas de Uso e Ocupação do Solo, sob Aspectos de Resiliência a Inundações e Requalificação Ambiental. In: Encontro Nacional de Águas Urbanas, 12., 2018, Maceió. Anais... Maceió: Associação Brasileira de Recursos Hídricos, 2018.

BERTILSSON, L.; WIKLUND, K. Urban Flood Resilience: A case study on how to integrate flood resilience in urban planning. 2015. 79f. Dissertação (Mestrado em Division of Water Resources Engineering) - Lund University, Lund, 2015.

CIRF - Centro Italiano per la Riqualificazione Fluviale. La riqualificazione fluviale in Italia: linee guida, strumenti ed esperienze per gestire i corsi d'acqua e il territorio. 1. ed. Nardini A \& Sansoni G (Ed). Venezia: Mazzanti, 2006.

IBGE - Instituto Brasileiro de Geografia e Estatística. Censo Demográfico 2010. Rio de Janeiro, 2011.

JHA, A. K.; MINER, T. W.; GEDDED, Z. S. Building Urban Resilience: Principles, Tools and Practice, Washington D. C.: The World Bank, 2012.

MASCARENHAS, F.C.B.; MIGUEZ, M.G. Urban Flood Control through a Mathematical Flow Cell Model. In: Water International Resources, 2002, Illinois. v. 27, n. 2, p. 208-218.

MIGUEZ, M. G.; BATTEMARCO, B. P.; DE SOUSA, M. M.; REZENDE, O.M.; VERÓL, A.P.; GUSMAROLI, G. Urban Flood Simulation Using MODCEL-An Alternative Quasi-2D Conceptual Model, Water, Basel, v. 9,n. 6, pp. 445, 2017.

TEBALDI, I. M.; MIGUEZ, M. G.; BATTEMARCO, B. P.; REZENDE, O. M.; VERÓL, A. P. Índice de Resiliência a Inundações: Aplicação para a Sub-bacia do Rio Joana, Rio de Janeiro, RJ. In: Simpósio Brasileiro de Recursos Hídricos, 21., 2015, Brasília. Anais... Brasília: Associação Brasileira de Recursos Hídricos, 2015. 
UNISDR - Estrategia Internacional para Reducción de Desastres de las Naciones Unidas, Terminología sobre reducción del riesgo de desastres. Ginebra: Naciones Unidas, 2009.

UNISDR - The United Nations Office for Disaster Risk Reduction, How To Make Cities More Resilient: A Handbook For Local Government Leaders. Geneva: United Nations, 2017.

VERÓL, A. P. Requalificação Fluvial Integrada ao Manejo de Águas Urbanas para Cidades mais Resilientes. 2013. 367 f. Tese (Doutorado em Engenharia Civil) - COPPE, Universidade Federal do Rio de Janeiro, Rio de Janeiro, 2013.

VERÓL, A. P.; MIGUEZ, M. G.; YAMAMOTO, L. M. T.; BRITO, F. A.; FERNANDEZ, F. F.; BATTEMARCO, B. P.; REGO, A. Q. S. F., Guidelines for the Urbanization of Environmentally Sensitive Areas Subjected to Floods, In: SDEWES Latin American Conference on Sustainable Development of Energy, Water, and Environment Systems, 1., 2018a. Rio de Janeiro, 2018, p. 1-19.

VERÓL, A. P.; MIGUEZ, M. G.; BATTEMARCO, B. P.; HADDAD, A. N., The Urban River Restoration Index (URRIx) as a Supporting Tool for Decision Making on Urban Flood Control Alternatives. In: SDEWES Latin American Conference on Sustainable Development of Energy, Water and Environment Systems, 1., 2018b. Rio de Janeiro, 2018, p. 1-19. 


\section{CAPÍTULO 7}

\section{MANIFESTAÇÕES PATOLÓGICAS EM EDIFICAÇÕES PÚBLICAS: ESTUDO DE CASO EM ALGUNS TEATROS NA CIDADE DO RECIFE/PE}

Carlos Fernando Gomes do Nascimento Universidade Católica de Pernambuco Recife - Pernambuco Eduardo José Melo Lins Universidade de Pernambuco Recife - Pernambuco Eliana Cristina Barreto Monteiro Universidade Católica de Pernambuco/ Universidade de Pernambuco Recife - Pernambuco

Amanda de Morais Alves Figueira Universidade de Pernambuco Recife - Pernambuco Cynthia Jordão de Oliveira Santos Universidade de Pernambuco Recife - Pernambuco

Débora Cristina Pereira Valões Universidade de Pernambuco

Recife - Pernambuco Edenia Nascimento Barros Universidade de Pernambuco Recife - Pernambuco

George da Mota Passos Neto Universidade de Pernambuco Recife - Pernambuco Gilmar Ilário da Silva Universidade de Pernambuco Recife - Pernambuco

Lucas Rodrigues Cavalcanti Universidade de Pernambuco Recife - Pernambuco
Marcionillo de Carvalho Pedrosa Junior Universidade de Pernambuco

Recife - Pernambuco

Maria Angélica Veiga da Silva Universidade de Pernambuco Recife - Pernambuco Mariana Santos de Siqueira Bentzen Universidade de Pernambuco

Recife - Pernambuco

Paula Gabriele Vieira Pedrosa Universidade Maurício de Nassau

Recife - Pernambuco

RESUMO: Edifícios históricos demandam uma abordagem especial no tocante à manutenção predial. Os Teatros A e B são edificações públicas relevantes do ponto de vista arquitetônico, histórico e cultural da cidade do Recife. Foram realizadas inspeções de forma visual nos dois teatros, tendo em vista a detecção das principais manifestações patológicas e o diagnóstico preliminar dos problemas que afetam a vida útil dos mencionados edifícios. A partir dos dados levantados e analisados foram detectadas corrosão de armaduras, deterioração de tijolos maciços cerâmicos, fissuras em alvenarias, eflorescência em concreto, bolor e manchas de infiltração. Nos dois prédios foram identificados, 
com maior frequência no Teatro $A$, fissuras nas paredes, bem como problemas causados por umidade, tendo como resultado a presença de manchas de infiltração. É recomenda a elaboração e implantação de um plano de manutenção preventiva e corretiva para os teatros. É necessário avaliar a espessura do cobrimento das peças estruturais, bem como proceder à recuperação dos pontos de corrosão nas vigas. A deterioração de tijolos das alvenarias no Teatro B exige uma ação de recuperação breve.

PALAVRAS-CHAVE: Degradação de Estruturas, Teatros Públicos, Patologias.

\section{PATHOLOGICAL MANIFESTATIONS IN PUBLIC BUILDINGS: CASE STUDY IN}

\section{SOME THEATERS IN THE CITY OF RECIFE/PE}

ABSTRACT: Historic buildings require a special approach to building maintenance. The Theaters $A$ and $B$ are public buildings relevant from the architectonic, historical and cultural point of view of the city of Recife. Visual inspections were carried out in both theaters, in order to detect the main pathological manifestations and the preliminary diagnosis of the problems affecting the useful life of the aforementioned buildings. From the collected and analyzed data were detected reinforcement corrosion, deterioration of solid ceramic bricks, cracks in masonry, efflorescence in concrete, mold and infiltration spots. In the two buildings were identified, more frequently in the Theater $A$, cracks in the walls, as well as problems caused by humidity, resulting in the presence of infiltration spots. It is recommended to prepare and implement a preventive and corrective maintenance plan for theaters. It is necessary to evaluate the thickness of the covering of the structural parts, as well as to recover the corrosion points on the beams. Brick deterioration of the masonry at the Theater $\mathrm{B}$ requires a brief recovery action.

KEYWORDS: Degradation of Structures, Public Theaters, Pathologies.

\section{I INTRODUÇÃO}

Os seres humanos vivem em ambientes construídos envelhecidos e com diversos problemas de manutenção, sendo a eficiente manutenção destas infraestruturas e dos materiais de construção que as constituem essenciais para o avanço a um futuro ambientalmente sustentável (RAKHA e GORODETSKY, 2018).

Dentre os principais problemas patológicos que podem ocorrer nas estruturas dos ambientes construídos (casas, edifícios, etc.), podem ser citados a corrosão, eflorescência, bolor e mofo, fissuras e trincas, dentre outras manifestações (NASCIMENTO et al., 2019).

Edifícios históricos ou emblemáticos têm valor estético e arquitetônico únicos, além das funções específicas para os quais foram concebidos, os quais, por consequência, demandam uma abordagem especial no tocante à conservação predial, reparo, recuperação e reforço estrutural, ou ainda quando do restauro de elementos 
construtivos singulares que os compõem (KAAMIN et al., 2017).

No Brasil, a falta de cuidado com os edifícios públicos, particularmente com a manutenção do ambiente construído, seja na fase de projeto, execução e uso, é conduta que em regra não integra o planejamento das obras, fazendo com que o risco de colapso estrutural dessas obras seja crescente ao longo dos últimos anos.

Segundo o que consta na Portaria $n^{\circ} 420 / 2010$ do Instituto do Patrimônio Histórico e Artístico Nacional (IPHAN), os estudos, projetos, obras ou intervenções em bens culturais tombados, dentre as quais as edificações, devem obedecer a alguns princípios, dentre eles, o princípio da prevenção, através do qual deve ser impedida a sua degradação, perda física ou de autenticidade, ou ainda a sua fragmentação.

Com construção iniciada em 1839 pela Sociedade Harmônico Theatral, o Teatro A é um dos mais antigos equipamentos culturais da cidade do Recife. As portas do teatro foram abertas pela primeira vez em 1842 e chegou a funcionar por 18 anos, mas foi vendido e transformado em um armazém de açúcar, tendo apenas sua fachada preservada.

Hoje, juntamente com o Teatro B, instalado no mesmo terreno, são edificações públicas relevantes do ponto de vista arquitetônico, histórico e cultural e, integram o Centro de Formação e Pesquisa das Artes Cênicas A, voltado para o desenvolvimento de projetos de formação e incentivo às artes cênicas (PREFEITURA DO RECIFE, 2019).

Tendo em vista a importância do Teatro A - edificação em processo de instrução para tombamento federal, bem como do Teatro B para o circuito histórico e cultural da cidade do Recife.

O presente estudo tem como objetivo a análise do estado atual, no que tange à integridade das estruturas que integram as mencionadas edificações históricas, após a qual é emitido um diagnóstico e recomendações para a ampliação da vida útil dos mesmos.

\section{I REVISÃO BIBLIOGRÁFICA}

\subsection{Patologias das construções}

Assim como os seres humanos, as edificações também sofrem com a ação do tempo, mudanças climáticas e outros males congênitos ou adquiridos. Em vista disto, existe a patologia, ciência responsável por estudar os desvios, sintomas, causas e origens das manifestações patológicas.

Na construção civil, é comum se observar a ocorrência de diversas manifestações patológicas, as quais causam desconforto e insegurança aos usuários, além de proporcionar eventuais danos às estruturas. O estudo e tratamento das manifestações devem ser sempre realizados visando a segurança dos usuários e o aumento da vida útil dos edifícios. 


\subsection{Vida útil e durabilidade}

Na norma da Associação Brasileira Regulamentadora NBR 6118 (ABNT, 2014) item 6.2, consta que a vida útil de projeto é o "período de tempo durante o qual se mantêm as características das estruturas de concreto, desde que atendidos os requisitos de uso e manutenção prescritos pelo projetista e pelo construtor".

Conforme consta na ISO 13823:2008, entende-se por vida útil o período de tempo efetivo em que a estrutura ou parte de seus componentes atendem suas funções com um desempenho mínimo de projeto, ausente de algum procedimento de manutenção. O não cumprimento das especificações acarreta reparos e recuperações, ou até mesmo reforço estrutural, os quais poderiam ser evitados se fossem realizados os procedimentos necessários.

Segundo Félix et al., (2018), entende-se durabilidade como o parâmetro que relaciona a aplicação das características de deterioração do material concreto, ou seja, da qualidade do concreto, e dos sistemas estruturais a uma determinada construção.

Assim a individualização pela avaliação da resposta que dará aos efeitos da agressividade ambiental, refere-se à capacidade de transporte dos líquidos e gases contidos no meio ambiente para a região interior do concreto, sendo definindo, então, a vida útil da mesma.

De acordo com a Norma Brasileira Regulamentadora NBR 6118 (ABNT, 2014), durabilidade "Consiste na capacidade de a estrutura resistir às influências ambientais previstas e definidas em conjunto pelo autor do projeto estrutural e o contratante, no início dos trabalhos de elaboração do projeto.

\section{I METODOLOGIA}

O estudo foi desenvolvido segundo cinco etapas (Figura 01), quais sejam: i) revisão bibliográfica relacionada ao tema; ii) elaboração de uma ficha de inspeção com o croquis de cada teatro; iii) inspeção em campo com coleta de dados; iv) análise dos dados; e v) compilação dos resultados e relatório fotográfico.

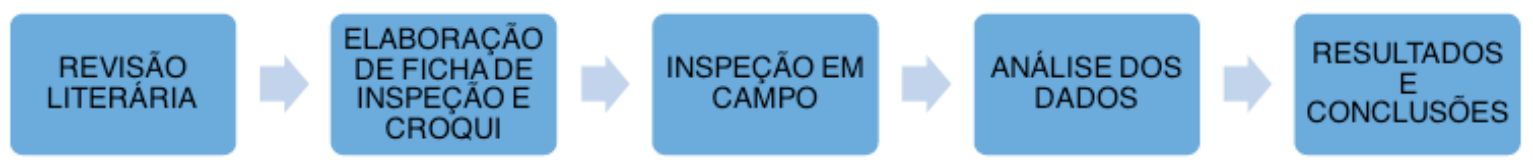

Figura 1 - Etapas de desenvolvimento do estudo.

Fonte: Autores, (2019).

As legendas estão subdivididas segundo os elementos construtivos, quais sejam: manifestações patológicas no piso; manifestações patológicas na parede; e manifestações patológicas no teto (Figura 02). 


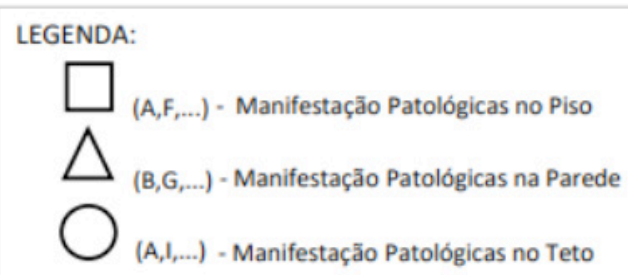

Tipologias das Manifestaçōes Patológicas:

(A) Desplacamento de concreto (B) Desplacamento de revestimento/alvenaria

$\begin{array}{lll}\text { (C) Armaduras expostas com corrosão incipiente } & \text { (D) Armaduras expostas em processo evolutivo de corrosão }\end{array}$

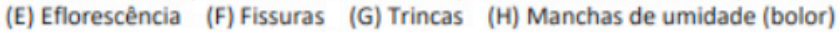

(I) Infiltração em concreto (J) Infiltração por capilaridade em alvenaria (K) Infiltração na coberta

(L) Estruturas metálicas com corrosão incipiente (M) Estruturas metálicas em processo evolutivo de corrosão

(N) Outras manifestaçōes (especificar)

Figura 2 - Legenda da ficha de inspeção.

Fonte: Autores, (2019).

Por fim, os dados foram compilados com uso do software Excel, após os quais foram quantificados e analisados. Estes dados permitiram a análise das manifestações patológicas por elementos construtivos, possibilitando a avaliação preliminar de quais foram os elementos mais atingidos e os tipos de manifestações mais frequentes.

\section{I RESULTADOS E DISCUSSÕES}

\subsection{Teatro $A$}

\subsubsection{Corrosão das armaduras}

Armadura exposta em processo evolutivo de corrosão e desplacamento (desagregação) de concreto localizados na laje da sala de ensaios (Figura 03). É provável que as causas dessas manifestações patológicas tenham sido a ausência de espaçadores e ou cobrimento mínimo das armaduras insuficiente, potencializadas pela presença de cloretos livres e CO2.

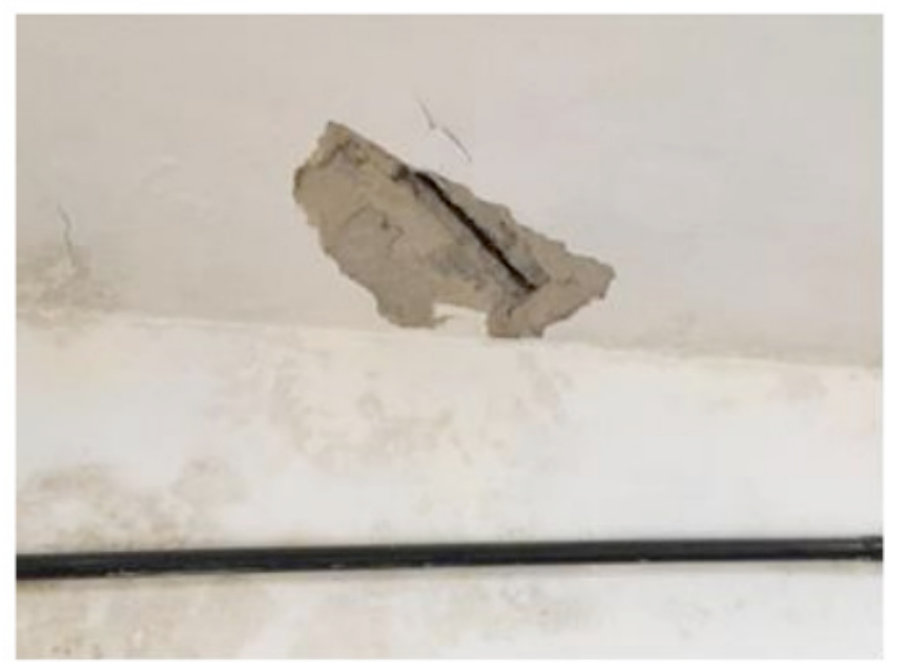

Figura 3 - Laje da sala de ensaios com armadura exposta e desplacamento de concreto.

Fonte: Autores, (2019). 


\subsubsection{Fissuras e manchas em alvenarias}

Fissuras em alvenaria a 45 graus e manchas em paredes sob a estrutura do tablado em madeira do palco - depósito (Figuras 04-A e 04-B).
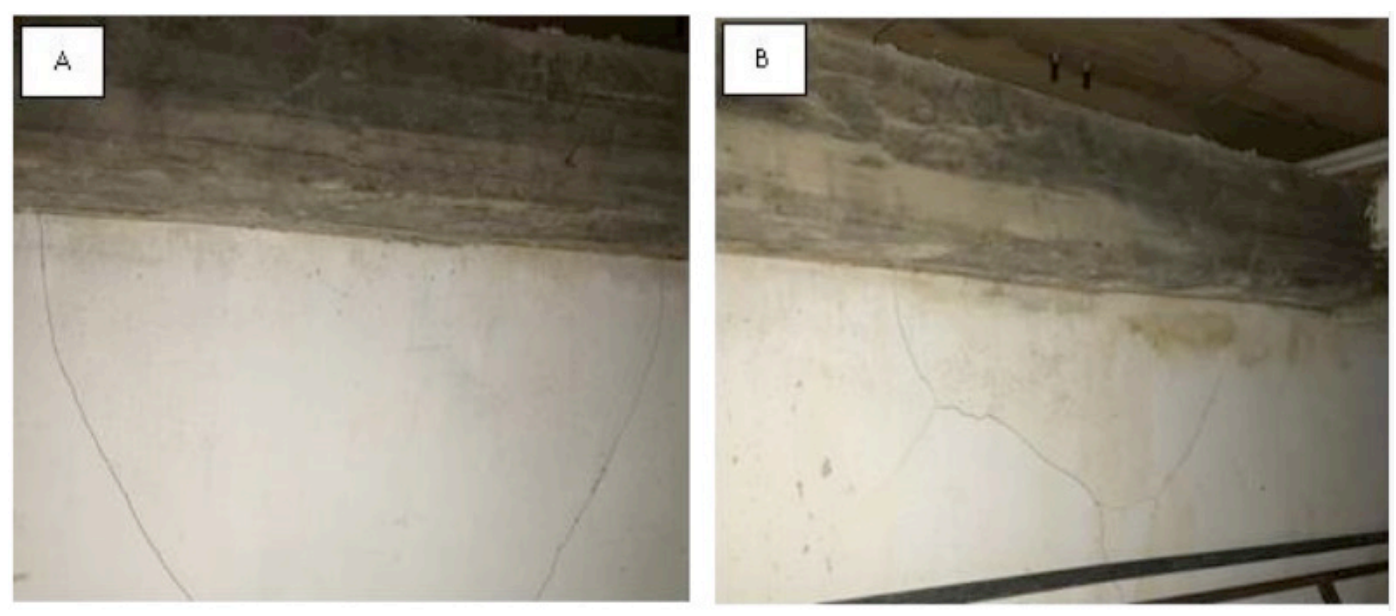

Figura 4 - (A) Fissuras em parede; e (B) Fissuras e manchas em parede.

Fonte: Autores, (2019).

As fissuras são uma das manifestações patológicas mais presentes nas estruturas, dentre elas nas alvenarias, as quais podem ter sido causadas devido as sobrecargas e ou temperaturas. No caso particular, a configuração em 45 graus das fissuras nas paredes sugere a incidência de esforços de flexão da viga de madeira sobre as alvenarias.

\subsubsection{Infiltração por capilaridade em alvenaria}

Manchas de infiltração por capilaridade nas alvenarias da sala de ensaios (Figura 05). As manchas estão provavelmente vinculadas à falha ou ausência do sistema de impermeabilização.

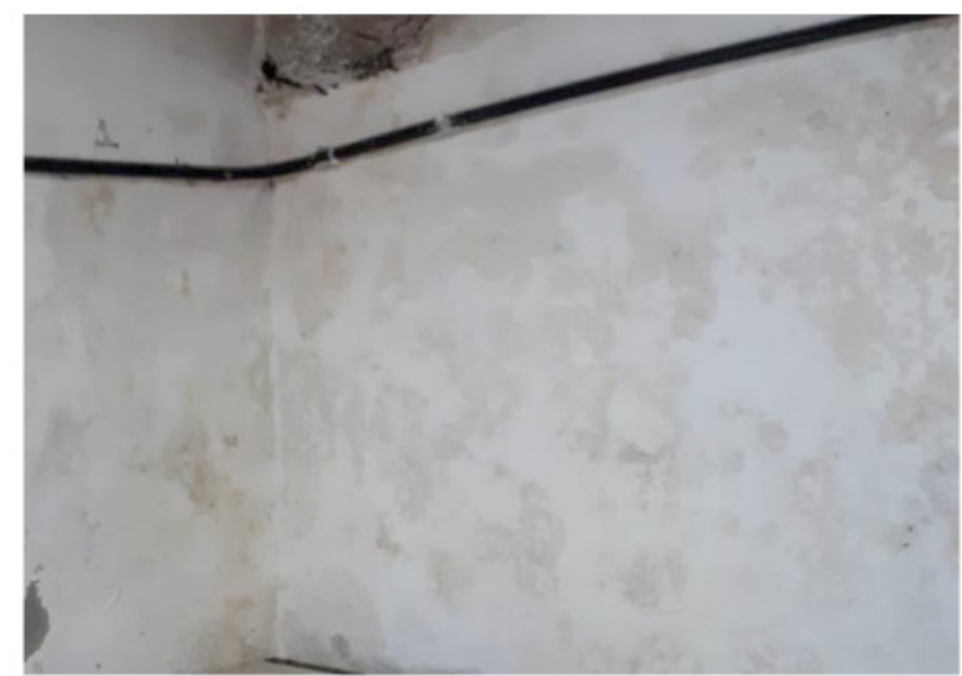

Figura 5 - Descascamento da pintura em paredes internas. Fonte: Autores, (2019). 


\subsubsection{Segregação de concreto (viga)}

A segregação dos materiais e a adesão dos mesmos à face da viga (Figura 06), pode ter ocorrido em função da abertura das formas pelo efeito das pressões sobre estas, as quais certamente foram provocadas pelo incorreto adensamento do concreto fresco (incorreto posicionamento dos vibradores de imersão).

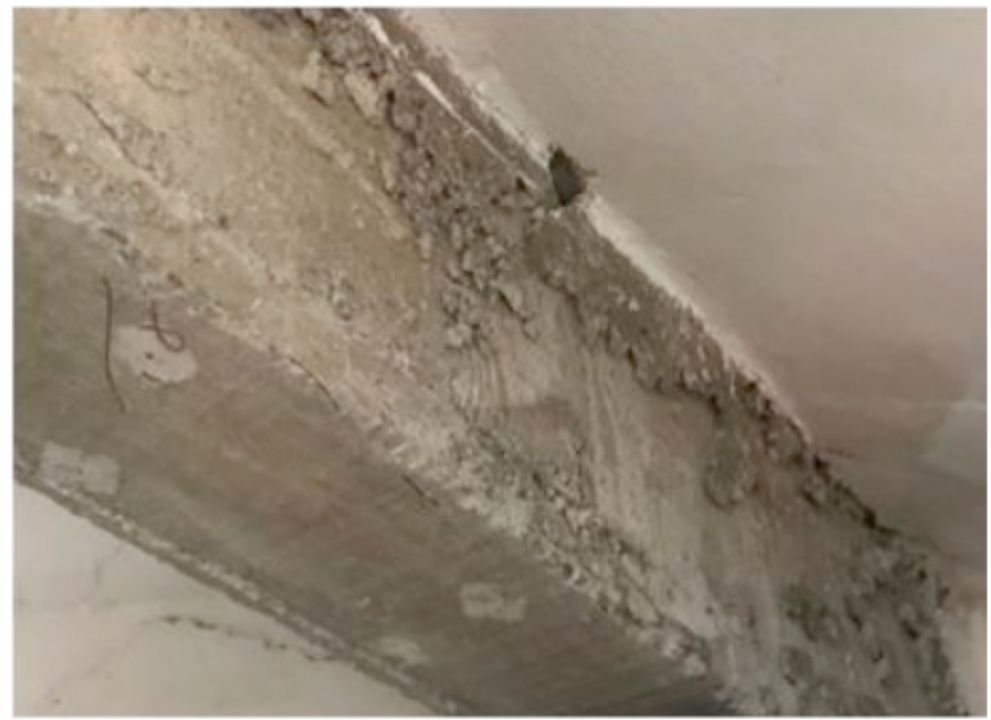

Figura 6 - Viga da sala de ensaios com concreto segregado aderido à fase.

Fonte: Autores, (2019).

\subsection{Teatro B}

\subsubsection{Degradação de alvenarias}

Degradação de alvenarias e respectiva argamassa de assentamento dos tijolos, as quais estão localizadas na sala de apresentações. A manifestação patológica foi provavelmente provocada pela perda de resistência dos materiais constituintes dos tijolos cerâmicos maciços e da argamassa de cimento e areia, derivada de fatores relacionados a reações e ou alterações físico-químicas, químicas e ou biológicas (Figura 07-A e 07-B).
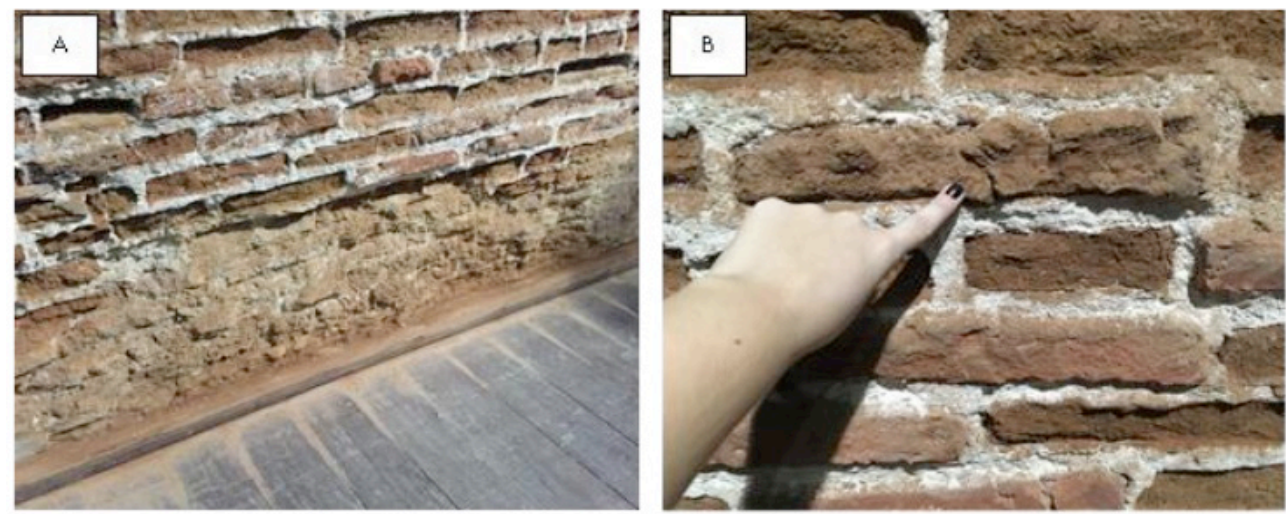

Figura 7 - (A) e (B) Degradação em alvenarias de tijolos cerâmicos maciços na sala de apresentações.

Fonte: Autores, (2019) 
Os citados fatores surgem, em geral, em decorrência da falta de cuidados na etapa de projeto, na escolha equivocada de materiais, da falta de controle durante a execução da obra ou, ainda, em virtude da não realização de manutenções preventivas durante a vida útil da edificação - o caso em apreço.

Importante destacar que as alvenarias de tijolos maciços, em franco processo de degradação, integram a estrutura de apoio à coberta da edificação, bem como as estruturas de apoio às cargas cênicas, quais sejam, os equipamentos de iluminação e som, bem como cabos para içamento/sustentação dos atores em cena.

\subsubsection{Armaduras expostas com corrosão incipiente}

As faces inferiores (bases) de algumas vigas transversais da estrutura de apoio da coberta apresentam, em pontos localizados, armaduras expostas com corrosão incipiente (Figura 08-A e 08-B). É provável que as causas destas manifestações patológicas tenham sido a ausência de espaçadores entre as armaduras e formas e o cobrimento de concreto insuficiente (abaixo do mínimo definido em norma).
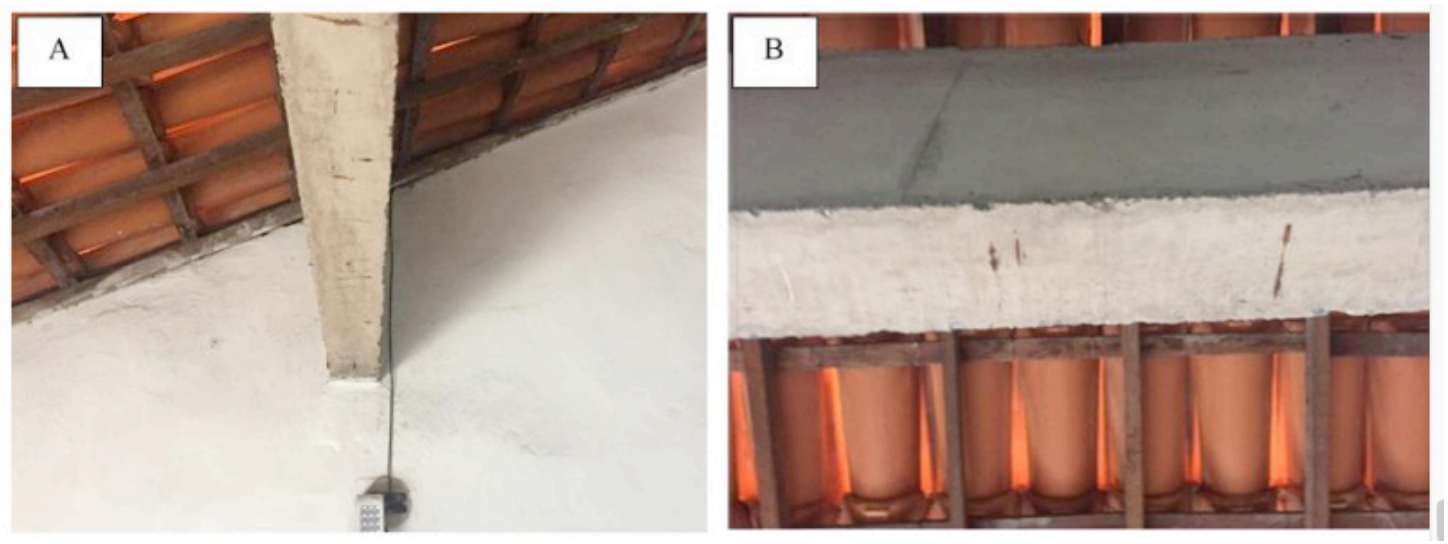

Figura 8 - (A) e (B) Vigas transversais da estrutura de apoio da coberta com armaduras expostas com corrosão incipiente.

Fonte: Autores, (2019).

\subsubsection{Fissuras em alvenaria (movimentações higroscópicas)}

Fissuras em alvenaria da fachada principal, as quais foram provocadas por variação de umidade dos materiais - movimentações higroscópicas (Figura 09-A e 09-B). As fissuras presentes na fachada provocam a penetração de umidade para o interior do edifício, particularmente quando da batida de chuvas sobre a face exterior da alvenaria da fachada. 

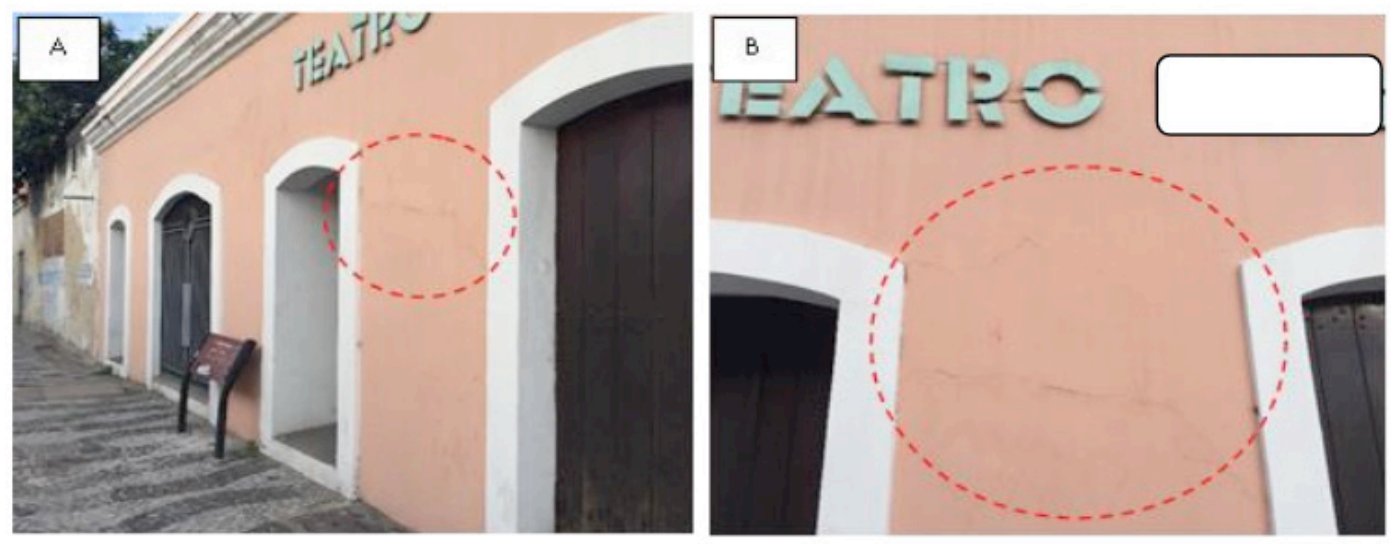

Figura $9-(A)$ e (B) Fissuras em alvenaria provocadas por movimentação higroscópica. Fonte: Autores, (2019).

Os autores Melo e Carasek (2014), Galletto e Andrello (2013), verificaram a influência de alguns parâmetros ambientais como radiação solar, direção das chuvas, variação térmica e umidade na incidência de manifestações patológicas em fachadas.

Estes fatores podem variar de intensidade segundo a posição geográfica da fachada do edifício, gerando uma maior incidência de danos em alguma das fachadas e na área interna dos mesmos derivados da associação dos mencionados fatores.

\subsubsection{Manchas de umidade (bolor) e infiltração na coberta}

Bolor (mofo) nos caibros e terças da coberta (Figura 10) devido ao excesso de umidade. As possíveis causas dessa manifestação patológica são: telhas fissuradas e ou quebradas; e ausência e ou deficiência de rufos e ou calhas.

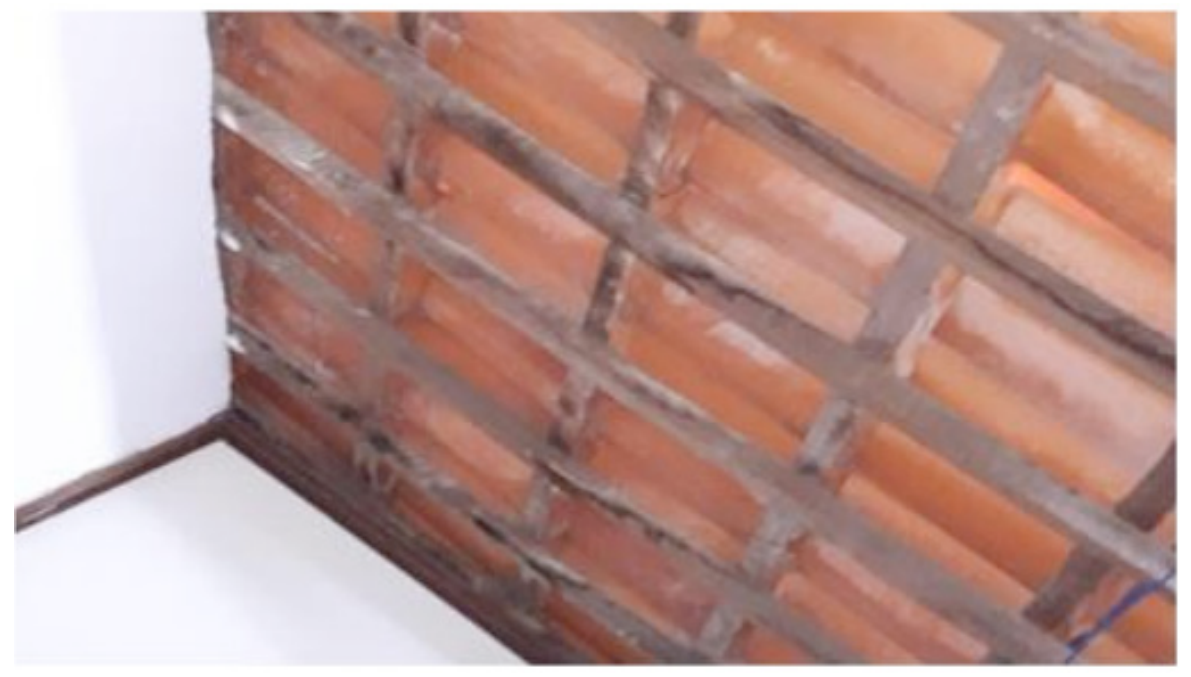

Figura 10 - Bolor nos caibros e terças do telhado.

Fonte: Autores, (2019).

Os problemas patológicos mais frequentes nas edificações são a formação de manchas de umidade, com o desenvolvimento de bolores (mofos), os quais são 
formados pela ação de agentes biológicos, principalmente os fungos, que necessitam de condições especiais para se desenvolverem. Assim, a presença de água, em qualquer estado, é fundamental para o desenvolvimento destes organismos.

\subsubsection{Saponificação e descamação da tinta}

Foram identificadas saponificação e descamações de tinta em paredes internas na entrada do Teatro (Figura 11-A), originadas de infiltração por capilaridade. Já a descamação da tinta presente no topo da alvenaria interna (Figura 11-B) é causada pela umidade da mesma, a qual é derivada de infiltrações de águas pluviais através do telhado.

É necessária a manutenção periódica da pintura, removendo as áreas afetadas para reaplicação da tinta, bem como o uso de tinta de boa qualidade e o correto preparo e aplicação da mesma, além do prévio e imprescindível reparo do sistema coberta, tendo em vista a eliminação de infiltrações.
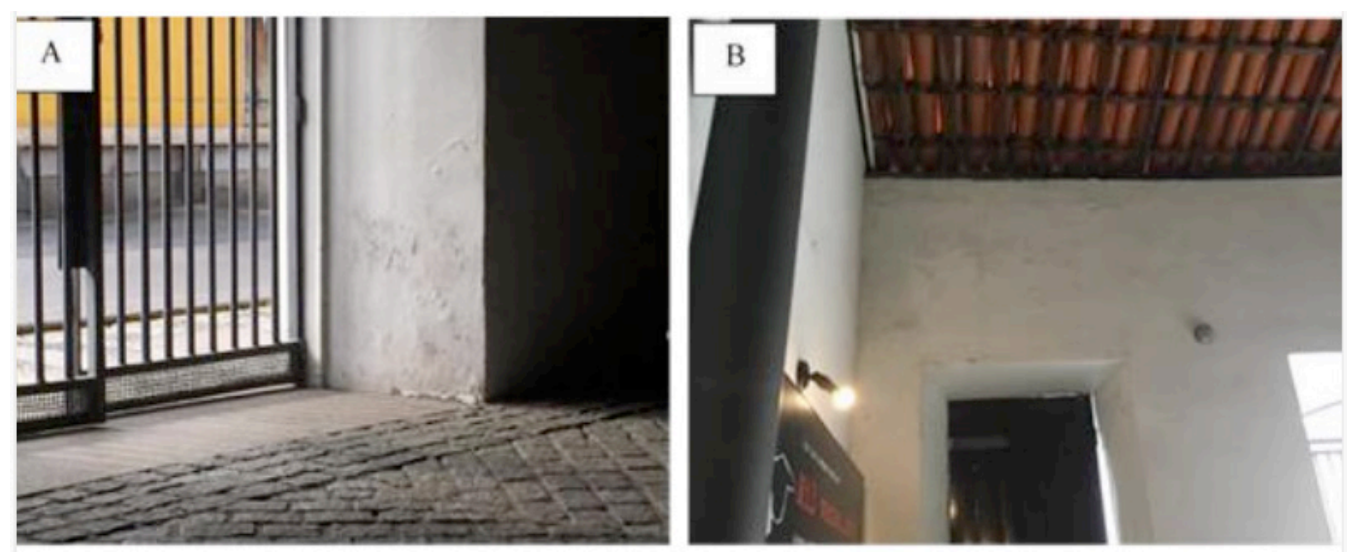

Figura 11 - (A) e (B) Descamação da pintura nas paredes internas da entrada devido à umidade por capilaridade.

Fonte: Autores, (2019).

\subsubsection{Eflorescência}

Foi observada a presença de eflorescência em viga da estrutura de sustentação da coberta (Figura 12-A e 12-B), a qual certamente é oriunda do processo de lixiviação dos materiais que constituem o concreto, o qual está exposto à umidade resultante da água de chuva. 

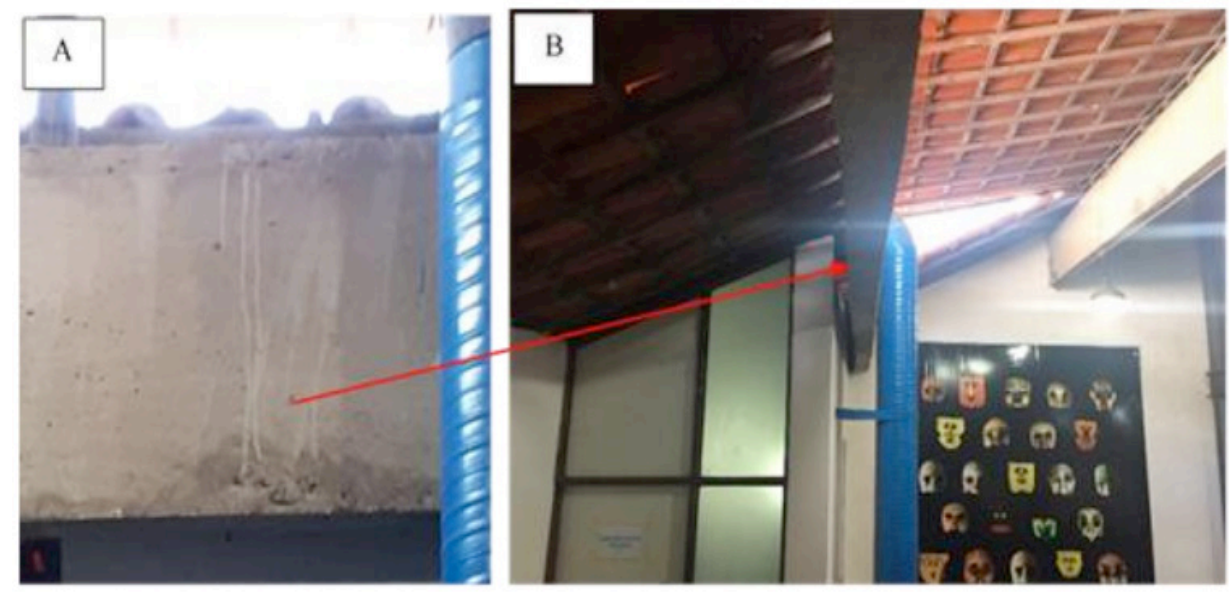

Figura 12 - (A) e (B) Descamação da pintura nas paredes internas da entrada devido à umidade por capilaridade.

Fonte: Autores, (2019).

De acordo com Mazer (2016), as eflorescências são um processo natural, onde a água, tendo entrado pelos poros capilares do concreto, dissolve o hidróxido de cálcio da pasta de cimento.

Ações podem ser executadas para inibir o processo de lixiviação do concreto, a exemplo da impermeabilização da área de contato do concreto da viga com material hidrofugante.

\section{I CONSIDERAÇÕES FINAIS}

Da análise do estado de conservação do Teatro Ae Teatro B, é possível observar que a maioria das manifestações patológicas se concentram nas vigas de concreto armado e nas paredes de alvenaria de tijolos cerâmicos.

Em alguns locais (a exemplo da coberta), há necessidade de reparos com o propósito da eliminação de infiltrações e melhoria na aparência visual, prejudicada por conta de algumas manchas de bolor na madeira e fendilhamento em algumas telhas.

Nas vigas, foram observados ninhos de concretagem devido à falta ou falha de vibração quando da execução das obras, manchas de corrosão por conta de cobrimento inadequado e manchas de eflorescência devido à umidade.

Também foram identificadas falhas na montagem de formas, o que ocasionou a falta de alinhamento de algumas dessas peças estruturais. Nos dois prédios foram identificados, com maior frequência no Teatro $A$, fissuras nas paredes.

Observou-se também problemas causados por umidade, os quais são resultado da ausência de sistema de impermeabilização, tendo como consequência a presença de manchas de infiltração.

O Teatro B merece uma atenção especial, visto que apresenta deterioração (desgaste) das alvenarias de tijolos aparentes que compõem as paredes do salão principal (sala de espetáculos), devido à umidade, associada as movimentações 
(vibrações) das estruturas.

Esses efeitos têm sido potencializados pelo trânsito de ônibus do sistema de transporte Bus Rapid Transit (BRT), cuja estação está localizada em frente ao Teatro. Portanto, há necessidade de uma recuperação estrutural, em caráter de urgência, uma vez que se trata de uma edificação histórica.

Também é recomenda a elaboração e implantação de um plano de manutenção preventiva e corretiva para os teatros, consoante instruções do IPHAN. Nos teatros é necessário avaliar a espessura do cobrimento das peças estruturais, bem como proceder à recuperação dos pontos de corrosão nas vigas.

No plano de manutenção preventiva deverá está previsto um projeto de conscientização, frente a importância dos prédios, os quais são patrimônio histórico de Pernambuco. Além disto, é importante a eliminação das infiltrações nas paredes, visto que tem diminuído a vida útil da estrutura.

Estudos futuros poderão utilizar tecnologias de inspeção para o auxílio em um diagnóstico amplo e completo das manifestações patológicas que acometem os teatros, a exemplo dos ensaios não destrutivos com uso de termografia, tendo em vista os muitos locais com infiltrações.

\section{I AGRADECIMENTOS}

À Prefeitura da Cidade do Recife, particularmente à Secretaria de Cultura, pela gentileza em conceder acesso às edificações que abrigam o Teatro A e Teatro B.

\section{REFERÊNCIAS}

ASSOCIAÇÃO BRASILEIRA DE NORMAS TÉCNICAS (ABNT). NBR 6118:2014 Projeto de estruturas de concreto - Procedimento. Rio de Janeiro, 2014. 170 p.

FELIX, et al. Análise da vida útil de estruturas de concreto armado sob corrosão uniforme por meio de um modelo com RNA acoplado ao MEF. Revista Alconpat, [s.I.], v. 8, n. 1, p.1-15, 1 fev. 2018. Revista ALCONPAT. http://dx.doi.org/10.21041/ra.v8i1.256.

GALLETTO, A; ANDRELLO, J. M. Patologia em fachadas com revestimentos cerâmicos. In: CINPAR - IX Congresso Internacional sobre Patología y Recuperación de Estruturas, João Pessoa (Brasil), 2013.

INSTITUTO DO PATRIMÔNIO HISTÓRICO E ARTÍSTICO NACIONAL (IPHAN). Portaria n 420, de 22 de dezembro de 2010. Dispõe sobre procedimentos a serem observados para a concessão de autorização para realização de intervenções em bens edificados tombados e nas respectivas áreas de entorno. Brasília - DF, 2010.

INTERNATIONAL ORGANIZATION FOR STANDARDIZATION (ISO). ISO 13823:2008. General principles on the design of structures for durability.

KAAMIN, M. IDRIS, N. A. BUKARI, S. M. ALI, Z. SAMION, N. AHMAD, A. Visual Inspection of Historical Buildings Using Micro UAV. MATEC Web of Conferences. v. 103, 2017. 
MELO, C. M., CARASEK, H. Relationship between the deterioration of multi story building facades and driving rain. Revista de la Construción, V. 13, No. 1, pp. 64-73, 2014.

NASCIMENTO, C. F. G; SOUZA, P. M. C. O.; TEXEIRA, I. A. R.; MONTEIRO, E. C. B. e COSTA E SILVA, A. J. Utilização do método dos fatores para priorização de incidências patológicas na ponte Barão de Jundiá, 48 anos de construção no município de Escada-PE. 2019.

RAKHA, T.; GORODETSKY, A. Review of Unmanned Aerial System (UAS) applications in the built environment: Towards automated building inspection procedures using drones. Automation in Construction. v. 93. 2018.

VISIT RECIFE. Teatros. Disponível em: https://visit.recife.br/. Acessado em: 30 Abr. 2019. 


\section{CARACTERIZAÇÃO E ANÁLISE COMPARATIVA DE PÓS NANOMÉTRICOS OBTIDOS POR MOAGEM DE ALTA ENERGIA COM E SEM LIXÍVIA ÁCIDA PARA APLICAÇÃO EM FOTOCATÁLISE}

Lucca Monteiro Silva Semensato Universidade Federal de Alfenas (UNIFAL-MG), Campus Poços de Caldas

Estudante de Iniciação Científica

Poços de Caldas - Minas Gerais

Luis Fernando Baldo Estorari Universidade Federal de Alfenas (UNIFAL-MG), Campus Poços de Caldas

Estudante de Iniciação Científica

Poços de Caldas - Minas Gerais

Maisa Helena Mancini Universidade Federal de Alfenas (UNIFAL-MG),

Campus Poços de Caldas

Estudante de Iniciação Científica

Poços de Caldas - Minas Gerais

Veridiana Magalhães Costa Moreira Universidade Federal de Alfenas (UNIFAL-MG),

Campus Poços de Caldas

Estudante de Iniciação Científica

Poços de Caldas - Minas Gerais

Ana Gabriela Storion

FZEA - USP

Doutoranda

Pirassununga - São Paulo

Eliria Maria de Jesus Agnolon Pallone

FZEA - USP

Professor titular

Pirassununga - São Paulo

RESUMO: Os corantes são substâncias amplamente utilizadas em diversos processos industriais, tornando-se resíduos bastante nocivos ao meio ambiente se descartados inadequadamente. A fotocatálise heterogênea é uma técnica alternativa para a despoluição, sobretudo no que se refere à utilização de sistemas óxidos multicomponentes para tal fim. Os óxidos de Zinco e de Titânio têm sido amplamente investigados devido às suas capacidades de degradação de corantes por fotocatálise heterogênea. $O$ presente trabalho visou investigar o efeito da lixívia ácida nas características de pós nanométricos obtidos através de moagem de alta energia, a qual destaca-se pela praticidade e menor custo se comparada às rotas químicas, em moinho vibratório do tipo SPEX Mixer/ Mill. Assim, foi investigada a influência da lixívia ácida para 
retirada do Ferro proveniente da moagem e nas características dos pós do sistema $\mathrm{ZnO}: \mathrm{TiO}_{2}(0: 100,25: 75,50: 50,75: 25$ e 100:0) obtidos após moagem durante 2 e 4 horas. Os pós precursores foram caracterizados através das técnicas de difração de raios $X(D R X)$ e B.E.T.. Após a MAE, os pós, lixiviados ou não, foram caracterizados por $\mathrm{DRX}$, sendo determinadas suas propriedades fotocatalíticas. Os resultados indicaram que a MAE foi eficiente na obtenção de nanopós; entretanto, o processo de lixívia não foi totalmente suficiente para retirar todo o ferro presente; ainda, comprovou-se que o ferro entrou na estrutura cristalina do material, comprometendo as propriedades fotocatalíticas do sistema. Para o $\mathrm{ZnO}$, houve a formação de Oxalato de Zinco após lixívia, provocando um aumento no tamanho médio de partículas, diminuindo a reatividade do pó.

PALAVRAS-CHAVE: Moagem de alta energia, fotocatálise, nanopartículas.

\section{CHARACTERIZATION AND COMPARATIVE ANALYSIS OF NANOMETRIC}

\section{POWDERS OBTAINED BY HIGH ENERGY MILLING WITH AND WITHOUT ACID}

\section{LEACHING FOR PHOTOCATALYTIC APPLICATION}

ABSTRACT: Dyes are substances widely used in several industrial processes and are very harmful to the environment if improperly discarded, especially regarding water resources. Heterogeneous photocatalysis is an alternative technique for decontamination, mostly regarding the use of multicomponent oxide systems for this purpose. Zinc oxide and Titanium dioxide, or titania, have been broadly investigated due to their heterogeneous photocatalytic degradation capabilities. The present paper aimed to investigate the effect of acid leaching in the properties of nanometric powders obtained by high energy milling, which stands out for its practicality and lower cost compared to chemical routes, in a SPEX type vibrating mill. Thus, the influence of the presence of Iron and its absence (with the use of acid leaching) in the properties of the powders of the system $\mathrm{ZnO}: \mathrm{TiO}_{2}$ obtained after milling for 2 and 4 hours were investigated. The precursors powders were evaluated using Nitrogen Physisorption (B.E.T.) and X-Ray Diffraction (XRD. After the milling in duplicate, for each composition of the $\mathrm{ZnO}$ :TiO2 system (0:100, 25:75, 50:50, 75;25 and 100:0), every powder, whether or not followed by acid leaching, was characterized by X-Ray diffraction and by its photocatalytic potential. The results indicated that the HEM was efficient in obtaining nanopowders; however, the leaching process in all systems studied was not enough to remove all the iron present; it was also verified that Iron entered the material's crystalline structure, which compromise the photocatalytic properties of the system. As for the $\mathrm{ZnO}$, there was the formation of Zinc Oxalate after the leaching, causing an increase in the average particle size, reducing the reactivity of the powder.

KEYWORDS: High energy milling, photocatalysis, nanoparticles. 


\section{I INTRODUÇÃO}

Processos físicos e físico-químicos como adsorção, flotação e precipitação são amplamente utilizados no tratamento de efluentes. Todavia, tais processos acarretam a geração de resíduos sólidos, necessitando também de tratamentos posteriores, o que aumenta o custo e prejudica o caráter ambiental (DIAS et al., 2016). Os Processos Oxidativos Avançados (POAs) se mostram uma alternativa eficiente no tratamento de tais efluentes, pois atuam de maneira a eliminar os contaminantes e não apenas transferir a poluição para resíduos sólidos.

Um dos principais desafios a ser superado para que os processos de fotocatálise heterogênea (um tipo de POA) se tornem economicamente praticáveis é a supressão da recombinação dos pares fotogerados e uma utilização eficiente da luz visível, para diminuição de custos energéticos utilizados para fornecimento da radiação necessária (RIBEIRO, 2013). A fim de contornar essas barreiras, estudos acerca da dopagem de $\mathrm{TiO}_{2}$ com impurezas metálicas e não-metálicas vêm sendo realizados, já que este é o semicondutor mais utilizado em fotocatálise, devido às suas características diferenciadas e alta eficiência (BIRBEN, 2015; RIBEIRO, 2013). Além do mais, é desejável a obtenção de pós de elevada área superficial, uma vez que os processos de degradação ocorrem na superfície do catalisador.

Métodos químicos de síntese apresentam alta eficiência na produção de pós nanométricos sob pequena dispersão na média do tamanho de partícula, porém constituem em uma via de custo elevado e de alta complexidade, o que limita sua produção em escala industrial (DIAS et al., 2016).

Neste contexto, este trabalho visou o estudo de obtenção de pós de ZnO:TiO2 e posterior tratamento via lixívia ácida a fim de verificar a influência da presença de Ferro nas características do pó obtido. Para isso foi utilizada Moagem de Alta Energia (MAE) como meio de obtenção de pós em escala nanométrica, uma vez que esta se apresenta como uma via de baixo custo e complexidade, surgindo como uma potencial rota industrial. Após a MAE, o material obtido foi avaliado quando ao seu potencial fotocatalítico na degradação do corante Rodamina-B.

\section{I MATERIAIS E MÉTODOS}

\subsection{Caracterização dos pós precursores}

Óxidos de Zinco (99\% de pureza, Synth) e Óxido de Titânio (99,9\% de pureza, Hombitan $®)$, na forma de partículas micrométricas, foram utilizados como matérias primas. Tais óxidos foram caracterizados previamente pelo grupo de pesquisa via Difração de Raios X (DRX) no Laboratório de Cristalografia da Universidade Federal de Alfenas (UNIFAL-MG). Também foi determinada a área superficial pela técnica de B.E.T no Laboratório de Materiais da Universidade Federal de Alfenas (UNIFAL-MG), 
campus de Poços de Caldas/ MG.

\subsection{Moagem de Alta Energia (MAE)}

Os pós precursores foram submetidos à moagem de alta energia no Laboratório de Materiais da Universidade Federal de Alfenas (UNIFAL-MG), no campus de Poços de Caldas/ MG, em um moinho de alta energia do tipo SPEX Mixer/Mill, com frasco e bolas feitos de aço endurecido. Foi utilizada proporção mássica de bola:material de $5: 1$.
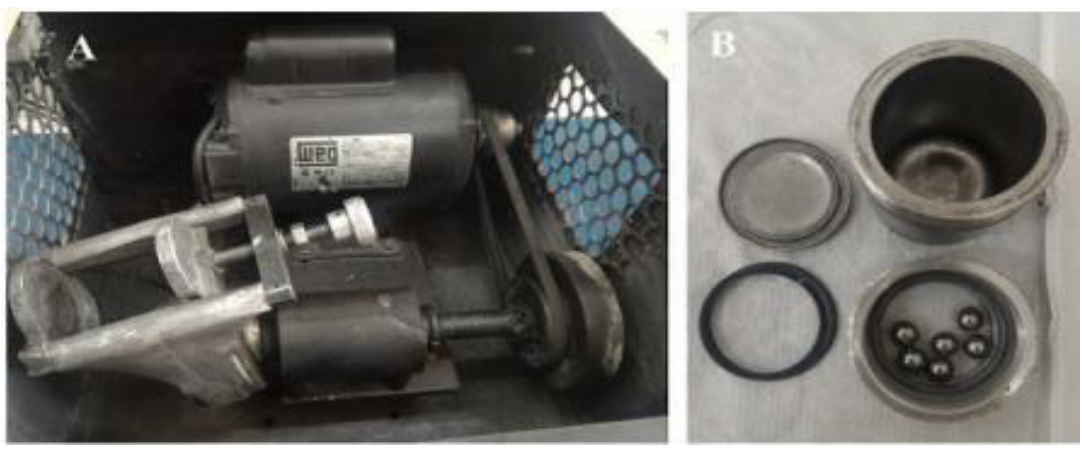

Figura 1 - Moinho de alta energia do tipo SPEX 8000 Mixer/Mill (A) e frasco e corpos moedores (B) feitos de aço endurecido (STORION, 2018).

As moagens foram realizadas a seco, variando-se as proporções mássicas de $\left[\mathrm{TiO}_{2}: \mathrm{ZnO}\right.$ ] conforme segue: [0:100], [30:70], [50:50], [70:30] e [100:0] e os tempos de moagem de 2 e 4 horas, sendo cada moagem realizada em duplicata (2 lotes). Após a obtenção dos pós moídos, foi realizado o tratamento via lixívia ácida em um dos lotes.

As amostras foram identificadas de acordo com a tabela 1, sendo o primeiro dígito referente ao tempo de moagem. Por exemplo, a amostra 4.3 possui $4 \mathrm{~h}$ de moagem e é composta por $25 \%$ de $\mathrm{TiO}_{2}$ e $75 \%$ de $\mathrm{ZnO}$. Os materiais identificados com as letras "WL" não passaram pelo tratamento via lixívia ácida. Já amostras identificadas apenas com a letra "L" foram submetidas ao tratamento.

\begin{tabular}{|c|c|c|c|}
\hline Nomenclatura & Percentual TiO2 & Percentual ZnO & Tempo de Moagem \\
\hline $2.1 \mathrm{WL}, 2.1 \mathrm{~L}$ & 0 & 100 & 2 \\
\hline $2.2 \mathrm{WL}, 2.2 \mathrm{~L}$ & 100 & 0 & 2 \\
\hline $2.3 \mathrm{WL}, 2.3 \mathrm{~L}$ & 50 & 50 & 2 \\
\hline $2.4 \mathrm{WL}, 2.4 \mathrm{~L}$ & 25 & 75 & 2 \\
\hline $2.5 \mathrm{WL}, 2.5 \mathrm{~L}$ & 75 & 25 & 4 \\
\hline $4.1 \mathrm{WL}, 4.1 \mathrm{~L}$ & 0 & 100 & 4 \\
\hline $4.2 \mathrm{WL}, 4.2 \mathrm{~L}$ & 100 & 0 & 4 \\
\hline $4.3 \mathrm{WL}, 4.3 \mathrm{~L}$ & 50 & 50 & 4 \\
\hline $4.4 \mathrm{WL}, 4.4 \mathrm{~L}$ & 25 & 75 & 4 \\
\hline $4.5 \mathrm{WL}, 4.5 \mathrm{~L}$ & 75 & 25 & \\
\hline
\end{tabular}

Tabela 1: Nomenclatura adotada na identificação das amostras que não passaram pela lixívia ácida. Amostras identificadas com "WL" não passaram pelo tratamento via lixívia ácida; amostras identificadas com "L" foram submetidas ao tratamento. 


\subsection{Lixívia ácida}

O tratamento via lixívia ácida para descontaminação do ferro oriundo da MAE foi feito utilizando uma proporção de $3 \mathrm{~g}$ do pó moído e $100 \mathrm{~mL}$ de uma solução de Ácido Oxálico 0.5M. O sistema foi mantido sob agitação e aquecimento (aproximadamente $100^{\circ} \mathrm{C}$ ) por 4 horas. Em seguida, a mistura foi deixada em repouso para que o pó decantasse, possibilitando a retirada do líquido reagido. Foram realizadas 3 repetições para cada sistema, baseando-se em resultados obtidos previamente pelo grupo de pesquisa (STORION 2018). As suspensões em que o pó apresentou dificuldade em decantar foram centrifugadas em Centrífuga LGI Scientific D1008 a 10000 rpm. Ao final do processo de lixiviação, os pós foram colocados em água destilada sob agitação por 30 minutos para remoção de eventuais ácidos residuais. Este processo de lavagem foi repetido 4 vezes. Após a lavagem, adicionou-se Álcool Isopropílico às amostras, que então ficaram 30 minutos sob agitação. Posteriormente, realizou-se a desaglomeração dos pós em lavadora Ultrassônica Sanders por 25 minutos. Em seguida, deixou-se as amostras em repouso para a secagem. Após a secagem dos pós, estes foram passados em peneira de abertura de $45 \mu \mathrm{m}$.

\subsection{Caracterização após MAE e lixívia ácida}

Após a MAE, os pós, tratados ou não por lixívia ácida, foram caracterizados via Difração de Raios X (DRX) para a análise da possível formação de heteroestruturas oriundas da MAE. Também foram realizados testes para determinação do potencial fotocatalítico de todos os pós (lotes 1 e 2).

\subsection{Determinação do potencial fotocatalítico}

Maiores detalhes destes procedimentos podem ser obtidos em Dias (2015) e Storion (2018). Os ensaios fotocatalíticos foram feitos utilizando-se a Espectrometria de Absorção no UV-Vis, tendo em vista obter uma análise quantitativa da degradação do corante Rh-B quando em presença dos pós preparados anteriormente (seguidos ou não de lixívia ácida), sob incidência de radiação UV-C. Foi utilizado um reator fotoquímico com quatro lâmpadas ultravioleta de $15 \mathrm{~W}$ e com água circulante em serpentina de cobre para o resfriamento e controle da temperatura, que foi bombeada por banho termostático Solab SL152/18, a uma temperatura controlada de $10^{\circ} \mathrm{C}$. No reator também se encontrava um ventilador na lateral direita com 1,4W para a circulação de ar. Na parte inferior do reator havia uma placa de agitação magnética (STORION, 2018; DIAS, 2015).

Nos ensaios utilizou-se a proporção de $10 \mathrm{mg}$ de pó para $50 \mathrm{~mL}$ de solução do corante Rh-B, sendo esta solução preparada a uma concentração de 5mg/L. Para cada ensaio foi preparada uma solução de $5 \mathrm{mg} / \mathrm{L}$ de Rh-B para comparação. As soluções preparadas foram levadas à lavadora ultrassônica Sanders por 5 minutos e então deixadas em repouso por 24 horas no escuro, para melhor difusão das moléculas 
do corante com a superfície dos pós fotocatalisadores. Após o repouso, as amostras foram levadas novamente à sonda ultrassônica Sanders por 5 minutos, a fim de evitar aglomerações residuais do pó na solução (STORION, 2018; DIAS, 2015).

No reator, os ensaios tiveram 15 minutos iniciais de agitação no escuro para definição do ponto inicial, e 120 minutos posteriores sob incidência de radiação UV-C. Foram coletados pontos a cada 15 minutos durante a primeira hora, e, até completar o tempo total da análise, a cada 30 minutos. A cada intervalo, interrompia-se a incidência de luz e coletava-se $3 \mathrm{~mL}$ de cada solução, que foram transferidos para dois microtubos eppendorf e centrifugados a 10000 rpm por 4 minutos. Em seguida, as amostras foram encaminhadas para análise espectrofotométrica, com varredura efetuada nos comprimentos de onda de 400 a 800 nm (STORION, 2018; DIAS, 2015).

\section{I RESULTADOS E DISCUSSÕES}

\subsection{Caracterização dos pós precursores}

Os pós precursores foram previamente caracterizados por STORION (2018). Os resultados de área superficial encontram-se na Tabela 2. A área superficial do pó de titânia apresentou resultado 2 vezes superior ao do óxido de zinco, evidenciando uma maior reatividade do pó.

\begin{tabular}{|c|c|c|}
\hline Amostra & $\mathrm{TiO}_{2}$ & ZnO \\
\hline Área Superficial $\left(\mathrm{m}^{2} / \mathrm{g}\right)$ & 10,9456 & 5,44 \\
\hline
\end{tabular}

Tabela 2: Área superficial dos óxidos precursores.

Fonte: STORION, 2018.

Os difratogramas de Raios $\mathrm{X}$ obtidos são apresentados na Figura 2 para os óxidos de titânio e zinco, respectivamente. No que diz respeito ao óxido de titânio, o difratograma evidencia que o $\mathrm{TiO}_{2}$ precursor encontra-se estável na fase anatase, com estrutura cristalina tetragonal (Ficha PDF 2003 \#21-1272 - JCPDS-ICDD); para o ZnO, a estrutura cristalina é hexagonal, correspondente ao mineral Zincita (Ficha PDF 2003 \#36-1451 - JCPDS-ICDD). 


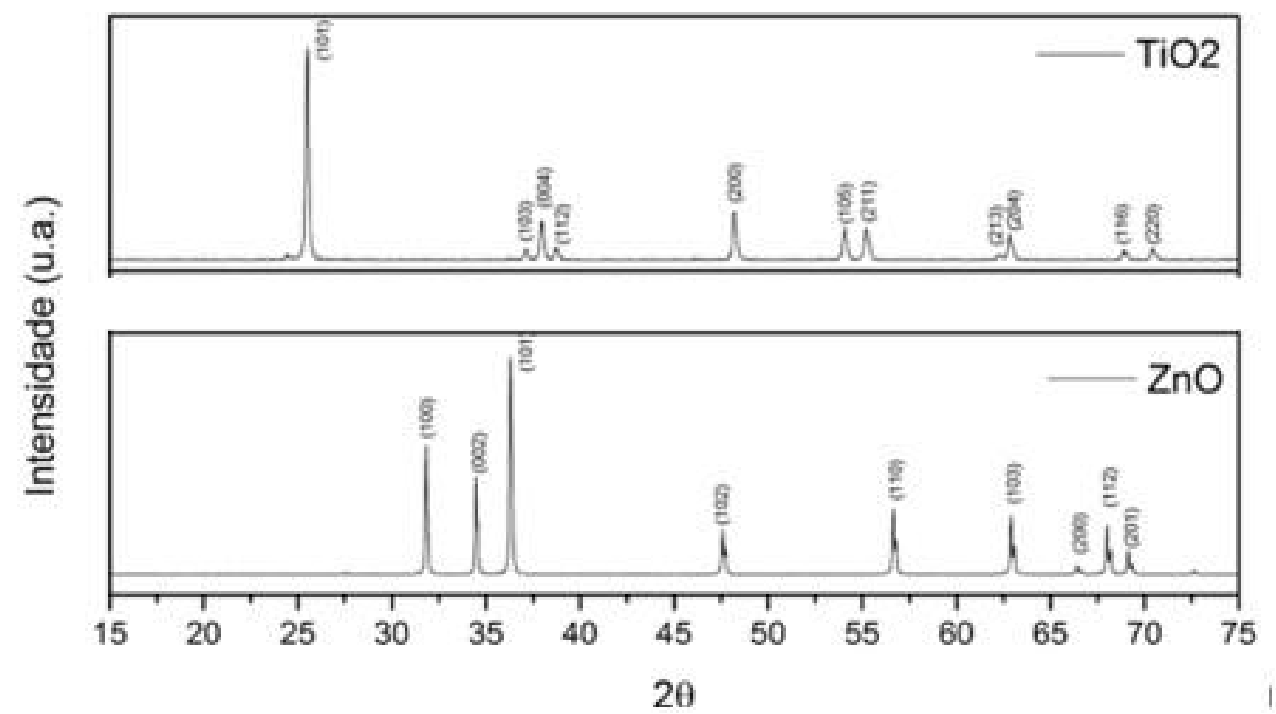

Figura 2 - Difratogramas de Raios X para as amostras dos pós precursores de $\mathrm{TiO}_{2}$ e $\mathrm{ZnO}$.

Fonte: STORION, 2018.

\subsection{Moagem de Alta Energia e tratamento via lixívia ácida}

Durante a MAE, foi possível observar a mudança na coloração dos pós (Figura 3), devido à contaminação por Ferro, após moagem e o efeito da lixívia na descontaminação dos pós por Ferro (Figuras 4 e 5). A lixívia, como já mencionada, foi realizada com Ácido Oxálico no lugar do Ácido Clorídrico, pois este último reage com o $\mathrm{ZnO}$ quando aquecido, eliminando o Ferro e o $\mathrm{ZnO}$. Observou-se que diversas amostras não apresentaram total remoção do Ferro (o que pode ser observado através da coloração amarelada da solução). Tais amostras são as que possuem maior percentagem de $\mathrm{TiO}_{2}$, visto que o ácido mais indicado para a realização de lixívia ácida deste composto é o Ácido Clorídrico, porém, como este reage com o ZnO, não foi possível utilizá-lo. 

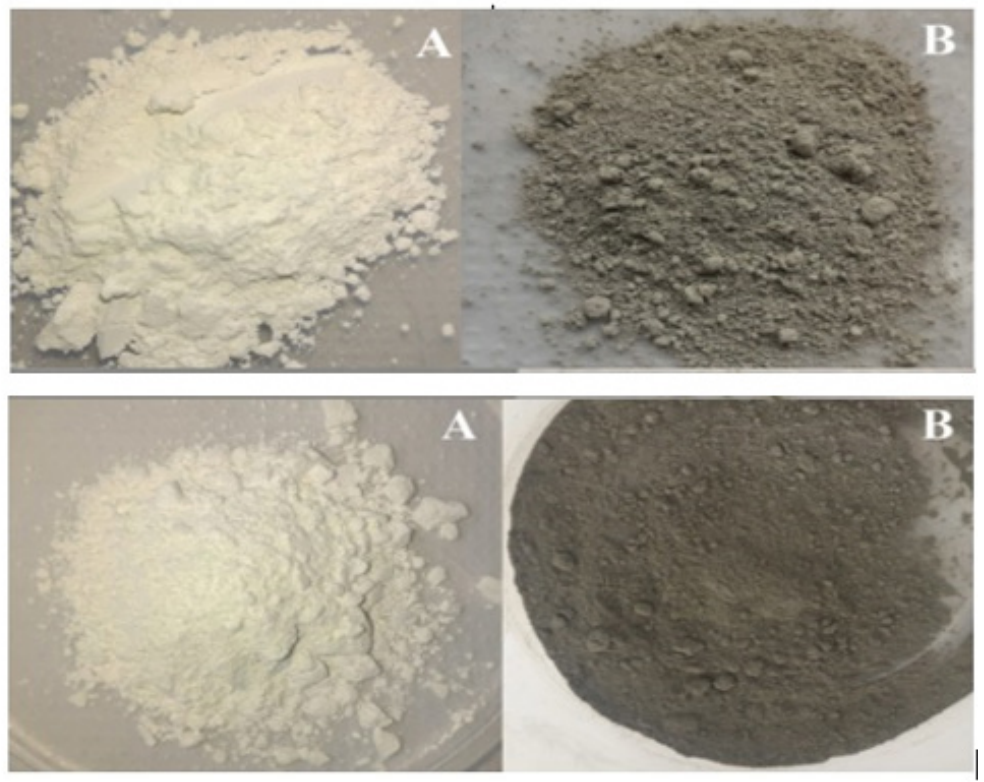

Figura 3- Comparação entre as colorações dos pós de $\mathrm{TiO}_{2}$ (imagens superiores) e $\mathrm{ZnO}$ (imagens inferiores) antes da moagem - precursores (A) e após moagem - processados (B), evidenciando a contaminação durante moagem.

Fonte: Autores.

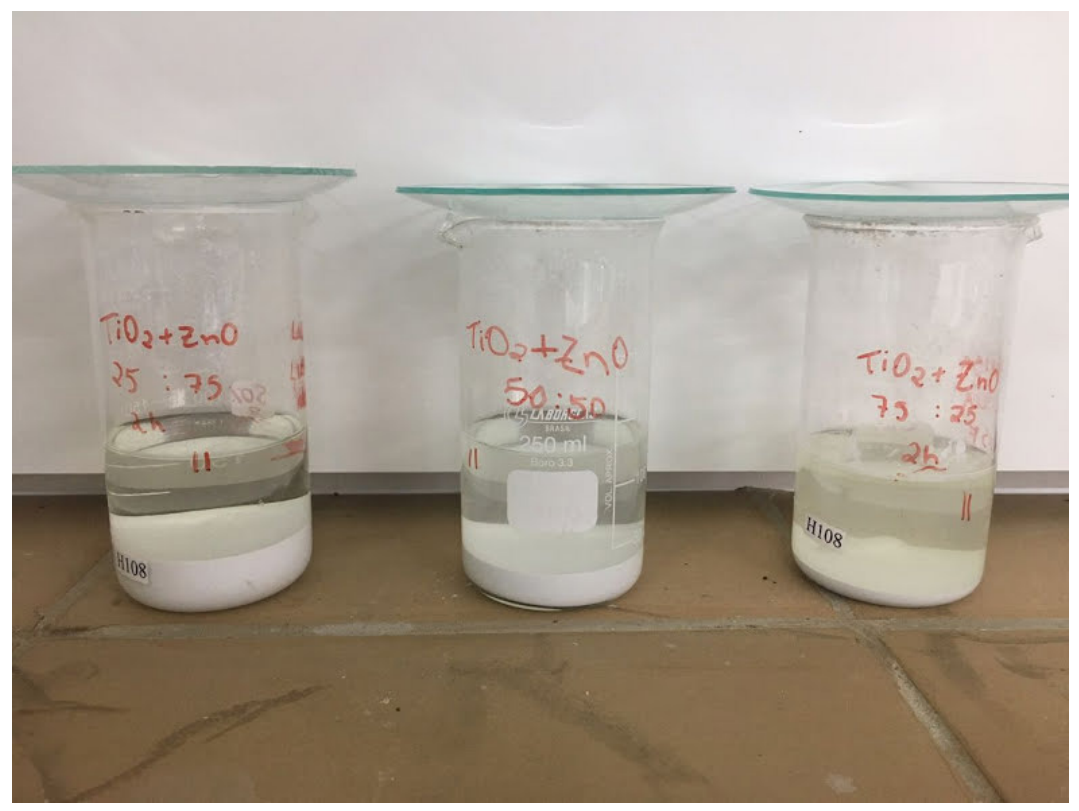

Figura 4- Amostras 2.4L, 2.3L e 2.5L após a primeira etapa da lixívia ácida em repouso para decantação do pó. A coloração amarelada da solução indica a presença do Ferro, ou seja, este está sendo removido do pó.

Fonte: Autores. 


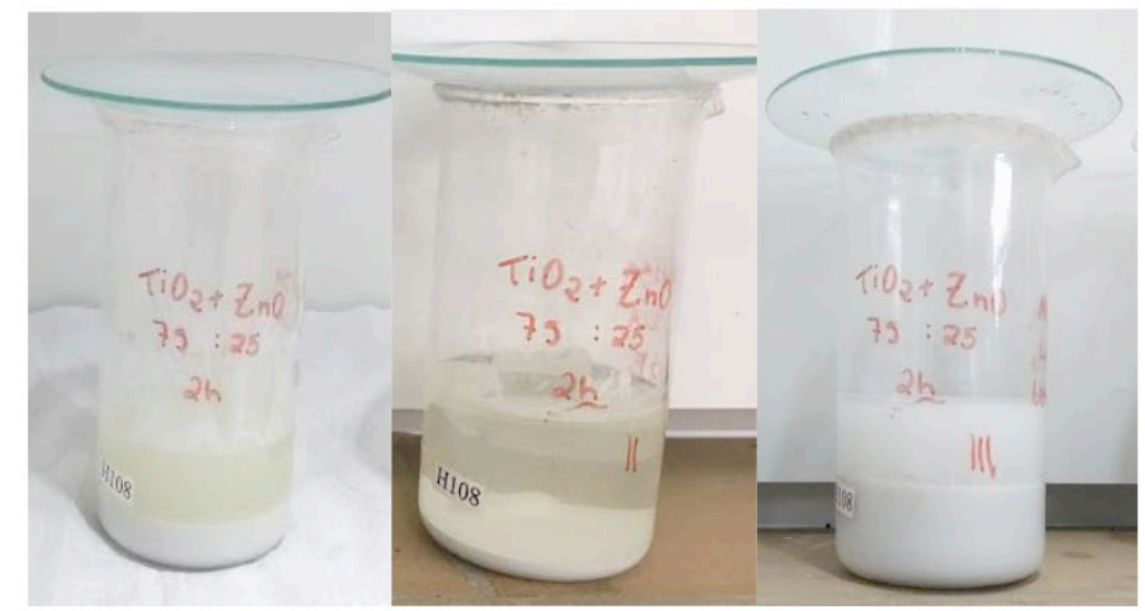

Figura 5 - Etapas da lixívia ácida da amostra 2.5L (75\% $\left.\mathrm{TiO}_{2}, 25 \% \mathrm{ZnO}\right)$. Nota-se que a coloração amarelada da solução vai se enfraquecendo até ela tornar transparente.

Fonte: Autores.

\subsection{Caracterização após MAE e lixívia ácida}

Os difratogramas das amostras após a MAE sem tratamento via lixívia ácida estão representados na Figura 6. Após a MAE, foi observada a presença do mineral zincita (estrutura hexagonal) e de $\mathrm{TiO}_{2}$ na fase anatase, provenientes dos pós precursores. Porém, foram também observadas as fases brookita e rutilo do Óxido de Titânio, formadas pela alta energia do processo de moagem. A contaminação por ferro proveniente do moinho foi confirmada através da presença de magnetita $\left(\mathrm{Fe}_{3} \mathrm{O}_{4}\right)$.

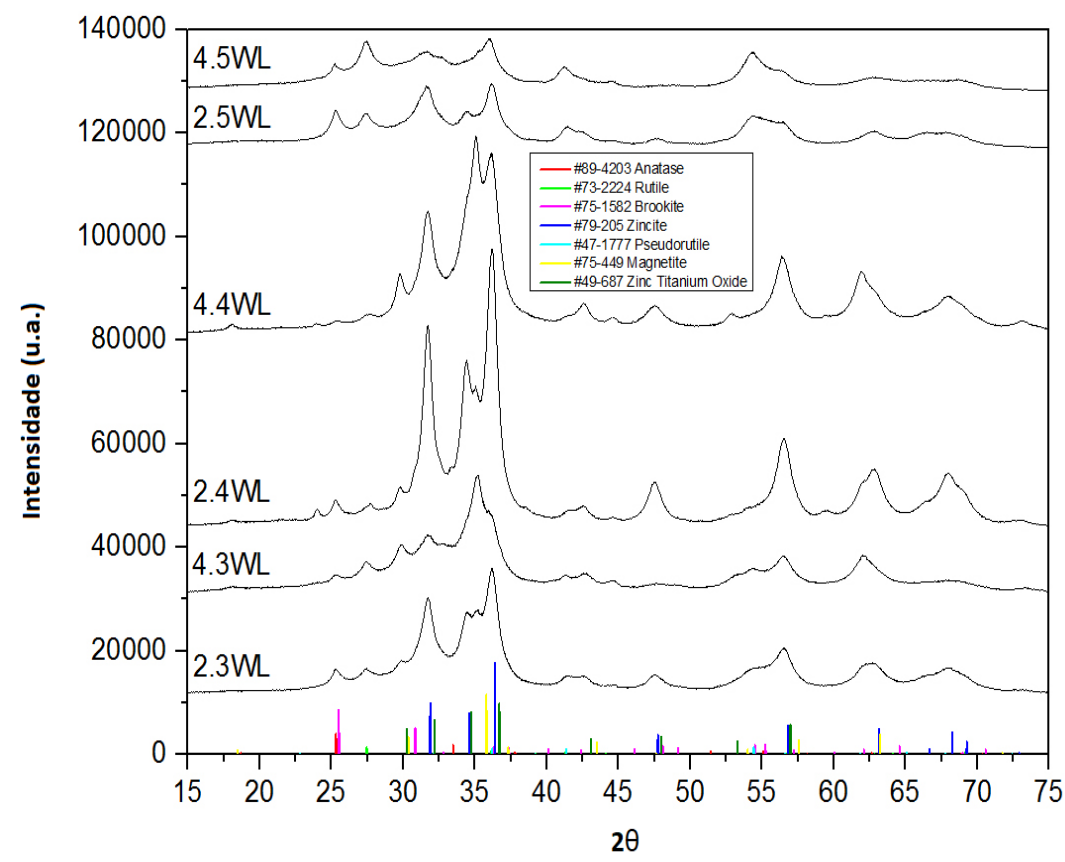

Figura 6 - Difratogramas das amostras que não foram submetidas ao tratamento via lixívia ácida após a MAE.

Fonte: Autores. 
Foi possível observar que com o aumento do tempo de moagem, houve maior amorfização do pó, juntamente com a presença do ferro. Também foi possível observar a transformação da estrutura anatase em rutilo (ALI, 2014).

$\mathrm{Na}$ figura 7 encontram-se os difratogramas das amostras submetidas ao tratamento via lixívia ácida. Foi possível observar a formação de Oxalato de Zinco Hidratado, devido à reação entre o ZnO e o ácido oxálico utilizado no procedimento da lixívia. Mesmo após o tratamento para descontaminação, ainda foi possível identificar a presença do ferro proveniente da moagem de alta energia.

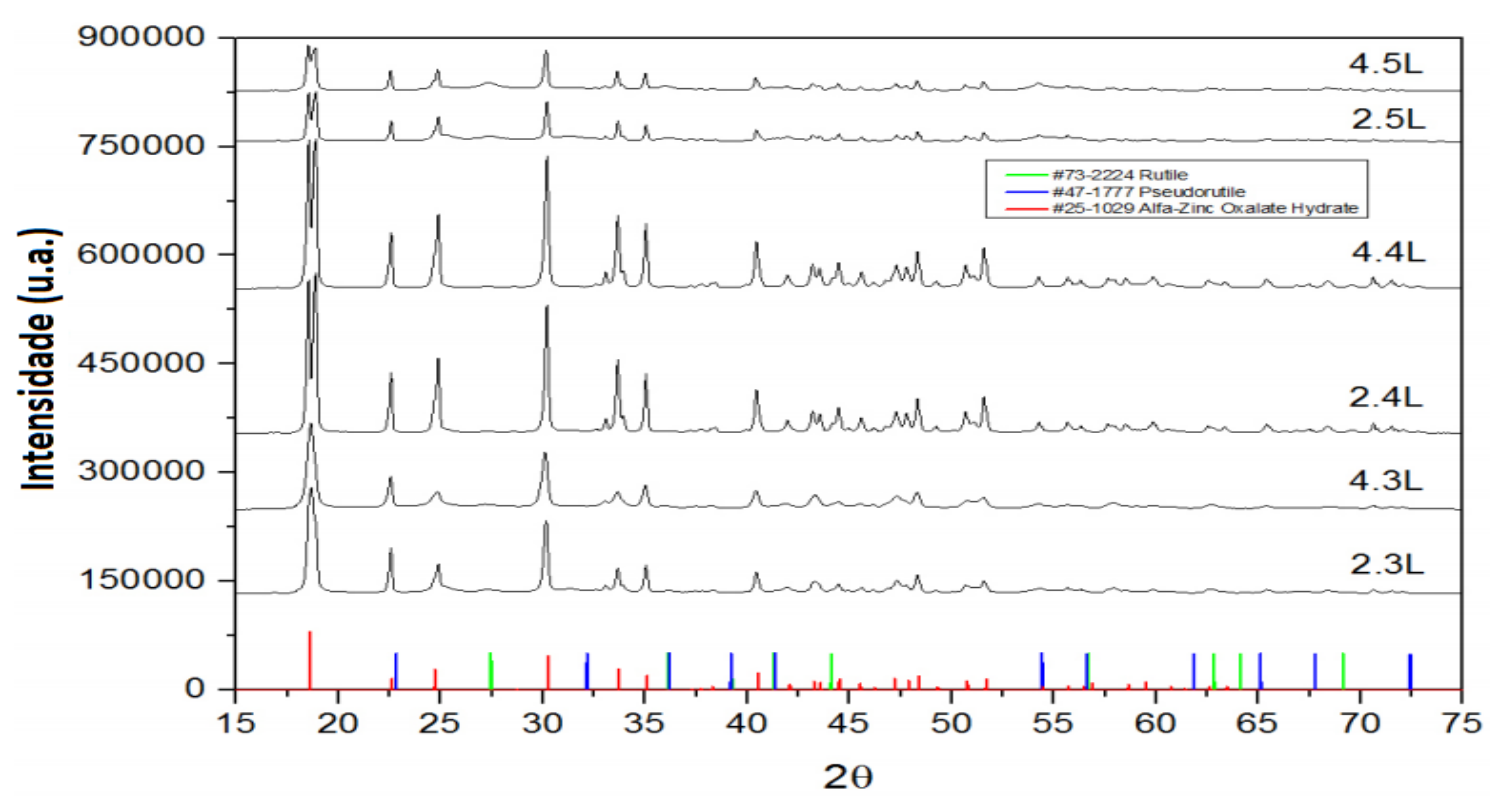

Figura 7 - Difratogramas das amostras que foram submetidas ao tratamento via lixívia ácida após a MAE.

Fonte: Autores.

\subsection{Determinação do potencial fotocatalítico}

Apesar de ser possível observar o efeito da lixívia na coloração dos pós, ensaios fotocatalíticos foram realizados com o intuito de confirmar o efeito deletério do Ferro presente nas amostras. Na figura 8 são apresentados os resultados de fotocatálise, os quais foram pouco promissores devido à presença, ainda que em baixo teor, do ferro contaminante. Na tabela 3 encontram-se os valores totais de degradação obtidos por cada amostra para cada tempo de moagem.

Mesmo após a lixívia ácida o potencial de degradação de Rodamina B dos óxidos ainda era baixo, o que pode ser explicado pela penetração do Ferro na estrutura do composto. Também se deve levar em conta o uso do Ácido Oxálico na lixiviação das amostras contendo $\mathrm{TiO}_{2}$, cujo ácido mais eficiente para tal procedimento seria o Ácido Clorídrico. Visto que o último, quando aquecido, reage com o $\mathrm{ZnO}$, não foi possível utilizá-lo nos procedimentos de lixívia ácida, pois além do Ferro, o ZnO também seria removido pelo $\mathrm{HCl}$. 

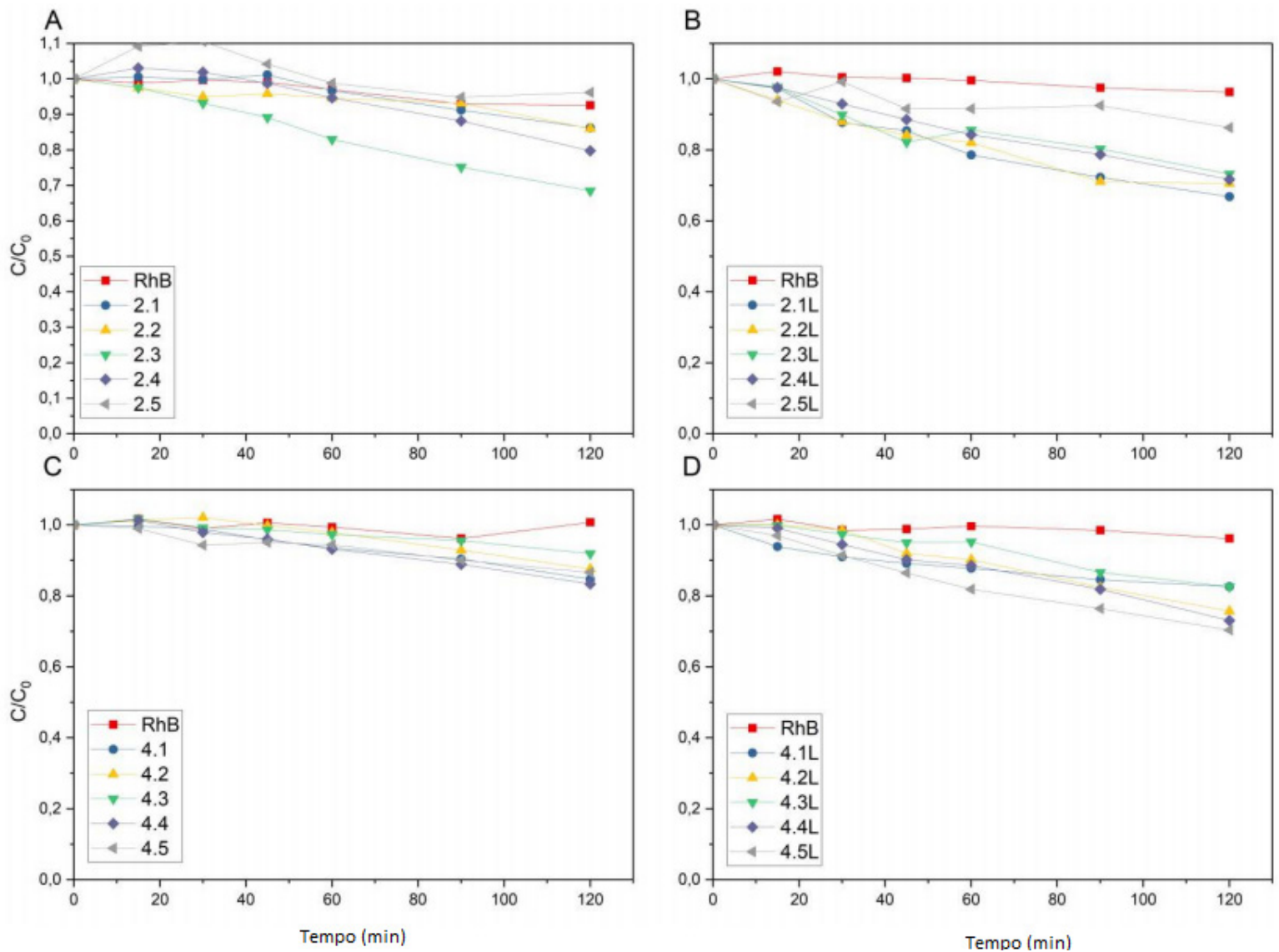

Figura 8 - Curvas de degradação do corante Rh-B.

Fonte: Autores.

\begin{tabular}{|c|c|c|c|c|}
\hline \multirow{2}{*}{ TiO $_{2}: Z n O$} & \multicolumn{2}{|c|}{$\mathbf{4}$ horas } & \multicolumn{2}{c|}{$\mathbf{2 ~ h o r a s ~}$} \\
\cline { 2 - 5 } & $\begin{array}{c}\text { Degradação sem } \\
\text { lixívia (\%) }\end{array}$ & $\begin{array}{c}\text { Degradação com } \\
\text { lixívia (\%) }\end{array}$ & $\begin{array}{c}\text { Degradação sem } \\
\text { lixívia (\%) }\end{array}$ & $\begin{array}{c}\text { Degradação com } \\
\text { lixívia (\%) }\end{array}$ \\
\hline $\mathbf{0 : 1 0 0}$ & 15,34 & 17,39 & 13,78 & 33,22 \\
\hline $\mathbf{1 0 0 : 0}$ & 12,41 & 24,32 & 13,98 & 29,43 \\
\hline $\mathbf{5 0 : 5 0}$ & 8,07 & 17,42 & 31,49 & 26,77 \\
\hline $\mathbf{2 5 : 7 5}$ & 16,59 & 26,93 & 20,25 & 28,26 \\
\hline $\mathbf{7 5 : 2 5}$ & 13,38 & 29,64 & 3,85 & 13,71 \\
\hline
\end{tabular}

Tabela 3: Porcentagem de degradação da Rodamina $\mathrm{B}$ em amostras do sistema $\mathrm{TiO}_{2}: \mathrm{ZnO}$ com e sem lixívia ácida, processadas via MAE por 2 e 4 horas.

Fonte: Autores.

As amostras que apresentaram maior porcentagem de degradação foram as amostras com maior quantidade de $\mathrm{ZnO}$ em sua composição, o que pode ser justificado pela excelente propriedade fotocatalítica do Óxido de Zinco e também pela eficácia da lixívia ácida utilizando Ácido Oxálico 0,5M. Apesar disso, nota-se que os valores encontrados são menores do que os advindos de ensaios utilizando $\mathrm{ZnO}$ puro. Deste modo, observa-se mais uma vez que a contaminação por Ferro obtida na MAE influenciou diretamente no potencial de degradação das amostras. 


\section{I CONCLUSÃO}

A lixívia ácida com Ácido Oxálico mostrou-se parcialmente eficaz na remoção do Ferro nas amostras com maior presença do $\mathrm{ZnO}$. Entretanto, nas amostras com $\mathrm{TiO}_{2}$, tal eficácia não foi observada, devido a este não ser o ácido mais indicado na lixiviação de tal óxido (o Ácido Clorídrico é mais eficiente, mas nas misturas de $\mathrm{TiO}_{2}$ e $\mathrm{ZnO}$ ele reage com o $\mathrm{ZnO}$ ).

Os óxidos $\mathrm{ZnO}$ e $\mathrm{TiO}_{2}$ mostram-se eficazes na degradação do corante Rh-B, conforme determinado pela literatura. Porém, o uso da Moagem de Alta Energia influenciou negativamente neste potencial de degradação que tais óxidos possuem, devido à contaminação por Ferro. Tal influência foi verificada de maneira mais expressiva nas amostras processadas por 4 horas, visto o maior contato das amostras com o Ferro das bolas de aço endurecido do moinho SPEX.

No que se refere ao $\mathrm{ZnO}$, a lixívia feita por ácido oxálico causa a formação de Oxalato de Zinco, comprovado por DRX e MEV, provocando um aumento no tamanho médio de partículas, o que também compromete suas propriedades fotocatalíticas, uma vez que ocorre uma diminuição na área superficial, com menor reatividade do pó. Assim, a utilização de moinho e meio de moagem de aço promove uma contaminação por Ferro difícil de ser retirada do pó, o que, direta ou indiretamente, afeta as propriedades fotocatalíticas do material.

\section{I AGRADECIMENTOS}

Os autores agradecem a FAPEMIG e CAPES pelo apoio financeiro a esta pesquisa, e a Universidade Federal de Alfenas (UNIFAL-MG) e FZEA - USP pelo uso das instalações e equipamentos.

\section{REFERÊNCIAS}

ALI, M. Transformation and powder Characteristics of TiO2 during high energy milling. Journal of Ceramic Processing Research, v. 15, n. 5, p. 290-293, 2014.

BIRBEN, N.C. et al. Comparative evaluation of anion doped photocatalysis on the mineralization and decolorization of natural organic matter. Catalysis Today, vol 240, pág. 125-131, 2015.

DIAS, J. A, et al. Characterization and photocatalytic evaluation of $\mathrm{ZnO}^{-} \mathrm{Co}_{3} \mathrm{O}_{4}$ particles obtained by high energy milling. Part I: Processing, physicochemical and thermal characterization. Ceramics International. v. 42, p. 1425-1431, 2016a.

DIAS, J. A. Avaliação fotocatalítica de partículas semicondutoras baseadas em óxidos de zinco e cobalto obtidas por moagem de alta energia. 2015. 90 f. Dissertação (mestrado) - Curso de Ciência e Engenharia dos Materiais, Universidade Federal de Alfenas - MG, 2015.

RIBEIRO, P.C. et al. Synthesis of $\mathrm{TiO}_{2}$ by the Pechini method and photocatalytic degradation of methyl red. Mat. Res. , V.16, p. 468-472, 2013. 
STORION, Ana Gabriela. Nanopartículas de TiO2:WO3 e ZnO obtidas pela utilização de moinho vibratório: caracterização e propriedade fotocatalíticas. 2018. 133 f. Dissertação (Mestrado) -

Curso de Programa de Pós-graduação em Ciência e Engenharia de Materiais, Universidade Federal de Alfenas, Poços de Caldas, 2018. 


\section{CAPÍTULO 9}

\section{CONTRIBUIÇÕES DA ANÁLISE DE REDES SOCIAIS A UM CLUSTER COMERCIAL PLANEJADO DE VAREJO DE AUTOMÓVEIS}

Marco Aurélio Sanches Fittipaldi Universidade São Caetano do Sul - São Caetano do Sul - SP

\section{Denis Donaire} Universidade São Caetano do Sul - São Caetano do Sul - SP

RESUMO: O varejo se transforma ao longo do tempo, se moderniza para atender os consumidores. Uma das principais mudanças observadas é a concentração de lojas em um mesmo local, especificamente um centro comercial que apresente estrutura para atrair e oferecer produtos e serviços específicos. Os shoppings centers especializados em um só tipo de produto tornam-se clusters comerciais planejados como afirmam Teller \& Elms (2010), sendo preferidos tanto por consumidores como por lojistas. O objetivo do presente estudo é identificar os relacionamentos existentes entre os atores participantes de um cluster comercial planejado de varejo de automóveis (Shopping $\mathrm{X}$ ), ao explorar as relações existentes entre seus participantes. Como metodologia de pesquisa neste estudo descritivo quantitativo foi empregada a técnica de análise de redes sociais (medidas degree, closeness e betweennes), disposta em figuras e métricas que evidenciaram os níveis de centralidade dos atores em suas relações. Constatou-se, em geral, baixa troca de informações entre seus membros, ainda que em diferentes graus, apesar de ser esta uma das principais características presentes num cluster, conforme Porter (1989). A administração do shopping pode promover maior contato entre as empresas, a fim de criar maior relacionamento, com o objetivo de promover e facilitar o fluxo de informações no cluster.

PALAVRAS-CHAVE: cluster comercial, análise de redes sociais, troca de informações

\section{CONTRIBUTIONS OF THE ANALYSIS OF}

SOCIAL NETWORKS TO A COMMERCIAL

\section{CLUSTER OF CAR RETAIL}

ABSTRACT: The retail turns over time, is modernized to meet consumers. A key change is the observed concentration of stores in one place, specifically a shopping center to present structure to attract and offer specific products and services. The shopping centers specialize in one type of product become planned as commercial clusters claim Teller \& Elms (2010), both being preferred by consumers and tenants. The aim of this study is to identify the relationships between the actors participating in a commercial cluster planned retail car (Shopping $\mathrm{X}$ ), to explore the relationships among its participants. The methodology of this research was descriptive quantitative study 
employed the technique of social network analysis (measures degree, closeness and betweennes) arranged in figures and metrics that showed levels of centrality of the actors in their relationships. We found that, in general, low exchange of information among its members, to varying degrees, although this is a major feature present in a cluster, as Porter (1989). The management of the mall can promote greater contact between firms in order to create greater relationship with the objective of promoting and facilitating the flow of information in the cluster.

KEYWORDS: commercial cluster, social network analysis, information exchange

\section{I INTRODUÇÃO}

O varejo se transforma ao longo do tempo, se moderniza para atender aos desejos e necessidades de seus consumidores. Uma das principais mudanças que se observa é a concentração de lojas em um mesmo local, especificamente um centro comercial que apresente estrutura para atrair e oferecer ao público produtos e serviços específicos. O agrupamento de atividades similares baseia-se no princípio da atração cumulativa segundo o qual a concentração tem maior poder de atração de consumidores, se comparado às lojas isoladas, especialmente as revendedoras de automóveis (LEVY, 2000).

A Associação Espanhola de Parques e Centros Comerciais classifica os centros comerciais como

um conjunto de estabelecimentos comerciais independentes, planejados e desenvolvidos por uma ou várias entidades gestoras e cujo tamanho, mix de produtos, serviços comuns e atividades complementares estão relacionados com seu entorno e que, por sua vez, dispõe de uma imagem e gestão próprias (PORRAL; DOPICO, 2013, p. 3).

Compreende-se que a definição de centro comercial pode ser entendida como a descrição de um shopping center. Neste sentido para Parente et al. (2012), o shopping center é um tipo de aglomerado varejista que compete com outros pela preferência do consumidor em um mercado. Há shoppings centers especializados em um só tipo de produto como artigos de decoração, moda, esportes ou automóveis (PARENTE, 2000). Pode-se citar, como exemplos atuantes no país: móveis e decoração (D\&D e Lar Center), automóveis (Shopping Cristal) entre outros existentes no município de São Paulo (SP).

Esse agrupamento planejado propicia um maior relacionamento entre as empresas que compõem o cluster comercial. Tomkins (2001) relata que uma rede é formada por complexas configurações de alianças e relacionamentos que se formam a partir das interações entre seus participantes, com diferentes tipos de relação e intensidade.

Para Porter (1998), uma das características de um cluster é o acesso à informação propiciada pela proximidade das empresas, pois favorece que seus membros tenham maior facilidade no acesso às informações técnicas, de mercado 
e competitivas. O relacionamento criado e os laços gerados promovem a confiança e facilitam o fluxo de informações no cluster.

\section{Problema de pesquisa e objetivo}

Desta forma o problema de pesquisa que se apresenta é: como ocorrem as trocas de informações entre empresas em um cluster comercial? O objetivo deste trabalho é mapear a rede social formada bem como, identificar os relacionamentos existentes entre as empresas pertencentes a um cluster comercial varejista planejado de automóveis, shopping center, sob a abordagem da análise de redes sociais.

Os resultados obtidos indicarão quais os atores principais e secundários presentes na rede analisada, bem como poderão propiciar possíveis melhorias nas relações entre os lojistas e entre estes e a administração do cluster comercial, o que poderá melhorar o ambiente interno entre todos os presentes. Também poderão auxiliar os gestores na condução do cluster comercial, uma vez que estes conhecerão os participantes que poderão exercer maior ou menor influência sobre os demais, fator este extremamente importante na implantação de estratégias voltadas à competitividade do aglomerado.

A estrutura do trabalho é composta por cinco seções, incluindo esta introdução. No tópico a seguir é apresentada breve revisão de literatura dos conceitos teóricos que embasaram o estudo. Na terceira seção é feita a descrição da metodologia utilizada na pesquisa. A quarta apresenta e analisa os resultados encontrados, apontando-se ainda na quinta as principais conclusões do estudo.

\section{I FUNDAMENTAÇÃO TEÓRICA}

\subsection{Clusters comerciais}

O conjunto de empresas concentrado geograficamente com o objetivo de produzir o mesmo tipo de produto para competir com outras empresas, que não pertencem ao agrupamento, foi denominado de cluster (PORTER, 1989; SCHMITZ; NADVI, 1999; LASTRES; CASSIOLATO, 2003; AMATO NETO, 2005; ZACCARELLI et al., 2008).

O agrupamento que se forma nos clusters, em função dos efeitos da concentração geográfica, adquire competitividade progressiva ao longo do tempo, que acaba por beneficiar todas as empresas que o compõem (ZACCARELLI et al.,2008). Berman e Evans (1998) acrescentam a esse contexto que os produtos podem ser similares ou compatíveis, sendo comercializados ao longo de uma rua ou rodovia. Para Rojo apud Nardis (2010), tais centros comerciais têm grande poder de atração de consumidores.

O aspecto da proximidade entre as lojas nos clusters comerciais beneficia as empresas e os consumidores pela cooperação e competição, que ocorrem 
simultaneamente entre as empresas ali localizadas, aumentando assim o fluxo de clientes nas lojas e o número de opções de produtos para os consumidores. Percebese também que as empresas comerciais ali estabelecidas tendem a compartilhar custos de infraestrutura entre si como limpeza, divulgação, entre outros (BACHION; ABE;MONFORTE, 2011; TELLER; REUTTERER, 2008).

Partindo-se da tendência de que as empresas varejistas buscam se agrupar em aglomerações, encontra-se o princípio da mínima diferenciação, no qual a proximidade dos concorrentes é um fator importante para o sucesso dos negócios. Ou seja, certo número de lojas que vendem as mesmas mercadorias venderão mais se estiverem localizadas de forma adjacente ou próximas umas das outras, do que se estiverem dispersas (SIQUEIRA; TELES, 2006; TELLER; ELMS, 2010).

As aglomerações que formam os clusters varejistas podem ser espontâneas ou planejadas. Os clusters comerciais espontâneos ou não planejados se originam a partir de um processo de auto-organização, normalmente nas regiões centrais dos municípios ou que apresentam grande fluxo de pessoas. Por sua vez, os clusters comerciais planejados atendem ao interesse de seu organizador e normalmente se situam em locais de fácil acesso e estacionamento, como é o caso dos shopping centers (BERMAN; EVANS, 1998). Para Teller (2008), em ambos os casos o agrupamento de lojas pode trazer benefícios e sinergia aos comerciantes.

O grande agrupamento de lojas presentes no cluster comercial planejado cria um ambiente em que há um intenso relacionamento entre seus partícipes. Entender este relacionamento é importante pois, com isto, pode-se compreender melhor quais atores trocam informações e com que frequência o fazem.

Britto e Marioto (2013) relatam que a troca de informações está associada a esforços mútuos ou comportamentos cooperativos. A cooperação, segundo Anderson e Narus (1990, p. 45), pode ser definida como "situações nas quais partes separadas trabalham juntas para atingir objetivos mútuos ou objetivos individuais com reciprocidade ao longo do tempo". Neste estudo entende-se cooperação como ajuda mútua entre empresas ao longo do tempo. Desta forma compreende-se que é comum em um cluster comercial a indicação de outra loja quando o consumidor não encontra o que busca na empresa em que se encontra. Assim, os comerciantes se ajudam de forma mútua o que reforça os laços nas relações estabelecidas nos clusters e possibilita uma melhor convivência e possíveis ganhos financeiros mútuos a posteriore, como pode ser observado nos trabalhos de Telles et. al. (2011), Siqueira, Lollo e Telles (2013) e Aguiar, Pereira e Donaire (2014).

As empresas que compõem o cluster formam grandes redes sociais pois, convivem por longo tempo em um mesmo local o que permite uma maior interação entre si. O ambiente formado, segundo Wasserman e Faust (1994/2009) expressa padrões ou regularidades nas relações estabelecidas entre as unidades interagentes, foco de estudo da análise de redes sociais. 


\subsection{Análise de redes sociais}

O estudo das redes organizacionais e de relacionamentos adquire dimensões importantes para a compreensão da dinâmica do ambiente organizacional (PASCOTTO et al., 2013). Sob esta ótica, uma rede pode ser definida como um conjunto que se relaciona entre si (MASTERALEXIS; BARR; HUMS, 2009) que se constitui a partir da interação entre os sujeitos (KIRSCHBAUM, 2006; PINTO; JUNQUEIRA, 2009).

Tais interações ocorrem principalmente por meio da comunicação e do conhecimento compartilhado que intensifica as trocas de informações e a reciprocidade entre indivíduos, bem como entre as organizações. Neste contexto, a existência de uma rede depende de uma realidade múltipla e complexa, em que o reconhecimento da importância do outro e a definição de objetivos comuns possibilitam a construção de um tecido social (MASTERALEXIS; BARR; HUMS, 2009; PINTO; JUNQUEIRA, 2009).

Assim, conforme sugere Marteleto (2001, p. 72), uma rede é "um conjunto de participantes autônomos que unem ideias e recursos em torno de valores e interesses compartilhados". Ou seja, uma rede é uma realidade operativa de construtos mentais, representada simbolicamente por nós (atores) que podem ser pessoas ou organizações. Esta rede permite o entendimento da realidade social e a superação dos problemas sociais que incidem sobre os diferentes atores (SILVEIRA et al., 2011).

Uma rede social é composta por medidas que ajudam a interpretar o seu funcionamento e a identificar atores relevantes à sua dinâmica. Conforme sugere Silveira et. al. (2011), um conceito importante na análise de redes sociais é o de centralidade, que se refere à posição do nó (ator) dentro de uma rede particular, no caso deste estudo um cluster comercial varejista de automóveis.

As medidas de centralidade, medidas dos atores, referem-se à quantidade de conexões que um ator possui em relação aos demais atores, ou seja, a quantidade de laços (elos). Os laços são vínculos que existem entre dois ou mais atores (nós). Tais vínculos podem ser fortes quando o ator estabelece ligação com muitos outros atores na rede, ou fracos quando a quantidade de laços é pequena (GRANOVETTER, 1973). Assim, um ator apresentará uma grande centralidade se este estiver vinculado a muitos outros atores na rede. Por outro lado, se o ator recebe poucas ligações (laços), sua centralidade é considerada baixa (SILVEIRA et al., 2011).

A conexão entre os nós pode representar o fluxo de informação de uma rede. Assim, atores com alto grau de centralidade indicam que o fluxo de informação passada por eles ocorre de forma frequente, isto é, quem está vinculado a estes pode receber mais informações. Por outro lado, a ausência dessas conexões (nós) forma buracos estruturais, ou seja, um ator não tem vínculo com outros na rede e, desta forma, não recebe informações destes, tornando-se isolado ou com baixa conectividade em relação aos demais.

As medidas de centralidade fornecem informações sobre como funciona a rede 
e indicam o grau com que as relações estão centradas em um ou mais atores, ou seja, para Wasserman \& Faust (1994/2009) tais medidas indicam quais são os atores mais importantes e quais são os mais isolados. Neste estudo, a centralidade será representada pelas medidas Degree, Closeness e Betweenness.

Degree centrality (grau de centralidade) busca medir o grau de interação de cada ator, não considerando a qualidade do contato realizado entre estes. Esta medida identifica os atores que possuem mais vínculos (conexões) com outros e evidencia que, em razão destes disporem de uma posição favorecida na rede, há a possibilidade de obterem ganhos diferenciados em relação a outros com níveis de interações mais baixos, tornando-se menos dependentes devido a sua posição diferenciada (HANNEMAN \& RIDDLE, 2005).

Closeness centrality (grau de proximidade) é a medida que analisa a proximidade dos atores e busca descrever a distância de um ator em relação aos outros na rede (WASSERMAN; FAUST, 1994/2009). Essa medida é mais complexa, uma vez que analisa também os laços indiretos de um determinado ator com a rede, indo muito além do simples entendimento do grau de centralidade (HANNEMAN; RIDDLE, 2005; FARINA et al., 2013). Wasserman \& Faust (1994/2009) afirmam que um ator é central se puder interagir rapidamente com todos os outros.

Outra métrica de centralidade importante é o Betweenness (grau de intermediação), que busca caracterizar os atores que têm posição de destaque na rede. Refere-se a um nó particular que fica entre os outros nós da rede, isto é, indica o quanto cada ator se situa entre dois pares de atores (o meio) componentes da rede na menor distância possível. Assim, quanto maior for a centralidade do ator mais poder ele tem, pelo fato de ser um intermediário na troca de informações (FREEMAN, 1992; FARINA et al., 2013; RIBEIRO, 2013). O que se verifica é o quanto um ator pode controlar as interações entre outros atores cuja comunicação passe pelo primeiro ator (WASSERMAN; FAUST,1994/2009).

Segundo Silveira et al. (2011), se a rede como um todo apresenta poucos vínculos entre os atores, então torna-se difícil para a informação fluir livremente de um grupo a outro, a menos que ela passe por indivíduos que conectam os grupos dentro da rede. Por esta razão, o indivíduo que preenche estes vácuos está numa posição de poder e poderia controlar o fluxo de informação influenciando inclusive quem será beneficiado.

A análise de redes sociais, por meio das medidas de centralidade, permite 0 entendimento das relações entre os atores nela inseridas. Tais medidas evidenciam o fluxo de informações, bem como os principais atores da rede. Assim, a análise de redes sociais, enquanto ferramenta, pode auxiliar e indicar como está o grau de conhecimento de cada membro em relação aos demais membros de um cluster. No caso do cluster comercial varejista planejado de automóveis, um maior conhecimento entre os membros pode significar a concretização de mais negócios no próprio cluster. 


\section{I MÉTODO}

Foi realizado um estudo descritivo, pois "busca descrever as características da situação que envolve um problema" (BOYD, 1978, p. 317). Neste caso, o objetivo é identificar os relacionamentos existentes entre os atores de um cluster comercial varejista planejado de automóveis, doravante denominado Shopping $\mathrm{X}$, que foi selecionado levando-se em conta a acessibilidade dos pesquisadores.

Esta pesquisa assume um caráter quantitativo visto que, procura enumerar e/ ou medir os eventos estudados (GODOY, 1995). Para tanto, foram entrevistados os proprietários, gerentes ou vendedores de lojas integrantes do Shopping $X$ que responderam ao questionário proposto.

Para a avaliação dos resultados utilizou-se a técnica de análise de redes sociais, buscando-se assim identificar e descrever os relacionamentos entre os atores presentes nesse cluster comercial varejista planejado de automóveis, localizado em um município próximo a São Paulo.

Para o levantamento de dados foi feito inicialmente um contato pessoal com a administração do shopping com o objetivo de pedir autorização para realização da pesquisa. Neste dia, um dos pesquisadores efetuou o mapeamento de todas as lojas existentes no cluster, uma vez que a proposta inicial era efetuar um censo. Foram identificadas 26 lojas de carros, uma loja de caminhões, oito lojas de prestadores de serviços (despachante, financeiras e seguradoras, dentre outras e ainda a administração), o que totalizava 36 possíveis participantes. Iniciou-se então uma fase de contato com as lojas para a aplicação do questionário. Do total, três lojas de carros e uma prestadora de serviço se recusaram a responder o questionário, o que reduziu a amostra a 32 inquiridos, Foram necessárias duas visitas ao local em dias diferentes ao da visita inicial descrita, isto ocorreu no mês de dezembro de 2013.

Utilizou-se como instrumento para a coleta de dados um questionário estruturado composto por dois conjuntos de perguntas: o primeiro bloco teve como objetivo identificar a loja quanto a seu tamanho físico, porte, tipo de veículo vendido e função do entrevistado. O segundo bloco foi composto por perguntas que tinham como objetivo esclarecer como o lojista entrevistado troca informações e coopera com os demais atores do Shopping $X$. Desta forma, cada sujeito entrevistado deveria atribuir uma nota numa escala entre 0 (zero) a 5 (cinco) a cada uma das outras lojas existentes e listadas previamente.

Cada entrevistado descreveu, com relação a cada questão, a intensidade com a qual se relacionava com os demais lojistas atuantes no Shopping $X$ ao trocar informações e cooperar com cada um dos demais atores do cluster analisado. Após o levantamento foram utilizados o software Excel para tabulação dos dados e o software Ucinet para a construção dos grafos de relacionamento e cooperação, conforme apregoado na técnica de análise de redes sociais.

As medidas utilizadas para análise da centralidade foram: degree (analisa o grau 
de interação de cada ator), closeness (analisa a proximidade dos atores, buscando descrever a distância de um em relação aos outros na rede) e betweenness (caracteriza os atores que tem posição de destaque como intermediário entre pares de atores na rede).

\section{I ANÁLISE DOS DADOS}

O Shopping X comercializa diversos tipos de veículos, conforme demonstrado na Tabela 1. Nota-se que a predominância é de lojas de carros de passeio novos e semi-novos (23\%) respectivamente, bem como carros e utilitários novos e seminovos (16\%) respectivamente. Constatou-se que não há lojas que vendam apenas carros novos, bem como não se identificou também a presença de concessionárias autorizadas de montadoras de veículos.

\begin{tabular}{lcc}
\hline \multicolumn{1}{c}{ Produto vendido pelas lojas } & Quantidade & Percentual \\
\hline Somente carros de passeio semi-novos & 7 & $23 \%$ \\
\hline Somente carros de passeio novos e semi-novos & 7 & $23 \%$ \\
\hline Somente utilitários semi-novos & 1 & $3 \%$ \\
\hline Somente utilitários novos e semi-novos & 1 & $3 \%$ \\
\hline Carros e utilitários semi-novos & 5 & $16 \%$ \\
\hline Carros e utilitários novos e semi-novos & 5 & $16 \%$ \\
\hline Caminhões e seguros & 1 & $3 \%$ \\
\hline Serviços & 4 & $13 \%$ \\
\hline
\end{tabular}

Tabela 1: Tipos de produtos comercializados no cluster.

Fonte: elaborado pelos autores

Com relação ao porte das empresas, foi utilizado como padrão a quantidade de funcionários por loja, segundo critérios do SEBRAE. Assim verifica-se, conforme Tabela 2, a predominância por microempresas (90\%).

\begin{tabular}{cccc}
\hline Porte da empresa & $\begin{array}{c}\text { Quantidade } \\
\text { funcionários }\end{array}$ & Empresas Pesquisadas \\
\hline Microempresas & Até 9 & Quantidade & Percentual \\
\hline $\begin{array}{c}\text { Empresas de } \\
\text { pequeno porte }\end{array}$ & De 10 a 49 & 3 & $90 \%$ \\
\hline $\begin{array}{c}\text { Empresas de } \\
\text { médio porte }\end{array}$ & Acima de 50 & 0 & $10 \%$ \\
\hline
\end{tabular}

Tabela 2: Porte das empresas do cluster comercial Fonte: elaborado pelos autores. 
Observa-se que o shopping em questão concentra trinta e uma empresas que comercializam um tipo de produto especializado na mesma área espacial, o que o caracteriza segundo Teller e Elms (2010) e Teller e Reutere (2008), como um cluster comercial. A presença da administração, uma entidade que organiza o espaço, caracteriza o cluster comercial analisado como planejado, conforme Teller e Reutere (2008).

A análise de redes sociais possibilita mostrar a qualidade no recebimento da informação passada aos indivíduos que integram a rede, melhorando dessa forma o desempenho empresarial, tanto ao nível individual, quanto ao nível da rede como um todo (CROSS; CUMMINGS, 2004). A Figura 1 expõe a rede de relacionamentos do cluster comercial varejista analisado, referentemente ao parâmetro informação, evidenciando assim as trocas de informações entre os atores participantes e a proximidade destes na rede. As tabelas a seguir servirão de base para a análise das medidas de centralidade Degree, Closseness e Betweennes.

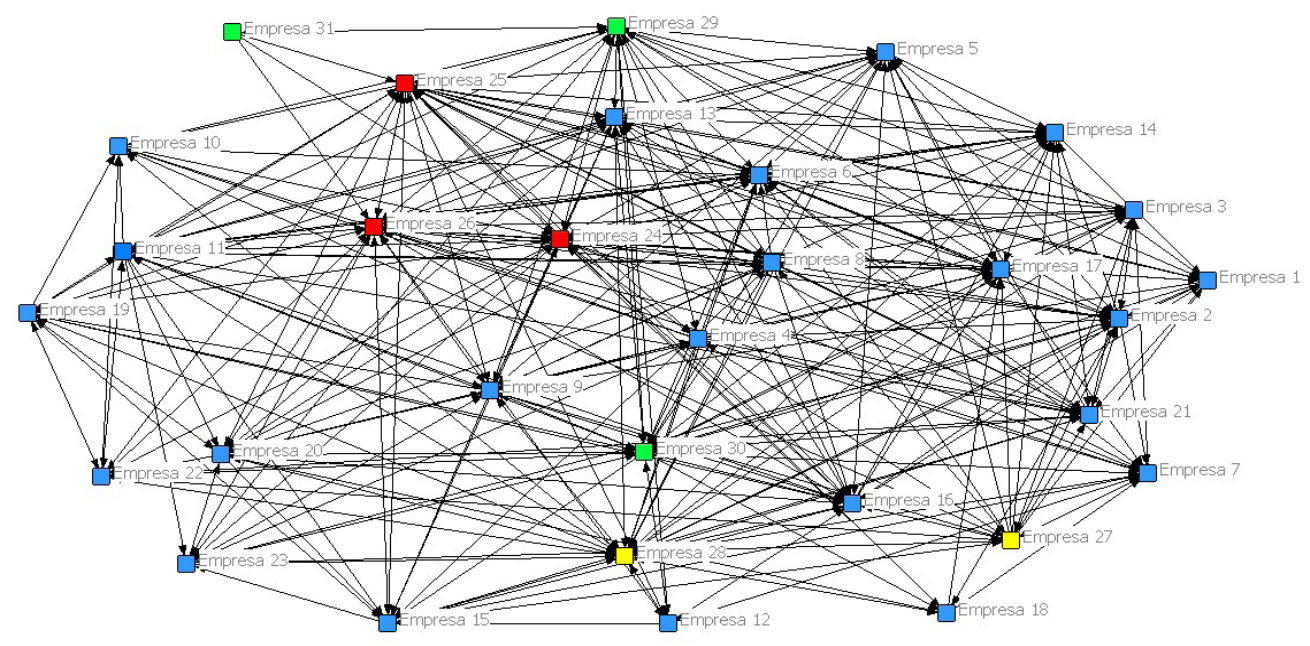

Figura 1: Grau de interação entre as empresas na troca de informação. Fonte: elaborado pelos autores.

Nota-se pela figura uma intensa troca de informações entre as lojas, ou seja, a capacidade de interligar os indivíduos em uma rede é intensificada conforme a frequência da comunicação entre estes (CROSS; CUMMINGS, 2004).

Com o intuito de facilitar a análise dos dados utilizou-se os quartis como critério para determinar quatro intervalos com mesmo número de empresas colocadas em ordem crescente. Assim, obteve-se três quartis: o primeiro quartil representa $25 \%$ dos valores menores, no segundo quartil $50 \%$ dos valores são menores e no terceiro quartil encontram-se $25 \%$ dos valores maiores (LAPPONI, 2000). A tabela 3 indica o terceiro quartil na extremidade superior e o primeiro quartil na extremidade inferior. $A$ tabela 4 descreve os quartis com as medidas de centralidade e as empresas que as compõem. 


\begin{tabular}{c|c|c|c}
\hline & Betweenness & Closeness & Degree \\
\hline $3^{\circ}$ quartil & 1,22 & 90,52 & 89,51 \\
\hline $1^{\circ}$ quartil & 0,29 & 75,61 & 67,74 \\
\hline
\end{tabular}

Tabela 3. Valores correspondentes aos quartis em cada medida de centralidade (\%)

Fonte: dados obtidos da pesquisa pelos autores

\begin{tabular}{c|c|c|c}
\hline & Betweenness & Closeness & Degree \\
\hline $3^{\circ}$ quartil & $1,11,30,32,26,29,24,7$ & $1,11,30,32,7,26,19,9$ & $1,11,30,32,7,26,19,9$ \\
\hline $1^{\circ}$ quartil & $14,8,13,10,23,12,18,31$ & $8,20,27,5,10,23,12,18,31$ & $8,20,27,5,10,23,12,18,31$ \\
\hline
\end{tabular}

Tabela 4. Comparativo entre as medidas de centralidade do cluster comercial

Fonte: dados obtidos da pesquisa pelos autores

O valor $89,51 \%$ para o degree indica que $25 \%$ das empresas trocam informações com mais de $89,51 \%$ das empresas desse cluster comercial. Os valores de intermediação betweenness são baixos, isto é, as empresas estão relacionadas diretamente, sem intermediação de outras. Nota-se que, independente da medida de centralidade a ser analisada, há nos dois quartis um grupo de empresas comuns. Desta forma, buscou-se inicialmente as empresas que estão presentes nas três medidas. No $3^{\circ}$ quartil encontram-se as lojas 1,11 e 7, estas exercem maior influência sobre as outras (betweenness), tem mais prestígio (degree) e estão mais próximas dos outros atores do cluster (closeness). Nota-se também neste quartil a presença de empresas complementares ao negócio central do cluster, como as empresas 30 (vistoria de veículos), 32 (administração) e 26 (financeira). As empresas 29 (despachante) e 24 (financeira) estão presentes apenas na medida betweenness, ou seja, constata-se que estas exercem maior influência sobre as demais empresas do aglomerado varejista. Isto demonstra quais são os atores mais importantes da rede segundo Wasserman e Faust (1994/2009).

As empresas comuns presentes no $1^{\circ}$ quartil são as lojas 8,10,23,12 e 18, estas exercem menos influência sobre as outras (betweenness), tem menos prestígio (degree) e estão mais distantes dos outros atores da rede (closeness). As lojas 5 e 20 e a empresa de seguros 27 dispõem de menor acesso aos outros atores (closeness) e, tem menor prestígio pois estão mais distantes dos atores centrais (degree). Percebe-se também que a loja 14 exerce menor influência sobre as outras nas trocas de informação (betweenness). Estas medidas demonstram os atores mais isolados conforme Wasserman e Faust (1994/2009) e devem ser estimulados a trocar mais informação com as demais empresas. 


\section{I CONCLUSÕES}

Conforme proposto, o presente trabalho teve como objetivo identificar os relacionamentos existentes entre os atores participantes do clustercomercial planejado, denominado Shopping $\mathrm{X}$, sob a abordagem da análise de redes sociais. Em relação à troca de informações entre os participantes, os resultados auferidos indicaram que há baixa troca de informações entre os atores analisados. Ainda que algumas lojas tenham se destacado, observou-se em geral que o nível de intensidade de troca de informações é, em geral, baixo. A administração do shopping pode promover maior contato entre as empresas, a fim de criar maior relacionamento, com o objetivo de promover a confiança e facilitar o fluxo de informações no cluster.

Os resultados encontrados indicam a real possibilidade de utilização da análise de redes sociais no sentido de melhor compreender as relações de interdependência existentes entre os atores atuantes num cluster. Não obstante, o presente estudo também auxilia os gestores de empresas e organizações a melhor compreender sua atuação enquanto membros de uma aglomeração comercial varejista.

Há de se apontar algumas limitações desta pesquisa, por se tratar de um estudo de caso único, circunscrito a um shopping de produto específico localizado na região metropolitana de São Paulo. O recorte transversal no tempo também é um aspecto a ser considerado como limitador, pois expõe a situação auferida num único momento, não interpretando o histórico de fatos que levou a tal contexto específico.

Face ao exposto, futuros estudos complementares ou extensivos à presente pesquisa poderiam contemplar clusters comerciais varejistas de outros produtos, como objeto de estudo. Além disso, também poderiam ser estudados clusters planejados ou espontâneos de outras regiões. Tais estudos poderiam assim buscar verificar se o fato de existir maior cooperação entre algumas lojas repercute num maior volume de vendas apenas para estas lojas tidas como mais cooperativas.

\section{REFERÊNCIAS}

AGUIAR, H.S.; PEREIRA, C.E.C; DONAIRE, D. Polo varejista do bom retiro: cluster de negócios da moda. Anais do Simpósio de Administração da Produção, Logística e Operações Internacionais, São Paulo, SP, Brasil, 17, 2014.

AMATO NETO, J. Redes entre organizações: domínio do conhecimento e da eficácia operacional. São Paulo: Atlas, 2005.

ANDERSON, J. C.; NARUS, J. A. A model of distributor firm and manufacturer firm working partnerships. Journal of Marketing, v.54, n.1, p.42-58, 1990.

BACHION, C. H.; ABE, D. N. S.; MONFORTE, M. E. Uma análise comparativa da satisfação dos consumidores em centros de compras planejados e não planejados. Revista Nucleus, v.8, n.2, p.23854, 2011. 
BERMAN, B.; EVANS, J. R. Retail management: a strategic approach. New Jersey: Prentice Hall, 1998.

BOYD, H. W. Administração de marketing. São Paulo: Saraiva, 1978.

CROSS, R.; CUMMINGS, J. N. Tie and network correlates of individual performance in knowledge intensive work. Academy of Management Journal, v.47, n.6, p. 928-937, 2004.

FARINA, M. C.; SILVA, R. S.; SILVA, J. R. T.; SILVEIRA, M. A. P.; OZAKI, M. T.; BENEVIDES, G. Uma investigação da centralidade e da densidade de uma rede de empresas que atuam na realização de festas e de casamentos. Revista Alcance - Eletrônica, v.20, n.2, p.170-185, 2013.

Freeman, L. C. Social networks and the structure experiment. In: L. C. Freeman, D. R. White \& A. K. Romney (Eds.). Research methods in social network analysis (p. 11-40). New Jersey: Transaction Publishers, 1992.

Godoy, A. S. Introdução a pesquisa qualitativa e suas possibilidades. Revista de Administração de Empresas, v.35,n.2, p.57-63, 1995.

GRANOVETTER, M. The strength of weak ties. American Journal of Sociology.Chicago, v.78, n.6, p.1360-1380, 1973.

HANNEMAN, R.; Riddle, M. (2005). Introduction to social network methods. University of California. January 3, 2014, from http://faculty.ucr. edu/ hanneman, 2005.

KIRSCHBAUM, C. Renascença da indústria brasileira de filmes: destinos entrelaçados? Revista de Administração de Empresas, v.46, n.3, p.58-71, 2006.

LAPPONI, J. C. Estatística usando Excel. São Paulo: Lapponi Treinamento e Editora, 2000.

LASTRES, H. M. M.; Cassiolato, J. E. Novas políticas na era do conhecimento: o foco em arranjos produtivos e inovativos locais. Revista Parcerias Estratégicas, V.17, p. 5-30, 2003.

LEVY, Michael. Administração de varejo. São Paulo: Atlas, 2000.

MARTELETO, R. M. Análise de redes sociais: aplicação nos estudos de transferência da informação. Ciência da Informação, v.30, n.1, p.71-81, 2001.

MASTERALEXIS, L.; BARR, C.; HUMS, M. Principles and practice of sport management. 3 ed. Sudbury, MA: Jones \& Bartlett Publishers, 2009.

NARDIS, S. G. Gestão de Marketing. São Paulo: Saraiva, 2010.

PARENTE, J. Varejo no Brasil: gestão e estratégia. São Paulo: Atlas, 2000.

; BRANDÃO, M. M.; MIOTTO, A. P.; Plutarco, F. Polos varejistas de rua ou shopping centers? comparando as preferências da baixa renda. BBR - Brazilian Business Review, Edição Especial, p.162-189, 2012.

PASCOTTO, S. M. P.; FARINA, M. C.; RODRIGUES, T. H.; PERCIAVALI, T.; DUGO, J. C. Análise de Rede Social para mensuração das estruturas formais e informais. Revista de Administração, Edição Especial, p.811-825, 2013.

PINTO, A. M. G.; JUNQUEIRA, L. A. P. Relações de poder em uma rede do terceiro setor: um estudo de caso. Revista de Administração Pública, v.43,n.5, p. 1091-1116, 2009. 
PORRAL, C. C.; DOPICO, D. C. Estudio exploratorio sobre los factores de atracción de centros comerciales: una aproximación al consumidor español. Ciencia ergo-sum, v. 20, n.2, p.107-120, 2013.

PORTER, M. A vantagem competitiva das nações. Rio de Janeiro: Campus, 1989.

Clusters and the new economics of competition. Harvard Business Review, 1998.

RIBEIRO, H. C. M. Características da Produção Veiculada na Revista de Educação e Pesquisa em Contabilidade no Período de 2007 a 2012. Revista de Educação e Pesquisa em Contabilidade, v. 7, n.4, p. 424-443, 2013.

SCHMITZ, H.; NADVI, K. Clustering and Industrialization: Introduction. World Development, v.27, n.9, p. 1503-1514, 1999.

SIQUEIRA, J. P. L.; TELLES, R. Clusters de negócios: estrutura regional com vocação para competitividade global. Revista da ESPM, v.13, n.4,p. 27-34, 2006.

SIQUEIRA, J.P.L., LOLLO, R.M.; TELLES, R. Feira das flores do Ceagesp: gênese e evolução de um cluster de negócios varejistas. Anais do Seminário em Administração, São Paulo, SP, Brasil, 16, 2013.

TELLER, C.; ELMS, J. Managing the attractiveness of evolved and created retail agglomerations formats. Marketing Intelligence\& Planning, v.28, n.1, p. 25-45, 2010.

TELLER, C.; REUTTERER, T. The evolving concept of retail attractiveness: what makes retail agglomerations attractive when customers shop at them? Journal of Retailing and Consumer Services, v.15,n.3, p.127-143, 2008.

TELLES, R.; ALTHEMAN, E.; SIQUEIRA, J. P. L.; ROMBOLI, S. M.. Clusters comerciais: um estudo sobre concentrações de bares na cidade de São Paulo. Gestão \& Regionalidade, v.27,n.81,p. 32-45, 2011.

TOMKINS, C. Interdependencies, trust and information in relationships, alliances and networks.

Accounting, Organizations and Society, v.26, p.161-191, 2001.

ZACCARELLI, S. B.; Telles, R.; Siqueira, J. P. L; Boaventura, J. M. G.; Donaire, D. Clusters e redes de negócios: uma nova visão para a gestão dos negócios. São Paulo: Atlas, 2008.

WASSERMAN, S.; Faust, K. Social analysis: methods and applications. Cambridge University Press, 1994/2009. 


\title{
CAPÍTULO 10
}

\author{
IMPLEMENTAÇÃO DE UMA MESA DE VARREDURA \\ XY E APRIMORAMENTO DO SISTEMA FOCAL DE UM \\ APARELHO DE LITOGRAFIA
}

Raul de Queiroz Mendes Universidade Federal de São Carlos (UFSCar) São Carlos - São Paulo Arlindo Neto Montagnoli Universidade Federal de São Carlos (UFSCar) São Carlos - São Paulo

RESUMO: Este trabalho propõe o desenvolvimento de um sistema de controle de posição para uma mesa cartesiana XY (mesa de varredura), a qual integra um equipamento de litografia óptica pré-desenvolvido. Objetivouse utilizar tal mesa como uma base de posição ajustável para resistes fotossensíveis durante o processo de fotogravação, automatizando assim o processo em questão e assistindo o mecanismo de alinhamento da amostra abaixo da torre de projeção (do equipamento litrográfico). Além disso, como objetivos específicos, visouse desenvolver softwares: para funcionar como interface de comunicação serial, para auxiliar o processo de microgravação de padrões e para gerar as imagens que representam tais padrões.

PALAVRAS-CHAVE: controle de posição; mesa cartesiana XY; equipamento de litografia óptica; microgravação.
IMPLEMENTATION OF AN XY

SCANNING TABLE AND FOCAL SYSTEM

\section{ENHANCEMENT OF A LITHOGRAPHY}

\section{APPARATUS}

ABSTRACT: This work proposes the development of a position control system for a Cartesian $X Y$ table (scan table), which integrates a pre-developed optical lithography equipment. It was intended to use such a table as an adjustable position base for photosensitive samples during the optical lithography process, hence automating the process in question and assisting the alignment mechanism of the sample below the projection tower (of the lithographic equipment). In addition, as specific objectives, it was aimed to develop softwares: to function as a serial communication interface, to aid the microgravation process of standards and to generate the images that represent such standards.

KEYWORDS: position control; scan table; optical lithography equipment; microgravation.

\section{I INTRODUÇÃO}

Os avanços nos estudos da microeletrônica tiveram como base a utilização do silício aliado às tecnologias de microfabricação (ARISTIZÁBAL, 2012). A 
microeletrônica procurou explorar as características elétricas e mecânicas do silício e isto favoreceu a produção em massa de chips que apresentam uma variedade de aplicações em produtos constituídos de Sistemas Micro-Eletro-Mecânicos (MEMS), tais como bocais de injeção de impressoras a jato de tinta e sistemas de comunicação por fibra ótica (PETERSEN, 1982).

Beneficiando-se dos MEMS, a microeletrônica passou a ser empregada em processos mais complexos que utilizam materiais como o PDMS (polidimetilsiloxano polímero de silicone), e o PMMA (polimetilmetacrilato - polímero termoplástico), além do Silício (ARISTIZÁBAL, 2012). Essa miniaturização de processos mais elaborados pode ser evidenciada no trabalho de Liu e Cui (2005) sobre o desenvolvimento de um microchip integrado aplicado a eletroforese capilar para aminoácidos. Em (LIU; CUI, 2005), o microchip de PDMS integrado com eletrodos de platina foi construído tendo como base a tecnologia de MEMS.

A partir destes progressos, criou-se o conceito dos Laboratórios em Chip (LOC), o qual consiste na realização de operações características de laboratório em escalas micro ou nanométricas (ARISTIZÁBAL, 2012). Sendo assim, tornaram-se executáveis o manuseio e a análise de reações de amostras com micro ou picolitros de volume, de modo automatizado, por meio da otimização de áreas como a microfluídica e a microeletrônica (ARISTIZÁBAL, 2012). Os LOC são amplamente empregados em: análises de motilidade bacteriana, estudos de crescimento confinado de microorganismos, estudos biofísicos de membranas e em estudos de cristalização de proteínas (Hansen et al., 2002).

Os LOCs, em propósitos de microfluídica (assim como em algumas aplicações em microeletrônica), podem ser produzidos por intermédio de aparelhos de litografia semelhantes ao mecanismo ilustrado na Figura 1. Os moldes simples são fabricados através de linhas no fotoresiste que originarão os canais no PDMS ou em algum outro material empregado como molde (ARISTIZÁBAL, 2012). Na Figura 1, observa-se que as linhas do fotorresiste podem ser geradas por meio da radiação da lâmpada UV, a qual passa pela matriz de micro espelhos do projetor, onde o estado binário dos micro espelhos formarão a imagem no fotorresiste (ARISTIZÁBAL, 2012). Além disso, na figura em questão, pode-se observar que a radiação UV passa pelo sistema focal onde a imagem formada na matriz de micro espelhos é ajustada de acordo com a posição do substrato (ARISTIZÁBAL, 2012). 


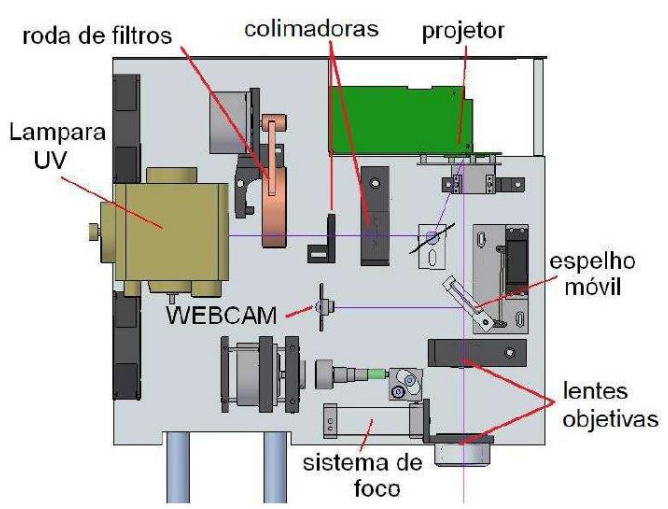

Figura 1 - Modelo da torre de projeção do aparelho de litografia (Aristizábal, 2012).

\subsection{Síntese da Bibliografia Fundamental}

O trabalho de Aristizábal (2012) é fundamentado na utilização de tecnologias de microfabricação para a produção de sistemas Lab On Chip empregados na área biomédica. Técnicas de moldagem e soldagem para o desenvolvimento de sistemas Lab On Chip em Polidimentilsiloxano e processos de ativação de PDMS também foram abordados nesse trabalho. O PDMS é um elastômero de silicone que apresenta aspectos propícios a aplicações biomédicas de baixo custo. Exemplos de tais aspectos do PDMS: possui propriedades isotrópicas e homogêneas, é quimicamente inerte, tem um custo menor que o silício e é permeável a gases (além de ser: transparente, não tóxico, não fluorescente e biocompatível) (MATA et al, 2005).

Contudo, o PDMS é um material hidrofóbico e, em decorrência disto, certas substâncias (compostos orgânicos) podem ser absorvidas em sua superfície, dificultando a quantificação e a separação desses tipos de substâncias em dispositivos feitos com o polímero em questão (ARISTIZÁBAL, 2012).

Apesar da superfície inerte do PDMS ser um empecilho a modificação de sua estrutura hidrofóbica, tal estrutura pode ser modificada com o uso de processos envolvendo sol-gel (ou com a deposição de polímeros hidrofílicos), com a finalidade de gerar camadas de $\mathrm{SiO} 2$ nestes polímeros de Polidimetilsiloxano, tornando sua superfície mais hidrofílica e resistente a absorção de compostos orgânicos (ROMAN et al, 2005).

Em uma seção do trabalho de Aristizábal (2012), é apresentado o desenvolvimento de um aparelho de litografia óptica com uma torre de projeção ilustrada pela Figura 1. Este aparelho é capaz de gerar gravações em substratos com limites de resoluções de: $5 \mu \mathrm{m}, 10 \mu \mathrm{m}$ e $15 \mu \mathrm{m}$, com relação as seguintes formas respectivamente: linhas abertas, círculos e retângulos (modelo exibido na Figura 2). O equipamento de litografia óptica é composto pela torre de projeção e por um sistema de varredura constituído de mesas cartesianas $\mathrm{XY}$. 


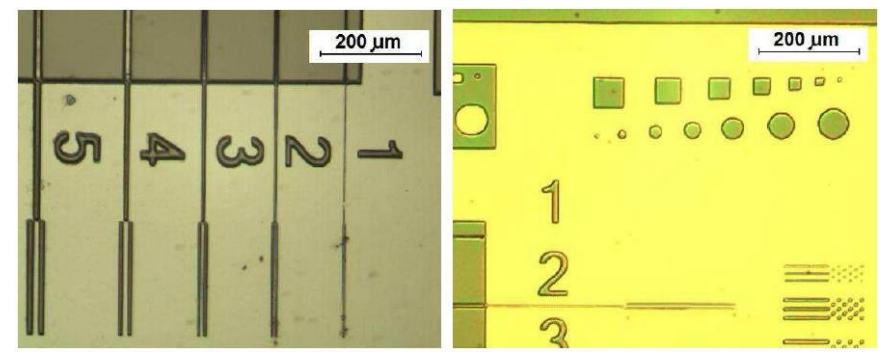

Figura 2 - Imagem da esquerda: resulção de linhas abertas; imagem da direita: resolução de círculos e retângulos (Aristizábal, 2012).

Internamente a torre de projeção, encontra-se uma lâmpada de mercúrio, cuja radiação é direcionada por uma matriz de micro-espelhos eletromecânicos (ARISTIZÁBAL, 2012). O estado binário dos micro-espelhos determinam se a luz será transmitida para as lentes objetivas e, posteriormente, para o resiste, ou se esta luz será refletida na própria estrutura do projetor, aparecendo como um ponto escuro no resiste (ARISTIZÁBAL, 2012).

O sistema de controle de foco, cuja estrutura é esquematizada na Figura 3, opera com base no arqueamento de chapas finas e flexíveis de aço por uma alavanca que pode ser impelida pelo mecanismo acoplado a um motor de passo (ARISTIZÁBAL, 2012). Assim, substratos com espessuras distintas podem ser gravados por meio deste sistema de controle de foco, o qual ajusta a lente objetiva em, no máximo, $6 \mathrm{~mm}$ de alcance vertical (ARISTIZÁBAL, 2012).

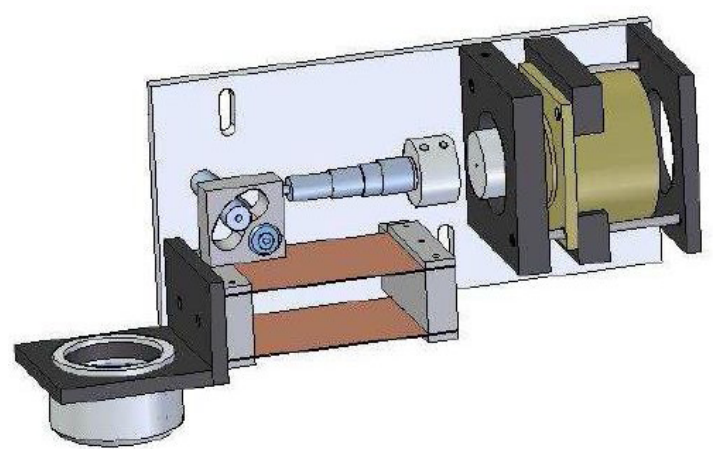

Figura 3 - Estrutura mecânica do sistema de controle de foco (Aristizábal, 2012).

De acordo com Aristizábal (2012), o sistema de varredura é composto por mesas cartesianas $\mathrm{XY}$ que operam com base nos sinais transmitidos por um microcontrolador. O microcontrolador é responsável por computar os sinais dos encoders que compõem as mesas cartesianas, os comandos enviados pelo PC (Personal Computer) e os comandos transmitidos por um joystick. Posto isso, o microcontrolador envia sinais de PWM (Pulse Width Modulation) para uma ponte H para controlar a posição da mesa. 


\section{I OBJETIVOS}

Neste trabalho, visou-se realizar o controle de posição em malha fechada de uma mesa de varredura $X Y$ para um equipamento de litografia óptica pré-desenvolvido. Acrescentando-se a isso, visou-se desenvolver novos hardwares e softwares para otimizar o processo de litografia óptica.

\section{I MATERIAL E MÉTODOS}

Equipamentos utilizados em laboratório:

- Fonte De Alimentação DC Minipa MPL-3303M;

- Multimetro Instrutherm MD-380;

- Osciloscópio Agilent Tecnologies DSO1072B;

- Bread board Shuiyunpu Wanjie BB-4T7D-01.

A placa apresentada na Figura 4 foi montada com o intuito de ligar ou desligar o LED UV e de fazer o controle em malha aberta do foco da lente externa do equipamento de litografia óptica da Figura 5. O algoritmo de controle de foco em questão foi desenvolvido no software MPLAB em linguagem Assenbly para ser programado no PIC 16F628A. Componentes utilizados para montar a placa da Figura 4:

- 3 bornes (cada um com 2 entradas);

- 2 capacitores de $27 \mathrm{pF}$;

- 1 capacitor de 100nF;

- 1 capacitor de $47 \mu \mathrm{F}$;

- 6 conectores do tipo "pin header";

- 1 cristal LGE $20 \mathrm{MHz}$;

- 2 diodos $1 \mathrm{n} 4007$;

- 1 microcontrolador PIC 16F628A;

- 1 relé HJR-3FF-S-Z

- 2 resistores de $1 \mathrm{k} \Omega$;

- 1 resistor de 2,2k $\Omega$;

- 1 transistor BC338. 


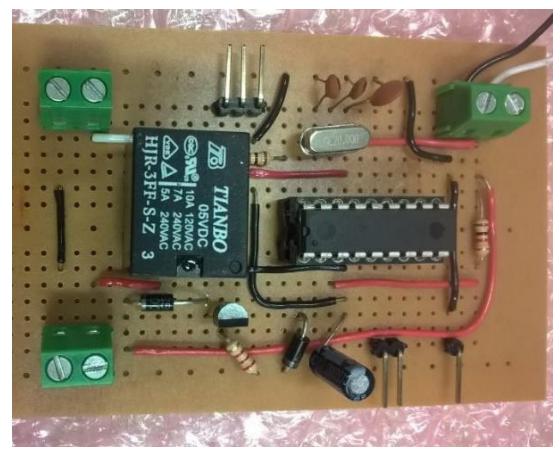

Figura 4 - Placa desenvolvida para ligar ou deligar o equipamento de litografia óptica e para fazer o controle do foco de sua lente externa.

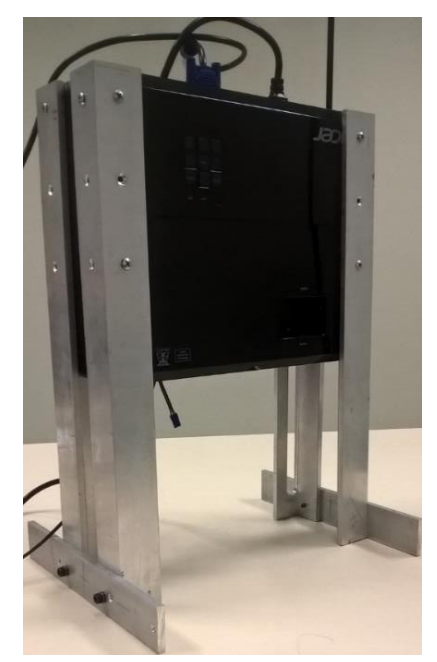

Figura 5 - Equipamento de litografia óptica pré-desenvolvido.

Por meio de um PC contendo o software Visual Studio 2015, desenvolveu-se dois programas em linguagem C\#, cujas interfaces estão expostas nas Figuras 6 e 7. Com o auxílio da interface da Figura 6 e da placa da Figura 4, é possível enviar comandos ao microcontrolador PIC 18F4520, a fim de que este possa desempenhar as seguintes funções: realizar o controle em malha aberta da angulação do servo motor acoplado à estrutura de ajuste focal do equipamento de litografia através de pulsos de PWM, e ligar ou desligar o LED UV de tal equipamento pela ativação e desativação do relé da placa da Figura 4. 


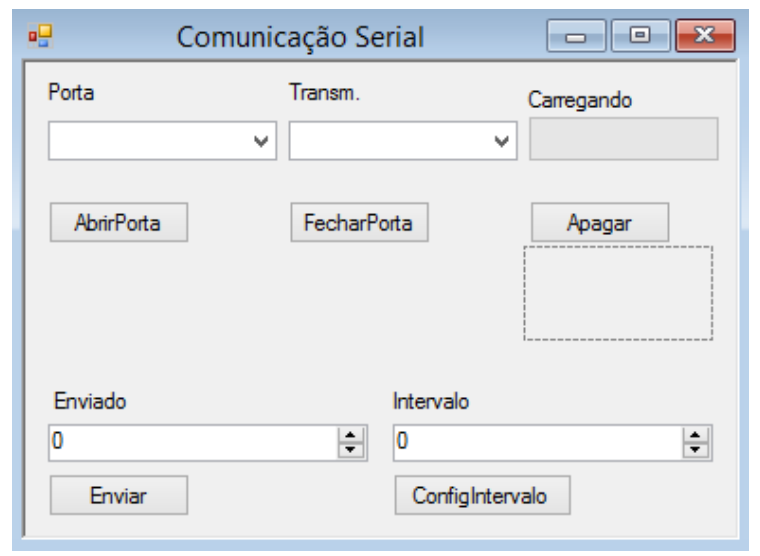

Figura 6 - Interface do programa aplicado no controle do foco, do LED UV e do processo de gravação do equipamento de litografia óptica.

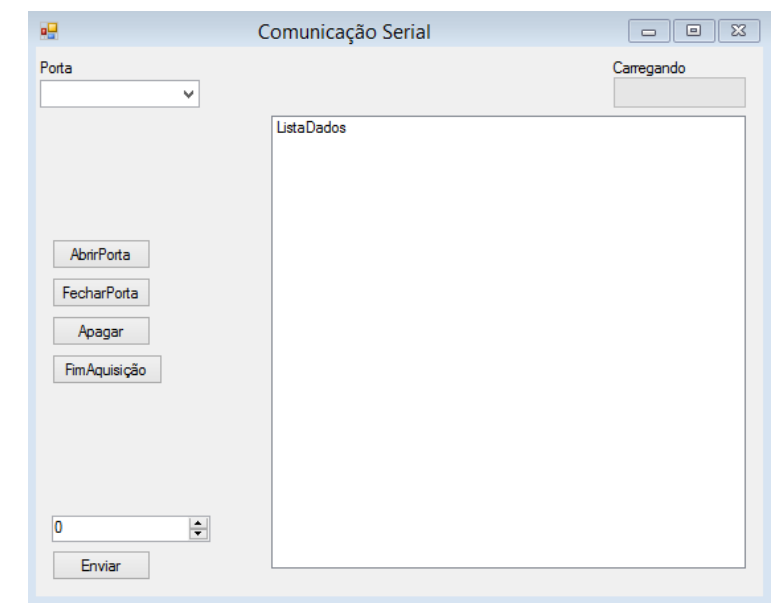

Figura 7 - Interface do programa aplicado no controle de posição da mesa de varredura.

Com o auxílio da placa de circuito impresso (PCB) da Figura 8, é possível realizar a comunicação serial entre a interface da Figura 7 e o PIC 18F4520, objetivando controlar a posição, em malha fechada, da mesa cartesiana da Figura 9. Além disso, utilizou-se um display LCD 16x2 para auxiliar na visualização da posição em tempo real da mesa em questão (em cm); e utilizou-se também um hardware de ponte USB para UART Cp2102 (betemcu, B75937), para que fosse possível realizar a comunicação serial entre o PC e o PIC 18F4520 via USB. Componentes utilizados para montar a PCB da Figura 8:

- 1 borne com 2 entradas;

- 1 botão;

- 1 capacitor de $100 \mathrm{nF}$;

- 2 capacitores de $10 \mathrm{nF}$;

- 6 conectores do tipo "pin header";

- 30 conectores do tipo "center header";

- 1 cristal LGE 20MHz; 


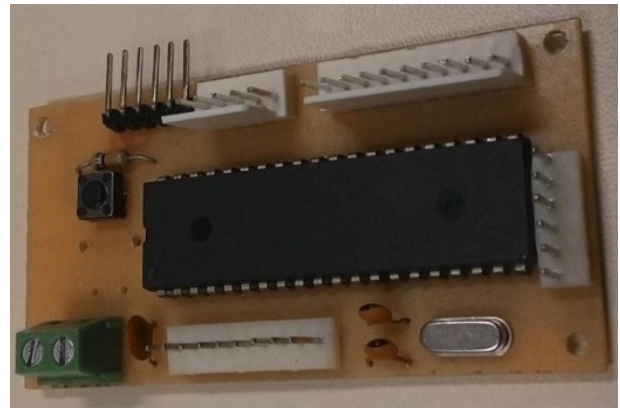

Figura 8 - PCB aplicada no controle da posição da mesa cartesiana.

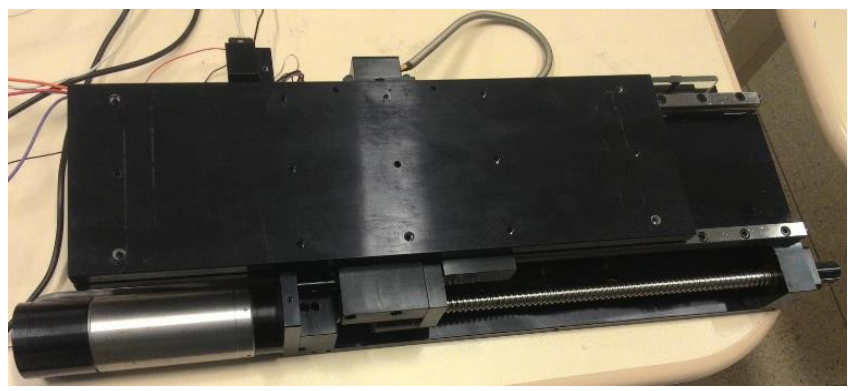

Figura 9 - Mesa cartesiana utilizada nos testes práticos de controle de posição.

A região deslizante superior da mesa cartesiana da Figura 9 se desloca horizontalmente devido a atuação de um motor DC, cujo eixo está acoplado a uma rosca sem fim. À medida que o eixo deste motor DC gira, a rosca sem fim faz movimentar linearmente um dispositivo composto internamente por um acoplador que está interligado a região deslizante da mesa e a própria rosca sem fim. Ao se movimentar linearmente devido ao giro da rosca sem fim, este dispositivo também faz a região deslizante da mesa cartesiana se movimentar linearmente.

A PCB da Figura 10 foi desenvolvida para tratar os sinais analógicos dos canais $A$ e $B$ do encoder óptico linear da mesa de varredura. Componentes utilizados para montar a PCB da Figura 10:

- 2 amplificadores operacionais (ampop) TL081;

- 1 borne com 3 entradas;

- 2 capacitores de $47 \mu \mathrm{F}$;

- 1 capacitor de $100 \mathrm{nF}$;

- 4 conectores do tipo "center header";

- 2 resistores de $39 \mathrm{k} \Omega$;

- 2 resistores de $1 \mathrm{k} \Omega$;

- 2 transistores BC548. 


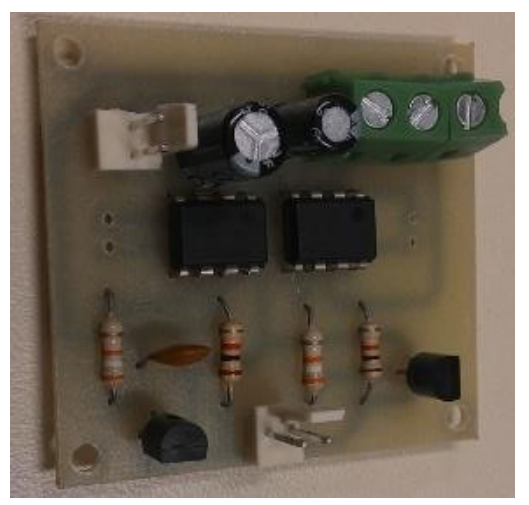

Figura 10 - PCB desenvolvida para tratar os sinais gerados pelos canais do encoder óptico.

A PCB da Figura 11 opera como uma ponte para o motor DC da mesa cartesiana e como um circuito desacoplador, protegendo o PIC 18 F4520 e todos os circuitos eletrônicos e digitais interligados a esta placa de sobrecorrentes.

Componentes utilizados para montar a PCB da Figura 11:

- 2 bornes (cada um com 2 entradas);

- 2 capacitores de $10 \mathrm{nF}$;

- 2 capacitores de $100 \mathrm{nF}$;

- 6 conectores do tipo "pin header";

- 3 optoacopladores 6 n136;

- 1 ponte para motor Im18201;

- 3 resistores de $100 \Omega$;

- 3 resistores de 2,2k $\Omega$;

- 1 resistor de $10 \mathrm{k} \Omega$.

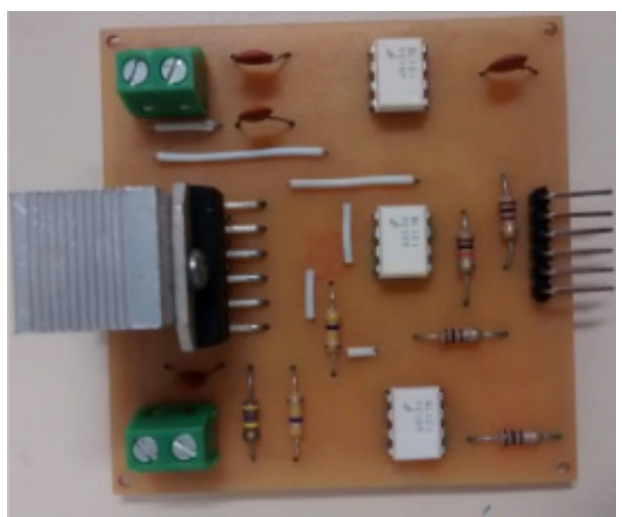

Figura 11 - PCB que funciona como ponte para motor DC e como desacoplador.

Os métodos utilizados para as análises de dados foram, principalmente, baseados em procedimentos empíricos realizados em laboratório. Os circuitos construídos e os algoritmos desenvolvidos foram testados em prática e os resultados foram registrados e analisados durante e após os testes respectivamente. 


\section{I RESULTADOS E DISCUSSÃO}

As ondas das Figuras 12 e 13 representam os sinais analógicos dos canais $A$ (amarelo) e B (verde) do encoder óptico. Os sinais da Figura 12 estão defasados entre si por um ângulo de $81^{\circ}$ devido ao deslocamento no sentido positivo (para à direita) da mesa cartesiana; e os sinais da Figura 17 estão defasados entre si por um ângulo de $-107^{\circ}$ devido ao deslocamento no sentido negativo (para à esquerda) de tal mesa.

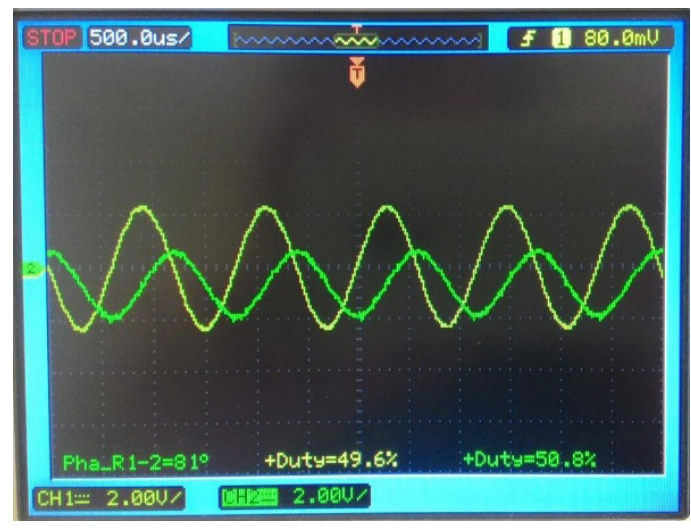

Figura 12 - Sinais analógicos dos canais A (amarelo) e B (verde) do encoder óptico. Tais sinais estão defasados entre si por um ângulo de $81^{\circ}$ devido ao deslocamento no sentido positivo (para à direita) da mesa cartesiana.

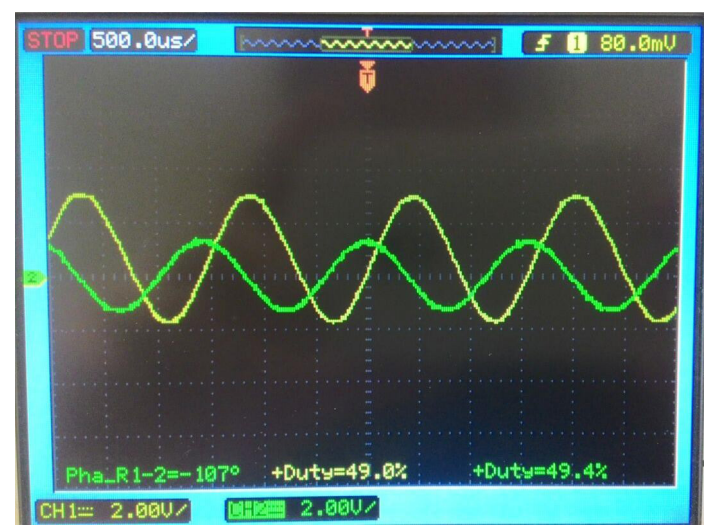

Figura 13 - Sinais analógicos e senoidais dos canais A (amarelo) e B (verde) do encoder óptico. Tais sinais estão defasados entre si por um ângulo de $-107^{\circ}$ devido ao deslocamento no sentido negativo (para à esquerda) da mesa de varredura.

As ondas das Figuras 14 e 15 representam os sinais dos canais A e B em quadratura tratados pela PCB da Figura 10. Os sinais da Figura 14 estão defasados entre si por um ângulo de $109^{\circ}$ devido ao deslocamento no sentido positivo da mesa cartesiana, e os sinais da Figura 15 estão defasados entre si por um ângulo de $-118^{\circ}$ devido ao deslocamento no sentido negativo de tal mesa. 


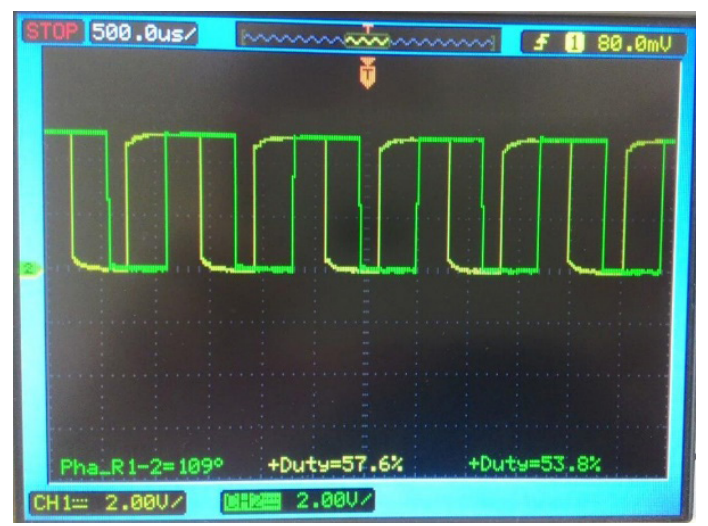

Figura 14 - Sinais dos canais A (amarelo) e B (verde) em quadratura do encoder óptico, tratados pela PCB da Figura 10. Tais sinais estão defasados entre si por um ângulo de $109^{\circ}$ devido ao deslocamento no sentido positivo (para à direita) da mesa de varredura.

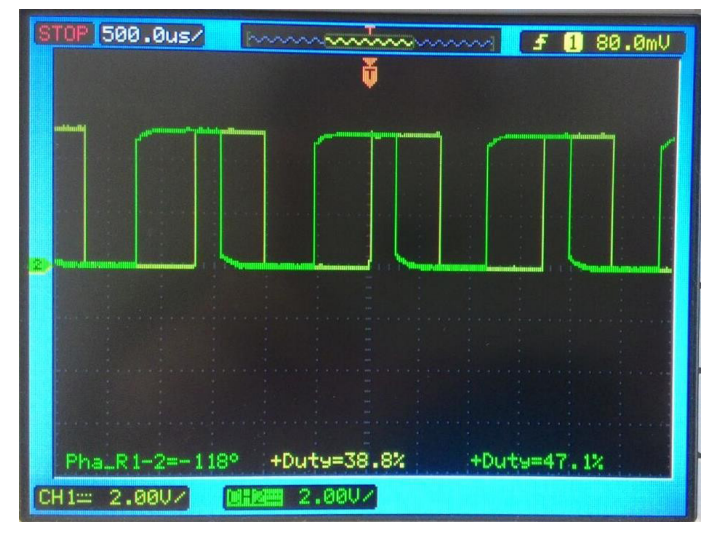

Figura 15 - Sinais dos canais A (amarelo) e B (verde) em quadratura do encoder óptico, tratados pela PCB da Figura 10. Tais sinais estão defasados entre si por um ângulo de $-118^{\circ}$ devido ao deslocamento no sentido negativo (para à esquerda) da mesa de varredura.

As Tabelas 1 e 2 mostram os valores dos ciclos de trabalho e defasagens dos sinais dos canais A e B do encoder óptico, antes e depois do tratamento de sinais executado pela PCB da Figura 10 respectivamente.

\begin{tabular}{|c|c|c|c|}
\hline Canal & $\begin{array}{c}\text { Sentido do Deslocamento } \\
\text { da Mesa Cartesiana }\end{array}$ & Defasagem $\left({ }^{\circ}\right)$ & $\begin{array}{c}\text { Ciclo de Trabalho } \\
(\%)\end{array}$ \\
\hline A & + & 81 & 49,6 \\
\hline B & + & -81 & 50,8 \\
\hline A & - & -107 & 49,0 \\
\hline B & - & 107 & 49,4 \\
\hline
\end{tabular}

Tabela 1 - Valores dos ciclos de trabalho e defasagens dos sinais dos canais A e B do encoder óptico, antes do tratamento de sinais executado pela PCB da Figura 10.

\begin{tabular}{|c|c|c|c|}
\hline Canal & $\begin{array}{c}\text { Sentido do } \\
\text { Deslocamento da } \\
\text { Mesa Cartesiana }\end{array}$ & $\begin{array}{c}\text { Defasagem } \\
\left({ }^{\circ}\right)\end{array}$ & $\begin{array}{c}\text { Ciclo de } \\
\text { Trabalho } \\
(\%)\end{array}$ \\
\hline A & + & 109 & 57,6 \\
\hline B & + & -109 & 53,8 \\
\hline A & - & -118 & 38,8 \\
\hline
\end{tabular}




\begin{tabular}{|c|c|c|c|}
\hline $\mathrm{B}$ & - & 118 & 47,1 \\
\hline
\end{tabular}

Tabela 2 - Valores dos ciclos de trabalho e defasagens dos sinais dos canais A e B do encoder óptico, após o tratamento de sinais executado pela PCB da Figura 10.

Após serem tratados, os sinais dos canais $A$ e $B$ do encoder óptico são transmitidos aos pinos $15(\mathrm{RC} 0)$ e $16(\mathrm{RC} 1)$, respectivamente, do microcontrolador PIC 18F4520 da PCB da Figura 8. Para estabelecer o controle PID de posição em malha fechada da mesa cartesiana, desenvolveu-se um algoritmo no software MPLAB em linguagem C. Neste algoritmo, a ação de controle opera a cada $50 \mathrm{~ms}$ (estouro do timer). Do mesmo modo, a visualização da posição em tempo real da mesa de varredura no display e na interface da Figura 7, além da visualização do erro de posição da mesa nessa mesma interface, ocorrem a cada 50ms. Acrescentandose a isso, determinou-se empiricamente o valor do fator de conversão de bits para distância (em cm), o qual é igual a 0,0064.

Os valores dos ganhos kp, ki e kd, do controle PID, foram determinados empiricamente e estão expostos na Tabela 3. O valor total do erro de posição, cuja expressão é apresentada na Equação 1, foi utilizado como o valor do ciclo de trabalho do PWM que representa o sinal de controle transmitido a ponte $\mathrm{H}$ para controlar $\mathrm{o}$ motor DC da mesa de varredura através do pino 17 CCP1 (RC2) do microcontrolador PIC 18F4520.

\begin{tabular}{|c|c|}
\hline Ganho & Valor \\
\hline $\mathrm{Kp}$ & 0,5 \\
\hline $\mathrm{Ki}$ & 0,05 \\
\hline $\mathrm{Kd}$ & 0,01 \\
\hline
\end{tabular}

Tabela 3 - Valores do ganhos kp; ki e kd do controlador PID determinados empiricamente.

$$
\text { Erro }_{\text {total }}=\left(K p \times \text { Erro }_{\text {Posição }}\right)+\left(K i \times \text { Soma }_{\text {Erro }}\right)+\left(K d \times \text { Diferença }_{\text {Erro }}\right)
$$

Equação 1 - Equação utilizada no cálculo do valor total do erro de posição.

Os pinos de saída da ponte H LM18201 são conectados diretamente as alimentações do motor DC da mesa de varredura. A Figura 16 diz respeito ao circuito completo de controle de posição da mesa cartesiana utilizado nos testes práticos em laboratório. Tais testes foram realizados tendo como posição inicial da mesa $(0 \mathrm{~cm})$ aquela indicada pela Figura 17. 


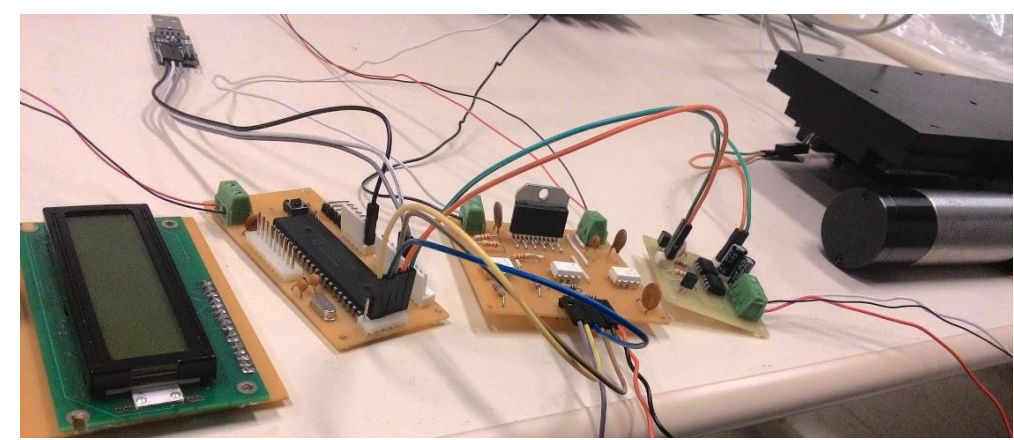

Figura 16 - Circuito completo de controle de posição da mesa de varredura.

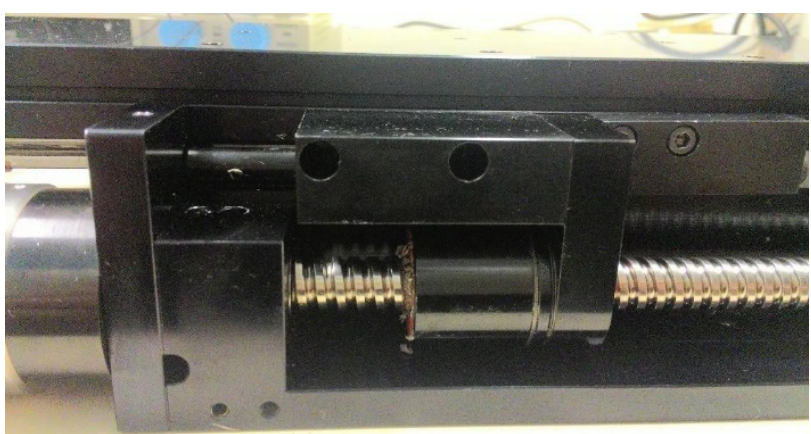

Figura 17 - Posição inicial da mesa de varredura $(0 \mathrm{~cm})$.

Sendo assim, executou-se 3 testes para validar o sistema de controle de posição da mesa de varredura. Nestes testes, controlou-se a mesa para as seguintes posições: $6 \mathrm{~cm}, 12 \mathrm{~cm}$ e $15 \mathrm{~cm}$, em relação a posição inicial da Figura 17. A Tabela 4 mostra os resultados obtidos para os 3 testes executados. Nesta tabela, também são apresentados os valores dos erros relativos entre a posição final no LCD (cm) e a posição desejada $(\mathrm{cm})$ da mesa.

\begin{tabular}{|c|c|c|c|}
\hline Teste & Posição Desejada (cm) & Posição Final no LCD $(\mathrm{cm})$ & Erro (\%) \\
\hline $1^{\circ}$ & 12 & 11,9248 & 0,6267 \\
\hline $2^{\circ}$ & 6 & 5,9974 & 0,0433 \\
\hline $3^{\circ}$ & 15 & 15,0539 & 0,3593 \\
\hline
\end{tabular}

Tabela 4 - Valores das posições desejadas e das posições finais, obtidas no LCD, para os 3 testes registrados.

\section{I CONCLUSÕES}

Por meio da placa da Figura 4 e da interface da Figura 6, otimizou-se o sistema focal do equipamento de litografia óptica, uma vez que o foco de sua lente externa, por onde a imagem atravessa para ser gravada no resiste fotossensível, passou a ser controlado pela placa e pela interface em questão. Tal controle favorece a projeção de imagens com uma melhor resolução. Além disso, a interface da Figura 6 torna o processo de litografia óptica mais simples e eficiente, visto que, por meio desta interface, é possível supervisionar todo o processo de litografia desde a escolha do 
padrão a ser gravado até o tempo de projeção sob o qual a amostra será exposta.

Acrescentando-se a isso, com o auxílio do sistema de controle de posição da mesa de varredura e da interface da Figura 7, realizou-se testes práticos em laboratório para validar o sistema em questão, considerando-se os seguintes valores de posições desejadas da mesa: $12 \mathrm{~cm}, 6 \mathrm{~cm}$ e $15 \mathrm{~cm}$. Desta forma, obteve-se os seguintes erros relativos entre as posições desejadas e as posições reais no visor digital do LCD: 0,6267\%, 0,0427\% e 0,003597\%, respectivamente. Portanto, a partir dos erros calculados, conclui-se que o circuito de controle de posição, juntamente com a interface citada, desempenha sua função como esperado e que a mesa cartesiana consegue atingir as posições desejadas.

\section{REFERÊNCIAS}

ARISTIZÁBAL, S. L. Desenvolvimento de sistemas Lab-on-a-Chip para análises em biofísica celular 2012. 163 f. 2012. Tese de Doutorado. Tese (Doutorado em Engenharia Elétrica)-Escola Politécnica da Universidade de São Paulo. São Paulo. Brasil.

HANSEN, Carl L. et al. A robust and scalable microfluidic metering method that allows protein crystal growth by free interface diffusion. Proceedings of the National Academy of Sciences, v. 99, n. 26, p. 16531-16536, 2002.

LEE, Jessamine Ng; PARK, Cheolmin; WHITESIDES, George M. Solvent compatibility of poly (dimethylsiloxane)-based microfluidic devices. Analytical chemistry, v. 75, n. 23, p. 6544-6554, 2003.

LIU, C. C.; CUI, D. F. Design and fabrication of poly (dimethylsiloxane) electrophoresis microchip with integrated electrodes. Microsystem Technologies, v. 11, n. 12, p. 1262-1266, 2005.

LIU, X. Y. et al. based piezoresistive MEMS force sensors. In: 2011 IEEE 24th International Conference on Micro Electro Mechanical Systems. IEEE, 2011. p. 133-136.

MATA, Alvaro; FLEISCHMAN, Aaron J.; ROY, Shuvo. Characterization of polydimethylsiloxane (PDMS) properties for biomedical micro/nanosystems. Biomedical microdevices, v. 7, n. 4, p. 281-293, 2005.

PETERSEN, Kurt E. Silicon as a mechanical material. Proceedings of the IEEE, v. 70, n. 5, p. 420$457,1982$.

ROMAN, Gregory T. et al. Sol- gel modified poly (dimethylsiloxane) microfluidic devices with high electroosmotic mobilities and hydrophilic channel wall characteristics. Analytical Chemistry, v. 77, n. 5, p. 1414-1422, 2005.

THANGAWNG, Abel L. et al. An ultra-thin PDMS membrane as a bio/micro-nano interface: fabrication and characterization. Biomedical microdevices, v. 9, n. 4, p. 587-595, 2007.

WONG, leong; HO, Chih-Ming. Surface molecular property modifications for poly (dimethylsiloxane) (PDMS) based microfluidic devices. Microfluidics and nanofluidics, v. 7, n. 3, p. 291, 2009. 


\section{ANÁLISE DO IMPACTO DO ROTEAMENTO FIXO EM REDES ÓPTICAS ELÁSTICAS TRANSLÚCIDAS CONSIDERANDO DIFERENTES CENÁRIOS DE DEGRADAÇÃO DA QUALIDADE DE TRANSMISSÃO}

Arthur Hendricks Mendes de Oliveira Universidade Federal de Campina Grande, Centro de Engenharia Elétrica e Informática, Unidade Acadêmica de Engenharia Elétrica Campina Grande - Paraíba Helder Alves Pereira Universidade Federal de Campina Grande, Centro de Engenharia Elétrica e Informática, Unidade Acadêmica de Engenharia Elétrica Campina Grande - Paraíba

RESUMO: Este capítulo apresenta uma avaliação do impacto no desempenho de redes ópticas elásticas translúcidas, bem conhecidas da literatura, de diferentes algoritmos de roteamento, considerando diversos cenários de degradação da qualidade de transmissão do sinal óptico propagante. Para isso, considerouse o ruído de emissão espontânea amplificada gerado nos amplificadores ópticos (de potência, de linha e pré-amplificador), formatos de modulação e taxas de transmissão de bit diferentes para as solicitações de chamada. O desempenho foi avaliado em termos da probabilidade de bloqueio de chamadas em função do número de regeneradores instalados na rede. Os resultados mostram que, além da característica do tipo de roteamento (fixo ou dinâmico), deve-se considerar também a política de utilização de regeneradores para otimizar o número de chamadas estabelecidas. PALAVRAS-CHAVE: Algoritmo de Roteamento, Algoritmo de Utilização de Regeneradores, Rede Óptica Elástica Translúcida.

\section{ANALYSIS OF THE IMPACT OF FIXED}

ROUTING IN TRANSLUCENT ELASTIC

OPTICAL NETWORKS CONSIDERING

DIFFERENT QUALITY OF TRANSMISSION

\section{DEGRADATION SCENARIOS}

ABSTRACT: This chapter presents an analysis of the impact of different routing algorithms on the performance of translucent elastic optical networks. We considered in our simulations the amplified spontaneous emission noise generated in the optical amplifiers (power amplifier, in-line and preamplifier), modulation formats and different transmission bit rates for the call requests. The performance was evaluated in terms of the blocking probability of call requests as a function of the number of regenerators installed in the network. The results show that, in addition to the characteristics of the routing type (fixed or dynamic), one should also consider the policy of assigning regenerators to optimize the number of established call requests.

KEYWORDS: Regenerator Assignment 
Algorithm, Routing Algorithm, Translucent Elastic Optical Network.

\section{I INTRODUÇÃO}

A transmissão de dados em redes ópticas elásticas (EON - Elastic Optical Network) possui uma característica bem interessante quando comparada com as redes ópticas que utilizam multiplexação por comprimento de onda (WDM Wavelength Division Multiplexing) (CHATTERJEE et al., 2015). Essa característica se refere à capacidade de tratar com a particularidade do atendimento das chamadas solicitadas na rede. Com relação às redes ópticas WDM, independente da taxa de transmissão de bit solicitada pela chamada e do formato de modulação utilizado, a largura de banda não varia para atender à solicitação de chamada. Enquanto que, nas redes ópticas elásticas, a largura de banda da chamada pode variar dependendo tanto da taxa de transmissão de bit solicitada quanto do formato de modulação utilizado para estabelecer a respectiva chamada (CAVALCANTE et al., 2015).

Essa característica das redes EONs se torna interessante devido à heterogeneidade do tráfego das redes ópticas atuais. Por exemplo, voz sobre o protocolo de internet (VoIP), vídeo sob demanda, transmissão/recepção de canais de televisão digitais, chamadas por vídeo na internet, são utilizações que possuem grandes variações de largura de banda e as redes EONs podem atender de forma eficiente quanto à utilização do espectro de frequência disponível (CHATTERJEE et al., 2015).

A propagação dos sinais ópticos no decorrer dos nós e enlaces dos caminhos ópticos (lightpath) pode sofrer degradação em sua qualidade de transmissão (QoT - Quality of Transmission) e comprometer a recepção do sinal. Dessa forma, pode ser necessário fazer uso de recursos de regeneração de modo a tornar a recepção do sinal óptico inteligível, ou seja, com valores de QoT em um limiar aceitável. Para isso, é importante que os nós da rede tenham a capacidade de possuir recursos de regeneração, sendo assim conhecidos como nós translúcidos (CAVALCANTE et al., 2017a; CAVALCANTE et al., 2017b). Diante disso, existem dois problemas bem conhecidos na literatura de redes ópticas elásticas translúcidas que tratam dos recursos de regeneração, são eles (CAVALCANTE et al., 2017a; CAVALCANTE et al., 2017b): (1) como alocar recursos de regeneração na rede, fazendo com que os nós tenham capacidade de regeneração dos sinais ópticos propagantes (RPP - Regenerator Placement Problem) e (2) visto que o nó seja translúcido, como utilizar de forma eficiente os recursos de regeneração disponíveis (RAP - Regenerator Assignment Problem)

Este capítulo envolve conteúdos abordados em outros trabalhos publicados na literatura (OLIVEIRA et al., 2018a; OLIVEIRA et al., 2018b). Em ambos os trabalhos (Oliveira et al., 2018a; Oliveira et al., 2018b), foi analisado um cenário específico de 
degradação da QoT do sinal óptico propagante em apenas uma topologia de rede bem conhecida na literatura. Oliveira et al. (2018a) analisaram a probabilidade de bloqueio de chamadas em função da variação de carga e Oliveira et al. (2018b) analisaram o mesmo parâmetro em função do número de regeneradores instalados na rede. Neste capítulo, a probabilidade de bloqueio de chamadas será analisada considerando dois cenários distintos de degradação da QoT do sinal óptico propagante em três topologias diferentes bem conhecidas na literatura.

\section{I ESTRATÉGIAS DE ROTEAMENTO E DESCRIÇÃO DOS CENÁRIOS DE SIMULAÇÃO}

Assim como em Oliveira et al. (2018a; 2018b), neste capítulo foram considerados os seguintes algoritmos de roteamento (CAVALCANTE et al., 2015; ZANG et al., 2000): (1) menor número de enlaces (MH - Minimum Hops); (2) menor distância física (SP - Shortest Path) e (3) distância e disponibilidade, adaptado para disponibilidade de intervalos de frequência (slots) (LORa - Lenght and Availability Routing). Esses algoritmos de roteamento foram considerados para se analisar o desempenho de três topologias diferentes com relação à degradação da QoT do sinal óptico propagante em dois cenários diversos. Dessa forma, contribuições inovadoras, bem como outros algoritmos de roteamento também podem ser considerados em estudos similares. No entanto, neste capítulo, observou-se o aspecto do roteamento fixo e da característica de adaptabilidade do roteamento com relação às condições de tráfego dinâmico.

Nas simulações, foram utilizadas três topologias bem conhecidas na literatura, são elas (CAVALCANTE et al., 2017a): (1) NSFNet, (2) US Backbone e (3) Europeia, conforme ilustrado na Figura 1. Os ganhos dos amplificadores ópticos foram dimensionados de modo a compensar exatamente as perdas dos nós e enlaces da rede.

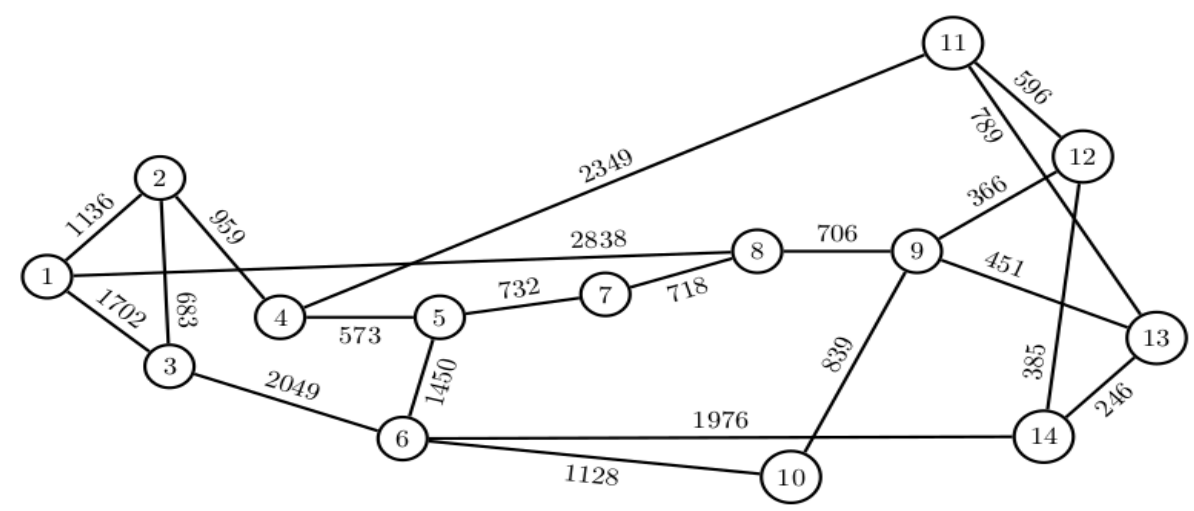

(a) NSFNet. 


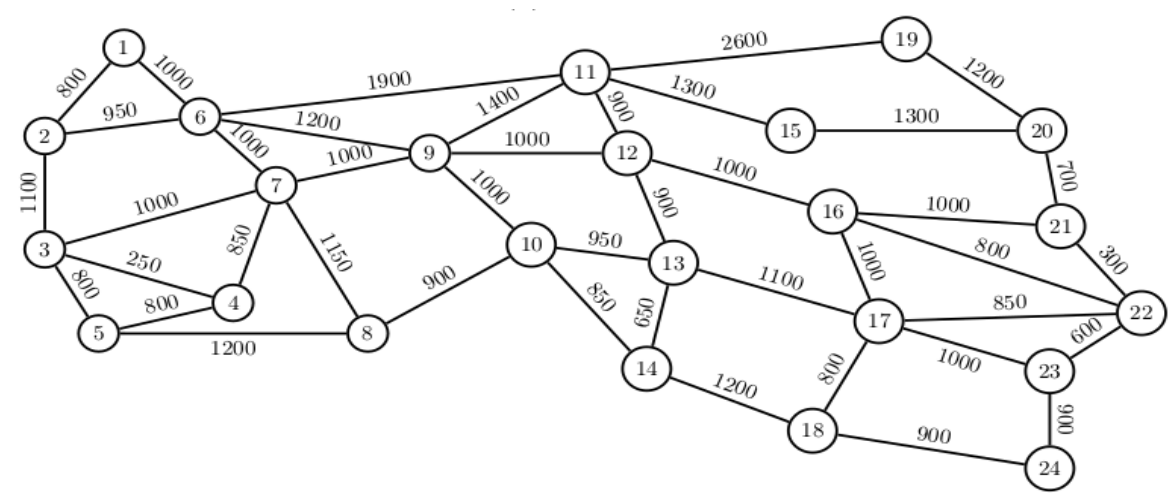

(b) US Backbone.

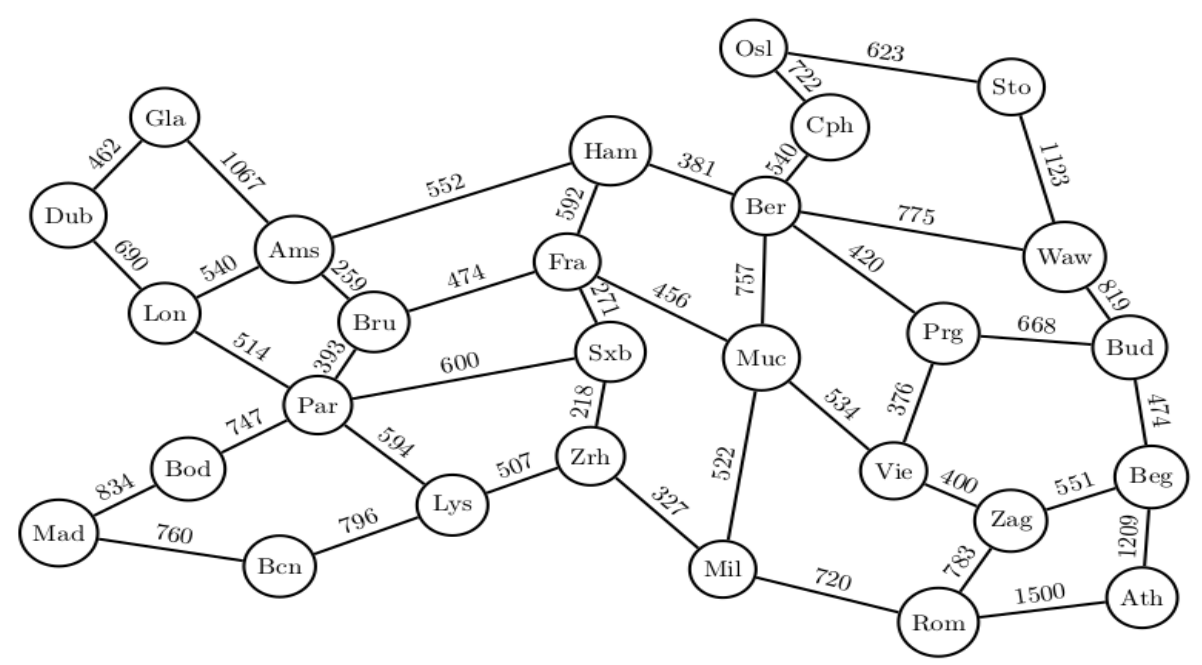

(b) European.

Figura 1: Topologias de redes ópticas translúcidas consideradas e bem conhecidas na literatura: (a) NSFNet, (b) US Backbone e (c) Europeia.

Cada nó possui arquitetura denominada de comutação de espectro (spectrum switching), adaptada para utilização de regeneradores (CAVALCANTE et al., 2015). A relação sinal-ruído óptica obtida no nó destino $\left(O S N R_{R X}\right)$ pode ser calculada conhecendo-se os valores das perdas nos dispositivos, dos ganhos e do ruído de emissão espontânea amplificada (ASE - Amplified Spontaneous Emission) gerado nos amplificadores ópticos, levando-se em conta a taxa de transmissão de bit e o formato de modulação (CAVALCANTE et al., 2015). Assumiu-se ainda que: (1) as chamadas solicitadas seguem uma distribuição poissoniana, (2) a duração de cada chamada estabelecida segue uma distribuição exponencial e (3) a seleção dos pares fonte-destino e da taxa de transmissão de bit, para um dado pedido de requisição de chamada, seguem uma distribuição uniforme.

O número de requisições de simuladas foi de um milhão de chamadas. Para um determinado pedido de requisição de chamada, o algoritmo de roteamento $(\mathrm{MH}$, SP ou LORa) e o de atribuição espectral de primeiro preenchimento (FF - First Fit) foram utilizados para verificar se a chamada poderia ser estabelecida. Considerou-se que, primeiro tenta-se estabelecer a requisição de chamada utilizando o formato de modulação com maior eficiência espectral. Caso esse formato de modulação não esteja disponível, utiliza-se o segundo de maior eficiência espectral e assim por diante. No 
caso de não ser possível o estabelecimento de um lightpath sem utilização de recursos de regeneração (totalmente transparente), foram considerados dois algoritmos de RA disponíveis na literatura (CAVALCANTE et al., 2017a; CAVALCANTE et al., 2017b): (1) o de maior alcance transparente (FLR - First Longest Reach) e (2) o de melhor atribuição espectral (FNS - First Narrowest Spectrum).

Para as simulações, foram utilizados os seguintes parâmetros: (1) para as topologias Europeia e NSFNet o espaçamento entre amplificadores ópticos de linha (span length) foi de 60 e $70 \mathrm{~km}\left(\mathrm{P}_{1}\right.$ e $\left.\mathrm{P}_{2}\right)$ e para a topologia US Backbone foi de 50 e $60 \mathrm{~km}\left(\mathrm{P}_{1}\right.$ e $\left.\mathrm{P}_{2}\right)$. $\mathrm{O}$ primeiro valor $\left(\mathrm{P}_{1}\right)$ corresponde a um cenário transparente e 0 segundo $\left(\mathrm{P}_{2}\right)$ corresponde a um cenário em que é necessário a utilização de recursos de regeneração devido à degradação da QoT do sinal óptico propagante, (2) $50 \%$ dos nós com capacidade de regeneração, selecionados pelo algoritmo de prioridade do grau do nó (NDF - Node Degree First) (CAVALCANTE et al., 2017a), (3) 320 slots por enlace, (4) formatos de modulação utilizados: 4, 8, 16, 32 e 64-QAM, (5) taxa de transmissão de bit variando de 100 a 500 Gbps com distribuição uniforme, (6) $12,5 \mathrm{GHz}$ de largura de banda de um slot, (7) 12,5 GHz de largura de banda de referência, (8) a carga da rede para as topologias Europeia e US Backbone foi de 800 Erlangs, enquanto que de 700 Erlangs para a NSFNet, (9) $5 \mathrm{~dB}$ de figura de ruído nos amplificadores ópticos, (10) $0 \mathrm{dBm}$ de potência de entrada do sinal óptico e (11) $30 \mathrm{~dB}$ de OSNR na transmissão $\left(O S N R_{T X}\right)$. Assumiu-se também que os regeneradores podem, além de regenerar o sinal óptico, realizar conversão espectral e de formato de modulação. Todas as simulações deste capítulo foram realizadas utilizando o software de código aberto SimEON (CAVALCANTE et al., 2017c). Todos os parâmetros utilizados nas simulações estão descritos na Tabela 1.

\begin{tabular}{|c|c|}
\hline Parâmetros & Valor \\
\hline Frequência central & $193,4 \mathrm{THz}$ \\
\hline Fator de ruído dos amplificadores ópticos & $5 \mathrm{~dB}$ \\
\hline Relação sinal-ruído óptica de entrada & $30 \mathrm{~dB}$ \\
\hline Potência óptica de entrada & $0 \mathrm{dBm}$ \\
\hline Perdas nos elementos de comutação & $5 \mathrm{~dB}$ \\
\hline Formatos de modulação utilizados & $4,8,16,32$ e 64-QAM \\
\hline Relação sinal-ruído óptica por bit & $\begin{array}{c}6,8 ; 8,6 ; 10,5 ; 12,6 \text { e } 14,8 \text { [dB] para } 4,8 \\
\quad 16,32 \text { e } 64 \text {-QAM, respectivamente }\end{array}$ \\
\hline Carga da rede & $\begin{array}{c}700 \text { Erlang (NSFNet) e } 800 \text { Erlang (US } \\
\text { Backbone e Europeia) }\end{array}$ \\
\hline Número de slots de frequência por enlace & 320 \\
\hline Largura de banda de referência & $12,5 \mathrm{GHz}$ \\
\hline Largura de banda do slot & $12,5 \mathrm{GHz}$ \\
\hline Taxas de bits de transmissão & $\begin{array}{c}100 \text { até } 500 \text { Gbps com distribuição } \\
\text { uniforme }\end{array}$ \\
\hline
\end{tabular}

Tabela 1: Parâmetros utilizados nas simulações. 


\section{I RESULTADOS}

A Figura 2 mostra a probabilidade de bloqueio de chamadas em função do número de regeneradores por nó, considerando os algoritmos de roteamento $\mathrm{MH}, \mathrm{SP}$ e LORa e os algoritmos de utilização de regeneradores FLR e FNS para as topologias NSFNet, US Backbone e Europeia, em dois cenários de degradação da QoT do sinal óptico propagante $\left(\mathrm{P}_{1}\right.$ e $\left.\mathrm{P}_{2}\right)$.

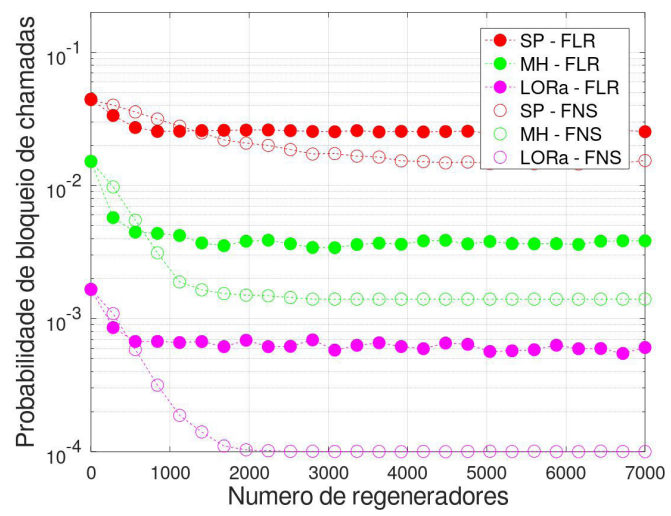

(a) NSFNet $\left(P_{1}\right)$

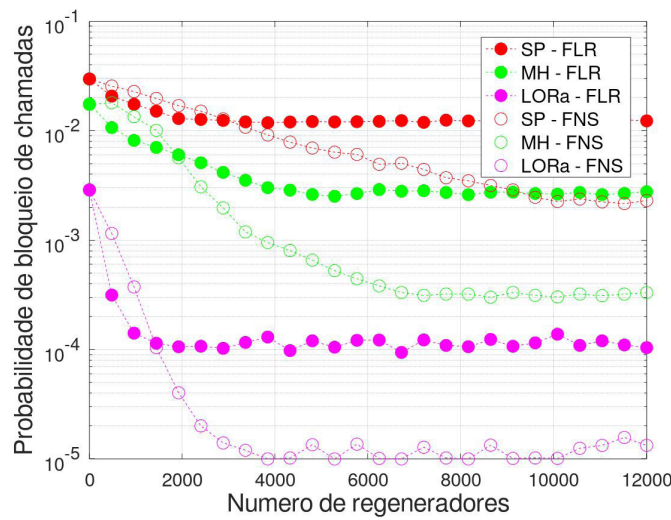

(c) US Backbone $\left(\mathrm{P}_{1}\right)$

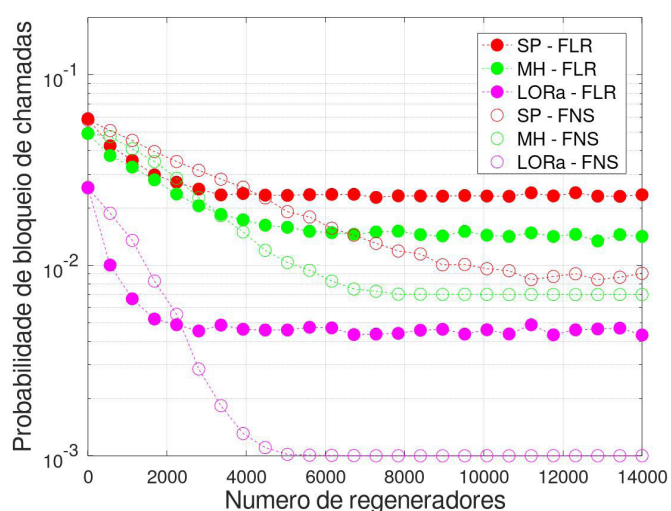

(e) Europeia $\left(P_{1}\right)$

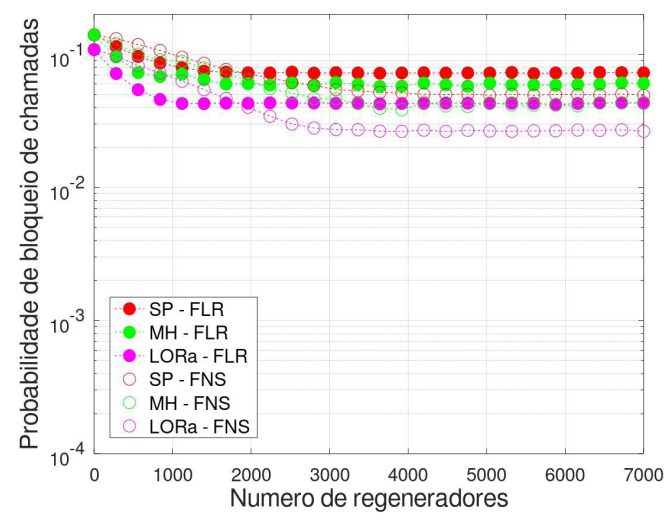

(b) NSFNet $\left(P_{2}\right)$

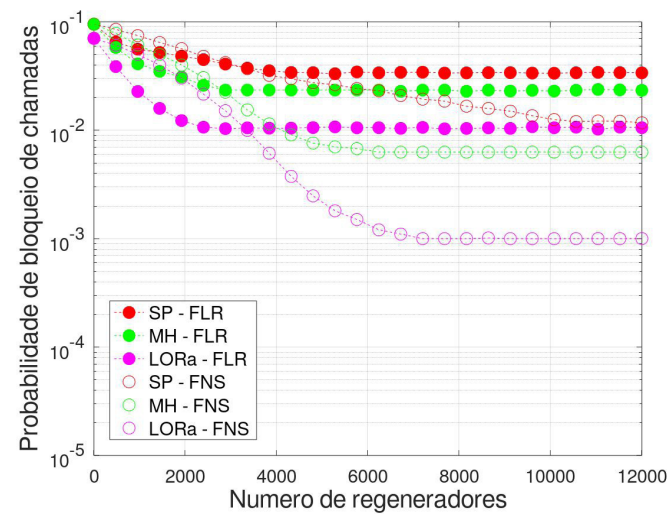

(d) US Backbone $\left(\mathrm{P}_{2}\right)$

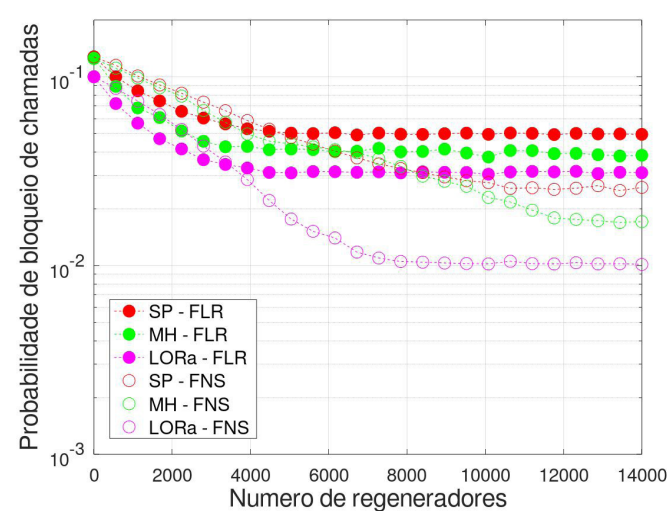

(f) Europeia $\left(P_{2}\right)$

Figura 2: Probabilidade de bloqueio de chamadas em função do número de regeneradores por nó, considerando os algoritmos de roteamento MH, SP e LORa e os algoritmos de utilização de regeneradores FLR e FNS para as topologias NSFNet, US Backbone e Europeia, em dois cenários de degradação da QoT do sinal óptico propagante $\left(\mathrm{P}_{1}\right.$ e $\left.\mathrm{P}_{2}\right)$. 
Como pode ser observado na Figura 2, percebe-se um ponto de encontro em todas as topologias e cenários considerados neste capítulo. Esse ponto de encontro é descrito na literatura (CAVALCANTE et al., 2017a; CAVALCANTE et al., 2017b; OLIVEIRA et al., 2018a) e determina o número de regeneradores instalados na rede em que tanto a política de utilização de regeneradores FLR como a FNS fornecem o mesmo desempenho em termos de probabilidade de bloqueio de chamadas. No entanto, algoritmos de roteamento fixo, que não mudam a respectiva rota entre os mesmos pares fonte-destino da rede, independente do tráfego considerado, apresentam pior desempenho com relação ao algoritmo LORa analisado. Isso porque o algoritmo de roteamento LORa depende do estado da rede, ou seja, considera em sua função custo a disponibilidade de slots em cada enlace, fazendo com que, para um mesmo par fonte-destino, obtenha rotas diferentes ao longo da operação da rede. Essa característica de operação reflete no desempenho das diferentes topologias, nos diversos cenários analisados, fornecendo menores valores de probabilidade de bloqueio de chamadas, permitindo assim maior admissibilidade de conexões. Em um cenário de maior degradação da QoT do sinal óptico propagante $\left(P_{2}\right)$, percebe-se também um pior desempenho dos três algoritmos de roteamento analisados neste capítulo. No entanto, ainda assim, o algoritmo LORa apresenta melhor desempenho que os outros algoritmos de roteamento fixo (MH e SP).

Quando se analisa do ponto de vista da política de utilização de regeneradores (FLR ou FNS), nota-se que os algoritmos que utilizam a política FLR apresentam melhor desempenho abaixo do ponto de encontro. Acima desse ponto, os algoritmos que utilizam a política FNS apresentam melhor desempenho. Constata-se, dessa forma, o comportamento das duas políticas descritas por Cavalcante et al. (2017a; 2017b).

\section{I CONCLUSÕES}

Este capítulo apresentou uma análise do impacto do roteamento em dois cenários de degradação da QoT do sinal óptico propagante para três topologias de redes ópticas elásticas translúcidas bem conhecidas na literatura. Observou-se que houve um aumento da probabilidade de bloqueio de chamadas ao aumentar a distância entre os amplificadores de linha da rede $\left(P_{1}\right.$ para $\left.P_{2}\right)$. Foi possível perceber que as políticas de utilização de regeneradores impactam no desempenho da rede (cenários de escassez e abundância de recursos de regeneração). A política FLR obteve melhor desempenho abaixo do ponto de encontro e a política FNS acima desse ponto, constatando resultados disponíveis na literatura.

Por fim, percebeu-se que a estratégia de roteamento dinâmico LORa obteve melhores resultados, em termos de probabilidade de bloqueio de chamadas, quando comparada com estratégias de roteamento fixo ( $\mathrm{MH}$ e SP). Isso se deve à característica 
de adaptação ao estado de operação da rede devido ao fato da função custo do algoritmo de roteamento LORa depender da disponibilidade de slots do enlace analisado, possibilitando dessa forma, maior admissibilidade de chamadas na rede.

\section{REFERÊNCIAS}

CAVALCANTE, Matheus A. et al. Applying power series routing algorithm in transparent elastic optical networks. In: SBMO/IEEE MTT-S International Microwave and Optoelectronics Conference (IMOC), Novembro 2015, pp. 1-5.

CAVALCANTE, Matheus A. et al. Heurística híbrida para alocação de regeneradores em redes Ópticas elásticas translúcidas. Revista de Tecnologia da Informação e Comunicação, vol. 7, no. 1, pp. 39-44, 2017.

CAVALCANTE, Matheus A. et al. Estado da Arte de Redes Ópticas Elásticas Translúcidas para Cenários de Tráfego Dinâmico em Redes Metropolitanas e de Longas Distâncias. Revista de Tecnologia da Informação e Comunicação, v. 7, n. 2, p. 24-32, 2017.

CAVALCANTE, Matheus A. et al. Simeon: an open-source elastic optical network simulator for academic and industrial purposes. Photonic Network Communications, vol. 34, no. 2, pp. 193-201, Outubro 2017.

CHATTERJEE, Bijoy C. et al. Routing and spectrum allocation in elastic optical networks: A tutorial. IEEE Communications Surveys \& Tutorials, v. 17, n. 3, p. 1776-1800, 2015.

OLIVEIRA, Arthur H. M. et al. Análise do impacto de estratégias de roteamento em uma rede óptica elástica translúcida. In: XXXVI Simpósio Brasileiro de Telecomunicações e Processamento de Sinais, Setembro 2018, pp. 1-2.

OLIVEIRA, Arthur H. M. et al. Análise de rede óptica elástica translúcida considerando diferentes algoritmos de roteamento. In: VIII Conferência Nacional em Comunicações, Redes e Segurança da Informação, Outubro 2018, pp. 1-2.

ZANG, Hui et al. A review of routing and wavelength assignment approaches for wavelength-routed optical WDM networks. Optical networks magazine, v. 1, n. 1, p. 47-60, 2000. 


\section{ANÁLISE DO IMPACTO DO CASCATEAMENTO DE FILTROS ÓPTICOS CONSIDERANDO DIFERENTES ARQUITETURAS DE REDES ÓPTICAS ELÁSTICAS}

Eloisa Bento Sarmento Universidade Federal de Campina Grande, Centro de Engenharia Elétrica e Informática, Unidade

Acadêmica de Engenharia Elétrica

Campina Grande - Paraíba

Helder Alves Pereira Universidade Federal de Campina Grande, Centro de Engenharia Elétrica e Informática, Unidade Acadêmica de Engenharia Elétrica Campina Grande - Paraíba

RESUMO: $O$ sinal óptico pode sofrer degradação em sua qualidade de transmissão de modo que efeitos lineares e não lineares podem reduzir sua inteligibilidade na recepção. Com relação aos dispositivos de comutação, presentes nos nós das redes ópticas elásticas, o efeito da imperfeição do filtro óptico pode causar estreitamento no sinal, ao longo da propagação nos enlaces dos caminhos ópticos, de modo que os amplificadores ópticos podem não compensar esse tipo de perda, além do que esse efeito também pode proporcionar distorção ao sinal óptico propagante. Neste capítulo, modelagens analíticas foram propostas com o objetivo de quantificar o efeito da imperfeição dos filtros ópticos. Para isso, analisou-se a propagação de um sinal óptico considerando a concatenação de diversos dispositivos de comutação, considerando duas arquiteturas de redes ópticas elásticas e duas modelagens de transmitância bem conhecidas na literatura.

PALAVRAS-CHAVE:

Arquitetura,

Concatenação, Filtro Óptico, Penalidade Física, Qualidade de Transmissão, Rede Óptica Elástica.

\section{ANALYSIS OF THE IMPACT OF OPTICAL \\ FILTER CONCATENATION CONSIDERING \\ DIFFERENT ELASTIC OPTICAL NETWORK}

\section{ARCHITECTURES}

ABSTRACT: The optical signal may suffer degradation in its quality of transmission, so that linear and nonlinear effects may reduce its reception intelligibility. With regard to switching devices, present in the elastic optical network nodes, the non-ideal optical filter effect may cause signal narrowing along the optical signal propagation in the lightpaths, so that optical amplifiers may not compensate exactly the devices losses and this effect may also provide distortion to the transmitted optical signal. In this chapter, analytical modeling was proposed in order to quantify the non-ideal optical filter effect. Therefore, the propagating optical signal was analyzed considering the concatenation of several switching devices, two architectures and two transmittance modeling well-known in the literature of elastic optical networks. 
KEYWORDS: Architecture, Concatenation, Elastic Optical Network, Optical Filter, Physical Penalty, Quality of Transmission Quality.

\section{I INTRODUÇÃO}

As redes ópticas elásticas (EON - Elastic Optical Network) possuem um diferencial com relação às redes ópticas que utilizam multiplexação por divisão de comprimento de onda (WDM - Wavelength Division Multiplexing) (ZHANG et al., 2013). Esse diferencial consiste em atribuir larguras de banda relacionadas com a taxa de transmissão de bit solicitada pela chamada no formato de modulação disponibilizado pela rede. Bem diferente das redes ópticas WDM, em que a largura de banda para cada requisição de chamada é sempre fixa (CHRISTODOULOPOULOS et al, 2011; CAVALCANTE et al, 2015).

Nas EONs, vários dispositivos podem estar presentes no decorrer dos nós e enlaces dos caminhos ópticos (lightpath). Dependendo da arquitetura de nó e de enlace consideradas, pode-se ter os seguintes dispositivos (SIMEONIDOU et al., 2012): (1) transmissores ópticos, (2) comutadores, (3) amplificador óptico de potência (booster amplifier), (4) fibra óptica, (5) amplificadores ópticos de linha (in-line amplifiers), (6) divisores de potência, (7) regeneradores eletrônicos, (8) pré-amplificador e (9) receptores ópticos, por exemplo.

Diversos trabalhos disponíveis na literatura abordaram penalidades físicas envolvendo o sinal óptico propagante ao longo das fibras ópticas e dos amplificadores ópticos presentes nos lightpaths (CHATTERJEE et al, 2015; CAVALCANTE et al, 2017a; CAVALCANTE et al, 2017b; OLIVEIRA et al, 2018). No entanto, poucos trabalhos tratam da especificidade da propagação do sinal óptico ao longo dos dispositivos de comutação (SSS - Spectrum Selective Switches), bem como quantificam a penalidade física responsável pela degradação da sua qualidade de transmissão (QoT - Quality of Transmission) (CARVALHO et al., 2015; CARVALHO et al., 2017).

Nos dispositivos SSSs, o efeito da imperfeição do filtro óptico pode causar estreitamento do sinal, de modo que os amplificadores ópticos podem não compensar esse tipo de perda, além do que esse efeito também pode proporcionar distorção no sinal óptico propagante. Neste capítulo, modelagens analíticas são propostas com o objetivo de quantificar essa penalidade física. Para isso, a propagação de um sinal óptico, considerando a concatenação de diversos SSSs, duas arquiteturas de nós e duas modelagens de transmitância, bem conhecidas na literatura de redes ópticas elásticas, são analisadas no contexto da potência óptica recebida com relação à transmitida em diversos cenários de operação dos amplificadores ópticos disponíveis ao longo dos enlaces. 


\section{I MODELAGEM ANALÍTICA DA IMPERFEIÇÃO DO FILTRO ÓPTICO}

Em uma rede óptica, o sinal pode percorrer vários nós intermediários até alcançar o nó destino. Dessa forma, dentre os dispositivos presentes ao longo dos ligthpaths, os SSSs podem atuar também como filtros ópticos. Dependendo do formato das respectivas transmitâncias desses elementos de comutação, é possível que o sinal óptico apresente perdas e distorções na recepção, devido ao efeito da imperfeição do filtro óptico. Esse efeito se relaciona ao estreitamento da largura de banda do sinal à medida em que se propaga ao longo dos nós intermediários da rota (MAROM et al., 2012; PULIKKASERIL, 2012; CARVALHO et al., 2015; CARVALHO et al., 2017).

A Figura 1 ilustra as arquiteturas de nós bem conhecidas na literatura e utilizadas em redes ópticas elásticas (CHATTERJEE, 2015): (a) broadcast and selecte (b) spectrum switching. É importante observar que a primeira arquitetura (broadcast and select) difere da segunda (spectrum switching) com relação ao dispositivo localizado do lado esquerdo da Figura 1(a) e da Figura 1(b), ou seja, na recepção do nó óptico. Para a primeira arquitetura, considera-se um divisor de potência óptica. Enquanto que, na segunda, utiliza-se mais um elemento de comutação. Desse modo, para a arquitetura broadcast and select, o sinal óptico atravessa apenas um SSS, enquanto que, para a arquitetura spectrum switching, o sinal óptico atravessa dois SSSs, quando considerado que o sinal óptico propagante atravessa apenas um enlace óptico. Esse fato permite perceber que o sinal óptico atravessa duas vezes mais dispositivos de comutação na arquitetura de nó spectrum switching em comparação com a broadcast and select para cada enlace percorrido pelo sinal óptico propagante.

Considerando um lightpath com $n$ enlaces, a densidade espectral do sinal óptico recebido no nó destino (), para a arquitetura broadcast and select, pode ser determinada a partir da seguinte equação:

$$
S_{R X}(f)=S_{T X}(f) \prod_{i=1}^{n}\left[\frac{G_{i, 1} G_{i, x} G_{i, 2}}{L_{S S S} L_{i, x}\left(g_{R X i}+1\right)}\right] T_{i}(f)
$$

em que $S_{T X}$ representa a densidade espectral de potência do sinal óptico transmitido, $G_{i}$ ${ }_{1}$ representa o ganho do amplificador de potência, $G_{i,,_{x}}$ o ganho total dos amplificadores de linha, $G_{i, 2}$ o ganho do pré-amplificador, $L_{s s s}$ a perda do SSS, $L_{i,{ }_{x}}$ a perda na fibra óptica, o grau de conectividade do nó destino e $T_{i}$ a transmitância do SSS, referentes ao $i$-ésimo enlace analisado. 


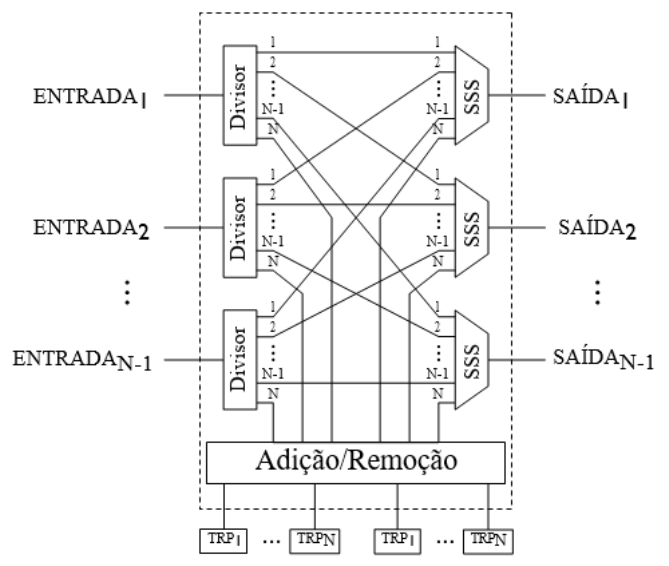

(a) Broadcast and Select.

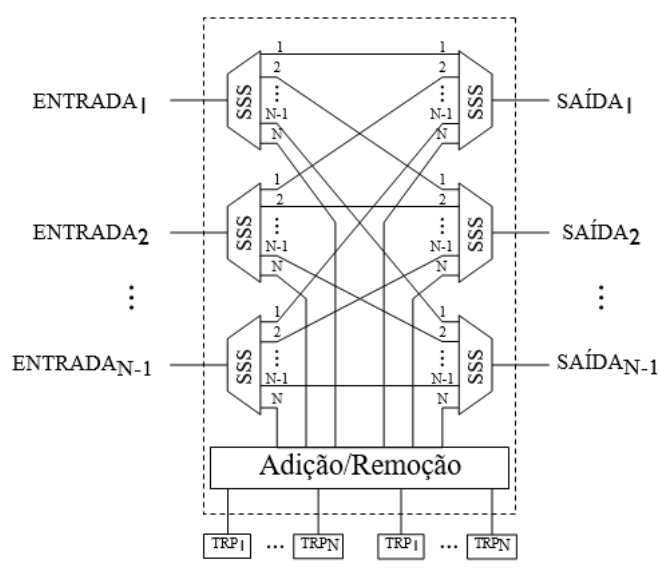

(b) Spectrum switching.

Figura 1: Arquiteturas de nós utilizadas em redes ópticas elásticas bem conhecidas na literatura (CHATTERJEE, 2015): (a) broadcast and select e (b) spectrum switching.

Para a arquitetura spectrum switching, a densidade espectral do sinal óptico recebido no nó destino pode ser determinada a partir da seguinte equação:

$$
S_{R X}(f)=S_{T X}(f) \prod_{i=1}^{n}\left[\frac{G_{i, 1} G_{i, x} G_{i, 2}}{L_{S S S} L_{i, x} L_{S S S}}\right] T_{i, 1}(f) T_{i, 2}(f)
$$

em que $T_{i, 1}$ representa a transmitância do primeiro e $T_{i, 2}$ a do segundo SSS, ambos presentes no $i$-ésimo enlace analisado.

\section{I CONFIGURAÇÃO DOS CENÁRIOS DE SIMULAÇÃO}

A densidade espectral de potência do sinal óptico transmitido pode ser modelada por meio de uma função Gaussiana de acordo com a seguinte equação (STRASSER et al., 2010):

$$
S(f)=A e^{-2 \ln (2)\left[2 \frac{(f-f c)}{S B W_{3} d B}\right]^{2 n}}
$$

em que A representa o fator de normalização da amplitude da densidade espectral, $f_{c}$ a frequência central, $S B W_{\text {эqB }}$ a largura de banda a $3 \mathrm{~dB}$ e $n_{\mathrm{s}}$ a ordem da função Gaussiana. A Tabela 1 apresenta os parâmetros utilizados nas simulações com relação ao sinal óptico transmitido.

\begin{tabular}{l|c|c}
\hline \multicolumn{1}{c|}{ Parâmetro } & Símbolo & Valor \\
\hline Fator de normalização & $A$ & $2,8 \times 10^{-14}$ \\
\hline Formato de modulação & - & $40 \mathrm{GHz}$ \\
\hline $\begin{array}{l}\text { Largura de banda do sinal óptico } \\
\text { transmitido }\end{array}$ & $\Delta f$ & $47,5 \mathrm{GHz}$ \\
\hline Largura de banda a 3 dB & $S B W_{3 d B}$ & 1 \\
\hline Ordem da função Gaussiana & $n_{S}$ & $0 \mathrm{dBm}$ \\
\hline Potência óptica do sinal transmitido & $P_{\text {in }}$ & $100 \mathrm{Gbps}$ \\
\hline Taxa de transmissão de bit & $t$ & \\
\hline
\end{tabular}


As funções de transmitância, utilizadas para análise da imperfeição do filtro óptico neste capítulo, são descritas pelas equações (4) e (5).

$$
\begin{gathered}
T_{1}(f)=e^{-2 \ln (2)\left[2 \frac{(f-f c)}{B W_{3 d B}}\right]^{2 n_{H}},} \\
T_{2}(f)=C \sigma \sqrt{2 \pi}\left[\operatorname{erf}\left(\frac{\frac{B}{2}-f}{\sqrt{2} \sigma}\right)-\operatorname{erf}\left(\frac{-\frac{B}{2}-f}{\sqrt{2} \sigma}\right)\right],
\end{gathered}
$$

e

$$
\sigma=\frac{B W_{\text {OTF }}}{2 \sqrt{2 \ln 2}},
$$

em que $B W_{\text {эdB }}$ representa a largura de banda a $3 \mathrm{~dB}$ do filtro óptico, $n_{H}$ a ordem da função Gaussiana do filtro óptico, $\sigma$ o desvio padrão, $C$ o fator de normalização da amplitude da função de transmitância, $B$ a largura de banda do filtro óptico, erf (·) a função erro, $B W_{\text {OTF }}$ a resolução do filtro óptico, indicando a frequência em que se configura a mudança entre os estados de bloqueio e de passagem do sinal, assim como o formato de suas bordas (MAROM et al., 2012). Neste capítulo, a equação (4) é referida como Gaussiana (STRASSER et al., 2010) e a equação (5) como Pulikkaseril (PULIKKASERIL, 2012). A Tabela 2 descreve os parâmetros utilizados nas simulações com relação às funções de transmitância analisadas neste trabalho.

Tabela 2: Parâmetros utilizados nas simulações com relação às funções de transmitância.

\begin{tabular}{l|c|c}
\hline \multicolumn{1}{c|}{ Parâmetro } & Símbolo & Valor \\
\hline Fator de normalização & $C$ & $4,7 \times 10^{-11}$ \\
\hline Largura de banda do filtro a 3 dB & $B W_{3 d B}$ & $47,5 \mathrm{GHz}$ \\
\hline Largura de banda do filtro óptico & $B$ & $50 \mathrm{GHz}$ \\
\hline Ordem da função Gaussiana & $n_{H}$ & 4 \\
\hline Resolução do filtro óptico & $B W_{O T F}$ & $10 \mathrm{GHz}$ \\
\hline
\end{tabular}

Tabela 2: Parâmetros utilizados nas simulações com relação às funções de transmitância.

O efeito da imperfeição do filtro óptico foi analisado considerando: (1) duas arquiteturas bem conhecidas na literatura de redes ópticas (broadcast and select e spectrum switching), (2) duas funções de transmitância (Gaussiana e Pulikkaseril) e (3) três cenários distintos de operação dos amplificadores ópticos presentes nos lightpaths: (3a) subcompensação das perdas dos enlaces ( $\alpha=0,8$ ), (3b) compensação exata das perdas dos enlaces $(\alpha=1,0)$ e (3c) sobrecompensação das perdas dos enlaces $(\alpha=1,2)$. A métrica de desempenho utilizada foi a relação entre as potências recebida e transmitida do sinal óptico propagante em um lightpath $(r)$ com 10 enlaces.

\section{I RESULTADOS}

A Figura 2 ilustra a magnitude da densidade espectral de potência do sinal óptico recebido após ter percorrido 10 enlaces, considerando as funções Gaussiana 
(STRASSER et al., 2010) e Pulikkaseril (PULIKKASERIL, 2012), nos diferentes cenários de operação dos amplificadores ópticos ( e ), para as arquiteturas de nó: (a) broadcast and select e (b) spectrum switching. Percebe-se que, independente da arquitetura de nó e do cenário de compensação dos amplificadores ópticos analisado, a função de transmitância Pulikkaseril fornece um menor estreitamento do sinal óptico com relação à função Gaussiana.

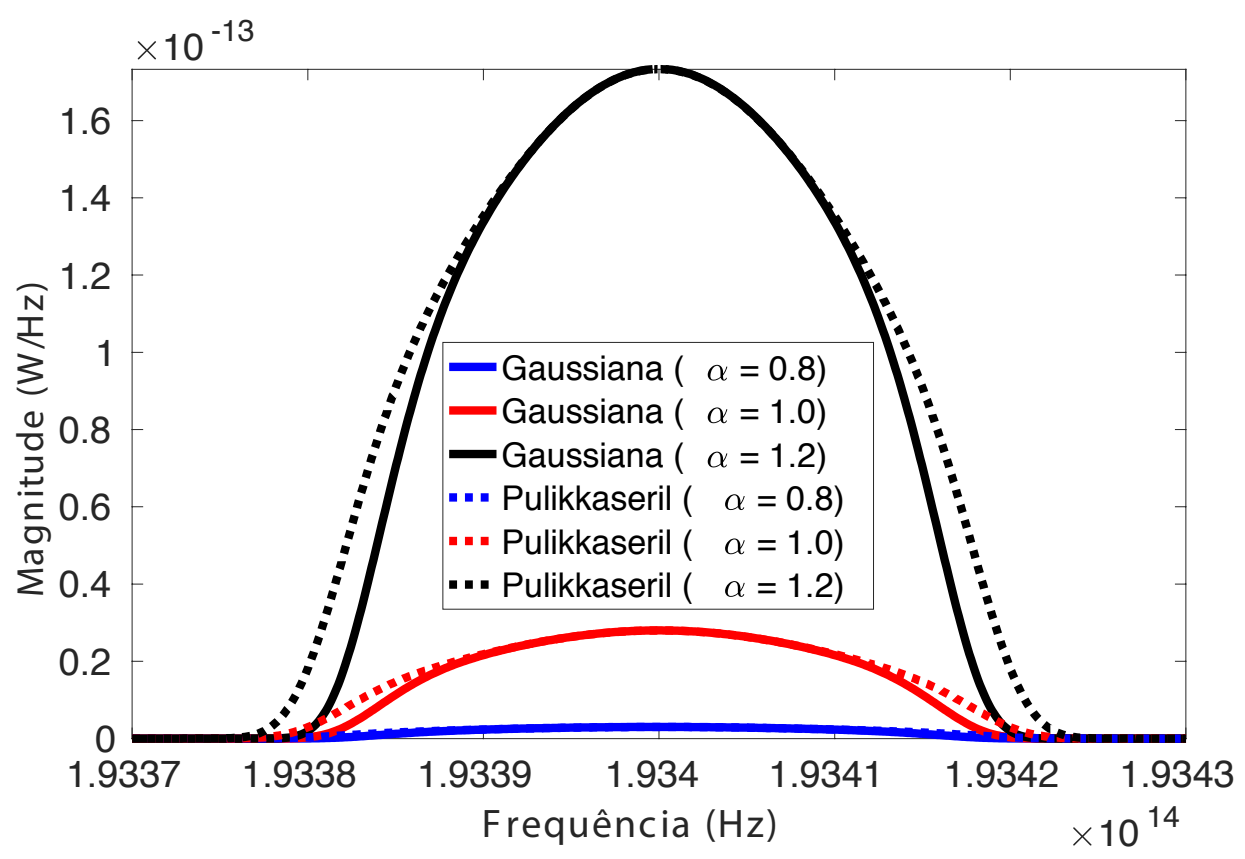

(a) Arquitetura broadcast and select.

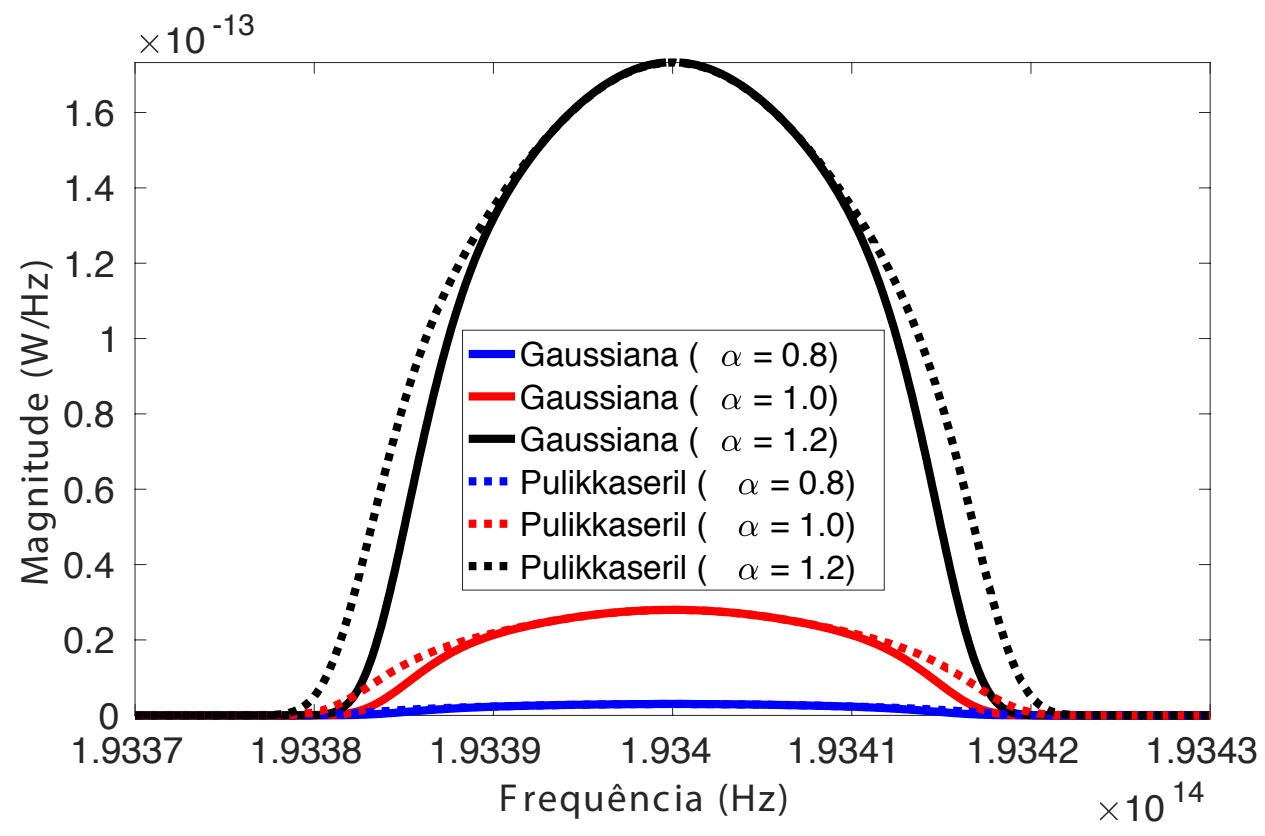

(b) Arquitetura spectrum switching.

Figura 2: Magnitude da densidade espectral de potência do sinal óptico recebido após ter percorrido 10 enlaces, considerando as funções Gaussiana (STRASSER et al., 2010) e 
Pulikkaseril (PULIKKASERIL, 2012), nos diferentes cenários de operação dos amplificadores ópticos ( e ), para as arquiteturas de nó: (a) broadcast and select e (b) spectrum switching.

A Figura 3 ilustra a razão entre as potências ópticas recebida e transmitida, considerando as funções de transmitância Gaussiana (STRASSER et al., 2010) e Pulikkaseril (PULIKKASERIL, 2012), após o sinal óptico propagante passar por 10 enlaces, nos diferentes cenários de operação dos amplificadores ópticos ( e ), para as arquiteturas de nó: (a) broadcast and select e (b) spectrum switching. Percebe-se que a função de transmitância Pulikkaseril (PULIKKASERIL, 2012) resulta em um valor maior de potência óptica recebida, fornecendo um valor de maior.
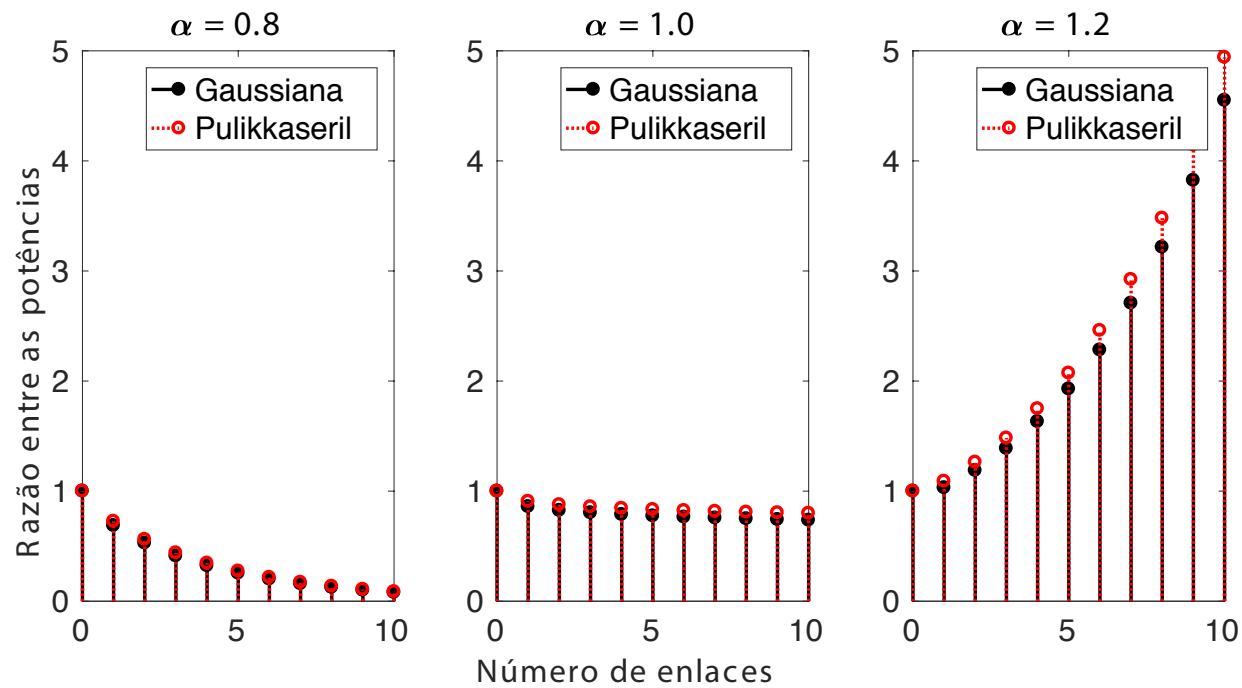

(a) Arquitetura broadcast and select.
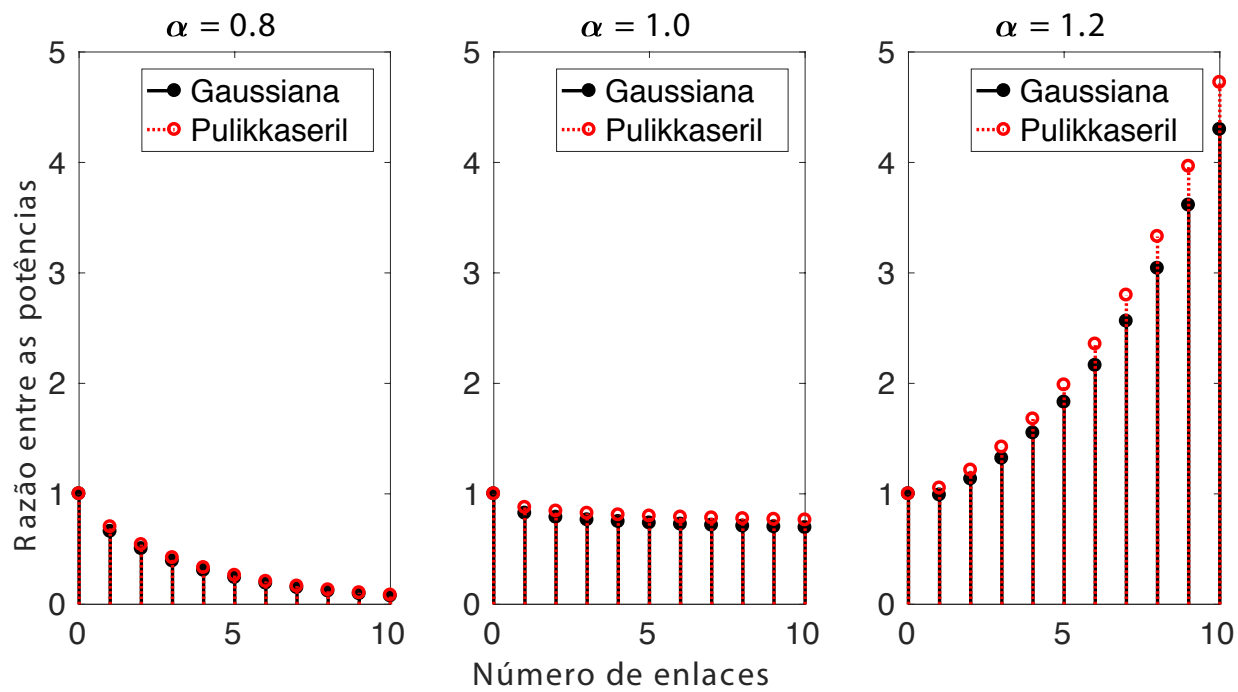

(b) Arquitetura spectrum switching.

Figura 3: Razão entre as potências ópticas recebida e transmitida, considerando as funções de transmitância Gaussiana (STRASSER et al., 2010) e Pulikkaseril (PULIKKASERIL, 2012), após o sinal óptico propagante passar por 10 enlaces, nos diferentes cenários de operação dos amplificadores ópticos ( e ), para as arquiteturas de nó: (a) broadcast and select e (b) spectrum switching. 
No entanto, devido à característica da arquitetura de nó spectrum switching possuir o dobro de SSSs, quando comparada com a arquitetura broadcast and select, o sinal óptico possui um maior estreitamento na recepção, resultando em valores de $r$ menores independente da função de transmitância considerada, conforme descrito nas Tabelas 3 e 4.

\begin{tabular}{c|c|c|c|c|c|c|c|c|c|c|c}
\hline Arquitetura & 0 & 1 & 2 & 3 & 4 & 5 & 6 & 7 & 8 & 9 & 10 \\
\hline BS $(a=0,8)$ & 1,00 & 0,69 & 0,53 & 0,41 & 0,32 & 0,25 & 0,20 & 0,16 & 0,13 & 0,10 & 0,08 \\
\hline BS $(a=1,0)$ & 1,00 & 0,86 & 0,82 & 0,80 & 0,79 & 0,78 & 0,77 & 0,76 & 0,75 & 0,74 & 0,74 \\
\hline BS $(a=1,2)$ & 1,00 & 1,03 & 1,19 & 1,39 & 1,63 & 1,93 & 2,28 & 2,71 & 3,22 & 3,83 & 4,55 \\
\hline SS $(a=0,8)$ & 1,00 & 0,66 & 0,50 & 0,39 & 0,31 & 0,24 & 0,19 & 0,15 & 0,12 & 0,09 & 0,07 \\
\hline SS (a=1,0) & 1,00 & 0,82 & 0,79 & 0,77 & 0,75 & 0,74 & 0,73 & 0,72 & 0,71 & 0,70 & 0,70 \\
\hline SS (a $=1,2)$ & 1,00 & 0,99 & 1,13 & 1,32 & 1,55 & 1,83 & 2,16 & 2,56 & 3,04 & 3,62 & 4,30 \\
\hline
\end{tabular}

Tabela 3: Razão entre as potências ópticas recebida e transmitida, considerando a função de transmitância Gaussiana (STRASSER et al., 2010), após o sinal óptico propagante passar por 10 enlaces, nos diferentes cenários de operação dos amplificadores ópticos ( e ), para a arquitetura de nó broadcast and select.

\begin{tabular}{c|c|c|c|c|c|c|c|c|c|c|c}
\hline Arquitetura & 0 & 1 & 2 & 3 & 4 & 5 & 6 & 7 & 8 & 9 & 10 \\
\hline BS $(a=0,8)$ & 1,00 & 0,73 & 0,56 & 0,44 & 0,35 & 0,27 & 0,22 & 0,17 & 0,14 & 0,11 & 0,09 \\
\hline BS $(a=1,0)$ & 1,00 & 0,91 & 0,88 & 0,86 & 0,84 & 0,83 & 0,82 & 0,82 & 0,81 & 0,80 & 0,80 \\
\hline BS $(a=1,2)$ & 1,00 & 1,09 & 1,26 & 1,48 & 1,75 & 2,07 & 2,46 & 2,92 & 3,48 & 4,15 & 4,94 \\
\hline SS (a=0,8) & 1,00 & 0,70 & 0,54 & 0,42 & 0,33 & 0,26 & 0,21 & 0,16 & 0,13 & 0,10 & 0,08 \\
\hline SS (a=1,0) & 1,00 & 0,88 & 0,84 & 0,82 & 0,81 & 0,80 & 0,79 & 0,78 & 0,78 & 0,77 & 0,76 \\
\hline SS (a=1,2) & 1,00 & 1,05 & 1,22 & 1,42 & 1,68 & 1,99 & 2,36 & 2,80 & 3,33 & 3,97 & 4,73 \\
\hline
\end{tabular}

Tabela 4: Razão entre as potências ópticas recebida e transmitida, considerando a função de transmitância Pulikkaseril (PULIKKASERIL, 2012), após o sinal óptico propagante passar por 10 enlaces, nos diferentes cenários de operação dos amplificadores ópticos ( e ), para a arquitetura de nó select e spectrum switching.

\section{I CONCLUSÕES}

Neste capítulo, modelagens analíticas foram propostas com o objetivo de quantificar o efeito da imperfeição dos filtros ópticos. Para isso, analisou-se a propagação de um sinal óptico considerando a concatenação de SSSs, ao longo de 10 enlaces, considerando duas arquiteturas de redes ópticas elásticas, duas modelagens de transmitância bem conhecidas na literatura e três cenários de compensação dos amplificadores ópticos presentes no lightpath analisado. 
De acordo com os resultados obtidos, independente da arquitetura de nó e do cenário de compensação dos amplificadores ópticos analisado, a função de transmitância Pulikkaseril forneceu menor estreitamento do sinal óptico com relação à função Gaussiana. Dessa forma, a função de transmitância Pulikkaseril resultou em um valor maior de potência óptica recebida, fornecendo um valor de $r$ maior. No entanto, devido à característica da arquitetura de nó spectrum switching possuir o dobro de SSSs, quando comparada com a arquitetura de nó broadcast and select, o sinal óptico apresentou um maior estreitamento na recepção, resultando em valores de $r$ menores, independente da função de transmitância analisada.

\section{REFERÊNCIAS}

CARVALHO, C. C. et al. Análise da imperfeição do filtro Óptico em um cenário de redes ópticas elásticas transparentes. In: Encontro Anual do lecom em Comunicações, Redes e Criptografia (ENCOM), vol. 1, 2015, pp. 1-2.

CARVALHO, G. S. D. et al. Análise do Impacto do Cascateamento de Filtros Ópticos em um Cenário de Redes Ópticas Elásticas. In: VII Conferência Nacional em Comunicações, Redes e Segurança da Informação, Outubro 2017, pp. 1-2.

CAVALCANTE, M. A. et al. Applying power series routing algorithm in transparent elastic optical networks. In: SBMO/IEEE MTT-S International Microwave and Optoelectronics Conference (IMOC), Novembro 2015, pp. 1-5.

CAVALCANTE, M. A. et al. Heurística híbrida para alocação de regeneradores em redes Ópticas elásticas translúcidas. Revista de Tecnologia da Informação e Comunicação, vol. 7, no. 1, pp. 39-44, 2017.

CAVALCANTE, M. A. et al. Estado da Arte de Redes Ópticas Elásticas Translúcidas para Cenários de Tráfego Dinâmico em Redes Metropolitanas e de Longas Distâncias. Revista de Tecnologia da Informação e Comunicação, v. 7, n. 2, p. 24-32, 2017.

CHATTERJEE, B. C. et al. Routing and spectrum allocation in elastic optical networks: A tutorial. IEEE Communications Surveys \& Tutorials, v. 17, n. 3, p. 1776-1800, 2015.

CHRISTODOULOPOULOS, K. et al. Elastic bandwidth allocation in flexible OFDM-based optical networks. Journal of Lightwave Technology, v. 29, n. 9, p. 1354-1366, 2011.

MAROM, D. M. et al. Beyond wavelength-selective channel switches: Trends in support of flexible/ elastic optical networks. In: International Conference on Transparent Optical Networks (ICTON). IEEE, 2012. p. 1-4.

OLIVEIRA, A. H. M. et al. Análise do impacto de estratégias de roteamento em uma rede óptica elástica translúcida. In: XXXVI Simpósio Brasileiro de Telecomunicações e Processamento de Sinais, Setembro 2018, pp. 1-2.

PULIKKASERIL, C. Filter Bandwidth Definition of the WaveShaper S-series Programmable Processor. Finisar product whitepaper. 2012.

SIMEONIDOU, D. et al. Infrastructure and architectures on demand for flexible and elastic optical networks. In: European Conference and Exhibition on Optical Communication. Optical Society of America, 2012. p. Tu. 3. D. 1. 
STRASSER, T. A. et al. Wavelength-selective switches for ROADM applications. IEEE Journal of Selected Topics in Quantum Electronics, v. 16, n. 5, p. 1150-1157, 2010.

ZHANG, G. et al. A survey on OFDM-based elastic core optical networking. IEEE Communications Surveys \& Tutorials, v. 15, n. 1, p. 65-87, 2013. 


\section{CAPÍTULO 13}

\section{MODELAGEM DO EQUILÍBRIO SÓLIDO-LÍQUIDO NA SOLUBILIDADE DE ÁCIDOS GRAXOS EM SOLVENTES ORGÂNICOS}

Bruno Rossetti de Souza

Universidade Federal de Alfena, Instituto de Ciência e Tecnologia

Poços de Caldas - Minas Gerais

Vanessa Vilela Lemos

Universidade Federal de Alfena, Instituto de Ciência e Tecnologia

Poços de Caldas - Minas Gerais Jessica Cristina Silva Resende Universidade Federal de Alfena, Instituto de Ciência e Tecnologia

Poços de Caldas - Minas Gerais

Karolina Soares Costa Universidade Federal de Alfena, Instituto de Ciência e Tecnologia

Poços de Caldas - Minas Gerais

Marlus Pinheiro Rolemberg Universidade Federal de Alfena, Instituto de

Ciência e Tecnologia

Poços de Caldas - Minas Gerais

Rodrigo Corrêa Basso

Universidade Federal de Alfena, Instituto de

Ciência e Tecnologia

Poços de Caldas - Minas Gerais

RESUMO: Os ácidos graxos são os compostos majoritários nos destilados de desodorização de óleos vegetais de elevada acidez. Uma alternativa a extração destes constituintes dos destilados de desodorização é a dissolução fracionada que depende do conhecimento da solubilidade destes constituintes nos solventes empregados. O ajuste de parâmetros de modelos termodinâmicos usados na descrição da solubilidade minimiza o tempo e o custo na obtenção de dados experimentais, bem como permite o uso destes modelos em simulação computacional. $\mathrm{O}$ objetivo do presente trabalho foi estudar o ajuste dos parâmetros dos modelos de Margules, Wilson e NRTL para o cálculo do coeficiente de atividade de modo a se calcular a solubilidade dos ácidos láurico, mirístico, palmítico e esteárico em acetona, etanol e 2-butanona. $\mathrm{O}$ uso dos três modelos resultou em boa representatividade das temperaturas de saturação, com o modelo de Margules resultando em maiores desvios máximos, 3,32 $\%$ e $4,56 \%$, respectivamente para os sistemas constituídos por ácido palmítico + etanol e ácido esteárico + etanol. $\mathrm{O}$ uso dos modelos de Wilson e NRTL resultaram em desvios máximos iguais a respectivamente 1,22 \% e 1,32\% para todos os sistemas.

PALAVRAS-CHAVES: equilíbrio sólido-líquido, solubilidade, modelagem termodinâmica, ácidos graxos, destilado de desodorização

SOLID-LIQUID EQUILIBRIUM MODELING ON SOLUBILITY OF FATTY ACIDS IN ORGANIC 


\section{SOLVENTS}

ABSTRACT: Fatty acids are the major compounds in the deodorization distillates of high acidity vegetable oils. An alternative to extracting these constituents from the deodorization distillates is the fractional dissolution which depends on the knowledge of the solubility of these constituents in the solvents employed. The adjustment of parameters of thermodynamic models used in the description of solubility minimizes the time and cost in obtaining experimental data, as well as allows the use of these models in computational simulation. The objective of the present work was to study the adjustment of the parameters of the Margules, Wilson and NRTL models for the calculation of the activity coefficient in order to calculate the solubility of lauric, myristic, palmitic and stearic acids in acetone, ethanol and 2-butanone. The use of the three models resulted in good representativeness of the saturation temperatures, with the Margules model resulting in higher maximum deviations, $3.32 \%$ and 4.56 $\%$, respectively, for systems composed of palmitic acid + ethanol and stearic acid + ethanol. The use of the Wilson and NRTL models resulted in maximum deviations equal to respectively $1.22 \%$ and $1.32 \%$ for all systems

KEYWORDS: solid-liquid equilibrium, solubility, thermodynamic modeling, fatty acids, deodorization distilled

\section{I INTRODUÇÃO}

Cerca de 95\% da composição de óleos vegetais é constituída por triacilgliceróis sendo o restante dividido entre ácidos graxos livres, acilgliceróis parciais (monoacilgliceróis e diacilgliceróis), fosfolipídios, esteróis, tocoferóis e tocotrienóis, carotenos, hidrocarbonetos e produtos de oxidação (GUNSTONE, 2005).

De modo que o óleo vegetal possa ser comercializado, o mesmo deve passar por diversas etapas de refino, dentre as quais está o processo de desodorização que remove os componentes com maior volatilidade por um processo de esgotamento, que geralmente utiliza vapor d'água a elevadas temperaturas (220 a $\left.260{ }^{\circ} \mathrm{C}\right)$ e baixas pressões (2 a 4 mbar). Óleos de elevada acidez são submetidos a este processo em condições mais severas visando a remoção dos ácidos graxos livres, até teores entre 0,03 e $0,05 \%(\mathrm{~m} / \mathrm{m})$, sendo que nestas condições, estes componentes apresentam-se como os constituintes majoritários dos DDs (GREYT; KELLENS, 2005).

Os ácidos graxos livres são utilizados na obtenção de uma grande quantidade de produtos importantes para a indústria química, farmacêutica e alimentícia, dentre eles: sabões e detergentes; ésteres de ácidos graxos, usados como lubrificantes, aromatizantes e solventes apolares de cadeia longa; álcoois graxos, utilizados como plastificantes e aditivos de tintas; surfactantes não iônicos, entre outros (GERVAJIO, 2005).

Os processos usados industrialmente para a extração e purificação dos componentes dos DDs, bem como aqueles mais estudados visando sua otimização, 
envolvem diversas das etapas dentre as citadas a seguir: metanólise, etanólise ou glicerólise, destilação molecular, extração for fluido em estado supercrítico, extração e, coluna de recheio, cristalização e filtração sob vácuo (SHI et al., 2011; VAZQUEZ et al., 2007; ITO et al., 2005; YAN et al., 2012; FREGOLENTE et al., 2010).

Por ser menos complexa e gerar menores custos, uma alternativa viável é a utilização da dissolução fracionada para a separação e purificação dos componentes dos DDs. Esta técnica se baseia na diferença de solubilidade dos constituintes do sistema em diversos solventes. A realização deste processo necessita do conhecimento prévio da solubilidade dos constituintes desta mistura em diversos solventes, em uma dada faixa de temperatura.

Dados experimentais devem ser utilizados para a análise da solubilidade dos DDs em diferentes solventes. Porém, para evitar gastos excessivos com a obtenção de muitos dados experimentais, podem ser usados modelos matemáticos e termodinâmicos que representam o comportamento de solubilidade de sistemas de interesse em função da temperatura a partir de uma quantidade reduzida destes dados.

O uso destes modelos depende do ajuste prévio de seus parâmetros a partir de uma reduzida quantidade de dados experimentais. Uma das formas de realizar este ajuste consiste na minimização de uma função objetivo que é dada pela diferença entre as temperaturas experimentais e as calculadas pelos modelos estudados.

Segundo o que foi exposto, o presente trabalho teve o objetivo de estudar o ajuste dos parâmetros dos modelos de Margules, Wilson e NRTL calculando a solubilidade dos ácidos láurico, mirístico, palmítico e esteárico em acetona, etanol e 2-butanona, bem como avaliar a representatividade do comportamento experimental pelos mesmos.

\section{I REVISÃO BIBLIOGRÁFICA}

\subsection{Modelagem da Solubilidade}

Ao se empregar modelos termodinâmicos para o cálculo da solubilidade deve-se partir de alguns conceitos inerentes ao equilíbrio sólido-líquido. Utilizando a definição de fugacidade, energia de Gibbs e o equacionamento da entalpia e entropia como funções de estado, obtém-se uma relação entre a fugacidade do líquido puro subresfriado à temperatura T e algumas propriedades mensuráveis, conforme equação (1) (SMITH; VAN NESS; ABBOTT, 2007).

$$
\ln \frac{f^{L}}{f^{S}}=\frac{\Delta h^{f}}{R T_{t}}\left(\frac{T_{t}}{T}-1\right)-\frac{\Delta C_{p}}{R}\left(\frac{T_{t}}{T}-1\right)+\frac{\Delta C_{p}}{R} \ln \frac{T_{t}}{T}
$$

Onde: $\Delta h^{f}$ e $T_{t}$ são a entalpia de fusão no ponto triplo e a temperatura do ponto triplo, respectivamente; $\Delta C_{p}$ é a diferença de capacidade calorífica entre o líquido e o sólido; $\mathrm{R}$ é a 
constante universal dos gases; $f^{L}$ e $f^{\mathcal{S}}$ respectivamente a fugacidade do líquido e do sólido.

Nesta equação, pode-se adotar simplificações substituindo a temperatura do ponto triplo $T_{t}$ pela temperatura de fusão $T_{f}$, e a entalpia de fusão em $T_{t}$ pela entalpia de fusão em $T_{f}$ obtendo assim a equação (2), em termos da solubilidade (SMITH; VAN NESS; ABBOTT, 2007).

$$
\ln \frac{1}{\gamma_{i} x_{i}}=\frac{\Delta h^{f}}{R T_{f}}\left(\frac{T_{f}}{T}-1\right)-\frac{\Delta C_{p}}{R}\left(\frac{T_{f}}{T}-1\right)+\frac{\Delta C_{p}}{R} \ln \frac{T_{f}}{T}
$$

Onde: $\gamma_{i}$ e $x_{i}$ são respectivamente o coeficiente de atividade e a fração molar do componente i em solução

Segundo Smith, Van Ness e Abbott (2007), na equação acima os dois termos da direita, de sinais opostos, tendem a se anular, podendo ser desprezados. Com isso, tem-se a equação para o cálculo da solubilidade dada por:

$$
\ln \frac{1}{\gamma_{i} x_{i}}=\frac{\Delta h^{f}}{R T_{f}}\left(\frac{T_{f}}{T}-1\right)
$$

A solubilidade ideal é válida para uma mistura ideal, em que o coeficiente de atividade é igual a 1. A representatividade do equilíbrio sólido-líquido deste tipo se sistema resultaria em desvios aceitáveis para misturas com soluto e solvente de natureza muito similar. A medida que a diferença desta natureza aumenta, modificando os parâmetros de interação entre as moléculas, o coeficiente de atividade se afasta da unidade, sendo geralmente maior que um para soluções apolares e menor que um para sistemas com forças polares significativas. Nestes casos o coeficiente de atividade deve ser calculado por meio de modelos termodinâmicos específicos que levem em consideração os desvios da idealidade, sendo os mesmos utilizados para a obtenção da solubilidade não-ideal (SMITH; VAN NESS; ABBOTT, 2007).

\subsection{Modelos para o Cálculo do Coeficiente de Atividade}

O cálculo do coeficiente de atividade de componentes de sistemas binários pode ser realizado pelo modelo Margules com dois parâmetros ajustáveis, sendo que para sistemas binários o modelo pode ser expresso pelas equações (4-5) (KONTOGEORGIS; FOLAS, 2010). A partir de sua concepção termodinâmica, o modelo de Margules foi desenvolvido originariamente para ser utilizado na descrição do coeficiente de atividade de soluções contendo moléculas com volumes molares similares. Entretanto, o mesmo tem sido usado com bons resultados matemáticos para sistemas que não apresentam esta característica.

$$
\begin{gathered}
\mathrm{RT} \ln \gamma_{1}=\left[\mathrm{A}_{12}+2\left(\mathrm{~A}_{21}-\mathrm{A}_{12}\right) \mathrm{x}_{1}\right] \mathrm{x}_{2}^{2} \\
\mathrm{RT} \ln \gamma_{2}=\left[\mathrm{A}_{21}+2\left(\mathrm{~A}_{12}-\mathrm{A}_{21}\right) \mathrm{x}_{1}\right] \mathrm{x}_{1}^{2}
\end{gathered}
$$


Onde: $A_{21}$ e $A_{12}$ são os parâmetros ajustáveis; $R$ é a constante universal dos gases (J/mol.K), T é a temperatura do sistema (K), $\mathrm{x}$ e $\gamma$ são respectivamente a a fração molar e o coeficiente de atividade dos componentes da solução.

O modelo de Wilson, representado para sistemas binários pelas equações (67), é mais preciso em relação ao modelo de Margules, podendo ser utilizado em soluções polares ou sistemas com solutos polares e solventes apolares (PRAUSNITZ; LICHTENTHALER; AZEVEDO, 1999).

$$
\begin{aligned}
& \ln \gamma_{1}=-\ln \left(x_{1}+A_{12} x_{2}\right)+x_{2}\left(\frac{A_{12}}{x_{1}+A_{12} x_{2}}-\frac{A_{21}}{x_{2}+A_{21} x_{1}}\right) \\
& \ln \gamma_{2}=-\ln \left(x_{2}+A_{21} x_{1}\right)-x_{1}\left(\frac{A_{12}}{x_{1}+A_{12} x_{2}}-\frac{A_{21}}{x_{2}+A_{21} x_{1}}\right)
\end{aligned}
$$

Onde: $A_{21}$ e $A_{12}$ são parâmetros ajustáveis do modelo; $R$ é a constante universal dos gases (J/mol.K), T é a temperatura do sistema (K), x e $\gamma$ são respectivamente a fração molar e o coeficiente de atividade dos componentes da solução

O modelo NRTL, dado para sistemas binários pelas equações (8-11), é um modelo robusto para o cálculo de coeficiente de atividade, especialmente para sistemas formados por misturas fortemente não ideias, principalmente para sistemas parcialmente imiscíveis (PRAUSNITZ; LICHTENTHALER; AZEVEDO, 1999).

$$
\begin{aligned}
& \ln \gamma_{1}= x_{2}^{2}\left[\tau_{21}\left(\frac{G_{21}}{x_{1}+x_{2} G_{21}}\right)^{2}+\frac{\tau_{12} G_{12}}{\left(x_{2}+x_{1} G_{12}\right)^{2}}\right] \\
& \ln \gamma_{2}= x_{1}^{2}\left[\tau_{12}\left(\frac{G_{12}}{x_{2}+x_{1} G_{12}}\right)^{2}+\frac{\tau_{21} G_{21}}{\left(x_{1}+x_{2} G_{21}\right)^{2}}\right] \\
& \tau_{12}=\frac{g_{12-} g_{22}}{R T}, \tau_{21}=\frac{g_{21} g_{11}}{R T} \\
& G_{12}=\exp \left(-\alpha_{12} \tau_{12}\right) ; G_{21}=\exp \left(-\alpha_{12} \tau_{21}\right) ;
\end{aligned}
$$

Onde $g_{12}$ e $g_{12}$ são os parâmetros de interação binária entre os componentes 1 e 2.; $\alpha_{12}$ é o parâmetro de não aleatoriedade entre os componentes 1 e 2; R é a constante dos gases ideais; $\mathrm{T}$ é a temperatura dada em $\mathrm{K}$.

\subsection{Solubilidade de Componentes dos Óleos Vegetais em Solventes Diversos}

Heryanto et al. (2007), utilizando análise gravimétrica para o estudo da solubilidade do ácido esteárico, reportou que a solubilidade do ácido esteárico em solventes orgânicos puros é inversa à polaridade dos solventes estudados. Também foi observado que a solubilidade pode ser consideravelmente alterada pela presença de componentes minoritários presentes na solução. Baseando nos modelos de soluções não ideais, Apelblat modificada e Buchowski, os desvios entre as solubilidades experimentais e calculadas, com exceção de um sistema, foram inferiores a 5\%.

Cuevas (2010) utilizou a análise gravimétrica para estudar a solubilidade do $\gamma$-orizanol em doze solventes, puros ou em combinações binárias, em sistemas entre 
10 e $50^{\circ} \mathrm{C}$. Foram observadas maiores solubilidades do $\gamma$-orizanol em metil-etilcetona, 26,7 e 49,7\% (m/m) e menores em etanol azeotrópico, 0,4 e 2, \% (m/m), com desvios entre valores experimentais e calculados de 5,8 e 2,9\%, usando os modelos termodinâmicos de Margules e Van Laar, respectivamente.

Shah e Venkatesan (1989) analisaram a separação de ácidos graxos livres em óleo de amendoim. Os solventes utilizados foram isopropanol e água, em diferentes proporções, a partir de duas extrações sequenciais em funil de separação. Foi relatado que apesar de teores baixos de água favorecerem a partição dos ácidos graxos para a mistura isopropanol e água, aumentam as concentrações de óleo neutro na mesma. Logo, concluiu-se que teores entre 75 e $80 \%$ de isopropanol são ideais para que haja uma extração seletiva eficiente de ácidos graxos em amendoim, e ao mesmo tempo evitam a solubilidade do óleo neutro no solvente.

Segundo um estudo de Wei et al. (2010), a solubilidade do $\beta$-sitosterol na faixa de temperatura de $278.15 \mathrm{~K}$ a $333.15 \mathrm{~K}$ em metanol, etanol, acetona, acetato de etila e n-hexano seguiu a seguinte ordem crescente em relação aos solventes: metanol < n-hexano < etanol < acetona e acetato de etila. Foi observado que a polaridade do solvente não foi o único fator determinante da solubilidade, devendo ser levada em consideração também a sua estrutura molecular, que afeta diretamente a interação soluto - solvente das moléculas em solução.

Ralston e Hoerr (1942) estudaram a solubilidade dos ácidos graxos saturados em diferentes solventes, sendo eles, água, etanol, acetona, 2-butanona, benzeno e ácido acético glacial, e então obtiveram para o ácido palmítico solubilidades de 0,00083, 23,9, 15,6, 20,6, 34,8 e 8,1 g/100g, e, para o ácido láurico, solubilidades de 0,0063, 292, 218, 202, 260, $297 \mathrm{~g} / 100 \mathrm{~g}$, respectivamente.

\section{I METODOLOGIA}

A partir dos dados experimentais foi realizado o ajuste dos parâmetros dos modelos termodinâmicos em planilhas eletrônicas, utilizando a ferramenta Solver do programa Excel Office®.

Os modelos termodinâmicos que tiveram seus parâmetros ajustados foram Margules, Wilson e NRTL. Estes modelos foram utilizados para o cálculo do coeficiente de atividade na equação (3).

O ajuste dos parâmetros dos modelos foi realizado a partir da minimização da função objetivo representada pela equação (12)

$$
\text { Função Objetivo }=\sum\left(T_{\text {experimental }}-T_{\text {Calculada }}\right)^{2}
$$

Os desvios entre os valores calculados e experimentais foram obtidos a partir dos desvios relativos entre cada temperatura experimental e calculada usando os modelos, conforme representado na equação (13). 


$$
D R(\%)=100 \cdot \frac{\left|T_{\text {experimental }}-T_{\text {calculada }}\right|}{T_{\text {experimental }}}
$$

Os dados experimentais utilizados para o ajuste dos parâmetros dos modelos de Margules, Wilson e NRTL foram aqueles reportados por Ralston e Hoerr (1942).

\section{I RESULTADOS E DISCUSSÕES}

$\mathrm{Na}$ Figura 1 pode ser observada a quase sobreposição entre as temperaturas experimentais e aquelas calculadas usando os modelos termodinâmicos de Margules, Wilson e NRTL para o ácido láurico dissolvido em acetona, etanol e 2-butanona. Este comportamento indica que os três modelos foram capazes de representar adequadamente o equilíbrio sólido-líquido do sistema a partir do ajuste de seus parâmetros.

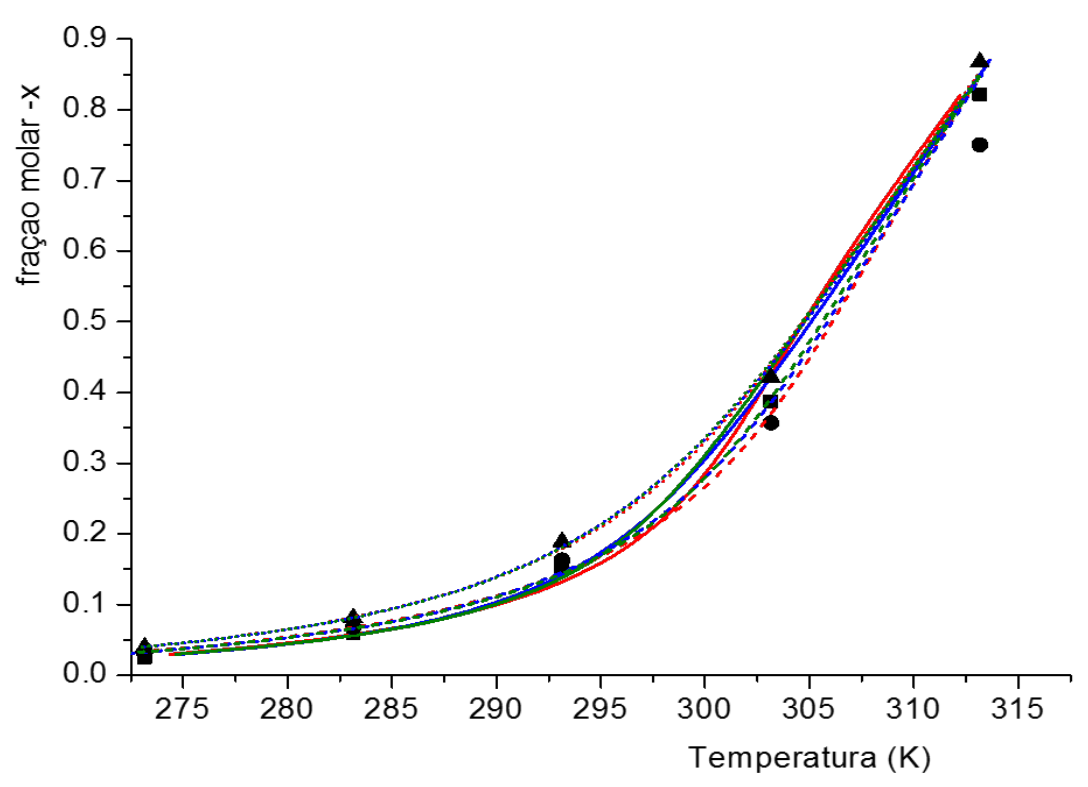

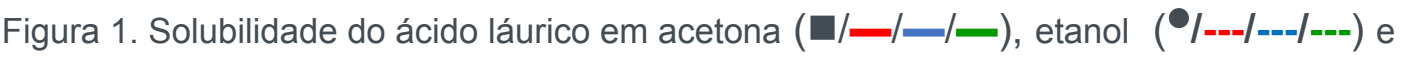

2-butanona $(\boldsymbol{\Delta} / \bullet \bullet / \cdot \bullet / \bullet \bullet \bullet)$ obtidas experimentalmente $(\boldsymbol{\square} / \boldsymbol{\bullet} / \mathbf{\Delta})$ e calculadas pelos modelos

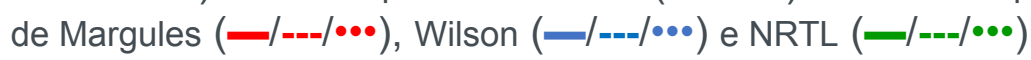

A mesma boa representatividade da solubilidade experimental usando os três modelos termodinâmicos foi obtida quando o soluto é o ácido esteárico, um ácido graxo com 6 átomos de carbono adicionais na molécula em relação ao ácido láurico, conforme observado na Figura 2.

De modo geral, os maiores desvios relativos ocorreram quando foi empregado o modelo de Margules com dois parâmetros para o cálculo dos coeficientes de atividade dos componentes na fase líquida, conforme apresentado na Tabela 1. Estes desvios foram maiores para os sistemas cujos solutos são constituídos por moléculas apolares saturadas de cadeia mais longas, ácido palmítico e ácido esteárico, em um solvente polar com apenas dois átomos de carbono na molécula, o etanol. A representatividade 
menos precisa da temperatura de saturação quando se usa o modelo de Margules para os sistemas constituídos por ácido palmítico + etanol e ácido esteárico + etanol está de acordo com a teoria termodinâmica que aponta a similaridade entre os volumes das moléculas do sistema como uma característica para o uso deste modelo

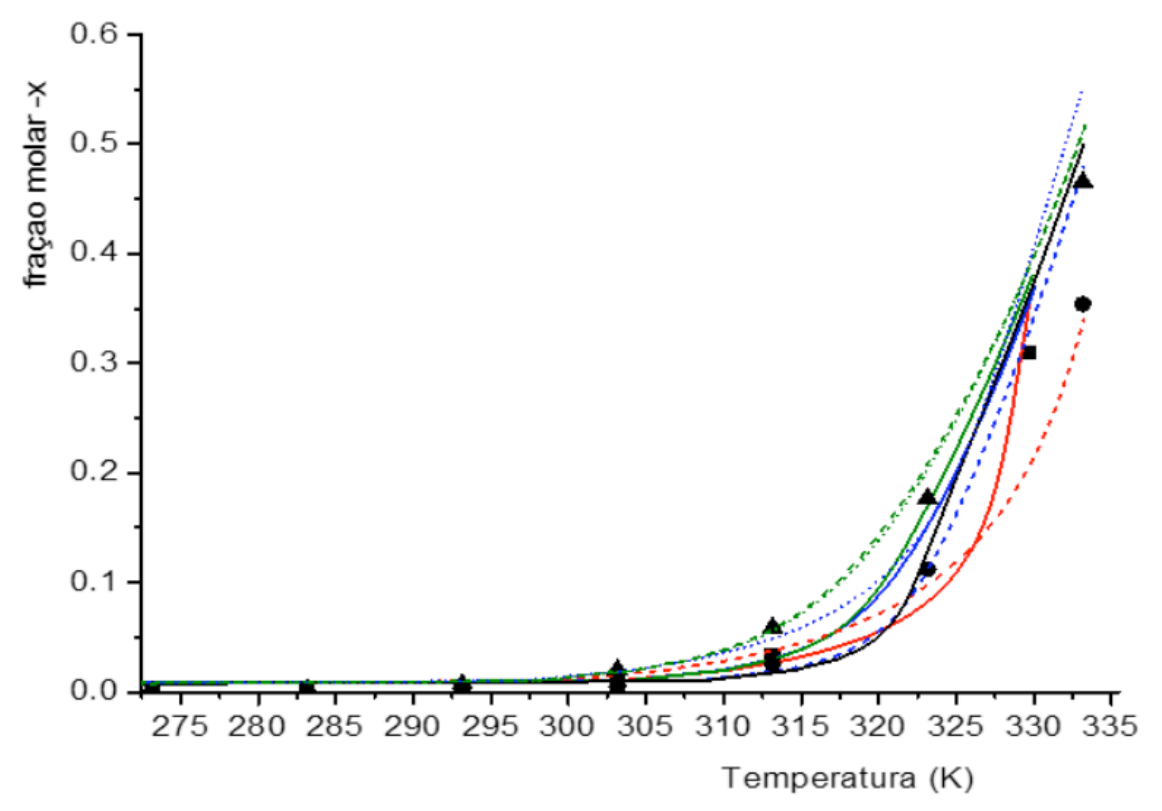

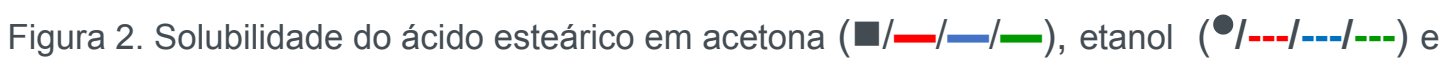

2-butanona $(\mathbf{\Delta} / \bullet \bullet / \bullet \bullet / \bullet \bullet)$ obtidas experimentalmente $(\mathbf{\square} / \bullet / \mathbf{\Delta})$ e calculadas pelos modelos

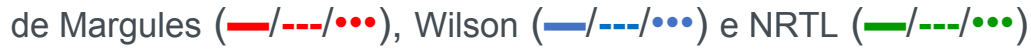

O uso dos modelos de Wilson e NRTL levaram ao cálculo de temperaturas de saturação com desvios máximos entre as temperaturas calculadas experimentais respectivamente iguais a 1,22 \% e 1,32 \%para todos os sistemas, apresentando resultados similares quanto a representatividades dos sistemas.

\begin{tabular}{ccccc}
\hline & & Margules & Wilson & NRTL \\
\hline \multirow{3}{*}{ ácido láurico } & DR (\%) & DR (\%) & DR (\%) \\
& acetona & $0,20-0,46$ & $0,20-0,29$ & $0,06-0,20$ \\
& etanol & $0,00-0,65$ & $0,10-0,64$ & $0,09-0,69$ \\
& 2-butanona & $0,04-0,22$ & $0,16-0,29$ & $0,01-0,16$ \\
\hline ácido mirístico & acetona & $0,11-0,37$ & $0,00-0,39$ & $0,12-0,57$ \\
& etanol & $0,15-1,64$ & $0,04-0,59$ & $0,03-0,48$ \\
& 2-butanona & $0,00-0,37$ & $0,02-0,29$ & $0,09-0,26$ \\
\hline ácido palmítico & acetona & $0,21-1,37$ & $0,24-0,92$ & $0,19-1,01$ \\
& etanol & $0,, 29-3,32$ & $0,06-0,77$ & $0,00-0,43$ \\
& 2-butanona & $0,01-1,37$ & $0,15-1,13$ & $0,05-1,21$ \\
\hline ácido esteárico & acetona & $0,04-0,78$ & $0,14-0,67$ & $0,18-0,63$ \\
& etanol & $0,10-4,56$ & $0,01-0,96$ & $0,04-0,95$ \\
& 2-butanona & $0,17-1,42$ & $0,14-1,22$ & $0,06-1,32$ \\
\hline
\end{tabular}

Tabela 1. Desvios relativos entre as temperaturas experimentais e calculadas usando-se os modelos de Margules, Wilson e NRTL para os ácidos láurico, mirístico e esteárico dissolvidos em acetona, etanol e 2-butanona 
Na Tabela 2 são apresentados os valores dos parâmetros ajustados dos modelos termodinâmicos de Margules e de Wilson, a partir dos quais pode-se calcular a temperatura de solubilização em qualquer temperatura dentro da faixa de temperatura para as quais foram realizados os ajustes.

\begin{tabular}{cc|cc|cc}
\hline Componente 1 & Componente 2 & \multicolumn{2}{|c|}{ Margules } & \multicolumn{2}{c}{ Wilson } \\
\hline \multirow{2}{*}{ ácido láurico } & & $\mathrm{A}_{12}$ & $\mathrm{~A}_{21}$ & $\mathrm{~A}_{12}$ & $\mathrm{~A}_{21}$ \\
& acetona & 3495,54 & 1602,81 & 0,1870 & 1,0192 \\
& etanol & 3009,51 & 2253,38 & 0,3001 & 0,8208 \\
& 2-butanona & 2622,63 & 1583,48 & 0,2979 & 1,0034 \\
\hline ácido mirístico & acetona & 3859,99 & 1764,27 & 0,1918 & 0,9390 \\
& etanol & 3434,00 & 2237,18 & 0,1488 & 1,0928 \\
& 2-butanona & 2717,35 & 1545,95 & 0,2896 & 1,0405 \\
\hline ácido palmítico & acetona & 4536,84 & $-773,09$ & 0,0650 & 1,6027 \\
& etanol & 3387,68 & 2733,78 & 0,0727 & 1,3618 \\
& 2-butanona & 3130,86 & 589,93 & 0,1310 & 1,5794 \\
\hline ácido esteárico & acetona & 4459,54 & $-380,18$ & 0,0701 & 1,6942 \\
& etanol & 3389,36 & 2524,28 & 0,0507 & 1,5487 \\
& 2-butanona & 2981,41 & $-300,26$ & 0,0981 & 1,9468 \\
\hline
\end{tabular}

Tabela 2. Parâmetros dos modelos de Margules e de Wilson ajustados para os sistemas binários compostos por ácidos graxos saturados e solventes orgânicos

Na Tabela 3 são apresentados os parâmetros ajustados do modelo NRTL que permite o cálculo da temperatura de solubilização para a faixa de temperatura estudada. O modelo NRTL é recomendado na descrição do coeficiente de atividade de sistemas fortemente não ideais, como os sistemas estudados no presente trabalho. Apesar de possuir um parâmetro adicional em relação ao modelo de Wilson, o que aumentaria a capacidade representativa do comportamento do sistema, o modelo NRTL não apresentou melhor capacidade representativa dos sistemas em relação ao primeiro.

Cuevas (2010) ao realizar a modelagem do gama-orizanol, um componente minoritário presente no óleo de arroz utilizando o modelo empírico de Apelblat, reportou desvios relativos médios variando entre 0,63\% até 12,69. Ao utilizar modelos termodinâmicos foram obtidos desvios relativos médios inferiores, sendo que para o modelo de Van Laar ficaram entre $0,41 \%$ e 5,83\%, e para o modelo de Margules ficaram entre $0,74 \%$ e $2,97 \%$. 


\begin{tabular}{lcrcc}
\hline Componente 1 & Componente 2 & \multicolumn{3}{c}{ NRTL } \\
\hline ácido láurico & & $\tau_{12}$ & $\tau_{21}$ & $\alpha_{12}=\alpha_{21}$ \\
& acetona & 0,6941 & 1,3440 & 0,9500 \\
& etanol & $-2,7103$ & 4,4415 & 0,0503 \\
& 2-butanona & 0,3901 & 0,9567 & 0,9500 \\
\hline ácido mirístico & acetona & $-0,3871$ & 2,0941 & 0,2821 \\
& etanol & 0,8938 & 1,4454 & 0,9500 \\
& 2-butanona & $-1,4444$ & 2,9021 & 0,1211 \\
\hline ácido palmítico & acetona & 0,2896 & 1,8826 & 0,9500 \\
& etanol & 1,9546 & 1,9710 & 0,9500 \\
& 2-butanona & 0,0716 & 1,3622 & 0,9500 \\
\hline ácido esteárico & acetona & 0,1323 & 1,8314 & 0,9500 \\
& etanol & 0,5558 & 2,0997 & 0,9500 \\
& 2-butanona & $-0,1457$ & 1,5119 & 0,9500 \\
\hline
\end{tabular}

Tabela 3. Parâmetros do modelo NRTL e de Wilson ajustados para os sistemas binários compostos por ácidos graxos saturados e solventes orgânicos

Estudando sistemas binários quanto a solubilidade dos ácidos láurico, palmítico e esteárico em etanol, 2-propano e n-propanol, Bonassoli et al. (2019) reportou que os três modelos representaram de maneira similar e adequada o comportamento dos sistemas, com desvio médio máximo de 0,824.

\section{I CONCLUSÃo}

O uso dos modelos de Margules, Wilson e NRTL para o cálculo do coeficiente de atividade empregado na descrição do equilíbrio sólido - líquido dos sistemas binários contendo os ácidos láurico, mirístico, palmítico ou esteárico e os solventes acetona, etanol e 2-butanona resultou em boa representatividade do comportamento dos sistemas. O uso modelo e Margules levou a desvios máximos superiores ao uso dos modelos Wilson e NRTL, os dois últimos mais apropriados a sistema fortemente não ideais como os estudados neste trabalho.

\section{Agências de Financiamento}

O presente trabalho foi realizado com apoio da Coordenação de Aperfeiçoamento de Pessoal de Nível Superior - Brasil (CAPES) - Código de Financiamento 001; do Conselho Nacional de Desenvolvimento Científico e Tecnológio (CNPq) - número do processo 420355/2016-2; da Fundação de Amparo à Pesquisa do Estado de Minas Gerais por meio da Bolsa de Iniciação Científica (Bruno Rossetti de Souza) e da bolsa de Mestrado (Vanessa Vilela Lemos). 


\section{REFERÊNCIAS}

BONASSOLI, A. B. G. et al. Solubility Measurement of Lauric, Palmitic, and Stearic Acids in Ethanol, n-Propanol, and 2-Propanol Using Differential Scanning Calorimetry. Journal of Chemical Engineering \& Engineering Data, v. 64, n. 5, p. 2084-2092, 2019

CUEVAS, M. S. Solubilidade de compostos minoritários do óleo de farelo de arroz em solventes orgânicos: determinação de dados experimentais e solubilidade. Dissertação de mestrado. Departamento de Engenharia de Alimentos da Faculdade de Engenharia de Alimentos. Universidade Estadual de Campinas, Campinas/SP, 2010.

FREGOLENTE, P. B. L. et al. Monoglyceride and diglyceride production through lipase-catalyzed glycerolysis and molecular distillation. Applied Biochemistry and Biotechnology, v. 160, p. 18791887, 2010.

GERVAJIO, G. C. Fatty acids and derivatives from coconut oil. In: SHAHID, F. Bailey's Industrial Oil and Fat Products. Hoboken (New Jersey), John Wiley \& Sons, Inc, 2005, v. 6, cap. 1, p. 1-56.

GREYT, W.; KELLENS, M. Deodorization. In: SHAHID, F. Bailey's Industrial Oil and Fat Products. Hoboken (New Jersey), John Wiley \& Sons, Inc, 2005, v. 5, cap. 8, p. 341-383.

GUNSTONE, F. D. Vegetable oils. In: SHAHID, F. Bailey's Industrial Oil and Fat Products. Hoboken (New Jersey), John Wiley \& Sons, Inc, 2005, v. 1, cap. 1, p. 213-267.

HERYANTO, R. et al. Solubility of stearic acid in various organic solvents and its prediction using nonideal solution models. Science Asia, v. 33, p. 469 - 472, 2007.

ITO, V. M. et al. Tocopherols and phytosterols concentration from soybean oil distillate. In: ENPROMER, 2005, Costa Verde, (Rio de Janeiro), Brasil.

KONTOGEORGIS, G. M.; FOLAS, G. K.; Thermodynamic Models for Industrial Application. Chichester: John Wiley \& Sons, 2010.

PRAUSNITZ, J. M.; LICHTENTHALER, R. N.; AZEVEDO, E. G.; Molecular thermodynamics of fluid-phase equilibria. 6. ed. Upper Saddle River, N.J: Prentice Hall PTR, 1999.

RALSTON, A. W.; HOERR, C. W. The solubilities of the normal saturated fatty acids. Journal of Organic Chemistry, v. 7, p. $546-555,1942$.

SHAH, K. J.; VENKATESAN, T. K. Aqueous isopropyl alcohol for extraction of free fatty acids from oils. Journal of American Oil Chemists Society, v. 66, p. 783-787, 1989.

$\mathrm{SHI}$, B. et al. Concentration of natural vitamin E using a continous countercurrent supercritical $\mathrm{CO} 2$ extraction-distillation dual column. Chemical Engineering \&Technology, v. 34, p. 914-920, 2011.

SMITH, J. M.; VAN NESS, H. C.; ABBOTT, M. M. Introdução à Termodinâmica da Engenharia Química. 7. ed. Rio de Janeiro: Ltc, 2007.

VAZQUEZ, L. et al. Recovery of squalene from vegetable oil sources using countercurrent supercritical carbon dioxide extraction. Journal of Supercritical Fluids, v. 40, p. 59-66. 2007.

WEI, D. et al. $\beta$-Sitosterol solubility in selected organic solvents. Journal of Chemical \& Engineering Data, v. 55, p. 2917-2019, 2010.

YAN, F. et al. Optimization of phytosterols recovery from soybean oil deodorizer distillate. Journal of American Oil Chemists Society, v. 89, p. 1363-1370, 2012. 


\section{AVALIAÇÃO DE NANOPARTÍCULAS DE TIO ${ }_{2}$ OBTIDAS POR MOAGEM DE ALTA ENERGIA COM E SEM LIXIVIAÇÃO}

Lucca Monteiro Silva Semensato Universidade Federal de Alfenas (UNIFAL-MG), Campus Poços de Caldas Estudante de Iniciação Científica Poços de Caldas - Minas Gerais Vanessa Vilela Lemos Universidade Federal de Alfenas (UNIFAL-MG), Campus Poços de Caldas Engenheira Química Poços de Caldas - Minas Gerais Gabriel de Paiva Universidade Federal de Alfenas (UNIFAL-MG),

Campus Poços de Caldas Engenheiro Químico Poços de Caldas - Minas Gerais

Luis Fernando Baldo Estorari Universidade Federal de Alfenas (UNIFAL-MG), Campus Poços de Caldas

Estudante de Iniciação Científica

Poços de Caldas - Minas Gerais

Maisa Helena Mancini Universidade Federal de Alfenas (UNIFAL-MG), Campus Poços de Caldas Estudante de Iniciação Científica Poços de Caldas - Minas Gerais

Ana Gabriela Storion FZEA - USP

Doutoranda

Pirassununga - São Paulo
Eliria Maria de Jesus Agnolon Pallone

FZEA - USP

Professor titular

Pirassununga - São Paulo

Tânia Regina Giraldi Universidade Federal de Alfenas (UNIFAL-MG), Campus Poços de Caldas

Professor Associado

Poços de Caldas - Minas Gerais

Sylma Carvalho Maestrelli Universidade Federal de Alfenas (UNIFAL-MG), Campus Poços de Caldas

Professora Associada Poços de Caldas - Minas Gerais

RESUMO: A aplicação de nanopós semicondutores na fotocatálise heterogênea tem se mostrado uma importante linha de estudos, que visa oxidar compostos orgânicos a formas inertes e menos tóxicas, diminuindo os impactos ambientais causados pelo descarte destes. Neste contexto, o presente trabalho objetivou a obtenção de nanopós de $\mathrm{TiO}_{2}$ através da moagem de alta energia, utilizandose moinho do tipo SPEX para aplicação em fotocatálise. Amostras de $\mathrm{TiO}_{2}$ comercial, sob a forma de pós, foram caracterizadas via Difração de Raios $X(D R X)$, fisissorção de nitrogênio (B.E.T.), Calorimetria Exploratória Diferencial (DSC), Termogravimetria (TG) e Microscopia 
Eletrônica de Varredura (MEV. Elas foram então moídas em moinho vibratório de alta energia tipo SPEX variando-se os tempos de moagem (1, 2, 3, 4 e 5h), a fim de se estudar a influência desta variável na obtenção de nanopartículas. O processo de lixívia ácida foi aplicado aos nanopós obtidos, objetivando a descontaminação causada pelo ferro liberado pelos corpos moedores e moinho (ambos constituídos de aço) sobre a amostra. Os pós moídos obtidos, já em escala nanométrica, foram caracterizados por DRX, determinando-se o tamanho de cristalitos por Rietveld. Ensaios fotocatalíticos também foram realizados. A lixívia ácida utilizando $\mathrm{HCl}$ mostrou-se parcialmente eficaz na remoção do ferro proveniente da MAE. Além da contaminação, a MAE também promoveu a transformação da fase anatase em rutilo, o que prejudicou no potencial fotocatalítico das amostras com maiores tempos de moagem. A amostra com $1 \mathrm{~h}$ de moagem obteve maior potencial de degradação fotocatalítica, devido ao menor contato com ferro e menor formação da fase rutilo.

PALAVRAS-CHAVE: Nanopós, $\mathrm{TiO}_{2}$, Moagem de Alta Energia, fotocatálise, lixívia ácida.

\section{EVALUATION OF $\mathrm{TIO}_{2}$ NANOPARTICLES OBTAINED BY HIGH ENERGY MILL WITH AND WITHOUT LEACHING}

ABSTRACT: The application of semiconductor nanopowders in heterogeneous photocatalysis is an important line of studies, whose purpose is to oxidize organic compounds to inert and less toxic forms, reducing the environmental impacts caused by their disposal. In this context, the focus of this work was to obtain $\mathrm{TiO}_{2}$ nanopowders through high energy milling, using a SPEX type mill for application in photocatalysis. Commercial $\mathrm{TiO}_{2}$ samples were characterized by X-Ray Diffraction (XRD), Nitrogen Screening (BET), Differential Scanning Calorimetry (DSC), Thermogravimetry (TG), Scanning Electron Microscopy (SEM) and FTIR. These samples were then milled in a high-energy SPEX type vibrating mill, varying the milling times (1, 2, 3, 4 and 5h) in order to study the influence of this variable on nanoparticles obtainment. The acidic leaching process was applied to the nanopowders obtained, with the purpose of obtaining decontamination by the iron released by the grinding and milling bodies (both made of steel) on the sample. The obtained milled powders, already in nanometric scale, were characterized by XRD, determining the size of crystallites by the Rietveld method. Photocatalytic tests were also performed. Acidic leaching using $\mathrm{HCl}$ was partially effective in the removal of iron from the MAE. In addition to the contamination, the MAE also promoted the transformation of the anatase phase into rutile, which impaired the photocatalytic potential of the samples with longer milling times. The sample with $1 \mathrm{~h}$ of milling obtained a greater potential of photocatalytic degradation, due to the lower contact with the iron and less formation of the rutile phase.

KEYWORDS: Nanopowders, $\mathrm{TiO}_{2}$, High Energy Milling, photocatalysis, acid leaching. 


\section{I INTRODUÇÃO}

Uma vez que os recursos ambientais têm se tornado cada vez mais escassos, é de suma importância que os resíduos tenham características adequadas para o descarte no meio ambiente, visto que a qualidade de vida das comunidades, da fauna e a flora dependem disso. Processos tradicionais de tratamento de efluentes ainda são utilizados, porém para algumas aplicações eles se mostram ineficazes e insuficientes (PASCOAL, 2007).

É neste contexto que os processos oxidativos avançados - POAs- se destacam como alternativa promissora para o tratamento de efluentes, por serem capazes de oxidar compostos orgânicos complexos, se mostrando um processo eficiente para eliminação de compostos resistentes aos tratamentos químicos, físicos e biológicos. Os poluentes tratados são mineralizados a formas menos tóxicas e inertes, como $\mathrm{CO}_{2}$ e $\mathrm{H}_{2} \mathrm{O}$ (FERREIRA, 2005).

Na fotocatálise heterogênea, um tipo de POA, a radiação solar pode ser utilizada como fonte de energia, ativando o catalisador e induzindo reações de oxirredução. Alguns semicondutores minerais vêm sendo aplicados neste processo como catalisadores, por exemplo, o $\mathrm{TiO}_{2}, \mathrm{ZnO}, \mathrm{ZnS}, \mathrm{CdS}, \mathrm{Bi}_{2} \mathrm{O}_{3}$, entre outros (FERREIRA, 2005).

A efetividade da fotocatálise heterogênea depende da área superficial do semicondutor, o que tem chamado atenção para fotocatalisadores obtidos a partir de pós nanométricos, visto que estes, pelo menor tamanho, possuem uma grande área superficial (MOURÃO; MENDONÇA, 2009).

Diversas técnicas podem ser utilizadas para a obtenção de pós nanométricos; a Moagem de Alta Energia (MAE) tem ganho destaque na comunidade científica uma vez que é uma técnica rápida, eficiente, de fácil transposição para a escala industrial e que envolve custo relativamente baixo, principalmente no que tange a questão das matérias primas utilizadas para obtenção de nanopós (TAKIMI, 2004). Esta pesquisa investigou a obtenção de nanopós para aplicação em fotocatálise de um material semicondutor $\left(\mathrm{TiO}_{2}\right)$ a partir da MAE, e o efeito da presença de ferro contaminante oriundo do frasco e meio de moagem nas propriedades fotocatalíticas de $\mathrm{TiO}_{2}$.

\section{I MATERIAIS E MÉTODOS}

Foi utilizado como matéria-prima o Óxido de Titânio em pó (TiO2, 99\% de pureza, MW:79,87 g/mol, Sigma-Aldrich®). Solução de $20 \%$ de ácido clorídrico foi utilizada para descontaminação dos nanopós pelo processo de lixívia ácida após moagem.

Para o desenvolvimento deste projeto de pesquisa, a metodologia foi dividida em três fases, na qual a fase A consistiu na caracterização do pó precursor (feita previamente pelo grupo de pesquisa), na fase $B$ na obtenção dos pós finos por meio da moagem de alta energia, e por fim, a fase $\mathrm{C}$ consistiu na caracterização do material 
obtido após a fase B.

Fase A: Realizada previamente pelo grupo de pesquisa (STORION, 2018). Para a caracterização por difração de Raios X dos pós de TiO2 antes da moagem (Laboratório de Cristalografia da Universidade Federal de Alfenas, campus de Alfenas/MG), foi empregado tubo de cobre ( $\mathrm{Ka}=0,1542 \mathrm{~nm}$ ), com potencial de aceleração de $40 \mathrm{kV}$ e $30 \mathrm{~mA}$, em varredura angular entre 15 e $75^{\circ}$, com passo de $2 \times 10-2^{\circ}$. A análise de DSC e TG (equipamento Netzsch Júpiter STA 449F3, UNIFAL, campus de Poços de Caldas/ MG) foi utilizada para avaliar eventos físico-químicos endo/exotérmicos e de alterações na massa das amostras em função do incremento da temperatura. Foi utilizado $10 \mathrm{mg}$ de óxido em cadinhos de liga platina-ródio sob a atmosfera de nitrogênio, com taxa de aquecimento de $10 \mathrm{~K} / \mathrm{min}$ e faixa de temperatura de 200 a $1100^{\circ} \mathrm{C}$. As caracterizações por microscopia eletrônica de varredura (MEV) e fisissorção de nitrogênio (BET) foram realizadas no DEMa/UFSCar. Para análise dos pós em termos de morfologia, distribuição e tamanho, foi utilizado o Microscópio Eletrônico de Varredura modelo Philips XL-30Field Emission Gun (MEV-FEG) e o software ImageJ 1.48v. A técnica de fisissorção de nitrogênio foi realizada em equipamento Micromeritcs ASAP 2020, na temperatura de $77 \mathrm{~K}$.

Fase B: A moagem dos pós precursores foi realizada em um moinho de alta energia do tipo SPEX Mixer/ Mill, cujo frasco e bolas são constituídos de aço endurecido (UNIFAL, campus de Poços de Caldas). Antes de cada moagem as bolas foram pesadas em balança analítica e a massa de $\mathrm{TiO}_{2}$ também foi medida seguindo a proporção mássica de Bola:Material de 5:1, relação ótima já investigada em trabalhos anteriores do grupo de pesquisa (STORION, 2018). As moagens foram realizadas a seco, variando-se o tempo de moagem total da titânia em 1, 2, 3 ,4 e 5h horas, sendo comparadas com o tempo zero que corresponde àquelas amostras submetidas somente à passagem em almofariz e pistilo.

Não foram necessários tempos de moagem mais longos, visto que o moinho vibratório tipo SPEX produz elevada energia, com elevado grau de moagem mesmo em tempos mais curtos de moagem, quando comparados a outros moinhos de alta energia, como é o caso do atritor ou planetário; além disso, tempos elevados de moagem encareceriam o projeto, o que seria contraditório com a pesquisa proposta uma vez que pretende-se obter os nanopós através de tecnologia de menor custo quando comparado aos processos químicos. Ao fim de cada tempo de moagem, os pós foram retirados do frasco com a ajuda de um pincel, e então foram transferidos para um béquer. Como alguns pós permaneceram aderidos à parede, foi adicionado álcool e o frasco foi levado novamente ao moinho, por mais cinco minutos, sendo o pó e álcool posteriormente retirados e transferidos para o mesmo béquer. Este foi deixado à temperatura ambiente para que o álcool evaporasse e o pó fosse então utilizado na lixívia.

Após a obtenção dos pós finos foi realizada a lixívia ácida utilizando solução de 20 \% de ácido clorídrico para a descontaminação e posterior desaglomeração do pó via 
ultrassom de ponto. Para a realização da lixívia ácida, $3 \mathrm{~g}$ do pó moído foram medidos em balança analítica e adicionados a um béquer com $100 \mathrm{~mL}$ da solução de ácido clorídrico. Eles foram agitados por 4 horas em uma temperatura entre 90 e $100^{\circ} \mathrm{C}$. $\mathrm{O}$ béquer foi então deixado em repouso para a decantação do pó e então retirada da solução residual. Após a retirada da parte líquida, o pó foi novamente misturado a 100 $\mathrm{mL}$ de solução de $\mathrm{HCl}$ e o procedimento foi repetido. A lixívia foi realizada quatro vezes para os pós moídos por 1, 2 e 3h e cinco vezes para os pós moídos por 4 e 5 h até eliminação aparente do ferro.

Quando a solução foi extraída pela última vez de cada amostra foi necessário realizar a lavagem do pó para retirar o ácido residual. Para isso, foi adicionado ao béquer $100 \mathrm{~mL}$ de água, e a mistura foi deixada sob agitação por $30 \mathrm{~min}$. Após alguns dias, para os pós que não decantaram completamente, a parte líquida foi centrifugada para a completa separação do pó e da água. Esta última foi então descartada e o pó novamente misturado a $100 \mathrm{~mL}$ de água destilada. O processo de lavagem foi repetido três vezes para cada amostra, e após a última retirada da parte líquida, o béquer foi deixado em uma estufa para completa evaporação da água. Por fim, álcool foi adicionado ao béquer e o pó foi desaglomerado na Sonda Ultrassônica Sanders, por 25 min. Após alguns dias em repouso, o álcool evaporou e os pós foram passados em uma peneira de abertura de $45 \mu \mathrm{m}$.

Fase C: Depois de obtidos os nanopós de titânia, utilizou-se novamente a Difração de Raios X para determinação do tamanho de cristalito pelo método de Rietveld. Foi utilizado para os testes fotocatalíticos um reator fotoquímico operante com radiação ultravioleta na região do UV-C presente no Laboratório de Espectroscopia e Cromatografia Ambiental da Universidade Federal de Alfenas, campus de Poços de Caldas. Foi o utilizado o corante Rodamina B Synth para mensurar a atividade fotocatalítica. Solução estoque desse corante foi previamente preparada a $1000 \mathrm{mg} \cdot \mathrm{L}^{-1}$ em água deionizada (3 $\left.\mu \mathrm{S} . \mathrm{cm}^{-1}\right)$ armazenada em frasco âmbar a $4^{\circ} \mathrm{C}$. Anterior a cada análise, foi preparada solução a $5 \mathrm{mg} \cdot \mathrm{L}^{-1}$ a partir da diluição da solução estoque em água com mesma procedência.

\section{I RESULTADOS E DISCUSSÕES}

\subsection{Fase A}

Durante a caracterização dos pós precursores determinou-se a área superficial do óxido de titânio pela técnica de fisissorção de nitrogênio, obtendo-se o valor de $A=$ 10,9456 m²/g (STORION, 2018).

A Figura 1 mostra o difratograma de Raios $\mathrm{X}$ para $\circ \mathrm{TiO}_{2}$ precursor, indicando que o óxido de titânio se encontra na fase anatase, com estrutura cristalina tetragonal (STORION, 2018). 


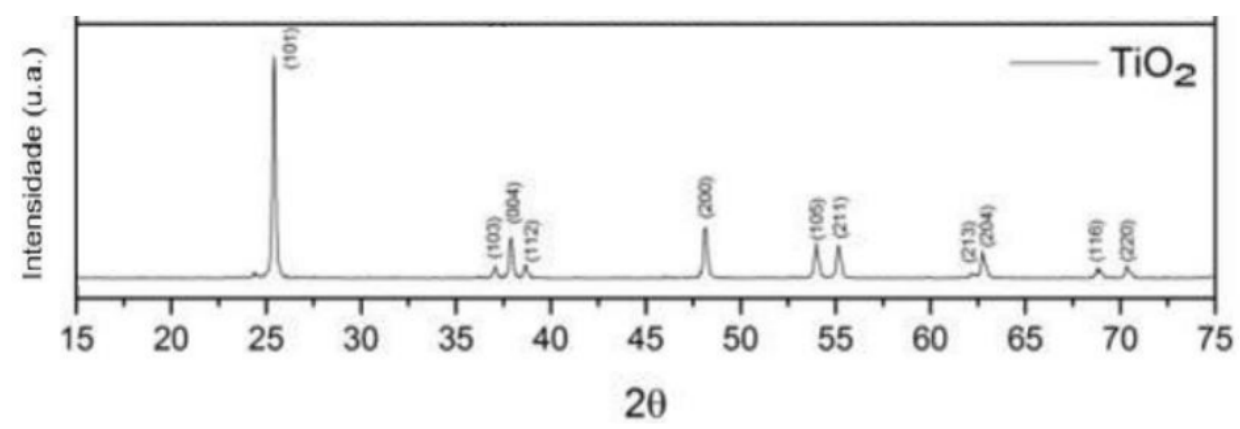

Figura 1 - Difratograma de Raios X para o pós precursor de $\mathrm{TiO}_{2}$.

Fonte: STORION, 2018.

A Figura 2 apresenta os resultados dos ensaios DSC/TG para o pó precursor. É possível notar que em torno de $500^{\circ} \mathrm{C}$, a curva de fluxo de calor, que antes estava caminhando para o sentido de diminuição da perda de calor, apresenta um pico exotérmico, enquanto que a curva termogravimétrica não sofreu alteração. A transição do pó de uma fase menos estável para uma mais estável, no caso em questão, da fase anatase para rutilo, pode ser a causa deste pico.

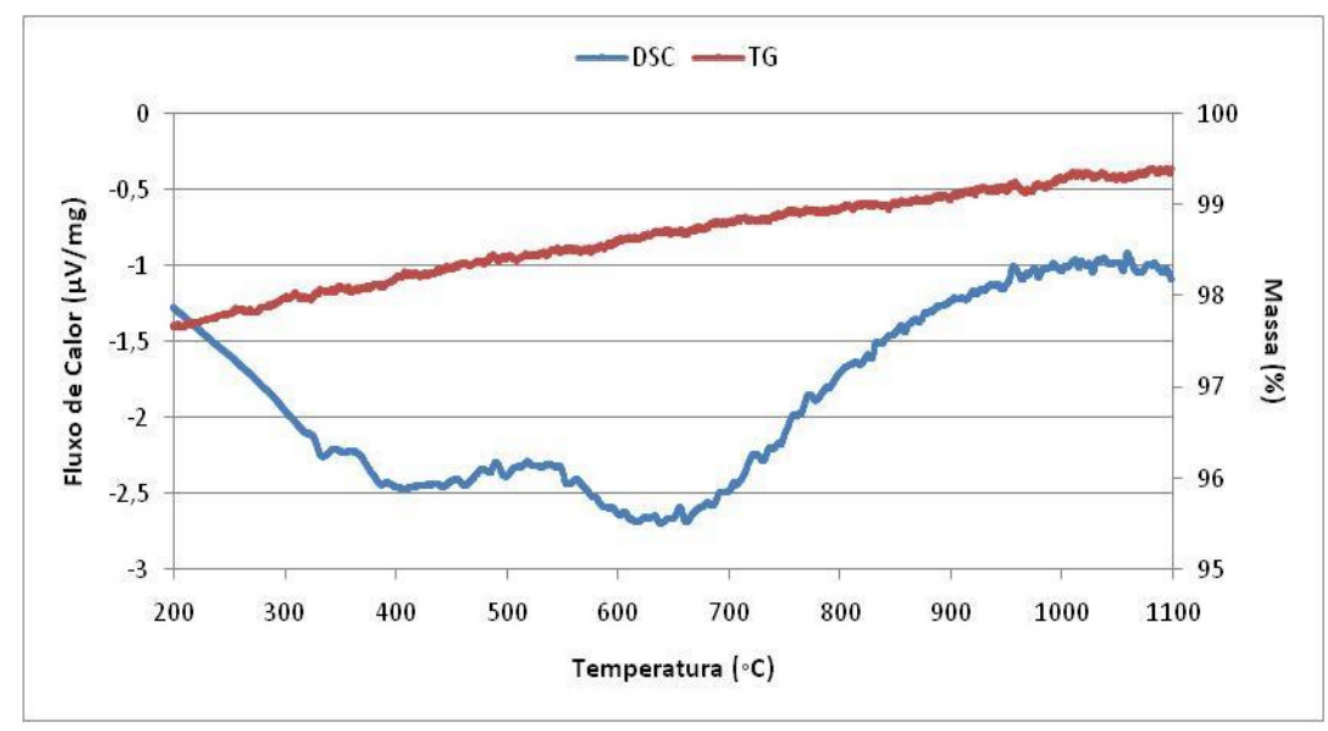

Figura 2 - Resultados do ensaio DSC/TG para o pó precursor.

Fonte: STORION, 2018.

Para a determinação do tamanho de partículas de TiO2 foi utilizado o Software Image $1.48 \mathrm{v}$, tendo sido obtido um tamanho médio de 166,30 $\pm 37,98 \mathrm{~nm}$ antes da moagem de alta energia (Figura 3). 


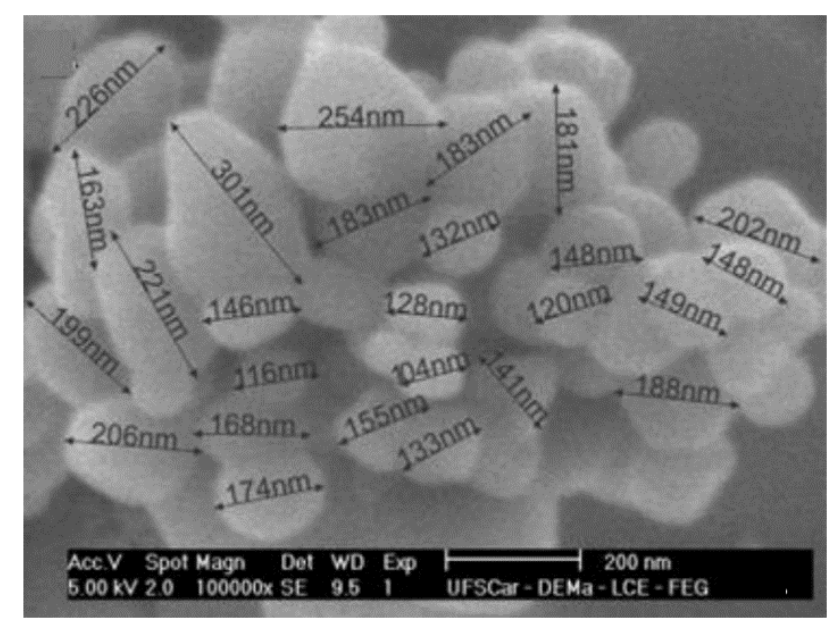

Figura 3 - Determinação do tamanho de partículas do $\mathrm{TiO}_{2}$ (100000x).

Fonte: Autores.

\subsection{Fase B}

Após realizar a moagem do óxido de titânio com diferentes tempos, foi possível perceber uma maior contaminação conforme o tempo de moagem aumentava, visto que a coloração do pó se tornou cada vez mais escura, o que já era esperado. Esse fato pode ser comprovado pela Figura 4.

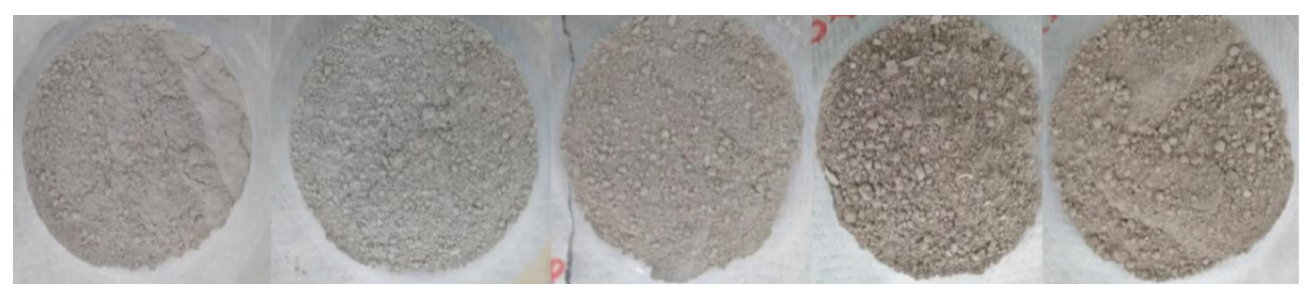

Figura 4 - TiO2 após 1, 2, 3, 4 e 5 h de moagem (da esquerda para direita).

Fonte: Autores.

Como já discutido na metodologia, a lixívia ácida foi empregada para descontaminar esse pó, por meio da reação do ácido com o ferro. Após a lixívia, a cor característica da solução é amarelada, e conforme a quantidade de ferro no pó diminui, a solução vai se tornando mais clara. Na maioria dos casos, conforme foram sendo realizadas mais lixívias, a solução foi se tornando menos amarela. Em poucos casos a solução se tornou mais escura novamente, mas isso provavelmente se deve ao fato de a lixívia anterior não ter sido realizada eficientemente. Isso pode ocorrer devido a diversos fatores, como um descontrole na temperatura, por exemplo. A Figura 5 mostra a mistura após cada uma das lixívias para a amostra moída por cinco horas. 


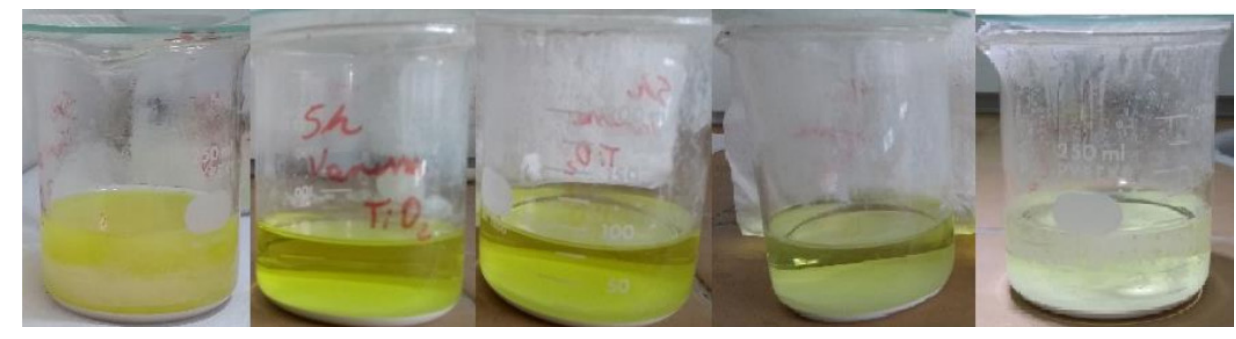

Figura 5 - Aparência da solução após cada lixívia para amostra moída por 5h. Fonte: Autores.

Após quatro lixívias nos pós que foram moídos por 1,2 e 3 h, a solução já se mostrou suficientemente clara, indicando que o ferro foi eliminado quase que totalmente. Já os pós que foram moídos por 4 e 5 h ainda apresentavam uma coloração pouco amarelada após a quarta lixívia, consequência da maior contaminação gerado pelo maior tempo de moagem. Por isso, nestes dois casos, a lixívia foi realizada cinco vezes.

Como já dito na metodologia, os pós foram lavados após a lixívia, para retirada do ácido residual. Todas as amostras mostraram uma total separação da água e do $\mathrm{TiO}_{2}$ após a primeira lavagem, porém após a segunda e terceira foi necessário utilizar a centrifugação para separá-los. A Figura 6 mostra a amostra de $1 \mathrm{~h}$ nos dois casos.

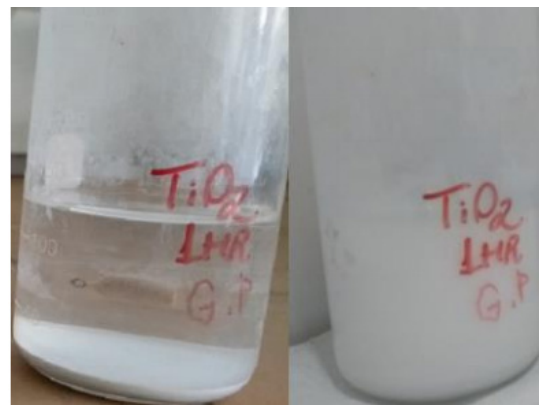

Figura 6 - Amostra moída por $1 \mathrm{~h}$ após primeira e segunda lavagem.

Fonte: Autores.

\subsection{Fase C}

\subsubsection{Análises de DRX}

As figuras 7 e 8 mostram os difratogramas obtidos para as amostras com e sem lixívia. Na figura 7, onde estão registrados os resultados das amostras que não passaram por lixívia ácida, nota-se que conforme o tempo de moagem aumenta, a amorfização do pó também aumenta, juntamente com a presença do ferro, na forma de magnetita. Além do mais, nota-se que para maiores tempos de MAE, a estrutura anatase (ortorrômbica) transforma-se em rutilo (ALI, 2014), o que também é evidenciado na figura 8 , que mostra os difratogramas das amostras submetidas a lixívia ácida. Após a lixívia ácida, foi possível verificar a remoção parcial ou completa do ferro através dos difratogramas da figura 8. 


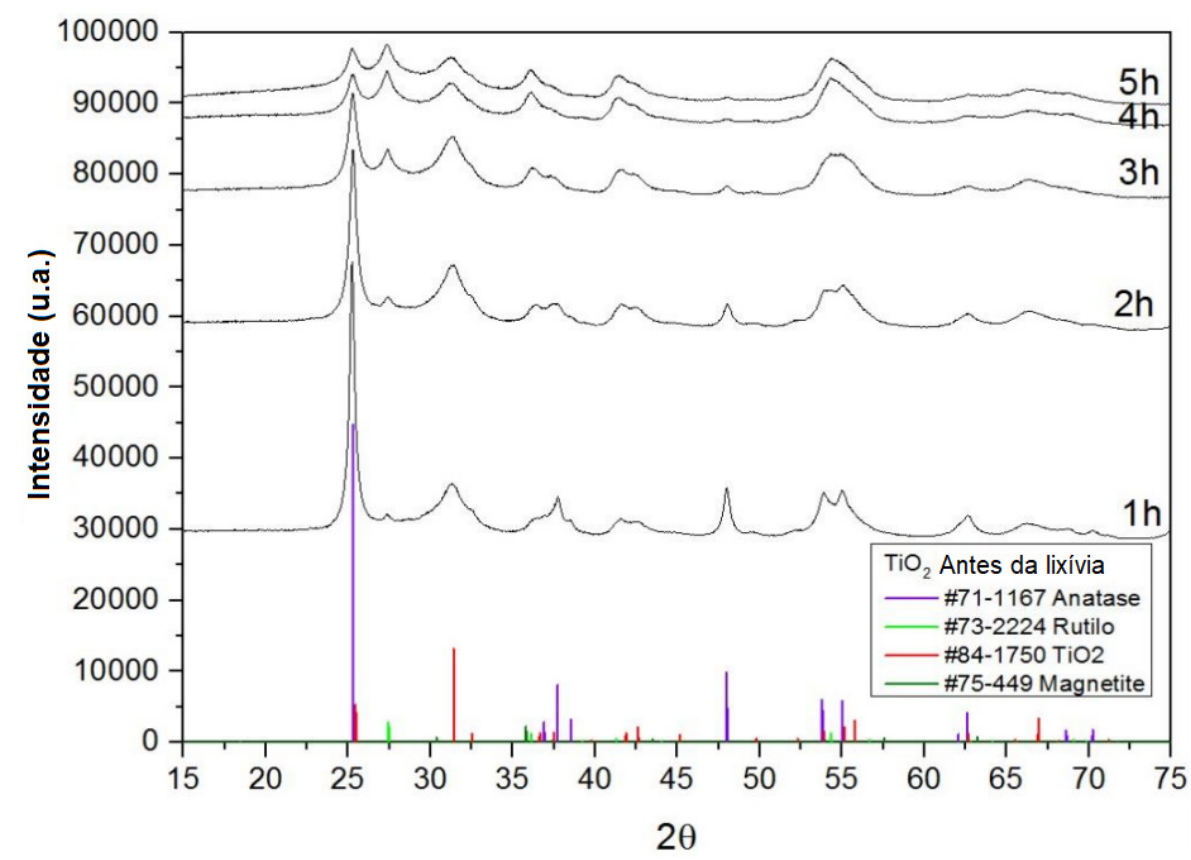

Figura 7 - Difratogramas para as amostras de $\mathrm{TiO}_{2}$ que não passaram pelo processo de lixívia ácida. Foram indicadas as fases anatase e rutilo $\left(\mathrm{TiO}_{2}\right)$ e a presença do ferro como magnetita.

Fonte: Autores.

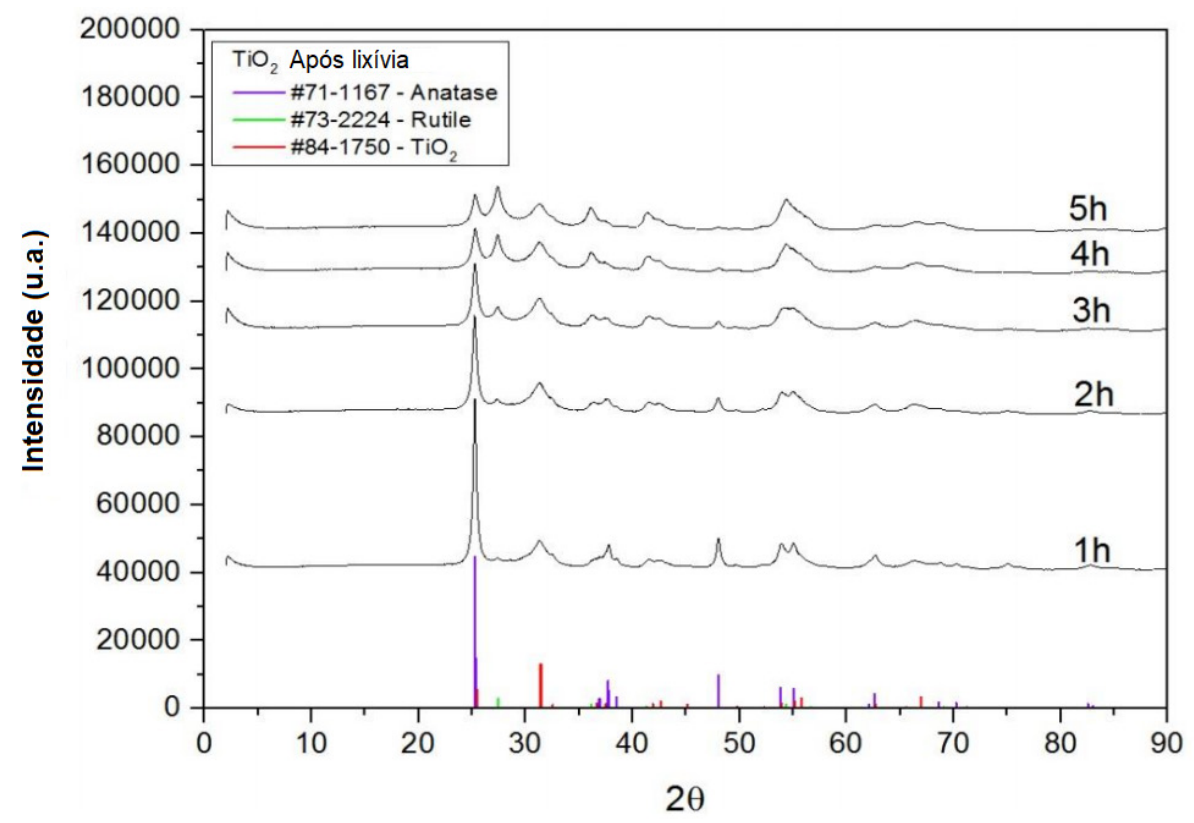

Figura 8 - Difratogramas para as amostras de TiO2 que passaram pelo processo de lixívia ácida. Foram indicadas as fases anatase e rutilo ( $\mathrm{TiO} 2)$.

Fonte: Autores.

A tabela 2 mostra os tamanhos de cristalito das amostras após moagem. Notase que quanto maior o tempo de moagem, menor o tamanho de cristalito, indicando a eficiência da MAE. Para tempos de moagem maiores do que 3 horas, não foram obtidos resultados devido à dificuldade na separação dos picos. 


\begin{tabular}{|l|l|l|l|l|l|}
\hline Tempo de moagem $(\mathbf{h})$ & 1 & 2 & 3 & 4 & 5 \\
\hline Tamanho de cristalito $(\mathbf{n m})$ & 55 & 18 & 15 & - & - \\
\hline
\end{tabular}

Tabela 2: Tamanho de cristalito para as amostras após a moagem.

Fonte: Autores.

\subsubsection{Ensaios fotocatalíticos}

Após a caracterização das amostras, foram realizados ensaios fotocatalíticos para determinação do potencial de degradação das amostras, utilizando Rodamina B como contaminante a ser degradado. Os resultados dos ensaios encontram-se nas figuras 9 e 10.

Os resultados não foram promissores para as amostras que não foram submetidas ao tratamento por lixívia ácida. Mesmo com a redução do tamanho de cristalito, a MAE causou a contaminação por ferro, o que comprometeu a eficiência fotocatalítica do $\mathrm{TiO}_{2}$. No entanto, para as amostras submetidas a lixívia ácida, os resultados mostraram altos valores de degradação da Rodamina. Assim, tornase evidente a necessidade da descontaminação dos pós para melhor eficiência fotocatalítica.

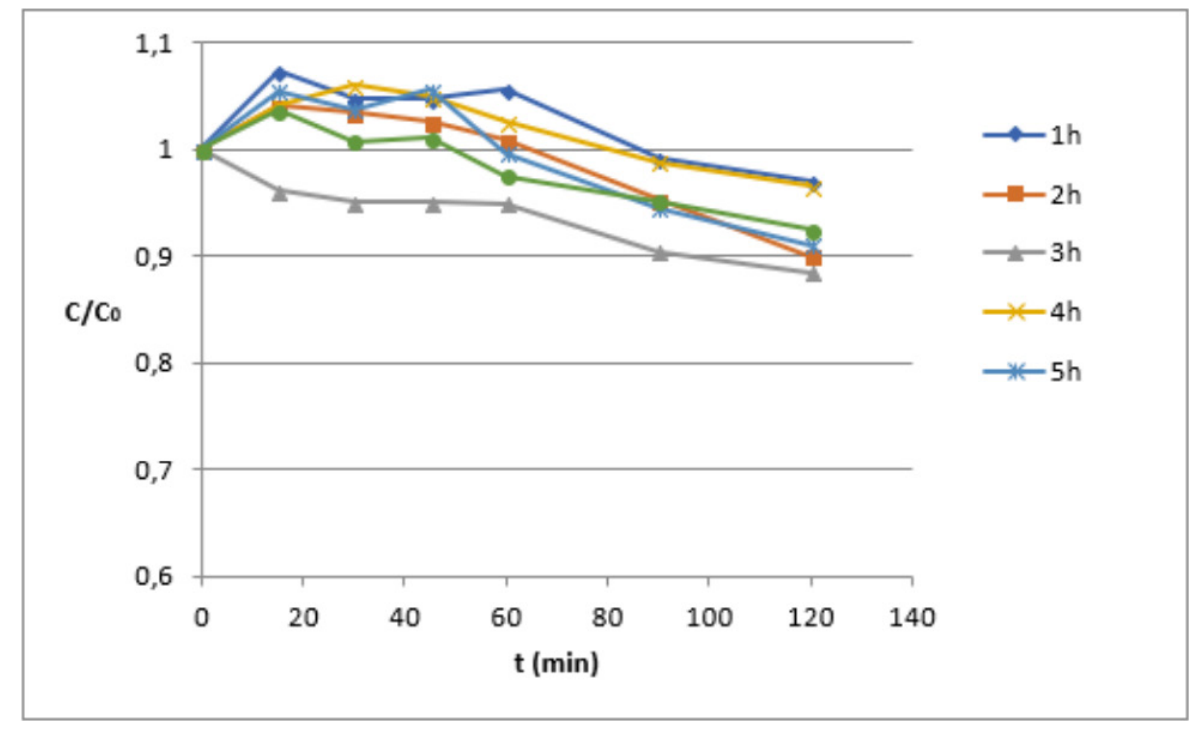

Figura 9 - Resultados dos ensaios fotocatalíticos das amostras de $\mathrm{TiO}_{2}$ moídas por 1, 2, 3, 4 e 5 horas que não foram submetidas a lixívia ácida.

Fonte: Autores. 


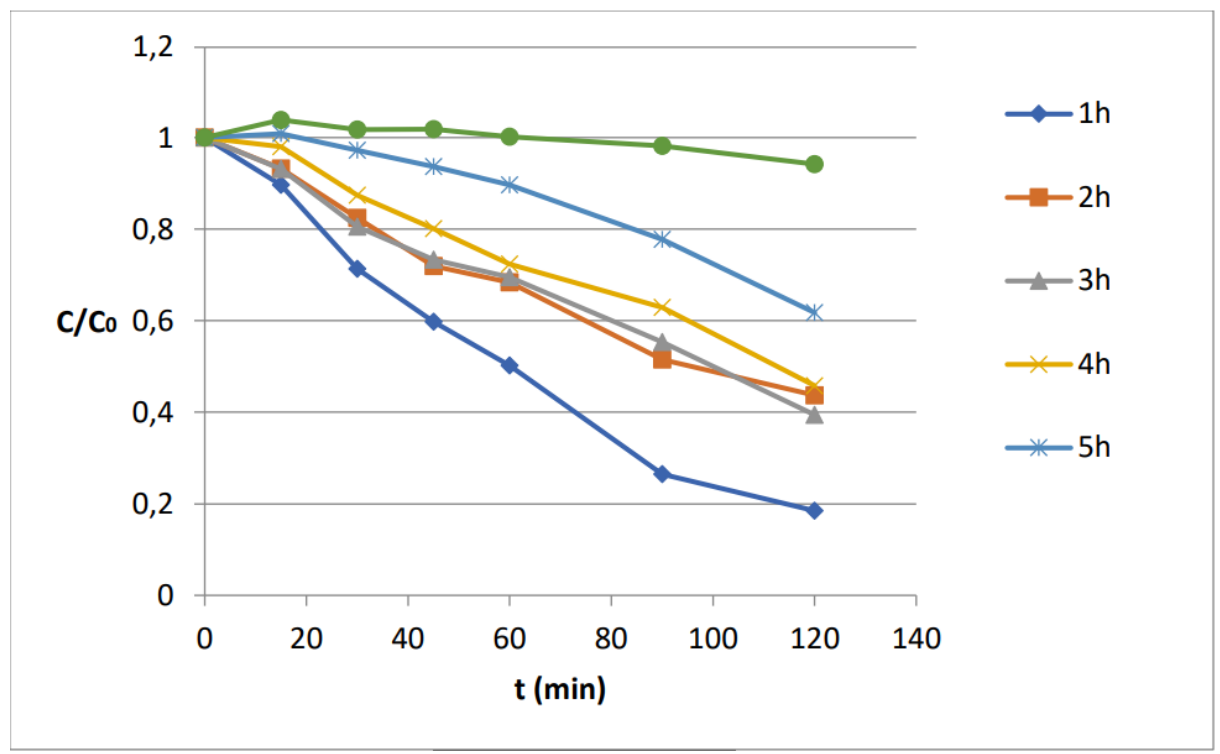

Figura 10 - Resultados dos ensaios fotocatalíticos das amostras de $\mathrm{TiO}_{2}$ moídas por 1, 2, 3, 4 e 5 horas após lixívia ácida.

Fonte: Autores.

Pela figura 10, nota-se que os melhores resultados foram os obtidos pelas amostras com menor tempo de moagem (1 hora), devido ao menor tempo de contato com o ferro na MAE. Além do mais, o aumento da fase rutilo nas amostras com maior tempo de moagem também contribui para a diminuição das propriedades fotocatalíticas.

\section{I CONCLUSÕES}

A moagem de alta energia em SPEX Mixer/Mill mostrou-se eficiente na diminuição do tamanho de cristalito das amostras de $\mathrm{TiO}_{2}$, porém, promoveu contaminação por ferro proveniente do meio de moagem, feito de aço. A moagem também promoveu a transformação da fase anatase do $\mathrm{TiO}_{2}$ em rutilo, o que, juntamente com a presença do ferro, afetou negativamente no potencial fotocatalítico das amostras.

A lixívia ácida utilizando $\mathrm{HCl}$ mostrou-se parcialmente eficaz na remoção do ferro das amostras, comprovado via DRX. Quanto maior o tempo de moagem, mais contaminação do pó foi observada, dificultando a eficiência da lixívia ácida na obtenção de pós isentos de Ferro contaminante. As amostras que passaram pelo processo de lixívia também apresentaram melhores potenciais de degradação do corante Rh-B, visto que quanto menor o tempo de moagem, maior degradação, devido ao menor tempo de contato com o ferro e menor presença da fase rutilo.

\section{I AGRADECIMENTOS}

Os autores agradecem ao CNPq e a CAPES pelo apoio financeiro a esta 
pesquisa, e a Universidade Federal de Alfenas (UNIFAL-MG) e FZEA - USP pelo uso das instalações e equipamentos.

\section{REFERÊNCIAS}

ALI, M. Transformation and powder Characteristics of TiO2 during high energy milling. Journal of Ceramic Processing Research, v. 15, n. 5, p. 290-293, 2014.

FERREIRA, I. V. L. Fotocatálise heterogênea com $\mathrm{TiO}_{2}$ aplicada ao tratamento de esgoto sanitário secundário. 2005. 160 f. Tese (Doutorado) - Curso de Hidráulica e Saneamento, Universidade de São Paulo, São Carlos, 2005.

MOURÃO, H. A. J. L.; MENDONÇA, V. R. de. Nanoestruturas em fotocatálise: uma revisão sobre estratégias de síntese de fotocatalisadores em escala nanométrica. Quim. Nova, São Carlos, v. 32, n. 8, p.2181-2190, 06 out. 2009.

PASCOAL, S. A. Aplicação de radiação UV artificial e solar no tratamento fotocatalítico de efluentes de curtume. Quim. Nova, Campina Grande, v. 30, n. 5, p.1082-1087, 17 jul. 2007.

STORION, Ana Gabriela. Nanopartículas de TiO2:WO3 e ZnO obtidas pela utilização de moinho vibratório: caracterização e propriedade fotocatalíticas. 2018. 133 f. Dissertação (Mestrado) Curso de Programa de Pós-graduação em Ciência e Engenharia de Materiais, Universidade Federal de Alfenas, Poços de Caldas, 2018.

TAKIMI, A. S. Obtenção de Superligas NiCrAIY Nanoestruturadas por Moagem de Alta Energia e sua Aplicação por Aspersão Térmica Hipersônica. 2004. 91 f. Dissertação (Mestrado) - Curso de Engenharia de Materiais, Universidade Federal do Rio Grande do Sul, Porto Alegre, 2004. 


\section{ANÁLISE DA INTERFERÊNCIA DO PRÉ- AQUECIMENTO DO ÓLEO E DA TEMPERATURA DE TRANSESTERIFICAÇÃO NAS CARACTERÍSTICAS FÍSICO-QUÍMICAS DO BIODIESEL}

\section{Gerd Brantes Angelkorte Universidade Federal do Rio de Janeiro, Programa de Planejamento Energético \\ Rio de Janeiro - Rio de Janeiro \\ Ivenio Moreira da Silva} Universidade Federal Fluminense, Departamento de Engenharia Agrícola e Meio Ambiente Niterói - Rio de Janeiro

RESUMO: O presente estudo tem por objetivo analisar as interferências da temperatura de pré-aquecimento e do processo de transesterificação, no rendimento do biodiesel $\mathrm{e}$ nas características físico químicas do biodiesel produzido. Para isso, utilizou-se o óleo de soja como fonte de triglicerídeo, o metanol como álcool na proporção de $30 \% \mathrm{~V} / \mathrm{N}$, o hidróxido de potássio $(\mathrm{KOH})$ como catalizador a $1 \%$ e utilizou-se o agitador magnético com o intuito de forçar o processo de transesterificação. Para as análises físico químicas utilizou-se o viscosímetro de capilar para determinar a viscosidade cinemática e o picnômetro para verificar a massa específica dos biodieseis. Os resultados revelaram que todos os biodieseis produzidos estavam dentro das normas NBR. Em relação ao rendimento, o biodiesel $70-70^{\circ} \mathrm{C}$ possui o maior rendimento de produção, 0 biodiesel $25-70^{\circ} \mathrm{C}$ possui a menor viscosidade cinemática e o biodiesel $50-50^{\circ} \mathrm{C}$ possui a maior massa específica.

PALAVRAS-CHAVE:

Biodiesel,

Biocombustível, Energia Alternativa, Biomassa.

ANALYSIS OF THE INTERFERENCE OF OIL PREHEATING AND TRANSESTERIFICATION

TEMPERATURE IN THE PHYSICOCHEMICAL

\section{CHARACTERISTICS OF BIODIESEL}

ABSTRACT: This study aims to analyze the interferences of the preheating temperature and the transesterification process, the biodiesel yield and the physical and chemical characteristics of the biodiesel produced. For this, soybean oil was used as the source of triglyceride, methanol as alcohol in the proportion of $30 \% \mathrm{~V} / \mathrm{V}$, potassium hydroxide $(\mathrm{KOH})$ as a $1 \%$ catalyst and the magnetic stirrer was used for the purpose to force the transesterification process. For the physical chemical analyzes the capillary viscometer was used to determine the kinematic viscosity and the pycnometer to verify the specific mass of the biodiesel. The results showed that all the biodiesel produced were within the NBR standards. In relation to yield, biodiesel $70-70^{\circ} \mathrm{C}$ has the highest production yield, biodiesel $25-70^{\circ} \mathrm{C}$ has the lowest kinematic viscosity and biodiesel $50-50^{\circ} \mathrm{C}$ has the highest specific mass.

KEYWORDS: Biodiesel, Biofuel, Alternative 


\section{I INTRODUÇÃO}

O primeiro motor ciclo diesel foi desenvolvido por Rudolf Diesel (1838-1913) e construído pela companhia francesa Otto no ano de 1900 para ser exposto e apresentado para a sociedade na Feira Mundial de Paris. Segundo Nitske e Wilson (1965) o motor funcionou plenamente com óleo de amendoim e funcionando tão bem, que aparentemente não houve qualquer estranheza em relação ao seu funcionamento por parte dos observadores. Isso deveu-se ao fato que o motor operou de forma idêntica aos demais motores lá expostos e que tinham como fonte de energia, outros óleos. Portanto, devido a esse fato, podemos destacar a suma importância de um estudo adequado sobre a utilização/fabricação de biodieseis de óleos vegetais em motores a diesel.

Conforme Barros (2007), a bioenergia está sendo avaliada como uma alternativa viável e promissora, em curto e médio prazo, para ocupar um maior espaço na matriz energética mundial, principalmente para atender parte das necessidades do setor de transportes. Porém, é importante também salientar que existe uma ampla gama de possibilidades de utilização dos biocombustíveis em todo o setor energético (BARROS, 2007).

O biodiesel é um biocombustível de origem renovável, que pode ser produzido a partir de diferentes fontes de matérias primas e o seu processo de produção da biodiesel demanda cuidado que refletem na sua qualidade. Assim, o biodiesel deve passar por uma série de análises que atestem sua aptidão ao uso. Propriedades físicas como a viscosidade cinemática e a massa específica influenciam na qualidade da combustão (ANGELKORTE, 2016).

O presente estudo, procura estudar a relação da viscosidade cinemática e da massa específica dos biodieseis de soja, com as temperaturas de pré-aquecimento e de produção do biodiesel no processo de transesterificação.

\section{I MATERIAL E MÉTODOS}

O estudo dividiu-se em duas etapas: a de produção do biodiesel através da transesterificação via cadeia metílica, e a caracterização físico química dos biodieseis.

Para a produção do biodiesel, variou-se o processo a fim de obter-se três diferentes tipos de biodiesel, variando primeiramente a temperatura de préaquecimento do óleo de soja e posteriormente, a temperatura durante o processo de transesterificação, conforme Tabela 1. 


\begin{tabular}{ccc}
\hline Biodiesel & Pré-Aquecimento & Transesterificação \\
\hline 1 & $50^{\circ} \mathrm{C}$ & $50^{\circ} \mathrm{C}$ \\
2 & $70^{\circ} \mathrm{C}$ & $70^{\circ} \mathrm{C}$ \\
3 & $25^{\circ} \mathrm{C}$ & $70^{\circ} \mathrm{C}$ \\
\hline
\end{tabular}

Tabela 1: Tipos de biodieseis

Fonte: Elaboração própria

O biodiesel foi produzido através de bateladas, nas quais, utilizou-se $100 \mathrm{ml}$ de óleo de soja de cozinha, pré-aquecido na estufa até estabilização, $30 \mathrm{ml}$ de metanol e $1 \%$ do catalizador hidróxido de potássio $(\mathrm{KOH})$, segundo Tomasevic e Marinkovic (2003), no Laboratório de Termociências - LATERMO - UFF.

Com o metanol no Erlenmeyer, adicionou-se o catalizador e o bastão magnético e em seguida, com o auxílio do agitador magnético, houve a dissolução dos compostos. Após esse processo, já com o óleo pré-aquecido e, novamente com o auxílio do agitador, acrescentou-se a solução metanol $+\mathrm{KOH}$ ao óleo em um processo de gotejamento, de modo a favorecer a transesterificação na temperatura adequada para cada biodiesel produzido, Figura 1. Posteriormente, esperou-se uma hora até que a reação fosse totalmente estabilizada e somente após, colocou-se a mistura no funil de bromo, de modo a permitir a separação do biodiesel e da glicerina, gerada durante a transesterificação.

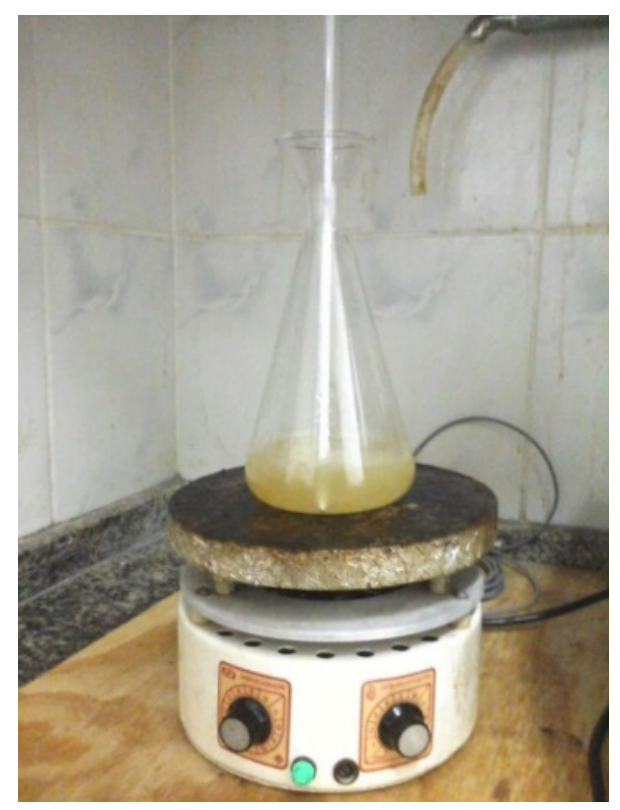

Figura 1: Processo de transesterificação Fonte: Elaboração própria

Com o intuito de assegurar uma completa separação entre as partes, aguardouse vinte e quatro horas até que o processo de separação fosse completamente estabilizado e com isso, como pode ser visto na Figura 2, a glicerina, mais densa 
do que o biodiesel, fica na parte de baixo do balão de decantação, facilitando a sua extração.

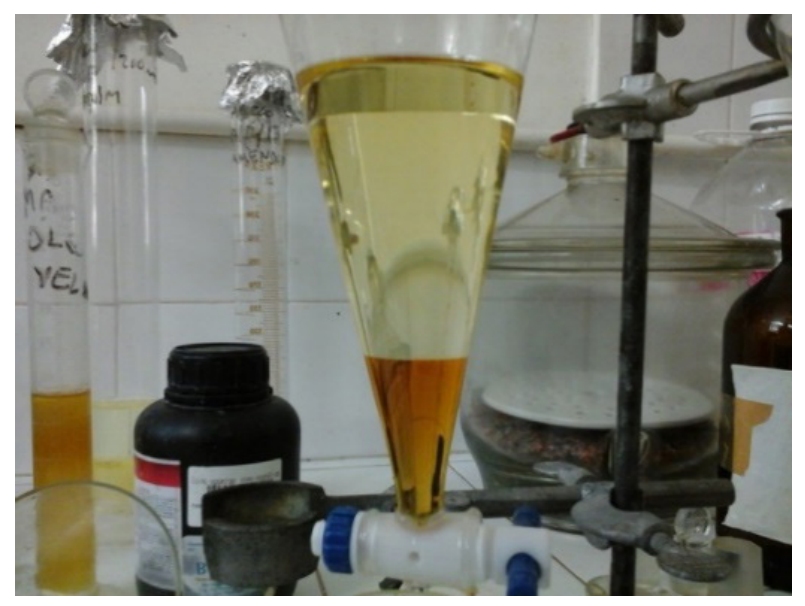

Figura 2: Processo de separação biodiesel e glicerina Fonte: Elaboração própria

Posteriormente, realizou-se a lavagem do biodiesel produzido, de modo a eliminar completamente qualquer tipo de impureza restante no mesmo. Esse processo foi realizado através de adição de água destilada e pré-aquecida a $50^{\circ} \mathrm{C}$, juntamente com gotas de $\mathrm{HCl}$ (ácido clorídrico) aguardando-se cerca de vinte minutos para haver uma completa separação das partículas de glicerina do biocombustível, Figura 3. A seguir, colocou-se o biodiesel lavado em um recipiente, indo diretamente para a estufa, onde permaneceu por duas horas a uma temperatura de $105^{\circ} \mathrm{C}$ assegurando-se que toda a água destilada e o $\mathrm{HCl}$ evaporassem.

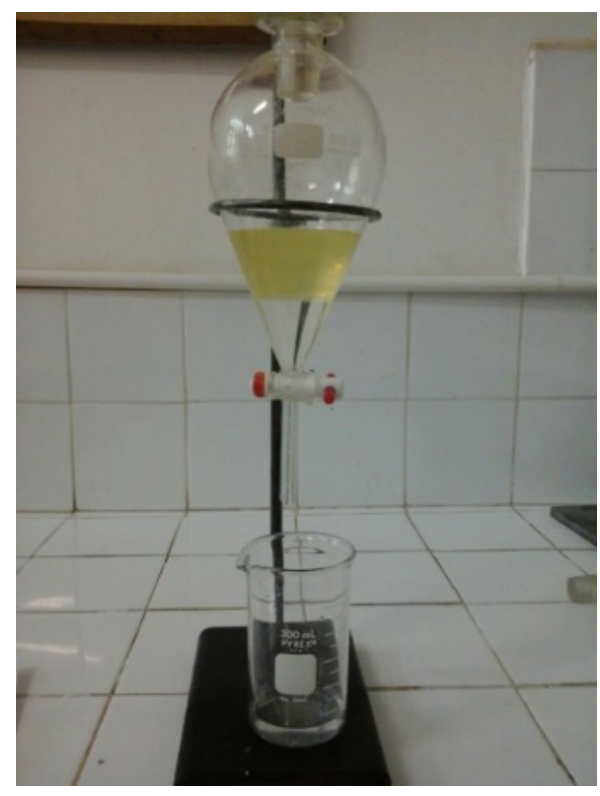

Figura 3: Processo de lavagem do biodiesel Fonte: Elaboração própria

Esse processo foi repetido por três vezes para cada tipo de biodiesel produzido, 
de forma a assegurar que houvesse uma quantidade adequada para o processo de caracterização.

E posteriormente, seguiu-se o processo de caracterização do biodiesel, no Laboratório de Reologia - LARE - UFF. O estudo priorizou o foco na determinação das diferenças entre as massas específicas e viscosidades cinemáticas dos três diferentes tipos de biodieseis produzidos.

No qual, para determinar a massa específica de cada biodiesel, utilizou-se o banho termostático, de modo a conseguir definir uma escada de temperatura por massa específica. Assim, colocou-se o biodiesel no picnômetro e ele foi preso em um suporte, Figura 4, possibilitando a submersão parcial do equipamento até que o combustível atingisse a temperatura necessária para o estudo. Após esse ponto, adotaram-se alguns métodos para o controle da temperatura no interior do picnômetro, como a verificação da temperatura da água do banho termostático, através de um termômetro digital de alta precisão e, da adição de alguns tubos de ensaio com quantidades de biocombustíveis semelhantes ao encontrado no picnômetro, novamente medindose a temperatura. Mediante essa verificação, utilizou-se uma balança analítica para determinar a massa do conjunto picnômetro + biodiesel. Repetiu-se esse procedimento cinco vezes para cada temperatura e biodiesel estudado, de forma a eliminar erros pertinentes a origem mecânica deste procedimento.

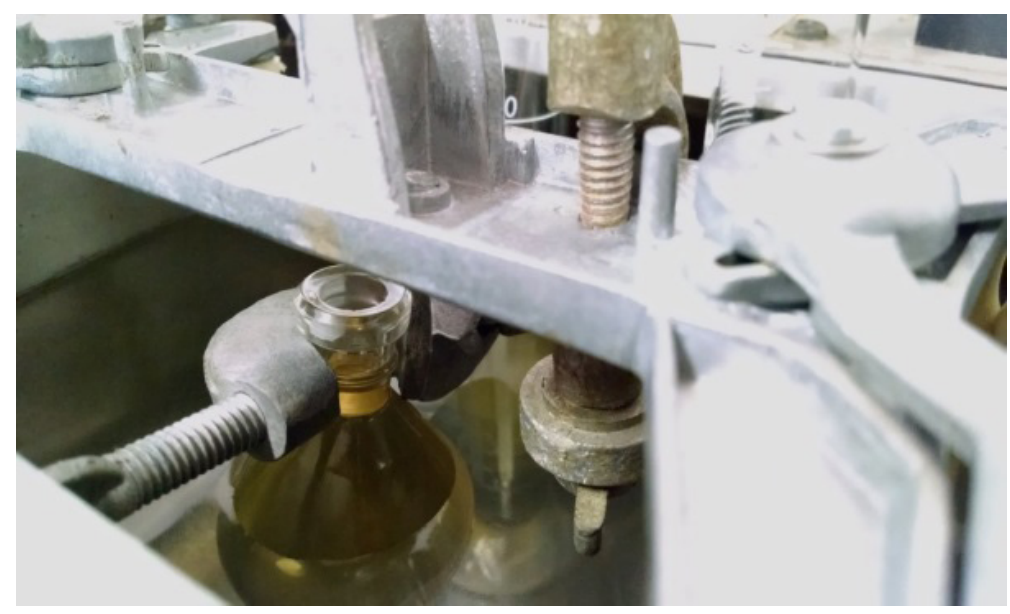

Figura 4: Resfriamento do picnômetro Fonte: Elaboração própria

Por sua vez, para determinar a viscosidade cinemática do biodiesel, utilizaram-se três viscosímetros com capilares distintos, submersos em um banho termostático com janelas para observação e verificação.

O procedimento para determinar a viscosidade cinemática dos biodieseis iniciou-se ajustando o banho termostático a uma temperatura de $40^{\circ} \mathrm{C}$ e em seguida, introduzindo uma pequena quantidade do fluido, suficiente para encher 2/3 do bulbo inferior do viscosímetro, colocando-o em submersão no banho termostático. Transcorrido o tempo para que o biocombustível chegasse à temperatura de $40^{\circ} \mathrm{C}$, 
aferiu-se mecanicamente o tempo gasto para que ele percorresse as duas marcas de controle do viscosímetro. Esse procedimento foi repetido cinco vezes para cada combustível, de modo a eliminar imprecisões óticas e mecânicas dessas medições.

\section{I RESULTADOS E DISCUSSÃO}

No processo de produção do biodiesel de soja, verificou-se que houve uma pequena melhora no rendimento quando o processo de transesterificação acontecia há uma temperatura de superior, como pode ser observado na Figura 5. Por outro lado, não foi possível observar melhoras na produção em relação ao pré-aquecimento do óleo.

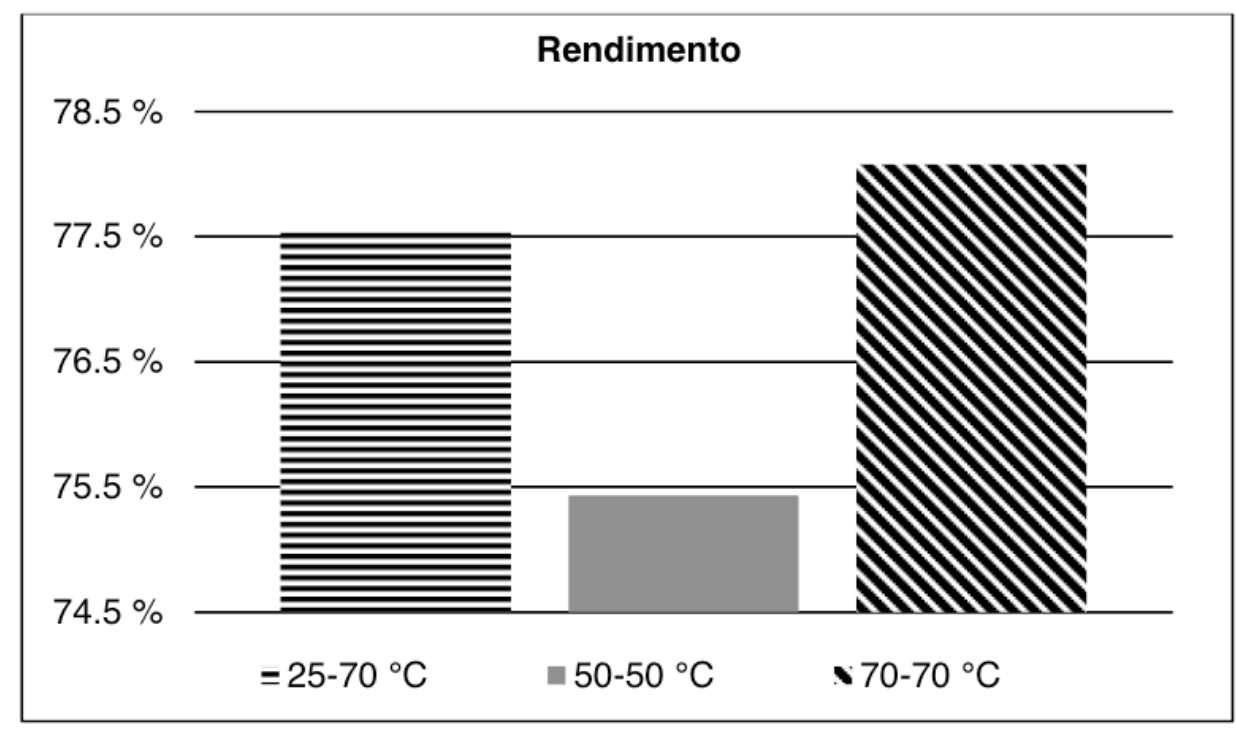

Figura 5: Gráfico do rendimento de produção

Fonte: Elaboração própria

Como pode-se observar na Tabela 2, o biodiesel que apresentou maior rendimento de produção, $78,1 \%$ da mistura óleo de soja mais metanol, foi o com pré-aquecimento a $70^{\circ} \mathrm{C}$ e produção a $70^{\circ} \mathrm{C}$, sendo o mesmo, cerca de $1 \%$ superior ao biodiesel com com pré-aquecimento a $25^{\circ} \mathrm{C}$ e produção a $70^{\circ} \mathrm{C}$ e $4 \%$ superior ao biodiesel com préaquecimento a $50^{\circ} \mathrm{C}$ e produção a $70^{\circ} \mathrm{C}$

\begin{tabular}{cc}
\hline Biodiesel & Rendimento (\%) \\
\hline $25-70{ }^{\circ} \mathrm{C}$ & 77,5641 \\
$50-50^{\circ} \mathrm{C}$ & 75,4308 \\
$70-70{ }^{\circ} \mathrm{C}$ & 78,0769 \\
\hline
\end{tabular}

Tabela 2: Rendimento de produção

Fonte: Elaboração própria

Porém, na caracterização físico-química dos biocombustíveis, observou-se que 
tanto para a análise da massa específica Figura 6, quanto para a análise da viscosidade cinemática Figura 7 , o biodiesel produzido com pré-aquecimento a $50^{\circ} \mathrm{C}$ e produção a $50^{\circ} \mathrm{C}$, possui os maiores resultados dentre todos os demais.

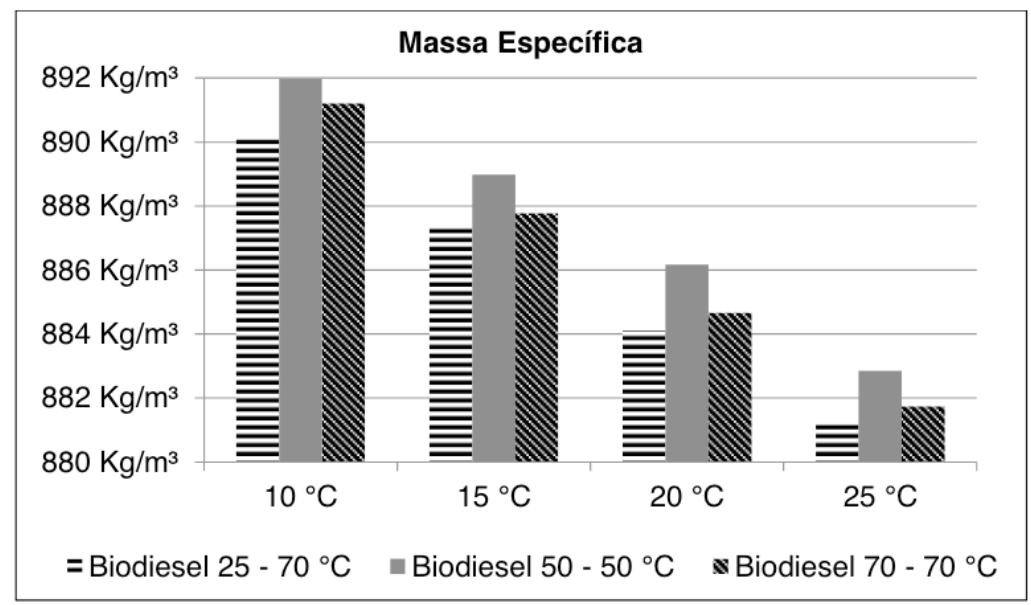

Figura 6: Gráfico da massa específica em rampa de temperatura

Fonte: Elaboração própria

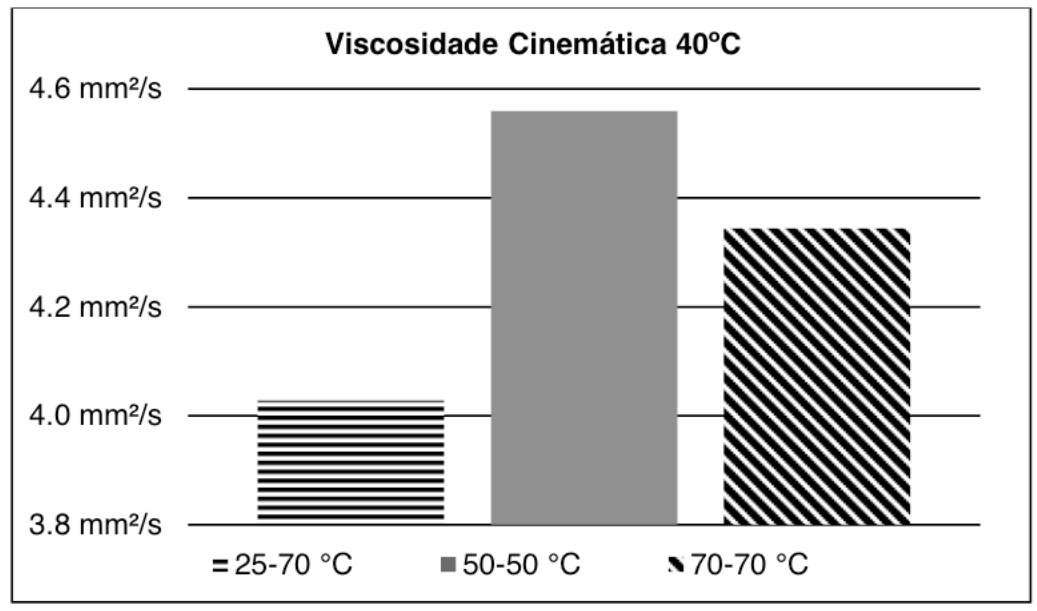

Figura 7: Gráfico da viscosidade cinemática a $40^{\circ} \mathrm{C}$ Fonte: Elaboração própria

$\mathrm{Na}$ análise da massa específica, é possível verificar que conforme o esperado houve um aumento da mesma a medida que a temperatura do banho termostático diminuiu. Chegando a haver uma variação de até $9,5 \mathrm{Kg} / \mathrm{m}^{3}$ como foi o caso do biodiesel $70-70^{\circ} \mathrm{C}$ e estando sempre na faixa de 1 a $1,1 \%$ de acréscimo na massa específica em todos os biodieseis, conforme Tabela 3 .

Biodiesel

Massa Específica $\left(\mathrm{Kg} / \mathrm{m}^{3}\right)$

$10^{\circ} \mathrm{C} \quad 15^{\circ} \mathrm{C} \quad 20^{\circ} \mathrm{C} \quad 25^{\circ} \mathrm{C}$




\begin{tabular}{rrrrr}
\hline $25-70^{\circ} \mathrm{C}$ & 890,1 & 887,3 & 884,1 & 881,3 \\
$50-50^{\circ} \mathrm{C}$ & 892,0 & 889,0 & 886,0 & 882,9 \\
$70-70^{\circ} \mathrm{C}$ & 891,2 & 887,8 & 884,7 & 881,7 \\
\hline
\end{tabular}

Tabela 3: Massa específica com rampa de temperatura

Fonte: Elaboração própria

Já na viscosidade cinémática, observa-se na Tabela 4 novamente o biodiesel 50 $50^{\circ} \mathrm{C}$ é o que possui maior valor, sendo o mesmo $13 \%$ superior ao biodiesel $25-70^{\circ} \mathrm{C}$ e $5 \%$ superior ao biodiesel $70-70^{\circ} \mathrm{C}$.

\begin{tabular}{cc}
\hline Biodiesel & Viscosidade Cinemática $\left(\mathrm{mm}^{2} / \mathrm{s}\right)$ \\
\hline $25-70{ }^{\circ} \mathrm{C}$ & 4,0280 \\
$50-50^{\circ} \mathrm{C}$ & 4,5596 \\
$70-70{ }^{\circ} \mathrm{C}$ & 4,3439 \\
\hline
\end{tabular}

Tabela 4: Viscosidade cinemática a $40^{\circ} \mathrm{C}$ Fonte: Elaboração própria

Portanto, apesar do biodiesel $25-70^{\circ} \mathrm{C}$ possuir um rendimento de produção e uma massa específica ligeiramente inferior ao biodiesel $70-70^{\circ} \mathrm{C}$, ele possui uma viscosidade cinemática $8 \%$ superior ao mesmo. Com isso, apesar do menor rendimento, esse biodiesel possui características que auxilia a haver uma melhor performance interna no motor diesel, visto que a menor viscosidade proporciona um menor desgaste e resistência ao conjunto de componentes do motor.

\section{I CONCLUSÕES}

Todos os biodieseis produzidos apresentaram um rendimento adequado de produção, sendo condizente com outros estudos já desenvolvidos anteriormente.

Em relação as características físico químicas, todos os biodieseis estão de acordo com as normas NBR 7.148, massa específica a $20^{\circ} \mathrm{C}$, e NBR 10.441 , viscosidade cinemática a $40^{\circ} \mathrm{C}$.

O presente trabalho pode determinar que existe uma relação direta com a temperatura do processo de transesterificação com o aumento do rendimento da produção do biodiesel.

Referindo-se a cada biodiesel produzido, verificou-se que cada um possui uma vantagem, o biodiesel $25-70^{\circ} \mathrm{C}$ é o que possui menor viscosidade cinemática entre todos, o que é de grande importância visto a diminuição da resistência causada pelo menos nos componentes internos do motor. Por outro lado, o biodiesel $70-70^{\circ} \mathrm{C}$ é o que possui o melhor rendimento de produção e o biodiesel $50-50^{\circ} \mathrm{C}$ apesar de ter 
menor rendimento, possui uma maior viscosidade cinemática, o que também pode ser importante para casos de trabalho em temperaturas elevadas ou em máquinas que necessitem de torque elevado, porém, ruim em climas mais frios.

\section{REFERÊNCIAS}

ANGELKORTE, G. B. Eficiência na Produção de Biodiesel a Partir de Misturas Prévias de Óleos Vegetais. Universidade Federal Fluminense, Trabalho de Conclusão de Curso, 2019.

BARROS, E. V. A matriz energética mundial e a competitividade das nações: bases de uma nova geopolítica. Engevista, v. 9 n. 1, p. 47-56, 2007.

NITSKE, W. R., WILSON, C. M. Rudolf Diesel, Pioneer of the Age of Power. University of Oklahoma Press, Norman, Oklahoma, 1965.

TOMASEVIC, A. V., MARINKOVIC, S. S. Methanolysis of used frying oils. Fuel Process Technol. Fuel Processing Technology, v.81, p. 1-6, 2003. DOI: 10.1016/S0378-3820(02)00096-6 


\section{CAPÍTULO 16}

\section{ASPECTOS BOTÂNICOS DOS ÓLEOS ESSENCIAIS}

Sebastião Gomes Silva

Universidade Federal do Pará, Programa de Pós-

Graduação em Química

Belém - Pará

Jorddy Neves da Cruz

Embrapa Amazônia Oriental

Belém - Pará

Pablo Luis Baia Figueiredo Universidade Federal do Pará, Programa de Pós-

Graduação em Química

Belém - Pará

Wanessa Almeida da Costa

Universidade Federal do Pará, LABEX - FEA

Belém - Pará

Mozaniel Santana de Oliveira Universidade Federal do Pará, LABEX - FEA

Belém - Pará

Rafael Henrique Holanda Pinto Universidade Federal do Pará, LABEX - FEA

Belém - Pará

Renan Campos e Silva Universidade Federal do Pará, Programa de Pós-

Graduação em Química

Belém - Pará

Fernanda Wariss Figueiredo Bezerra Universidade Federal do Pará, LABEX - FEA

Belém - Pará

Raul Nunes de Carvalho Junior Universidade Federal do Pará, LABEX - FEA

Belém - Pará
Eloisa Helena de Aguiar Andrade Universidade Federal do Pará, Programa de Pós-

Graduação em Química

Belém - Pará

RESUMO: Os óleos essenciais (OE's) vêm sendo utilizados pelas comunidades mundiais há séculos, em diversas áreas e para diversos fins como medicinais, aromatizantes, em perfumaria, cosméticos, inseticida, fungicida, bactericida, dentre outros. Eles são substâncias naturais e biodegradáveis, geralmente atóxicos ou com baixa toxicidade aos seres humanos. Desse modo, as constantes pesquisas nessa área representam uma alternativa de busca de novos medicamentos mais eficientes e com menores efeitos colaterais, assim como a obtenção de produtos e insumos diversos, além de serem fonte de obtenção de moléculas com grande valor agregado. Nesse sentido, este capítulo tem como objetivo descrever o aspecto botânico dos OE's.

PALAVRAS-CHAVE: óleos essenciais, aspectos botânicos, propriedades medicinais.

\section{BOTANICAL ASPECTS OF ESSENTIAL OILS}

ABSTRACT: Essential oils (EO's) have been used by the world's communities for centuries, 
in various areas and for various purposes such as medicinal, flavoring, perfumery, cosmetics, insecticide, fungicide, bactericide, among others. They are natural and biodegradable substances, generally nontoxic or with low toxicity to humans. Thus, constant research in this area represents an alternative to searching for new drugs that are more eficiente, and with less side effects, as well as the obtaining of diverse products and inputs. It is also a source of obtaining molecules with great added value. In this sense, this chapter aims to describe the botanical aspect of EO's.

KEYWORDS: essential oils, botanical aspects, medicinal properties.

\section{I INTRODUÇÃO}

Os OE's são metabólitos secundários dos vegetais, e que são biossintetizados em diferentes órgãos vegetais como botões florais, flores, folhas, caules, ramos, sementes, frutos, raízes, ou casca de madeira e armazenados em células secretoras, cavidades, canais, células epidérmicas ou tricomas glandulares. Os constituintes voláteis de todos esses órgãos vegetais podem ser extraídos através de vários métodos como: enfloração, extração com solvente orgânico, por prensagem, $\mathrm{CO}_{2}$ supercrítico e arraste a vapor de água (um dos mais utilizados) (El Asbahani et al., 2015; Bakkali et al., 2008; Baser e Buchbauer, 2015).

Esses métodos podem variar de acordo com a finalidade da utilização dos constituintes voláteis, localização do óleo na planta e quantidade de material vegetal disponível (El Asbahani et al., 2015; Bakkali et al., 2008; Baser e Buchbauer, 2015).

As diversas propriedades dos OE's podem ser atribuídas a uma mistura complexa formada sobretudo por monoterpenos, sesquiterpenos e seus derivados oxigenados (álcoois, aldeídos, ésteres, cetonas, fenóis e óxidos) (Bakkali et al., 2008; Baser e Buchbauer, 2015; Ahl Hahs et al., 2015).

Existe atualmente um grande interesse de diversas áreas pelos OE's por seus altos valores agregados, por possuírem muitas atividades biológicas e por serem um produto de origem natural, logo biodegradável e renovável ajudando assim com a preservação do meio ambiente.

Desse modo, o presente capítulo tem como objetivo descrever os aspectos botânicos dos OE's.

\section{I FUNÇÕES DOS ÓLEOS ESSENCIAIS NOS VEGETAIS}

Os OE's são produtos do metabolismo secundário de vegetais que atuam como mecanismo de proteção e resistência a fatores ambientais aumentando sua capacidade de sobrevivência (Kennedy e Wightman, 2011). No entanto, durante muitos anos os OE's foram relatados como desperdício fisiológico ou como produtos de desintoxicação do metabolismo secundário dos vegetais. No texto de Julius Sachs (1873), os metabólitos secundários foram definidos pela primeira vez como 
"co-produtos" do metabolismo vegetal, sem qualquer benefício conhecido para o metabolismo primário da planta. Os termos "metabolismo primário" e "metabolismo secundário", até então conhecidos respectivamente como "inner economy" e "byproducts", foram introduzidos pela primeira vez em 1891 por Albrecht Kossel (Hartmann, 2007; Sachs, 1873)

Os OE's são misturas complexas de compostos voláteis sintetizados em diversos órgãos da planta e são armazenados em células secretoras, cavidades, canais, células epidérmicas ou tricomas glandulares. Nos vegetais, tais misturas atuam como agentes antibacterianos, antivirais, antifúngicos, e inseticidas, atraindo alguns insetos que agem na dispersão de pólens e sementes; repelindo insetos, moluscos, e/ou vertebrados que trazem prejuízos; também agem na sinalização envolvida na comunicação plantaplanta; e além disso, há relatos que os compostos orgânicos voláteis liberados pelas plantas podem regular a capacidade oxidativa da troposfera em relação ao monóxido de carbono, ozônio e aerossóis (Maffei et al., 2011), além de proteger o vegetal da perda de água e do aumento de temperatura (Baser e Buchbauer, 2015).

Estudos relatam a atividade alelopática de OE's associada à sua composição química, namaioria das vezes, predominante emterpenoides lipofílicos, fenilpropanoides ou derivados de hidrocarbonetos alifáticos de cadeia curta, que operam na inibição da via citrocômica da respiração através do bloqueio do ciclo do nitrogênio ou inibindo a germinação e elongação de sementes de plantas. Desta forma, ressalta-se a sua importância no desenvolvimento de produtos agroquímicos utilizando fontes naturais (Maffei et al., 2011).

\section{I ÓRGÃOS VEGETAIS EM QUE SE ENCONTRAM OE'S E AS ORGANELAS RESPONSÁVEIS POR ARMAZENAR ESSES CONSTITUINTES VOLÁTEIS}

As plantas são capazes de sintetizar, armazenar e/ou expelir diversos tipos de secreções. As secreções produzidas pelas plantas podem variar desde soluções mais simples, compostas basicamente por açúcares, sais e aminoácidos, até soluções mais complexas (Rojas et al., 2014). No metabolismo primário, são produzidos basicamente macromoléculas como proteínas e polissacarídeos que irão desempenhar funções essenciais à sobrevivência do vegetal. Enquanto que no metabolismo secundário, são produzidas misturas complexas formadas por dezenas de compostos químicos de diferentes classes como alcaloides, terpenoides, glicosídeos, dentre outros e que irão desempenhar funções de proteção contra o ataque de patógenos, alelopatia, atração de agentes polinizadores, etc. (Rojas et al., 2014).

Os OE's são líquidos concentrados contendo compostos aromáticos voláteis que possuem diferentes propriedades físico-químicas e que podem ser armazenados em órgãos fora da planta (papilas, por exemplo) e dentro da planta (células secretoras, canais secretores e bolsas secretoras) (El Asbahani et al., 2015). Deve-se levar em 
consideração que o tempo de crescimento do órgão, período de colheita e outros fatores bióticos e abióticos podem influenciar significativamente na produção, rendimento e composição química do OE (Moghaddam e Mehdizadeh, 2017).

O OE pode ser obtido de diferentes órgãos da mesma planta, como: raízes, flores, casca e caule. Nessa seção iremos abordar uma breve descrição morfológica desses órgãos.

\subsection{Raízes}

A raiz é formada a partir do meristema apical do embrião e nesse estágio de desenvolvimento geralmente a raiz é denominada de raiz primária. Após o seu desenvolvimento, as raízes podem ser classificadas, de acordo com um sistema radicular, em raiz pivotante ou axial que são características de dicotiledôneas e gimnospermas; e raiz fasciculada encontrada em monocotiledôneas (Figura 1) (Liu et al., 2018).

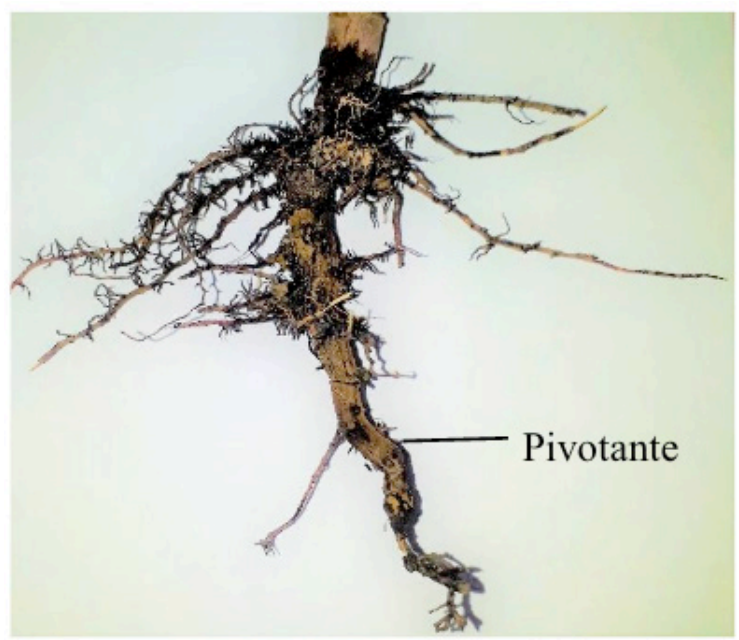

(a)

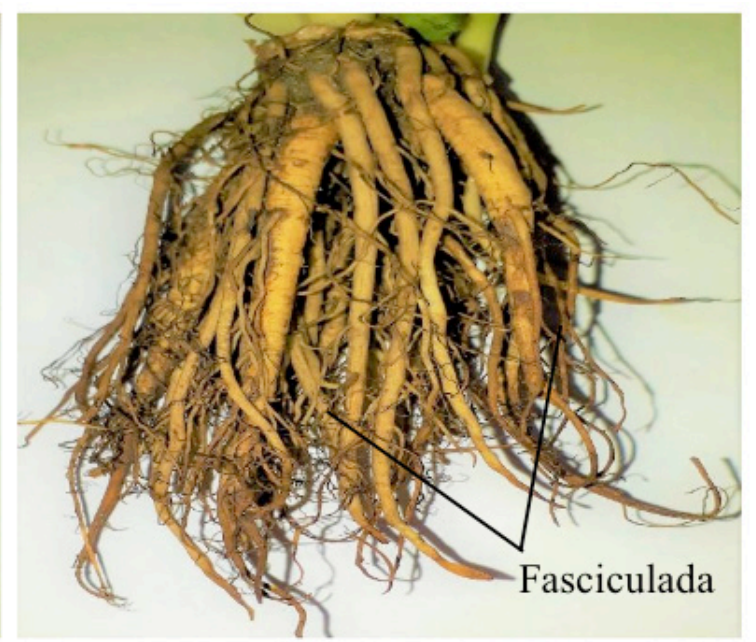

(b)

Figura 1. Imagem esquemática de raízes vegetais. (a) Raiz pivotante e (b) raiz fasciculada.

As raízes são estruturas que podem ser aquáticas, subterrâneas ou aéreas; e também são responsáveis pela absorção e condução de água e nutrientes, reserva de substâncias como amido, além de realizarem a fixação da planta (Kim et al., 2019).

$\mathrm{Na}$ morfologia externa das raízes, pode-se identificar as seguintes estruturas: colo, raiz primária, raiz secundária, zona pilífera, zona lisa e coifa, sendo o colo a parte de transição entre raiz e caule. Da raiz primária surgem as ramificações ou raízes secundárias; a zona pilífera é composta por pelos que vão absorver água e sais minerais do solo que irão compor a seiva; zona lisa corresponde a parte em que ocorre o alongamento vertical e consequente crescimento da raiz; a coifa é a estrutura protetora da ponta da raiz (Sattler e Rutishauser, 1997).

A composição química do OE pode variar de acordo com o órgão utilizado para obtê-lo. Vukovic et al. (2009) investigaram as diferenças na composição química 
do OE de Ballota nigra, extraído das raízes, caules e folhas, utilizando análises de cromatografia gasosa/espectrometria de massa (CG/EM). O óleo encontrado nos caules e folhas demonstrou ser rico em sesquiterpeno, tendo como compostos majoritários o $\beta$-cariofileno, germacreno $D$ e a-humuleno. Em contraste, o OE obtido da raiz apresentou, como componentes majoritários, o p-vinilguiacol, borneol e mirtenol.

\subsection{Folhas}

A folha é o órgão vegetal responsável pela fotossíntese, transpiração, trocas gasosas e atração de agentes polinizadores. Sua estrutura, em grande maioria, é laminar e de cor esverdeada devido a presenta de clorofila, pigmento fotorreceptor no processo de fotossíntese (Terashima et al., 2011).

As folhas são constituídas por: a) tecidos que formam o sistema dérmico e que revestem toda a estrutura da folha. Aí pode-se destacar a presença de células que compõem o tricoma e os estômatos; b) sistema fundamental que compõe o mesófilo da lamina foliar e o córtex da nervura mediana; e c) o sistema vascular composto pelo xilema, tecido condutor de água, nutrientes e sais minerais, e floema responsável pelo transporte de seiva elaborada (Lawson e Vialet-Chabrand, 2019).

Os tricomas localizados na epiderme das folhas podem ou não produzir substâncias. Os tricomas glandulares secretam OE's que são utilizados para finalidades medicinais, mas que também são capazes de auxiliar a planta na sua proteção contra patógenos e herbívoros. A estrutura do tricoma glandular é semelhante à de um fio de cabelo em que na ponta pode-se encontrar o local de armazenamento das substâncias (Figura 2) (Kim, 2018).
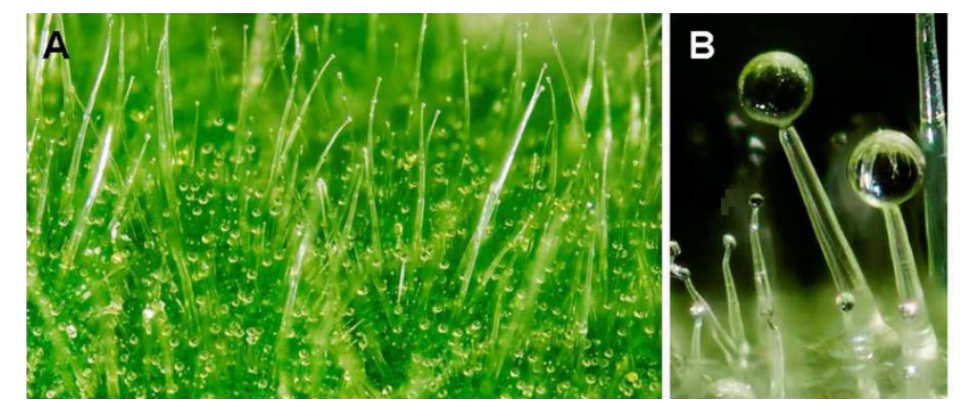

Figura 2. Tricomas glandulares de $S$. habrochaites. (a) Superfície da folha e (b) Zoom na estrutura do tricoma glandular. Adaptado de Glas et al. (2012).

A extração de OE dos tricomas é relativamente fácil. Dessa maneira, a análise detalhada das moléculas que compõem a mistura, das proteínas envolvidas na síntese, da excreção dos compostos e também dos genes envolvidos ficaram relativamente fáceis. Assim, diversos grupos de pesquisas têm direcionado seus esforços para compreender esses mecanismos (Glas et al., 2012).

Barbosa et al. (2007) apontaram que os tricomas glandulares e não glandulares da Climedia sp. conferem à planta maior defesa contra herbívoros. Os tricomas 
glandulares protegem a estrutura foliar ao produzirem OE, que devido sua viscosidade, dificulta a locomoção e tempo de permanência do inseto na superfície da folha. Os tricomas não glandulares funcionam como uma barreira mecânica que dificulta a penetração de pequenos herbívoros para os tecidos mais internos das folhas.

Oliveira et al. (2019) avaliaram as propriedades antioxidantes, capacidade de inibição da acetilcolinesterase in vitro e in silico do OE extraído das folhas de Piper divaricatum utilizando $\mathrm{CO}_{2}$ supercrítico. O óleo apresentou boa capacidade antioxidante e bom efeito de inibição da acetilcolinesterase in vitro. As interações dos compostos majoritários do óleo ( $\beta$-elemeno, eugenol, acetato de eugenila e metil eugenol) foram avaliadas in silico usando docagem molecular, simulações de dinâmica molecular e cálculos de energia livre. Os resultados demonstraram que os compostos majoritários foram capazes de interagir com resíduos catalíticos da acetil que são essenciais para sua inibição.

\subsection{Flores}

As flores desempenham funções de proteção e reprodução, sendo estruturas que surgiram evolutivamente no grupo das angiospermas. Sua distribuição nas plantas pode ocorrer de maneira isolada ou estarem agrupadas formando inflorescências. As flores são formadas por uma estrutura central que serve de suporte, o pedicelo, de onde surge uma porção dilatada chamada de receptáculo formado por sépalas, pétalas, estames e carpelos (Figura 3) (Melzer et al., 2010).

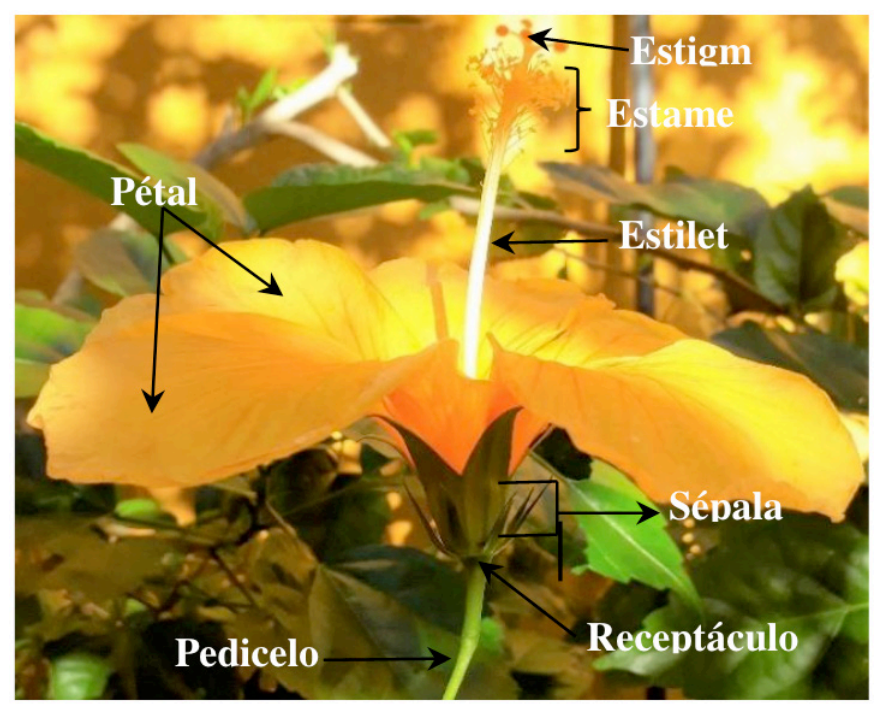

Figura 3. Morfologia esquemática de uma flor.

Devido as flores serem sensíveis ao calor, perda de umidade e outros fatores ambientais, elas necessitam de operações de manejo pós-colheita adequadas para sua conservação. Além disso, a vida pós-colheita das flores é influenciada por características de cada espécie como fatores genéticos e químicos, plantio e irrigação. Devido a isso, a indústria da floricultura enfrenta um grande problema com a vida de prateleira ou duração flores ornamentais usadas em decorações de eventos como 
casamentos e funerais. Atualmente, para prolongar o tempo de vida dessas flores alguns pesquisadores têm sugerido a utilização de OE para sua conservação, pois esses óleos apresentam propriedades antimicrobianas (Schneider et al., 2003; Tanko et al., 2005)

Shanan et al. (2010) utilizaram OE para prolongar a vida de prateleira de flores de Dianthus caryophyllus L.: Farida e Madam Collate. Em seus experimentos foram usados os óleos extraídos de tangerina, coentro, endro e cravo, além de dois cultivares tratados com água e 8-Hidroxiquinolina (8-HQ) como controles. A captação liquida de água pelas flores, importante para o desenvolvimento e manutenção da planta, foi avaliado após a planta ser mantida em solução contendo OE. Os maiores aumentos na captação de água foram observados nas plantas tratadas com os óleos de endro e cravo. Os pesquisadores puderam observar que há estreita relação entra a captação líquida de água e o tempo de prateleira, pois as plantas que tiveram sua capacidade de captação de água aumentada puderam sobreviver mais tempo em vaso. Também foi possível observar que os OE diminuíram a quantidade de bactérias formadoras de esporos. Os melhores resultados foram obtidos para óleo de endro, enquanto que as plantas que foram tratadas apenas com água de torneira tiveram a maior quantidade de bactérias formadoras de esporos. Os endro, cravo e coentro também foram capazes de diminuir a quantidade de decompositores de celulose, o que resultou no aumento da densidade de flores comparado às plantas do grupo controle tratadas com água de torneira.

Outro processo em que os OE's podem ser úteis é para auxiliar na polinização das plantas superiores. A polinização consiste na transferência de células reprodutivas de uma planta para outra, desempenhando um papel crítico para o sucesso da evolução de diversas espécies vegetais. Alguns animais participam desse processo como agentes polinizadores, sendo responsáveis pelo transporte de pólen. Para atrair com maior sucesso os agentes polinizadores muitas espécies vegetais produzem OE em diferentes órgãos florais como pétalas, sépalas, nectários e outros. A combinação dos compostos presente nos OE's produzidos nesses órgãos é o que confere à planta suas fragrâncias características (Cseke et al., 2007).

\subsection{Fruto}

Alguns frutos são formados somente do ovário da flor, após seu processo de fecundação e amadurecimento, contudo suas origens podem ser mais diversificadas havendo o envolvimento, durante as etapas de formação, de partes das flores, como estames, sépalas, pétalas e pedúnculo. Algumas espécies, mesmo sem fecundação, dão origem a frutas, mas sem sementes, sendo chamados de partenocárpicos (Van der Knaap e Østergaard, 2018).

$\mathrm{Na}$ composição do fruto podemos identificar o pericarpo e as sementes. $\mathrm{O}$ pericarpo é a parte comestível do fruto que envolve toda a semente auxiliando em seu desenvolvimento e proteção. O tegumento, camada mais externa da semente, 
envolve o embrião e o endosperma, que vai fornecer nutrientes durante a germinação do embrião. O pericarpo é divido em três camadas: epicarpo ou casca, camada mais externa; mesocarpo, camada mediana; e endocarpo, camada mais interna (Figura 4) (Dardick e Callahan, 2014).

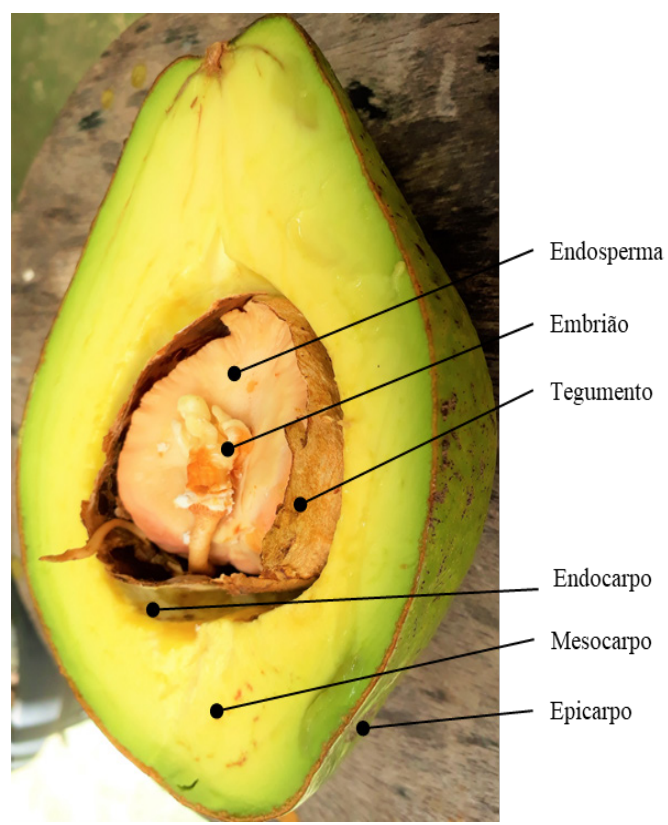

Figura 4. Imagem esquemática de um fruto com a representação das partes que o compõem.

O OE de frutas cítricas é obtido principalmente a partir do epicarpo ou casca usando tradicionalmente o método prensagem a frio. $O$ óleo armazenado em sacos ou glândulas, que estão distribuídos em diferentes profundidades da casca, são extraídos mecanicamente pela prensagem a frio formando uma emulsão aquosa que é levada ao centrifugador para separar o OE das demais substâncias (Ferhat et al., 2007).

As cascas de frutas também podem ser submetidas a processos de destilação sendo expostas a água fervente ou vapor para que sejam liberados os compostos voláteis. O vapor carregado de OE, ao percorrer as tubulações do condensador, vai liquefazer e ser depositado num frasco coletor. Devido a imiscibilidade do óleo e da água, a recuperação do OE é facilitada, pois o óleo sendo menos denso que água vai formar uma mistura heterogênea que estará flutuando sobre a água (Lucchesi et al., 2004).

Alternativamente aos métodos tradicionais estão sendo usadas as técnicas de extração por fluido supercrítico, extração por ultrassom, extração com água subcrítica, processo controlado de queda de pressão e extração por micro-ondas para obter o $\mathrm{OE}$ de frutas cítricas. A vantagem dessas técnicas está intimamente relacionada à qualidade do óleo extraído, maior volume de OE produzido e diminuição do consumo energético. Além disso, não degradam alguns compostos voláteis devido ao uso de altas temperaturas como ocorre no processo de destilação a vapor.

Ferhat et al. (2007) compararam a utilização dessas três técnicas para obter OE de cascas de frutas cítricas frescas. O método de destilação acelerada por 
micro-onda (DAM) foi o que apresentou menor tempo extração (30 m), enquanto que a hidrodestilação (HD) foi o processo mais demorado $(3 \mathrm{~h})$. A prensagem a frio (PF) apresentou tempo intermediário entre essas técnicas de 1 hora. Os melhores rendimentos foram encontrados, respectivamente, para micro-ondas $(0,24 \%)$, hidrodestilação $(0,21 \%)$ e prensagem a frio (0,05\%). Ao comparar o tempo de extração com o rendimento, a técnica de micro-ondas possui impacto ambiente menor quando comparada às técnicas de hidrodestilação e prensagem a frio. Adicionalmente, a extração assistida por micro-ondas pode ser considerada limpa, pois não há geração de resíduos e não consome solventes orgânicos e água. Nos três métodos, os monoterpenos foram majoritários (DAM: 86.03\%; HD: 92.23\%; PF: 95.37\%), sendo seguido pelos monoterpenos oxigenados (DAM: 3.93\%; HD: 4.53\%; PF: $2.00 \%$ ) e sesquiterpenos (DAM: 1.59\%; HD: 1.15\%; PF: 1.61\%). O limoneno foi o composto que esteve em maior quantidade nos OE's obtidos (DAM: 69.65\%; HD: $72.90 \%$; PF: $75.68 \%)$.

\subsubsection{Caule}

O caule sustenta as folhas e os órgãos de reprodução do vegetal, além de realizar, por meio de vasos condutores, o transporte de seiva bruta e elaborada da raiz para o topo da planta e vice-versa. Na Figura 5 podemos observar as partes que formam o caule, como: gema auxiliar que origina a folha; entrenó, região que está localizada entre dois nós; nó, que pode dar origem à folha; flor ou ramificação do caule; e gema terminal responsável pelo crescimento do vegetal (Nadezhdina, 2010).

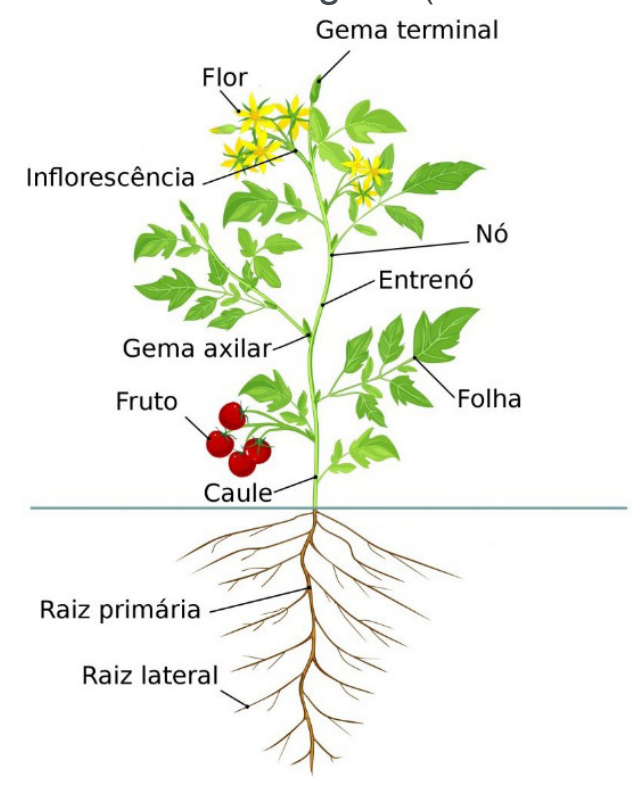

Figura 5. Representação esquemática do caule e seus componentes.

Diferentes métodos de extração têm sido aplicados para obter OE do caule de diferentes plantas. Oladipupo e Adebola (2009) compararam a composição química do OE de Senecio polyanthemoides coletada em duas localidades diferentes da cidade 
de uMhlathuze (Província de KwaZulu-Natal - África do Sul). Os compostos foram isolados por hidrodestilação a partir do caule e analisados por CG e CG/EM. Nas duas amostras, os componentes monoterpenoides foram predominantes, apesar de haver diferenças na porcentagem de cada composto presente na fração total do óleo das amostras. Na amostra A, quantidade total de monoterpenoides correspondeu a $85.3 \%$, enquanto que na amostra $B$ o resultado foi de $71.6 \%$.

Hung et al. (2019) avaliaram o potencial larvicida do óleo das espécies Erechtites hieraciifolius e Erechtites valerianifolius como alternativa ao uso de herbicidas para o combate de mosquitos vetores de doenças. As partes aéreas da planta envolvendo caule, flor e folha foram colhidas no distrito de Dong Giang eHoa Vang (Vietnam). O óleo foi obtido por hidrodestilação e sua composição química foi avaliada usando CG/EM. Na espécie E. hieraciifolius foram encontrados os compostos a-pineno (14.5\%), limoneno (21.4\%) e óxido de cariofileno (15.1\%) como majoritários; enquanto que na espécie E. valerianifolius, os majoritários foram mirceno (47.8\%) e a-pineno (30.2\%). Os OE's das duas espécies apresentaram atividade larvicida contra Aedes aegypti e Aedes albopictus, vetores da dengue, zika, febre amarela e chikungunya. Adicionalmente o óleo de E. valerianifolius apresentou boa atividade contra larvas do mosquito Culex quinquefasciatus, vetor da filariose.

\section{REFERÊNCIAS}

AHL HAHS, A., ABBAS, Z.K., SABRA, A.S., TKACHENKO, K.G. Essential Oil Composition of Hyssopus Officinalis L . Cultivated in Serbia. Int J Plant Res 1:49-53.2015

BAKKALI, F., AVERBECK, S., AVERBECK, D., IDAOMAR, M. Biological effects of essential oils-a review. Food and chemical toxicology, 46(2), pp.446-475. 2008.

BARBOSA, J.M., GOEDERT, D., SANTOS, M.B., LOIOLA, M., MARTINS, T.K. Tricomas glandulares conferem defesa contra herbivoria em Clidemia sp. (Melastomataceae). Livro do curso de campo "Ecologia da Mata Atlântica"(G. Machado \& PIKL Prado, eds.). Universidade de São Paulo, São Paulo. 2010.

Baser, K.H.C., Buchbauer, G. Handbook of essential oils: science, technology, and applications. CRC press. 2015.

CSEKE, L.J., KAUFMAN, P.B., KIRAKOSYAN, A. The biology of essential oils in the pollination of flowers. Natural Product Communications, 2(12), p.1934578X0700201225. 2007.

DARDICK, C., CALLAHAN, A.M. Evolution of the fruit endocarp: molecular mechanisms underlying adaptations in seed protection and dispersal strategies. Frontiers in plant science, 5, p.284. 2014.

EL ASBAHANI, A., MILADI, K., BADRI, W., SALA, M., ADDI, E.A., CASABIANCA, H., EL MOUSADIK, A., HARTMANN, D., JILALE, A., RENAUD, F.N.R., ELAISSARI, A. Essential oils: from extraction to encapsulation. International journal of pharmaceutics, 483(1-2), pp.220-243. 2015.

FERHAT, M.A., MEKLATI, B.Y., CHEMAT, F. Comparison of different isolation methods of essential oil from Citrus fruits: cold pressing, hydrodistillation and microwave 'dry'distillation. Flavour and Fragrance Journal, 22(6), pp.494-504. 2007. 
GLAS, J., SCHIMMEL, B., ALBA, J., ESCOBAR-BRAVO, R., SCHUURINK, R., KANT, M. Plant glandular trichomes as targets for breeding or engineering of resistance to herbivores. International journal of molecular sciences, 13(12), pp.17077-17103. 2012.

HARTMANN, T. From waste products to ecochemicals: fifty years research of plant secondary metabolism. Phytochemistry, 68(22-24), pp.2831-2846. 2007.

HUNG, N.H., SATYAL, P., HIEU, H.V., CHUONG, N.T.H., DAI, D.N., HUONG, L.T., TAI, T.A., SETZER, W.N. Mosquito Larvicidal Activity of the Essential Oils of Erechtites Species Growing Wild in Vietnam. Insects, 10(2), p.47. 2019

KENNEDY, D.O., WIGHTMAN, E.L. Herbal extracts and phytochemicals: plant secondary metabolites and the enhancement of human brain function. Advances in Nutrition, 2(1), pp.32-50. 2011.

Kim, K.W. Plant trichomes as microbial habitats and infection sites. European Journal of Plant Pathology, pp.1-13. 2018.

KIM, Y.X., RANATHUNGE, K., LEE, S., LEE, Y., LEE, D., SUNG, J. Composite transport model and water and solute transport across plant roots: An update. Frontiers in plant science, 9, p.193. 2018. 2019.

LAWSON, T., VIALET-CHABRAND, S. Speedy stomata, photosynthesis and plant water use efficiency. New Phytologist, 221(1), pp.93-98.

LIU, Y., WANG, G., YU, K., LI, P., XIAO, L., LIU, G. A new method to optimize root order classification based on the diameter interval of fine root. Scientific reports, 8(1), p.2960. 2018.

LUCCHESI, M.E., CHEMAT, F., SMADJA, J. Solvent-free microwave extraction of essential oil from aromatic herbs: comparison with conventional hydro-distillation. Journal of Chromatography A, 1043(2), pp.323-327. 2004.

MAFFEI, M.E., GERTSCH, J., APPENDINO, G. Plant volatiles: production, function and pharmacology. Natural product reports, 28(8), pp.1359-1380. 2011.

MELZER, R., WANG, Y.Q., THEIBEN, G. February. The naked and the dead: the ABCs of gymnosperm reproduction and the origin of the angiosperm flower. In Seminars in cell \& developmental biology (Vol. 21, No. 1, pp. 118-128). Academic Press. 2010.

MOGHADDAM, M., MEHDIZADEH, L. Chemistry of Essential Oils and Factors Influencing Their Constituents. In Soft chemistry and food fermentation (pp. 379-419). Academic Press. 2017.

NADEZHDINA, N. Integration of water transport pathways in a maple tree: responses of sap flow to branch severing. Annals of Forest Science, 67(1), p.107. 2010

OLADIPUPO, L., ADEBOLA, O. Chemical composition of the essential oils of the flowers, leaves and stems of two Senecio polyanthemoides Sch. Bip. samples from South Africa. Molecules, 14(6), pp.2077-2086. 2009.

OLIVEIRA, M.S., CRUZ, J.N., SILVA, S.G., COSTA, W.A., SOUSA, S.H.B., BEZERRA, F.W.F., TEIXEIRA, E., SILVA, N.J.N., ANDRADE, E.H.A., NETO, A.M.D.J.C., Carvalho Junior, R.N. Phytochemical profile, antioxidant activity, inhibition of acetylcholinesterase and interaction mechanism of the major components of the Piper divaricatum essential oil obtained by supercritical CO2. The Journal of Supercritical Fluids, 145, pp.74-84. 2019.

ROJAS, C.M., SENTHIL-KUMAR, M., TZIN, V., MYSORE, K. Regulation of primary plant metabolism during plant-pathogen interactions and its contribution to plant defense. Frontiers in 
SACHS, J. Lehrbuch der botanik. W. Engelmann, Leipzig, 1873.

SATTLER, R., RUTISHAUSER, R. The fundamental relevance of morphology and morphogenesis to plant research. Annals of Botany, 80(5), pp.571-582. 1997.

SCHNEIDER, S.M., ROSSKOPF, E.N., LEESCH, J.G., CHELLEMI, D.O., BULL, C.T., MAZZOLA, M. United States Department of Agriculture-Agricultural Research Service research on alternatives to methyl bromide: pre-plant and post-harvest. Pest Management Science: formerly Pesticide Science, 59(6-7), pp.814-826. 2003

SHANAN, T.N., EMARA, K.S., BARAKAT, S.O. Prolonging vase life of carnation flowers using natural essential oils and its impact on microbial profile of vase solutions. Australian Journal of Basic and Applied Sciences, 4(8), pp.3559-3574. 2010.

TANKO, H., CARRIER, D.J., DUAN, L., CLAUSEN, E. Pre-and post-harvest processing of medicinal plants. Plant Genetic Resources, 3(2), pp.304-313. 2005

TERASHIMA, I., HANBA, Y.T., THOLEN, D., NIINEMETS, Ü. Leaf functional anatomy in relation to photosynthesis. Plant Physiology, 155(1), pp.108-116. 2011.

VAN DER KNAAP, E., ØSTERGAARD, L. Shaping a fruit: Developmental pathways that impact growth patterns. In Seminars in cell \& developmental biology (Vol. 79, pp. 27-36). Academic Press. 2018

VUKOVIC, N., SUKDOLAK, S., SOLUJIC, S., NICIFOROVIC, N. Antimicrobial activity of the essential oil obtained from roots and chemical composition of the volatile constituents from the roots, stems, and leaves of Ballota nigra from Serbia. Journal of medicinal food, 12(2), pp.435-441. 2009. 


\section{CAPÍTULO 17}

\section{ESTUDO DOS EFEITOS DAS VARIÁVEIS DE IMPRESSÃO 3D POR EXTRUSÃO SOBRE AS PROPRIEDADES MECÂNICAS DO ÁCIDO POLILÁTICO (PLA) OBTIDAS POR INTERMÉDIO DE ENSAIO DE TRAÇÃO}

Camila Colombari Bomfim Faculdade Anhanguera, Polo Franca

Franca - São Paulo

Antônio Carlos Marangoni Universidade do Estado de Minas Gerais, Unidade Frutal

Frutal - Minas Gerais

Rafael Junqueira Marangoni Universidade de São Paulo, Campus São Carlos São Carlos - São Paulo

RESUMO: Devido à sucessiva implementação das tecnologias que cingem as impressoras 3D, tal ferramenta tem deixado de ser utilizada apenas como um meio de prototipagem rápida, fazendo-se uma importante forma de manufatura. Quando um objeto construído por uma impressora 3D torna-se um elemento de utilização imediata em um equipamento, é necessário conhecer as propriedades mecânicas finais do material quando submetido ao processo de prototipagem rápida, pois 0 conhecimento das propriedades mecânicas de um material é fundamental para estabelecer quais são os limites de resistência à qual aquele objeto pode ser submetido. Tais impressoras utilizam, em sua maioria, polímeros como material de impressão por extrusão, ou seja, o material fundido é depositado, filamento após filamento, atéque o objeto seja construído. Nesse sentido, o projeto analisa, por intermédio de análises estatísticas dos resultados de ensaios mecânicos de tração, realizados segundo as normas da American Society for Testing and Materials (ASTM), quais são as propriedades mecânicas do polímero Ácido Polilático (PLA), quando são alterados o diâmetro do filamento de impressão e a composição da estrutura interna do corpo de prova, mantendo-se a densidade constante à noventa por cento.

PALAVRAS-CHAVE: ácido polilático, ensaio de tração, propriedades mecânicas, prototipagem rápida.

\section{STUDY OF THE EFFECTS OF THE}

$$
\text { VARIABLES OF 3D PRINTING BY }
$$

EXTRUSION ON THE MECHANICAL

\section{PROPERTIES OF POLYLATIC ACID (PLA) \\ OBTAINED BY TRATION TEST}

ABSTRACT: Due to the successive implementation of technologies that surround 3D printers, this tool has stopped being used only as a mean of rapid prototyping, and has becoming an important form of manufacturing. When an object constructed by a 3D printer becomes an element of immediate use in an equipment, it is necessary to know the final mechanical properties of the material when submitted to the process, because the 
knowledge of the mechanical properties of a material is fundamental to establish the limits of resistance that an object can be submitted. Most printers use polymers as extrusion-printing material, what means that the molten material is deposited, filament after filament, until the object is constructed. Due to the exposed, the project analyzes the mechanical properties of the Polylactic Acid (PLA) polymer by means of statistical analyzes of the results of mechanical tensile tests carried out according to the standards of the American Society for Testing and Materials (ASTM), when the diameter of the printing filament and the composition of the internal structure of the specimen are changed, and the density remaining constant at ninety percent.

KEYWORDS: mechanical properties, polylactic acid, rapid prototyping, tration test.

\section{I INTRODUÇÃO}

Para elaborar um projeto, é primordial a análise das propriedades mecânicas do material a ser utilizado. A seleção do material correto leva em consideração o aspecto econômico e as condições de trabalho ao qual o projeto será submetido, uma vez que são essas condições que impõem quais propriedades mecânicas o material deve possuir, para que a deformação não seja excessiva e não ocorra fratura (CALLISTER JÚNIOR; RETHWISCH, 2012).

De acordo com Donald R. Askeland e Pradeep P. Phulé (2008), as propriedades mecânicas dependem da composição interna da peça e de sua composição química, e são determinadas, segundo Cassu e Felisbert (2005) a partir de uma solicitação constante e monitorada feita no material, como o ensaio mecânico de tração.

O ensaio de tração consiste na aplicação de uma carga de uniaxial crescente em um corpo de prova normatizado. O ensaio é destrutivo, uma vez que uma de suas funções é determinar qual é a propriedade limite daquele material naquelas condições, ou seja, qual é a máxima solicitação permitida. É realizado em larga escala nas indústrias, por oferecer dados quantitativos das características do material (GARCIA e SPIM, 2012).

A máquina de ensaios mede variação do comprimento do objeto em função da carga aplicada, e após isso, obtém uma curva de tensão versus deformação, que fornece dados referentes ao limite de resistência à tração, limite de escoamento, módulo de elasticidade, módulo de resiliência, módulo de tenacidade e coeficiente de encruamento (GARCIA e SPIM, 2012). Um exemplo do diagrama tensão-deformação é ilustrado na figura 01 : 


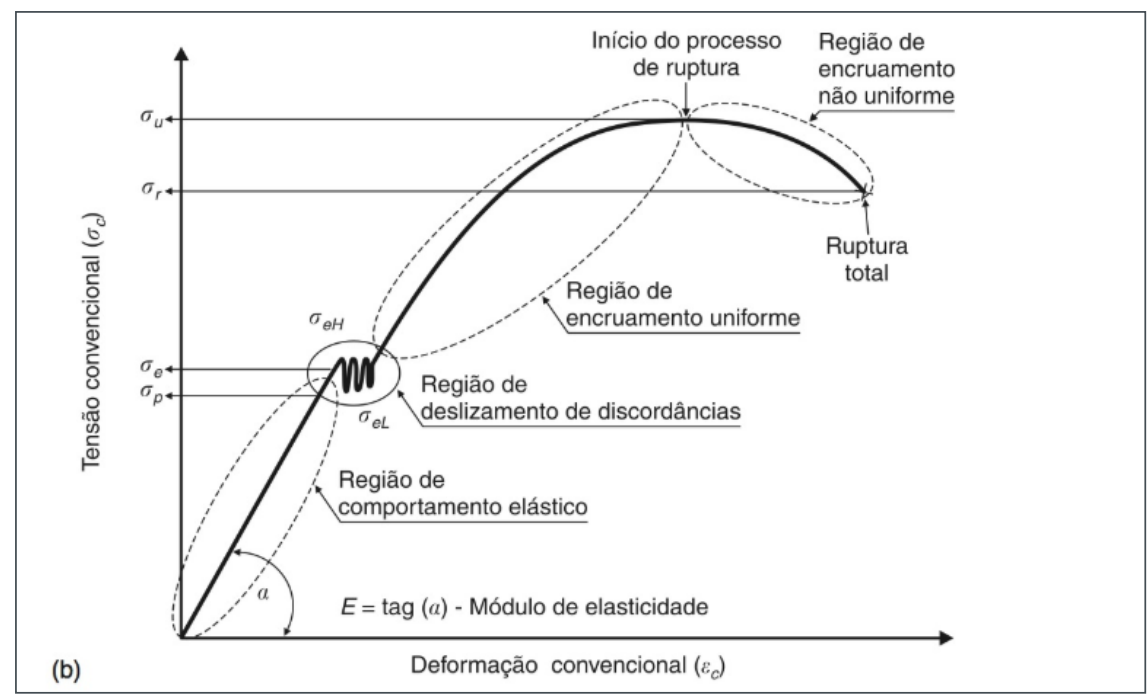

Figura 01: Esboço de curva obtida no ensaio de tração de material dúctil. Fonte: GARCIA; SPIM, 2012.

Segundo Cassu e Felisbert (2005), o ensaio mecânico de tração apenas pode ser realizado em materiais sólidos, como polímeros.

Os polímeros são materiais que incluem as borrachas e os plásticos. Baseados nos elementos carbono, hidrogênio, oxigênio e nitrogênio, no geral, possuem baixa densidade e condutividade elétrica, são inertes quimicamente, extremamente dúcteis e flexíveis, ou seja, podem ser moldados nas mais complexas formas (CALLISTER, Jr., 2008).

James M. Gere e Barry J. Goodno (2010, p.16) explicitam que, atualmente, mesmo com sua baixa resistência à elevadas temperaturas, muitos polímeros, com diversas propriedades mecânicas distintas, têm sido utilizados em projetos estruturais devido ao seu baixo peso específico e à sua alta resistência à corrosão.

Entre os polímeros mais estudados durante os últimos dez anos, encontra-se o polímero sintético Polylactic Acid (PLA), ou Ácido Polilático, por ser biodegradável e possuir propriedades próximas aos polímeros derivados de petróleo. É produzido por meio de síntese química do ácido lático por meio de fermentação bacteriana do amido ou de glicose extraída do milho (WANG et al., 2008).

O PLA, atualmente, é um dos materiais mais comumente utilizados em impressoras 3D por extrusão. Nesse modelo, o material se funde dentro de uma cabeça de impressão e é empurrado através de um pequeno orifício, construindo um pequeno cordão, que é depositado sobre uma plataforma, camada por camada, até que a peça seja completamente construída (TAKAGAKI, 2012). Esse processo é ilustrado na figura 02. 


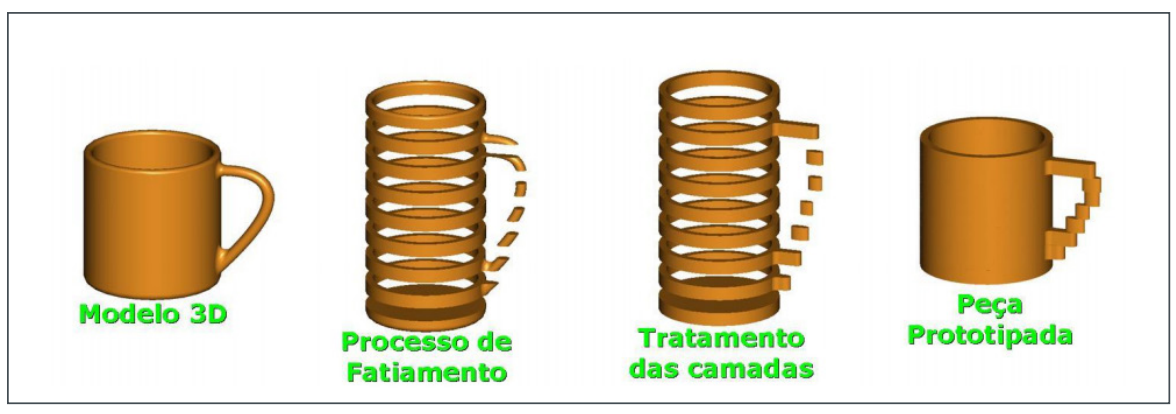

Figura 02: Princípio de manufatura por camada.

Fonte: VOLPATO, 2007.

De acordo com o SINDPLAST (Sindicato da Indústria de material Plástico, 2011), o processo mais comum de transformação do plástico é a extrusão. A impressão 3D permite a construção de objetos personalizados, e por isso, teve seu uso ampliado ao longo dos últimos anos já como fabricação de itens para uso imediato, permitindo a personalização dos produtos de acordo com a preferência do indivíduo; possível complexidade de estruturas internas quando comparadas à peças fundidas ou moldadas; sustentabilidade, devido à redução da quantidade de material desperdiçado durante outros processos de fabricação, à consequente economia de capital, e também à possibilidade de utilizar polímeros biodegradáveis na sua produção (HAUSMAN e HORNE, 2014).

Aliado às vantagens de utilização das impressoras 3D, tem-se o crescente aumento da urbanização, em escala global, ocasionando a multiplicação da geração de resíduos. Tal geração de lixo representa uma fração significativa dos impactos ambientais conhecidos. A evolução do descarte de materiais plásticos nãobiodegradáveis no Brasil e no mundo destaca-se dentro dessa situação (CARR, 2007).

Em contrapartida, mercado mundial de polímeros biodegradáveis cresceu de 18.400 toneladas em 2006 para 24.350 toneladas em 2007. A produção estimada para o ano de 2012 foi de 54.000 toneladas (PELICANO et al., 2009). Dentre os polímeros biodegradáveis conhecidos, encontra-se o PLA, que é utilizado principalmente na confecção de embalagens, o que representa $70 \%$ de sua aplicação. O restante encontra-se em eletrônicos, aparelhos e utilidades domésticas (PRADELLA, 2006).

\section{I OBJETIVO}

Analisar comparativamente os resultados obtidos nos ensaios mecânicos de tração em corpos de prova dimensionados de acordo com a ASTM D638-08 e construídos por extrusão em impressora 3D, quando são alteradas as seguintes variáveis físicas: composição da estrutura interna e espessura dos filamentos de impressão; e, dessa maneira, determinar a influência dos parâmetros de impressão sobre as propriedades mecânicas do objeto impresso. 


\section{I MATERIAIS E MÉTODOS}

O corpo de prova foi prototipado em PLA na cor branca, sendo desenhado e dimensionado utilizando o software SolidWorks \& (2014), conforme figura 03, de acordo com a norma ASTM D638-08, que padroniza os testes para propriedades de tração e compressão dos plásticos.

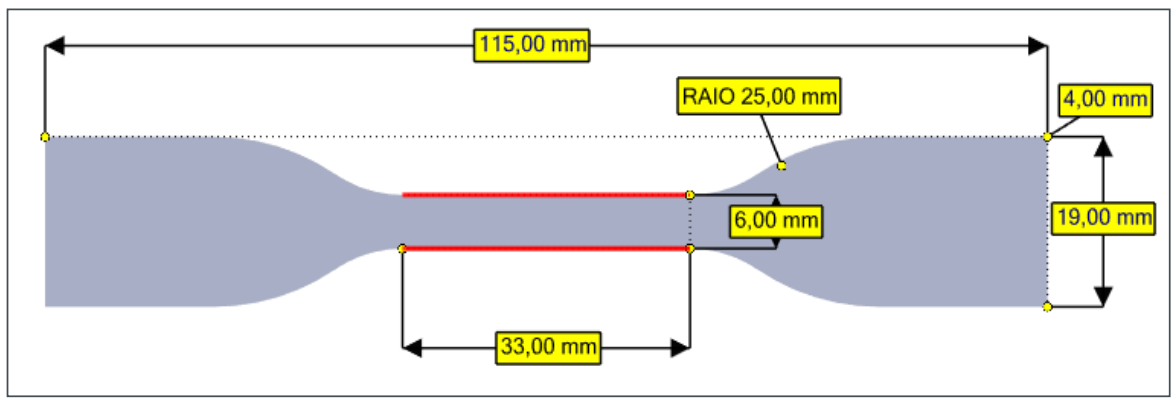

Figura 03: Corpo de prova de acordo com a norma ASTM 638-08.

Fonte: os autores.

As variáveis analisadas são: espessura do filamento de impressão e composição interna. Tais variáveis são determinadas por meio do software de impressão 3D Axon 3.0 B. A interface do software onde pode-se determinar os parâmetros de impressão encontra-se na figura 04.

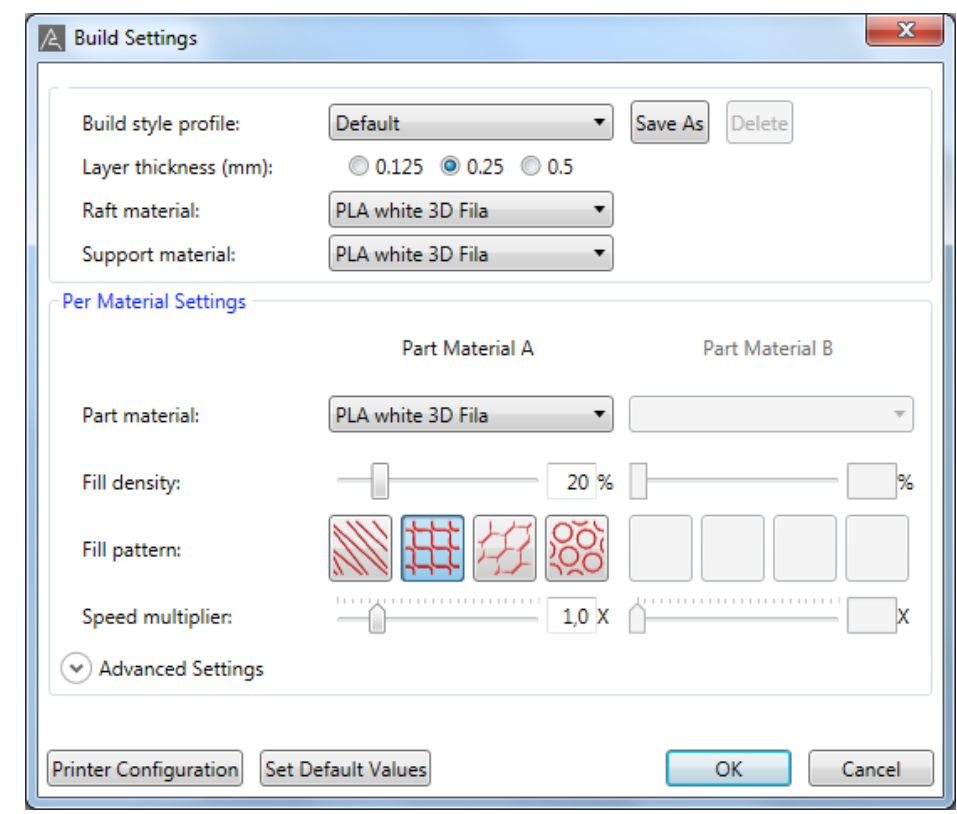

Figura 04: Interface do software Axon 3.0 ®.

Fonte: os autores.

Durante a construção, foi mantida fixa a densidade à $90 \%$. São três espessuras de filamento possíveis, sendo essas $0,125 \mathrm{~mm}, 0,250 \mathrm{~mm}$ e $0,500 \mathrm{~mm}$; e quatro disposições geométricas da estrutura interna, sendo essas "linear", "treliça", "hexagonal" e "cilíndrica". Portanto, tem-se as seguintes combinações de impressão, expressas no quadro 01 abaixo: 


\begin{tabular}{|l|l|l|l|l|l|l|l|}
\hline & $0,125 \mathrm{~mm}$ & $0,250 \mathrm{~mm}$ & $0,500 \mathrm{~mm}$ & Linear & Treliça & Hexagonal & Cilíndrica \\
\hline 01 & & & & & & & \\
\hline 02 & & & & & & & \\
\hline 03 & & & & & & & \\
\hline 04 & & & & & & & \\
\hline 05 & & & & & & & \\
\hline 06 & & & & & & & \\
\hline 07 & & & & & & & \\
\hline 08 & & & & & & & \\
\hline 09 & & & & & & & \\
\hline 10 & & & & & & & \\
\hline 11 & & & & & & & \\
\hline 12 & & & & & & & \\
\hline
\end{tabular}

Quadro 01: Variáveis de construção de corpos de prova por impressão 3D por extrusão.

Foram prototipados dez corpos de prova para cada parâmetro de comparação analisado no projeto, os quais foram descritos no quadro 01, totalizando 120 corpos de prova, em conformidade com norma a ASTM D638-08. O software Axon 3.OB converte o arquivo do Solidworks® para o formato BFB, lido pela impressora 3D. Na figura 05, pode-se observar a entrada do desenho dos cinco corpos de prova que foram impressos em conjunto, desenhados de acordo com as medidas expostas na figura 03.

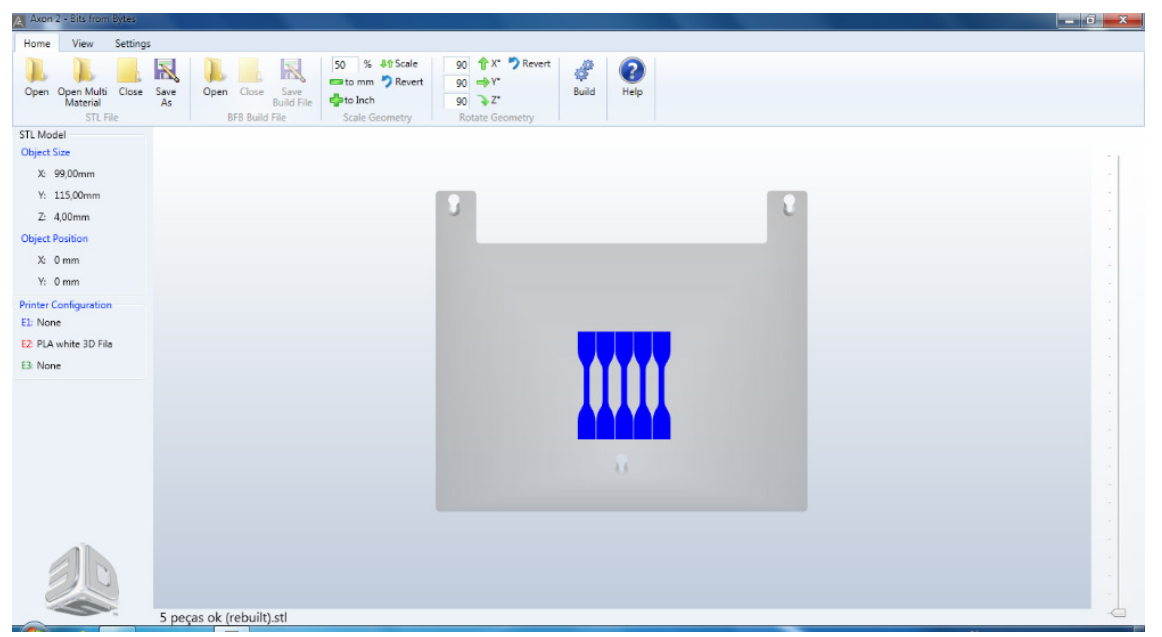

Figura 05: Interface do Software Axon $3.0{ }^{\circledR}$ antes da conversão.

Fonte: os autores.

Após a seleção dos parâmetros de impressão no software, conforme exposto na figura 04, tem-se como resultado o arquivo de impressão, conforme figura 06, já com o número de camadas de impressão delimitado pelo processo de fatiamento conforme explicitado na figura 02. 


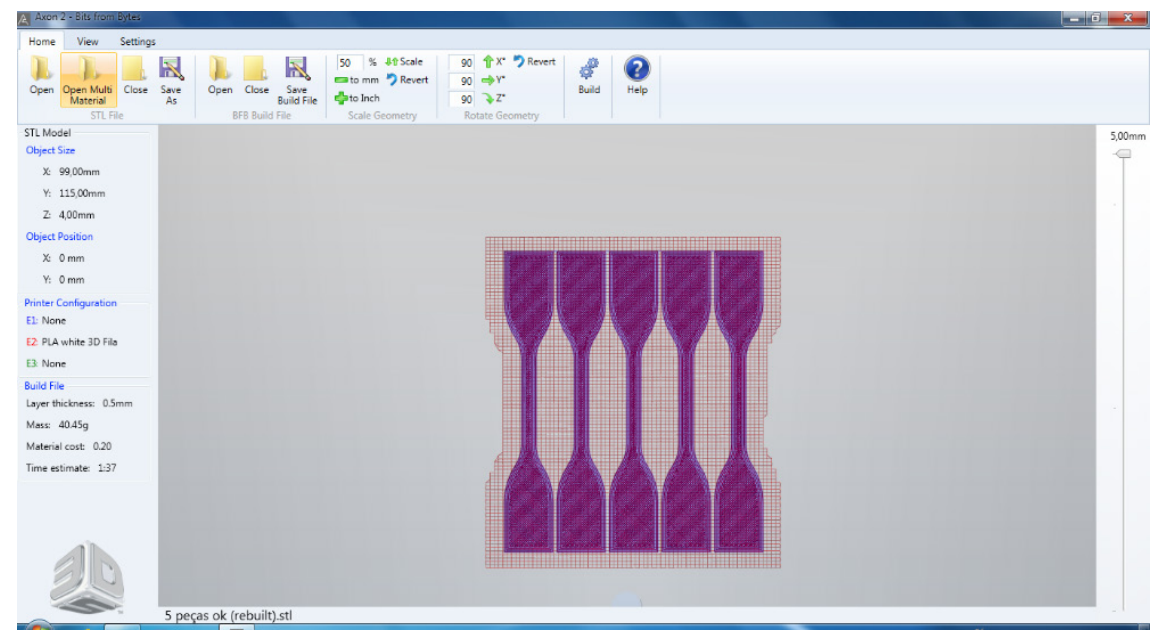

Figura 06: Interface do Software Axon 3.0® após conversão para BFB. Fonte: os autores.

A construção foi feita em impressora 3D, modelo BFB Touch - Dual head-smoke, conforme figura 07.

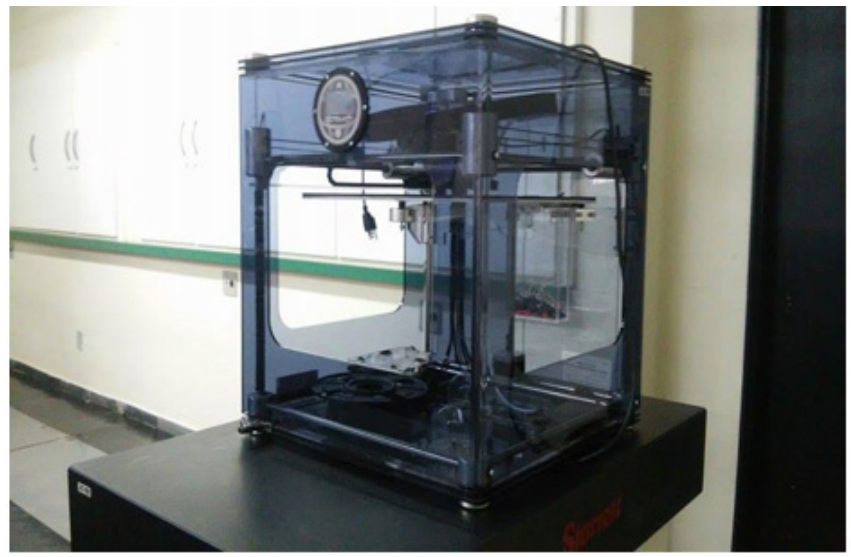

Figura 07: Impressora 3D modelo BFB Touch - Dual head-smoke

Fonte: os autores

Após a construção dos corpos de prova em ambiente sem ventilação e termicamente controlado, foram realizados ensaios de tração utilizando a máquina universal de ensaio EMIC modelo DL10000, conforme ilustrado nas figuras 08 e 09. A figura 10, em sequência, ilustra a amostragem de corpos de prova do tipo $01(0,125$ mm e estrutura interna linear) após a realização do ensaio. 

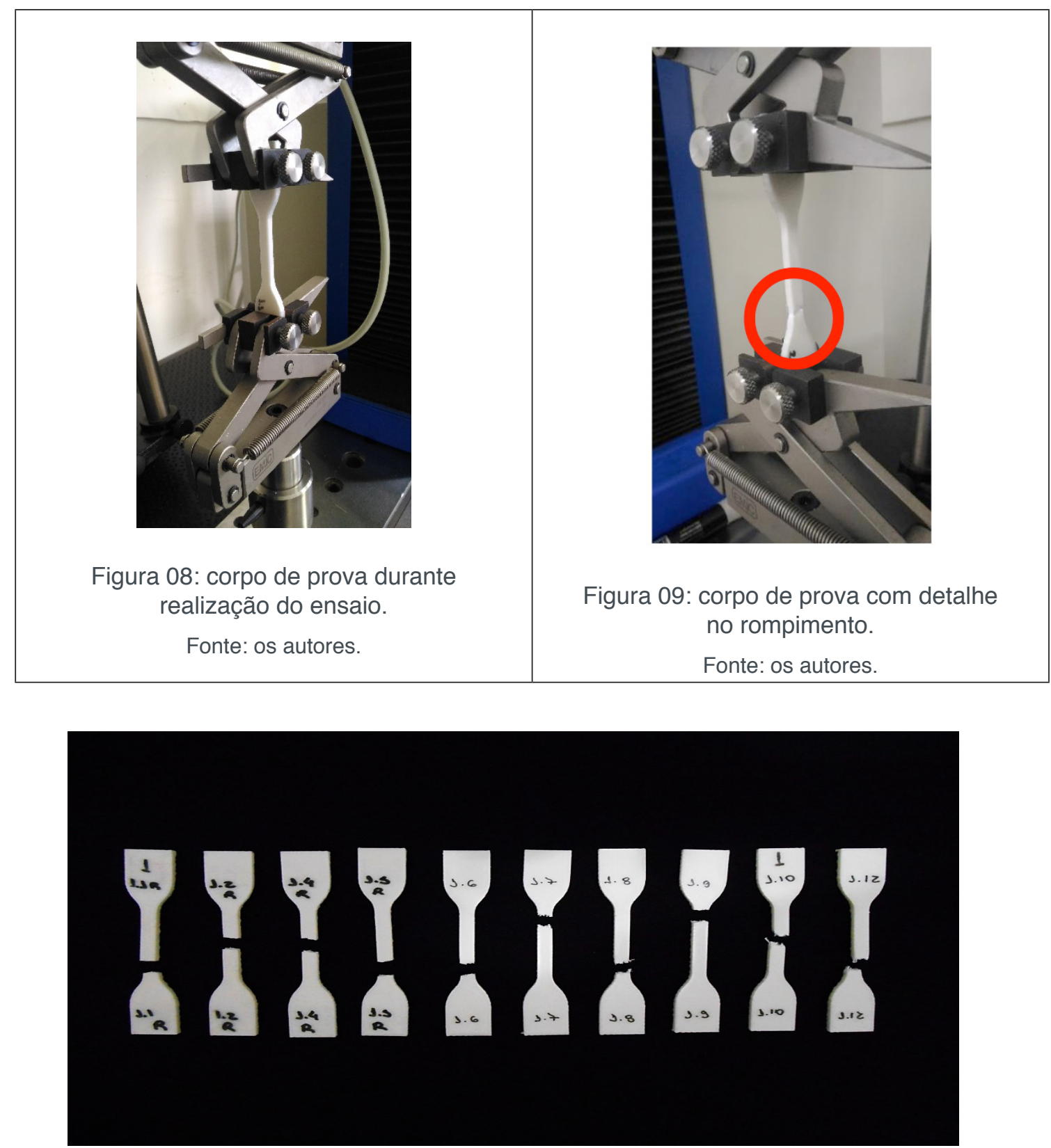

Figura 10: Corpos de prova do tipo 01 rompidos após ensaio de tração. Fonte: os autores.

Para cada ensaio realizado, a máquina de tração emite um relatório com os dados obtidos, sendo eles: tensão máxima, tensão de ruptura e deformação de ruptura, conforme figura 11. 


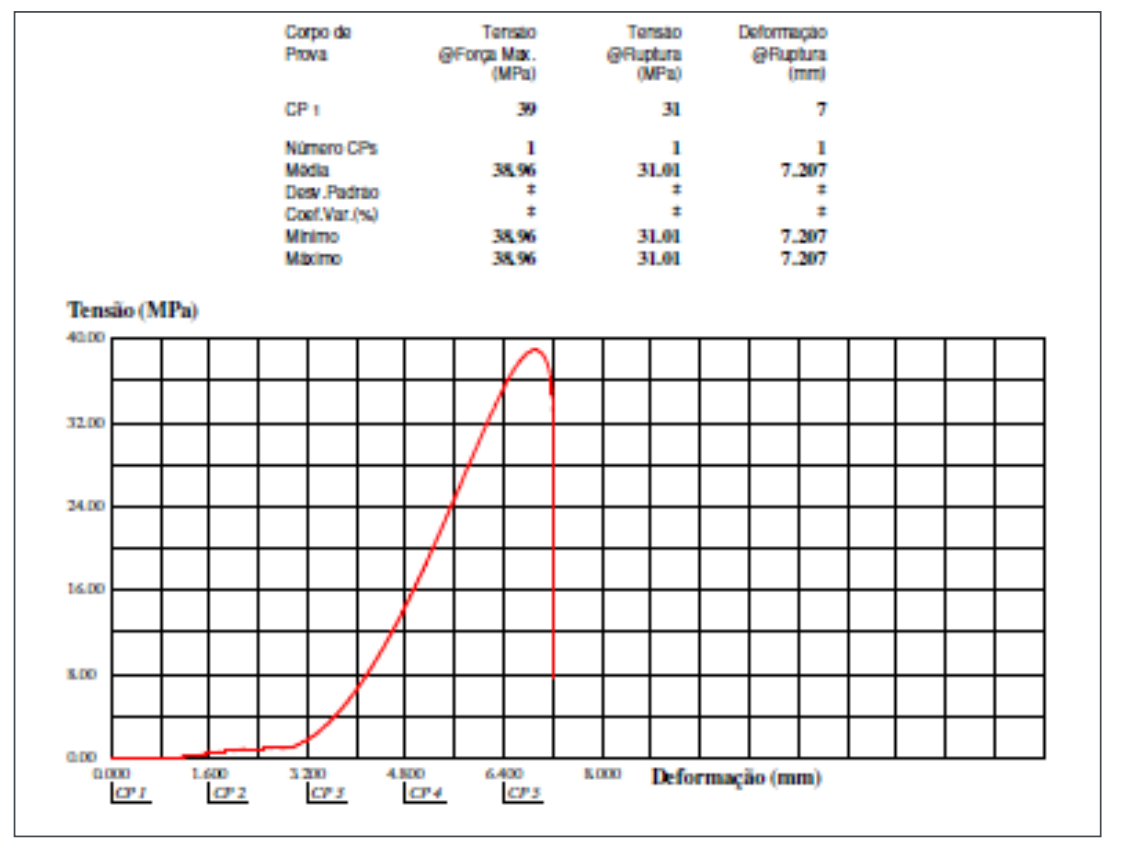

Figura 11: Exemplo de relatório de ensaio de tração.

Fonte: os autores.

Após a realização dos ensaios, os dados foram analisados estatisticamente, no intuito de determinar a correlação entre as propriedades mecânicas do polímero quando alterado os parâmetros de impressão.

\section{I RESULTADOS}

Após análise estatística dos dados obtidos nos 120 ensaios de tração, obtém-se os seguintes resultados para cada tipo de corpo de prova.

\begin{tabular}{|l|c|c|c|c|}
\hline \multicolumn{1}{|c|}{ ESPESSURA 0,125 mm } & Linear & Treliça & Hexagonal & Cilíndrica \\
\hline Área $\left(\mathrm{mm}^{2}\right)$ & 27,0 & 27,0 & 27,0 & 27,0 \\
\hline Força máxima $(\mathrm{N})$ & 773,1 & 756,9 & 656,8 & 773,1 \\
\hline Deformação $(\mathrm{mm})$ & 5,2 & 5,8 & 5,3 & 5,2 \\
\hline Deformação específica (\%) & 7,5 & 8,3 & 7,6 & 7,5 \\
\hline Tensão máxima (MPa) & 28,5 & 27,8 & 24,2 & 31,1 \\
\hline Módulo de elasticidade (MPa) & 746,6 & 811,0 & 720,3 & 753,0 \\
\hline
\end{tabular}

Quadro 02: resultados após análise estatística para o corpo de prova tipo 01, 02, 03 e 04.

\begin{tabular}{|l|c|c|c|c|}
\hline \multicolumn{1}{|c|}{ ESPESSURA 0,250 mm } & Linear & Treliça & Hexagonal & Cilíndrica \\
\hline Área $\left(\mathrm{mm}^{2}\right)$ & 27,0 & 27,0 & 27,0 & 27,0 \\
\hline Força máxima $(\mathrm{N})$ & 770,9 & 658,7 & 707,7 & 748,9 \\
\hline Deformação $(\mathrm{mm})$ & 5,5 & 5,0 & 5,1 & 6,3 \\
\hline Deformação específica (\%) & 7,8 & 7,2 & 7,4 & 8,9 \\
\hline Tensão máxima (MPa) & 28,4 & 24,3 & 26,1 & 27,6 \\
\hline Módulo de elasticidade (MPa) & 781,4 & 675,0 & 639,1 & 704,6 \\
\hline
\end{tabular}

Quadro 03: resultados após análise estatística para o corpo de prova tipo 05, 06, 07 e 08. 


\begin{tabular}{|l|c|c|c|c|}
\hline \multicolumn{1}{|c|}{ ESPESSURA 0,500 mm } & Linear & Treliça & Hexagonal & Cilíndrica \\
\hline Área $\left(\mathrm{mm}^{2}\right)$ & 27,0 & 27,0 & 27,0 & 27,0 \\
\hline Força máxima (N) & 628,9 & 562,7 & 558,6 & 600,4 \\
\hline Deformação (mm) & 4,7 & 7,2 & 6,1 & 4,6 \\
\hline Deformação específica (\%) & 6,7 & 10,3 & 8,8 & 6,6 \\
\hline Tensão máxima (MPa) & 23,2 & 20,8 & 20,6 & 24,4 \\
\hline Módulo de elasticidade (MPa) & 655,5 & 415,4 & 456,4 & 686,9 \\
\hline
\end{tabular}

Quadro 04: resultados após análise estatística para o corpo de prova tipo 09, 10, 11 e 12.

Durante a realização dos ensaios, os corpos de prova não foram rompidos abruptamente. Como corpos de prova são constituídos por filamentos de PLA que foram depositados ordenadamente durante o seu processo de construção, o comportamento assemelha-se ao de fibras submetidas ao ensaio de tração. O rompimento não simultâneo dos filamentos fica evidente em alguns corpos de prova, conforme detalhe ilustrado na figura 12 abaixo.

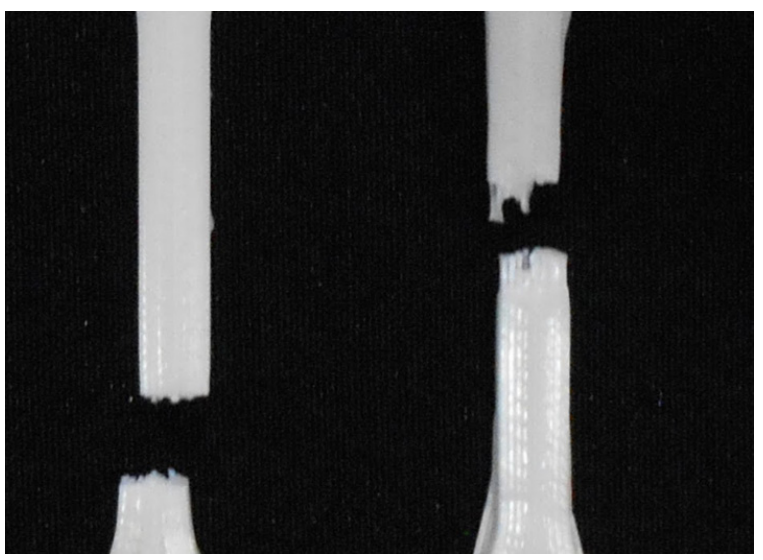

Figura 12: Rompimento não simultâneo dos filamentos.

Fonte: os autores

Conforme a espessura do filamento aumenta, a seção transversal de cada filamento constituinte do corpo de prova também aumenta, sendo necessária uma maior tensão para provocar o rompimento das mesmas e, consequentemente, o corpo de prova atinge uma tensão máxima mais elevada quando comparada aos de filamentos de espessura inferior.

Analisando a estrutura interna de preenchimento, observa-se que os corpos de prova das configurações 04, 08 e 12 suportam tensões menores quando comparados com outros tipos de preenchimento interno. Isso deve-se ao fato da existência reduzida de fibras posicionadas na direção de realização do ensaio de tração, fazendo com que seja necessária uma tensão menor para o rompimento.

Quando se mantem a espessura do filamento constante e analisa-se a variação causada pela treliça interna de composição do corpo de prova, a estrutura cilíndrica é a que possui menor massa final de impressão. Para produções em larga escala, a economia de material implica também na redução de custos. Portanto, quando a 
aplicação não exige uma resistência à tração elevada, as configurações cilíndricas são mais adequadas devido à contenção de gastos.

\section{I CONCLUSÕES}

Diante dos resultados determinados, pode-se concluir que a tensão máxima e a resistência à fratura aumentam à medida que a espessura do filamento de impressão aumenta. Em média, os corpos de prova preenchidos de forma cilíndrica suportam tensões menores quando comparados a outros tipos de preenchimento. Esse mesmo tipo também é o que possui massa final de impressão menor quando mantemos a variável "espessura do filamento" constante e avaliamos apenas a estrutura interna, portanto, são mais econômicos para produção em larga escala.

O objetivo do trabalho foi atingido, visto que os resultados obtidos nos ensaios mecânicos de tração em corpos de prova dimensionados de acordo com a ASTM D638-14 e construídos por extrusão em impressora 3D quando alteram-se as variáveis físicas "estrutura do filamento" e "disposição geométrica da estrutura interna", foram expostos e analisados comparativamente, no intuito de fornecer informações sobre as suas propriedades mecânicas, para que pesquisadores, indústrias e demais interessados possam avaliar o melhor custo benefício para diversas aplicações dos aspectos econômicos e as condições de trabalho ao qual o projeto será submetido para que não ocorra fratura.

\section{REFERÊNCIAS}

ASKELAND, Donald R.; PHULÉ, Pradeep P. Ciência e Engenharia dos Materiais. São Paulo: Cengage Learning, 2008.

ASTM - American Society for Testing Materials. ASTM D638-14, Standart Test Method for Tensile Properties of Plastics, 2014.

CALLISTER, Jr., William D.: RETHWISCH, David G. Ciência e engenharia de materiais: uma introdução. 7. Ed. Rio de Janeiro: LTC, 2012.

CARR, Laura G. Desenvolvimento de embalagens biodegradável tipo espuma a partir de fécula de mandioca. 2007. 107 f. Tese (Doutorado em Engenharia) - Escola Politécnica da Universidade de São Paulo, São Paulo, 2007.

CASSU, Silvana N.; FELISBERTI, Maria I.; O comportamento dinâmico-mecânico e relaxações em polímeros e blendas poliméricas. Revista Química Nova, São Paulo, vol. 28, no. 2, p. 255-263, fev. 2005.

GARCIA, Amauri; SPIM, Jaime Alvares; SANTOS, Carlos Alexandre dos. Ensaios dos materiais. 2.ed. Rio de Janeiro: LTC, 2012. 365p.

GERE, J.M; GOODNO, B.J. Mecânica dos Materiais. São Paulo: Cengage Learning, 2010. 
Guia ambiental da indústria de transformação e reciclagem de materiais plásticos. SINDIPLAST, 2011. Disponível em: <http://www.cetesb.sp.gov.br/tecnologia-ambiental/Produ??o-e-ConsumoSustent?vel/11-Documentos>. Acesso em 16 de set. 2016.

HAUSMAN, Kalani Kirk; HORNE, Richard. 3D Printing For Dummies. Hoboken, New Jersey: John Wiley \& Sons, 2014. 384 p.

PELICANO, M; PACHEKOSKI, W.; AGNELLI, J. A. M. Influência da Adição de Amido de Mandioca na Biodegradação da Blenda Polimérica PHBV/Ecoflex®. Polímeros: Ciência e Tecnologia, v.19, n.3, p. 212-217, 2009.

PRADELLA, José G. C. Biopolímeros e Intermediários Químicos. Relatório Técnico no 84 396-205. Centro de Tecnologia de Processos e Produtos - Laboratório de Biotecnologia Industrial. São Paulo, 2006.

TAKAGAKI, Luiz Koiti. Tecnologia de Impressão 3D. Revista Inovação Tecnológica, São Paulo, v.2, n.2, p.2840, jul./dez.2012.,

VOLPATO, Neri. Prototipagem rápida: tecnologias e aplicações. São Paulo. Edgar Blucher. 2007.

WANG, Ning. et.al. Influence of formamide and water on the properties of thermoplastic stach/ poly(lactic acid) blends. Carbohydrate Polymers, v.71, p.109-118, 2008. 


\section{ESTUDO DO ASPECTO GEOMÉTRICO DOS CORDÕES DE SOLDA COMO ORIENTAÇÃO OPERACIONAL PARA O USO NA SOLDAGEM MAG ROBOTIZADA}

\section{Everaldo Vitor \\ Escola de Engenharia de Mecânica \\ Universidade Presbiteriana Mackenzie \\ São Paulo, SP \\ Paulo Eduardo Alves Fernandes \\ Faculdade SENAI de Tecnologia em Processos \\ Metalúrgicos \\ Nadir Dias de Figueiredo \\ Osasco, SP.}

RESUMO: A proposta deste trabalho é proporcionar aos trabalhadores da área de soldagem uma base de conhecimento e orientação para a sua aplicação na parametrização e na realização de soldas robotizadas pelo processo MAG. Com a finalidade de obter cordões de solda com aspectos geométricos aceitáveis de acordo com os critérios de qualidade exigidos, proporcionando uma condição ótima para o processo.

Diante destes fatos, a expectativa deste estudo é determinar a melhor configuração dos parâmetros de soldagem: tensão, velocidade de soldagem, intensidade da corrente, velocidade de alimentação do arame, vazão do gás de proteção, energia teórica de soldagem.

Realizou-se neste estudo, a união de chapas de aço com baixo teor de carbono, na posição horizontal em juntas de angulo e metal de adição AWS ER70S-6.

Foram realizados, ensaios visuais das juntas soldadas, ensaios das características macroestruturais, verificação das dimensões geométricas: garganta teórica, perna horizontal e vertical, analise das imagens da microestrutura pelo método MEV e EDS, análise comparativa do cálculo da energia de soldagem e analise da equação de regressão linear.

PALAVRAS-CHAVE: Soldagem Robotizada MAG, Parâmetros de Soldagem e Geometria do cordão de solda.

ABSTRACT: The purpose of this study is to provide welding area workers a knowledge base and guidance for their application in the parameterization and conducting robotic welding by MAG process. In order to obtain weld beads with acceptable geometric aspects in accordance with the required quality criteria, providing an optimum condition for the process. According to these facts, the expectation of this study is to determine the best setting of the welding parameters: voltage, welding speed, amperage, wire feed speed, flow of the shielding gas, welding theoretical energy.

We conducted this study, the union of steel sheet with low carbon content, horizontally angled joints and AWS ER70S-6 filler metal.

Were performed, visual testing of welds, testing of macro-structural characteristics, verification 
of the geometric dimensions: theoretical throat, horizontal and vertical leg, analyze the images of the microstructure by SEM and EDS method, comparative analysis of the welding energy calculation and analysis of the equation linear regression.

KEYWORDS: Robotic Welding MAG, welding and weld bead geometry parameters.

\section{I INTRODUÇÃO}

É cada vez mais frequente na Indústria de fabricação de peças automobilísticas, a utilização do processo de soldagem MAG robotizada na união de seus componentes metálicos, devido às exigências impostas pelo mercado referente: a qualidade, produtividade, repetibilidade e redução de custos de fabricação. Tem movido as indústrias de fabricação a investir cada vez mais neste segmento tornando-as mais competitivas, minimizando os custos com retrabalhos e com a mão de obra.

Diante destes fatos, os técnicos e especialistas devem possuir o conhecimento e o domínio desta tecnologia destas variáveis do processo de soldagem automatizado MAG, possibilitando a escolha da melhor configuração dos parâmetros de soldagem: tensão, velocidade de soldagem, intensidade da corrente, velocidade de alimentação do arame, vazão do gás de proteção, energia teórica de soldagem, com a finalidade de buscar uma condição ótima para o processo e com os resultados apresentados, aplicarem em uma situação real na indústria de fabricação de componentes metálicos e automobilísticos.

Com este estudo não serão questionados e apresentados os resultados pertinentes à taxa de deposição do metal de adição, valores e custos com energia de soldagem, consumo e custos com os gases de proteção, dimensões geométricas referentes ao reforço, penetração horizontal e vertical, garganta efetiva e real e com a dimensão da penetração da raiz.

A soldagem MIG/MAG robotizada apresenta o mesmo princípio de funcionamento do processo MIG/MAG convencional de funcionamento semiautomático, entretanto, com sua automação este processo ganha uma melhor rendimento na fabricação de peças em série, uma vez que o robô seja programado, utilizando a escolha dos melhores parâmetros de soldagem, este mesmo realiza cordões de solda, sempre na mesma sequência de soldagem de forma precisa e repetitiva, proporcionando soldas com excelência de qualidade, com menos descontinuidades e possíveis defeitos.

Gimenes e Tremonti (2013) descreveram que o robô, deve estar dimensionado para o peso do elemento terminal, no caso da soldagem a ponto, o peso da pinça, dos cabos elétricos e dos tubos de refrigeração podem chegar a $90 \mathrm{~kg}$. Na soldagem por arco elétrico, o elemento terminal é conhecido como tocha ou pistola, com dimensões e peso menores que as pinças de solda a ponto. Os elementos terminais são fixados no punho do robô. A tocha de soldagem deverá ter uma orientação com relação ao punho, compatível com requisitos e exigências da soldagem. Esse fator pode reduzir até $50 \%$ o volume do trabalho do robô. 
Michelan (2011) em sua dissertação de mestrado descreveu que o processo de soldagem MIG/MAG possui uma facilidade de automação, o desenvolvimento dos processos de soldagem se deve em grande parte aos avanços na área de automação e eletrônica, entre os quais se destacam: a difusão da utilização de robôs industriais de soldagem, que possibilitam operações em altas velocidades em peças de geometria complexa e o emprego de novas fontes eletrônicas utilizadas em soldagem, que permitem um melhor controle da fusão dos materiais, por meio do emprego de diferentes formas de onda de corrente.

\subsection{Vantagens da soldagem robotizada MIG / MAG}

Como mencionado anteriormente, É cada vez mais frequente a utilização do processo de soldagem robotizada na indústria tornando-se crescente o seu uso em larga escala a cada dia na indústria de fabricação de manufaturas de produtos soldados devido às exigências impostas pelo mercado no que diz sobre respeito da qualidade, produtividade e competividade.

Diversos autores, Rosário (2010), Gimeneses e Tremonti (2013), Alves (2009) e Schnee (1996) citaram em seus trabalhos as principais vantagens da utilização do processo MAG robotizado na união dos componentes metálicos. Conforme descritos abaixo:

- Melhoria na qualidade da solda;

- Redução dos custos e tempo gastos na realização de retrabalhos;

- Redução dos custos com energia;

- Redução do consumo de metal de adição devido ao fato de consumir somente o necessário para realização da solda de acordo com a geometria imposta;

- Economia do gás de proteção;

- Ganhos em produtividade;

- Redução de custo de mão de obra;

- Ergonomia no trabalho;

- Redução da fadiga de soldador;

- Repetibilidade;

- Menor tendência a defeitos e descontinuidades;

- Padronização dos parâmetros de soldagem;

- Velocidades de soldagem altas;

- Sequência de trabalho bem definida;

- Facilidade na programação e uso dos robôs de soldagem;

- Capacidade trabalhos sem interrupções por longos períodos. 


\section{I MATERIAIS, EQUIPAMENTOS E MÉTODOS}

As soldas foram realizadas em chapas de aço com baixo teor de carbono SAE 1020 é rígido pela Norma J403 sob a, cuja composição química encontra-se descrita na tabela 1 Nas dimensões de 9,5 mm de espessura, com largura de 50,8 mm e no comprimento de $250 \mathrm{~mm}$ os quais, foram seccionadas em uma máquina de serra de fita horizontal.

Para as montagens das peças a serem soldadas, utilizou-se o dispositivo desenvolvido, optando-se por fixa-las através de grampos para fixação, os mesmos utilizados em máquinas ferramentas conforme demonstradas na Figura 1.

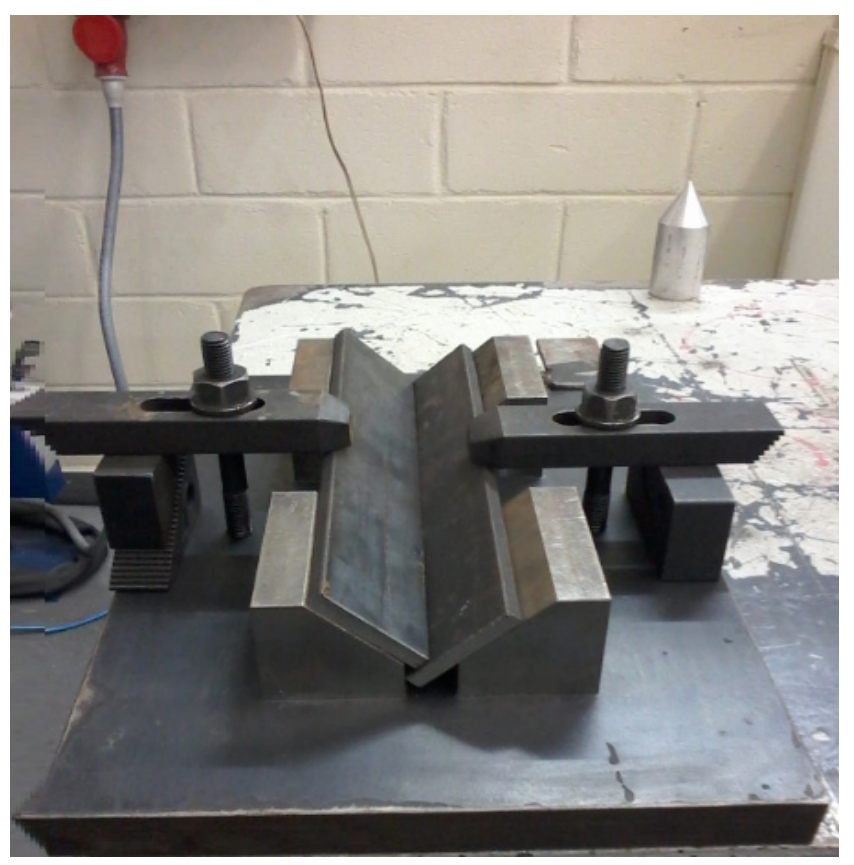

Figura 1 - Fixação e montagem do corpo de prova no dispositivo de solda

Todos os cordões de solda foram realizados em uma mesma posição plana, com a tocha de solda posicionada num ângulo de $45^{\circ}$ entre as duas chapas, $90^{\circ}$ em relação ao eixo da solda, em alguns testes a distância bico contato peça e o comprimento do arame oscilaram de $15-20 \mathrm{~mm}$, conforme a programação, estas distâncias serão indicadas nas tabelas dos resultados dos cordões e, as soldas foram aplicadas somente em um lado da junta conforme ilustrado na figura 2.

Uma vez estabelecida à posição de solda de ataque do arame, a mesma manterá constante, pois o robô posicionará a tocha sempre na mesma localização. 


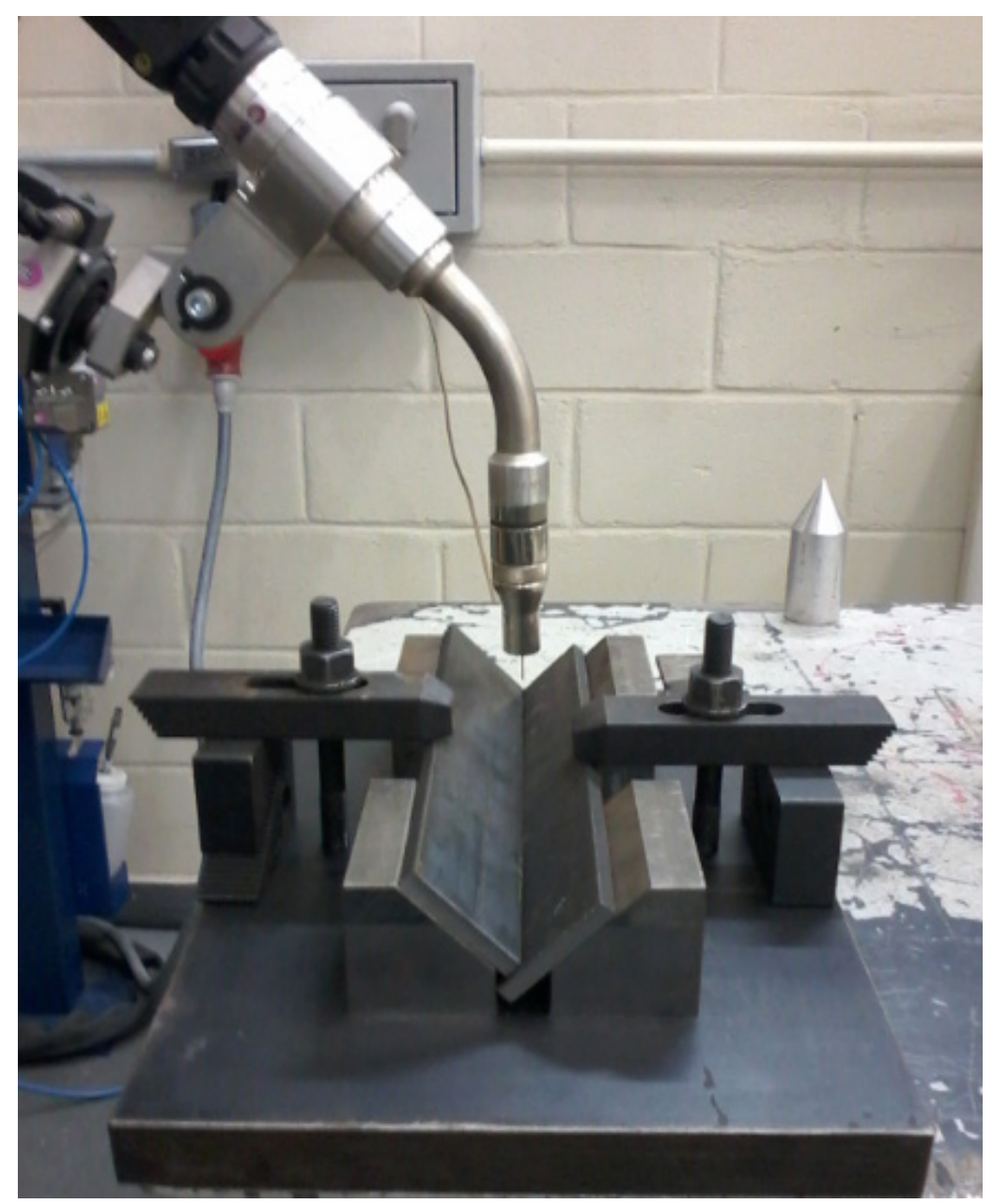

As condições de soldagem foram selecionadas de modo que a solda aplicada atendesse os requisitos de uma junta soldada. Denomina-se aqui, como um cordão de solda que atende os requisitos sob o aspecto técnico e operacional, aquele que represente uma boa aparência, arco elétrico mais estável, livre de descontinuidades superficiais.

\begin{tabular}{|c|c|c|c|c|}
\hline $\begin{array}{c}\text { Corpo de } \\
\text { prova }\end{array}$ & Corrente (A) & Tensão (V) & $\begin{array}{c}\text { Velocidade de } \\
\text { Soldagem. (mm/s) }\end{array}$ & $\begin{array}{c}\text { Velocidade de } \\
\text { alimentação do arame } \\
\text { (m/min) }\end{array}$ \\
\hline $\mathbf{1}$ & 164 & 23,3 & 8,9 & 8 \\
\hline $\mathbf{2}$ & 164 & 23,3 & 8,9 & 8 \\
\hline $\mathbf{3}$ & 194 & 24,5 & 7,3 & 9,9 \\
\hline $\mathbf{4}$ & 220 & 27,2 & 5 & 12,5 \\
\hline $\mathbf{5}$ & 236 & 27,2 & 7,3 & 12,5 \\
\hline $\mathbf{6}$ & 245 & 28,9 & 6,7 & 14,4 \\
\hline $\mathbf{7}$ & 280 & 30,4 & 6,7 & 17,6 \\
\hline $\mathbf{8}$ & 200 & 24,8 & 5 & 10,2 \\
\hline $\mathbf{9}$ & 250 & 28,9 & 5 & 17,6 \\
\hline $\mathbf{1 0}$ & 280 & 30,4 & 5 & 17,6 \\
\hline $\mathbf{1 1}$ & 280 & 30,3 & 10 & 21 \\
\hline $\mathbf{1 2}$ & 315 & 31 & 10 & 21 \\
\hline $\mathbf{1 3}$ & 315 & 31 & 6,7 & \\
\hline
\end{tabular}




\begin{tabular}{|c|c|c|c|c|}
\hline 14 & 330 & 31 & 5 & 21 \\
\hline 15 & 250 & 28,9 & 3 & 14,4 \\
\hline 16 & 285 & 30,3 & 4 & 17,6 \\
\hline 17 & 315 & 31 & 4 & 21 \\
\hline 18 & 315 & 30,5 & 6,7 & 21 \\
\hline 19 & 320 & 31,1 & 6,7 & 22 \\
\hline
\end{tabular}

Tabela 1 - Condições de soldagem proposta para o estudo

Fonte: O próprio autor

\section{I RESULTADOS COMPARATIVOS DA ENERGIA DE SOLDAGEM}

Um fator importante neste trabalho foi à verificação pelo método comparativo do resultado do valor da energia de soldagem em relação à geometria do cordão de solda no que se refere às dimensões da perna vertical e horizontal e no aspecto visual da penetração da raiz. Comparando - se aos valores dimensionais próximos em comparação a dois corpos de provas.

\begin{tabular}{|c|c|c|c|c|c|}
\hline $\mathbf{C P}$ & $\begin{array}{c}\text { HEAT- INPUT } \\
(\mathbf{J} / \mathbf{m m})\end{array}$ & $\begin{array}{c}\text { Garganta Teórica } \\
\mathbf{( m m})\end{array}$ & $\begin{array}{c}\text { Perna } \\
\text { Horizontal(mm) }\end{array}$ & $\begin{array}{c}\text { Perna } \\
\text { Vertical } \\
\mathbf{( m m}\end{array}$ & $\begin{array}{c}\text { Velocidade de } \\
\text { Soldagem } \\
(\mathbf{m m} / \mathbf{s})\end{array}$ \\
\hline $\mathbf{1}$ & 429 & 2,35 & 4,76 & 5,40 & 8,90 \\
\hline $\mathbf{2}$ & 429 & 2,94 & 4,04 & 4,32 & 8,90 \\
\hline $\mathbf{3}$ & 651 & 3,10 & 3,79 & 5,00 & 7,30 \\
\hline $\mathbf{4}$ & 1197 & 4,05 & 5,20 & 6.50 & 5,00 \\
\hline $\mathbf{5}$ & 879 & 4,12 & 5,19 & 6,79 & 7,30 \\
\hline $\mathbf{6}$ & 1057 & 4,04 & 4,81 & 7,48 & 6,70 \\
\hline $\mathbf{7}$ & 1270 & 4,99 & 7,01 & 7,13 & 6,70 \\
\hline $\mathbf{8}$ & 992 & 3,56 & 4.54 & 5,76 & 5,00 \\
\hline $\mathbf{9}$ & 1445 & 4,42 & 6,22 & 6,30 & 5,00 \\
\hline $\mathbf{1 0}$ & 1702 & 4,83 & 6,40 & 7,38 & 5,00 \\
\hline $\mathbf{1 1}$ & 848 & 4,75 & 6,20 & 7,40 & 10,00 \\
\hline $\mathbf{1 2}$ & 977 & 4,86 & 6,11 & 8,01 & 10,00 \\
\hline $\mathbf{1 3}$ & 1457 & 4,48 & 5,72 & 7,20 & 6,70 \\
\hline $\mathbf{1 4}$ & 2046 & 4,90 & 6,51 & 7,44 & 5,00 \\
\hline $\mathbf{1 5}$ & 2408 & 4,27 & 6,20 & 5,9 & 3,00 \\
\hline $\mathbf{1 6}$ & 2159 & 4,56 & 5,60 & 7,86 & 4,00 \\
\hline $\mathbf{1 7}$ & 2441 & 4,49 & 5,50 & 7,8 & 4,00 \\
\hline $\mathbf{1 8}$ & 1434 & 5,22 & 6,90 & 8 & 6,70 \\
\hline $\mathbf{1 9}$ & 1485 & 5.13 & 7,20 & 7,3 & 6,70 \\
\hline
\end{tabular}

Tabela 2 - Valores da energia de soldagem e dimensões dos cordões de solda

Fonte: O próprio autor

Com o objetivo de uma identificação do aspecto visual da macrografia dos cordões de solda com seus respectivos parâmetros de soldagem, optou-se por este tipo de apresentação dos resultados em formas de tabelas, para que os trabalhadores da área de soldagem robotizada MAG possam utilizar estas tabelas na aplicação em 
sua célula de soldas, tornando - se de fácil visualização.

Os valores demonstrados nas tabelas: referentes ao comprimento do arco, indutância, e processos foram obtidos através da programação da fonte Fronius TPS 4000.

\begin{tabular}{|c|c|c|}
\hline Parâmetros de soldagem & Valores / Unidades & Figura 3 - corpo de prova 1 \\
\hline Corrente & $164 \mathrm{~A}$ & $4 \mathrm{~mm}$ \\
\hline Tensão & $23,3 \mathrm{~V}$ & \\
\hline Diâmetro do arame & $1 \mathrm{~mm}$ & \\
\hline Velocidade de soldagem & $8,9 \mathrm{~mm} / \mathrm{s}$ & \\
\hline Gás de proteção & $85 \% \operatorname{Ar}$ e $15 \% \mathrm{CO}_{2}$ & \\
\hline Vazão dos Gases & $7 \mathrm{l} / \mathrm{min}$ & \\
\hline Velocidade de alimentação & $8,0 \mathrm{~m} / \mathrm{min}$ & \\
\hline DBCP & $15 \mathrm{~mm}$ & \\
\hline Stick-out & $10 \mathrm{~mm}$ & Geometria \\
\hline Ângulo e Inclinação da tocha & $90^{\circ}$ e $0^{\circ}$ & Heat input - $429 \mathrm{~J} / \mathrm{mm}$ \\
\hline Comprimento do Arco & 0 & Garg. Teórica - 2,94 mm \\
\hline Indutância & 0 & Perna Hor. - 4,04 mm \\
\hline Processo & MIG/MAG Synergic-Pulse & Perna Vert. - 4,32 mm \\
\hline
\end{tabular}

Tabela 3 - Referente ao corpo de prova 1

Fonte: O próprio autor

\begin{tabular}{|l|l|l|}
\hline Parâmetros de soldagem & Valores / Unidades & Figura 4 - corpo de prova 2 \\
\hline Corrente & $194 \mathrm{~A}$ & \\
\hline Tensão & $24,5 \mathrm{~V}$ & \\
\cline { 1 - 2 } Diâmetro do arame & $1 \mathrm{~mm}$ & \\
\cline { 1 - 2 } Velocidade de soldagem & $7,3 \mathrm{~mm} / \mathrm{s}$ & \\
\hline Gás de proteção & $85 \% \mathrm{Ar}$ e 15\% CO $\mathrm{CO}_{2}$ & \\
\hline Vazão dos Gases & $7 \mathrm{I} / \mathrm{min}$. & \\
\hline Velocidade de alimentação & $9,9 \mathrm{~m} / \mathrm{min}$. & \\
\hline DBCP & $15 \mathrm{~mm}$ & Geometria \\
\hline Stick-out & $10 \mathrm{~mm}$ & Heat input $-651 \mathrm{~J} / \mathrm{mm}$ \\
\hline Ângulo e Inclinação da tocha & $90^{\circ}$ e $0^{\circ}$ & Garg. Teórica $-3,10 \mathrm{~mm}$ \\
\hline Comprimento do Arco & 0 & Perna Horiz.. $-3,79 \mathrm{~mm}$ \\
\hline Indutância & 0 & Perna Vert. $-5,00 \mathrm{~mm}$ \\
\hline Processo & MIG/MAG Synergic-Pulse & \\
\hline
\end{tabular}

Tabela 4- Referente ao corpo de prova 2

Fonte: O próprio autor 


\begin{tabular}{|c|c|c|}
\hline Parâmetros de soldagem & Valores / Unidades & Figura 5 - corpo de prova 3 \\
\hline Corrente & $245 \mathrm{~A}$ & \\
\hline Tensão & $28,9 \mathrm{~V}$ & \\
\hline Diâmetro do arame & $1 \mathrm{~mm}$ & \\
\hline Velocidade de soldagem & $6,7 \mathrm{~mm} / \mathrm{s}$ & \\
\hline Gás de proteção & $85 \% \mathrm{Ar} \mathrm{e} 15 \% \mathrm{CO}_{2}$ & \\
\hline Vazão do Gás & $7 \mathrm{I} / \mathrm{min}$. & \\
\hline Velocidade de alimentação & $14,4 \mathrm{~m} / \mathrm{min}$ & \\
\hline $\mathrm{DBCP}$ & $20 \mathrm{~mm}$ & \\
\hline Stick-out & $15 \mathrm{~mm}$ & Geometria \\
\hline Ângulo e Inclinação da tocha & $90^{\circ}$ e $0^{\circ}$ & Heat input - $1057 \mathrm{~J} / \mathrm{mm}$ \\
\hline Comprimento do Arco & 0 & Garg. Teórica-4,04 mm \\
\hline Indutância & 0 & Perna Hor. $-4,81 \mathrm{~mm}$ \\
\hline Processo & MIG/MAG Synergic-Pulse & Perna Vert. $-7,48 \mathrm{~mm}$ \\
\hline
\end{tabular}

Tabela 5: Referente ao corpo de prova 3

Fonte: O próprio autor

\begin{tabular}{|c|c|c|}
\hline Parâmetros de soldagem & Valores / Unidades & Figura 6 - corpo de prova 4 \\
\hline Corrente & $245 \mathrm{~A}$ & \\
\hline Tensão & $28,9 \mathrm{~V}$ & \\
\hline Diâmetro do arame & $1 \mathrm{~mm}$ & \\
\hline Velocidade de soldagem & $6,7 \mathrm{~mm} / \mathrm{s}$ & \\
\hline Gás de proteção & $85 \% \mathrm{Are} 15 \% \mathrm{CO}_{2}$ & \\
\hline Vazão do Gás & $7 \mathrm{l} / \mathrm{min}$. & \\
\hline Velocidade de alimentação & $14,4 \mathrm{~m} / \mathrm{min}$ & \\
\hline DBCP & $20 \mathrm{~mm}$ & \\
\hline Stick-out & $15 \mathrm{~mm}$ & Geometria \\
\hline Ângulo e Inclinação da tocha & $90^{\circ}$ e $0^{\circ}$ & Heat input - $1057 \mathrm{~J} / \mathrm{mm}$ \\
\hline Comprimento do Arco & 0 & Garg. Teórica - 4,04mm \\
\hline Indutância & 0 & Perna Hor. $-4,81 \mathrm{~mm}$ \\
\hline Processo & MIG/MAG Synergic-Pulse & Perna Vert. $-7,48 \mathrm{~mm}$ \\
\hline
\end{tabular}

Tabela 6: Referente ao corpo de prova 4

Fonte: O próprio autor 


\begin{tabular}{|l|l|l|}
\hline Parâmetros de soldagem & Valores / Unidades & \multirow{2}{*}{ Figura 7 - corpo de prova 5 } \\
\hline Corrente & $250 \mathrm{~A}$ & \\
\hline Tensão & $28,9 \mathrm{~V}$ & \\
\cline { 1 - 2 } Diâmetro do arame & $1 \mathrm{~mm}$ & \\
\cline { 1 - 2 } Velocidade de soldagem & $5 \mathrm{~mm} / \mathrm{s}$ & \\
\hline Gás de proteção & $85 \%$ Ar e $15 \% \mathrm{CO}_{2}$ & \\
\hline Vazão dos Gases & $7 \mathrm{l} / \mathrm{min}$. & \\
\hline Velocidade de alimentação & $14,4 \mathrm{~m} / \mathrm{min}$. & \\
\hline DBCP & $20 \mathrm{~mm}$ & Geometria \\
\hline Stick-out & $15 \mathrm{~mm}$ & Heat input $-1445 \mathrm{~J} / \mathrm{mm}$ \\
\hline Ângulo da tocha & $90^{\circ}$ e $0^{\circ}$ & Garg. Teórica $-4,42 \mathrm{~mm}$ \\
\hline Comprimento do Arco & 0 & Perna Horiz. $-6,22 \mathrm{~mm}$ \\
\hline Indutância & 0 & Perna Vert. $-6,30 \mathrm{~mm}$ \\
\hline Processo & MIG/MAG Synergic-Pulse & \\
\hline
\end{tabular}

Tabela 7 - Referente ao corpo de prova 9

Fonte: O próprio autor

\begin{tabular}{|l|l|l|}
\hline Parâmetros de soldagem & Valores / Unidades & \multirow{3}{*}{ Figura 8 - corpo de prova 6} \\
\hline Corrente & $280 \mathrm{~A}$ & \\
\hline Tensão & $30,3 \mathrm{~V}$ & \\
\hline Diâmetro do arame & $1 \mathrm{~mm}$ & \\
\hline Velocidade de soldagem & $10 \mathrm{~mm} / \mathrm{s}$ & \\
\hline Gás de proteção & $85 \% \mathrm{Ar}$ e $15 \% \mathrm{CO}_{2}$ & \\
\hline Vazão dos Gases & $7 \mathrm{l} / \mathrm{min}$. & \\
\hline Velocidade de alimentação & $17,6 \mathrm{~m} / \mathrm{min}$. & \\
\hline DBCP & $20 \mathrm{~mm}$ & Geometria \\
\hline Stick-out & \multicolumn{2}{|l}{ Heat input $-848 \mathrm{~J} / \mathrm{mm}$} \\
\hline Ângulo e Inclinação da tocha & $90^{\circ}$ e $0^{\circ}$ & Garg. Teórica $-4,75 \mathrm{~mm}$ \\
\hline Comprimento do Arco & 0 & Perna Horiz. $-6,20 \mathrm{~mm}$ \\
\hline Indutância & 0 & Perna Vert. $-7,40 \mathrm{~mm}$ \\
\hline Processo & MIC/MAG Synergic-Pulse & \\
\hline
\end{tabular}

Tabela 8 - Referente ao corpo de prova 6

Fonte: O próprio autor 


\begin{tabular}{|l|l|l|}
\hline Parâmetros de soldagem & Valores / Unidades & \multirow{2}{*}{ Figura 9 - corpo de prova 7} \\
\hline Corrente & $315 \mathrm{~A}$ & \\
\hline Tensão & $31 \mathrm{~V}$ & \\
\hline Diâmetro do arame & $1 \mathrm{~mm}$ & \\
\hline Velocidade de soldagem & $6,7 \mathrm{~mm} / \mathrm{s}$ & \\
\hline Gás de proteção & $85 \% \mathrm{Ar}$ e $15 \% \mathrm{CO}_{2}$ & \\
\hline Vazão dos Gases & $7 \mathrm{l} / \mathrm{min}$. & \multirow{2}{*}{} \\
\hline Velocidade de alimentação & $21 \mathrm{~m} / \mathrm{min}$. & Geometria \\
\hline DBCP & 20 & Heat input $-1457 \mathrm{~J} / \mathrm{mm}$ \\
\hline Stick-out & 15 & Garg. Teórica $-4,48 \mathrm{~mm}$ \\
\hline Ângulo e Inclinação da tocha & $90^{\circ}$ e $0^{\circ}$ & Perna Hor. $-5,72 \mathrm{~mm}$ \\
\hline Comprimento do Arco & 0 & Perna Vert. $-7,2 \mathrm{~mm}$ \\
\hline Indutância & 0 & \\
\hline Processo & MIG/MAG Synergic-Pulse & \\
\hline
\end{tabular}

Tabela 9 - Referente ao corpo de prova 7

Fonte: O próprio autor

\section{CONCLUSÃO}

Com a realização do estudo do processo de soldagem robotizado MAG referente aos aspectos geométricos do cordão de solda e com o objetivo de servir de orientação operacional aos profissionais que trabalham com células de soldagem podem- se tirar as seguintes conclusões:

- O cálculo da energia de soldagem é uma ferramenta importante na otimização do processo de soldagem robotizado MAG, podendo facilmente ser aplicada em uma célula de soldagem, com o objetivo de ganho em aumento de produtividade na execução de cordões de soldas. Mantendo-se a mesma geometria dimensional do cordão de solda.

- Os parâmetros de soldagem utilizados na realização dos cordões de solda nos corpos de provas: 1;2;3;4;5;6 e 7. Apresentaram aspectos geométricos com excelentes características de penetração e dimensional. Possibilitando a utilização destes resultados na aplicação prática em uma célula de soldagem robotizada.

- Pelo método comparativo da dimensão geométrica do cordão de solda é possível produzi-la empregando uma menor quantidade de energia de soldagem.

- É notável em um processo de soldagem robotizado MAG a economia do gás de proteção, verificada através de uma programação específica, a real vazão dos gases de proteção, aferido no bocal da tocha com o auxílio do aparelho fluxômetro. 
- A definição dos melhores parâmetros de soldagem é um fator de elevada importância no processo de soldagem robotizado MAG devido ao fato dos resultados influenciarem diretamente nos aspectos geométricos dos cordões de solda.

- O conhecimento da programação do robô e da fonte de soldagem aplicado na soldagem robotizada MAG, são complexos devido à existência de inúmeras variáveis do processo.

- As tabelas contendo os principais parâmetros de soldagem associado à imagem das macrografias da região das soldas. Já estabelecidas e otimizadas tornar-se de fácil visualização, aplicação e orientação para o uso no processo de soldagem MAG fatos estes confirmado pelos profissionais envolvidos na célula de soldagem da empresa Axmol, durante a ministração de um minicurso.

\section{REFERÊNCIAS}

ALVES, V. J. Desenvolvimentos de envelopes Operacionais para o processo MIG/MAG com diferentes gases de proteção. Dissertação de Mestrado, Universidade Federal do Rio Grande do Sul, 172 p, 2009.

Welding Handbook v. 1: Welding Science \& Technology. 9 ed. International

Standard Book Number. 08456b6 0016831-2. American Welding Society. 550N. W. LeJeune Rd., P. O. Box 351040, Miami, FL 33135, 2001.

AMERICAN WELDING SOCIETY. ANSI/AWS D1.1/D1.1M: 2004: Structural Welding

Code - Steel, 19th Edition. Miami, Florida: AWS, 2004.

BRACARENSE A., ZEEMANN A., ALMEIDA D., URTADO E., FERRER S., PEREIRA U. A Soldagem GMAW (ou MIG - MAG). Revista de Soldagem: Ensino ABC ABS, a.1, n. 04, 6-17p.

FREITAS, E.N.; BRAGA, E. M.; ASUNÇÃO, P. A.C.; RODRIGUES, L. A. S.; SILVA, I.R.P. Estudo operacional de manipulador robótico aplicado a soldagem na construção naval. In: Libro de Ponencias y Conferencias del XXIII Congresso Panamericano de Ingenieria Naval, Costa Afuera e Ingenieria Portuaria COPINAVAL 2013. Disponível em: <http://www.copinaval.org/venezuela/ downloads/ct_06_14.pdf>. Acesso em: 23 dez. 2014.

GIMENES JR, TREMONTI M. A. Soldagem, Área Metalurgia. São Paulo: SENAI - SP editora, 2013 p.536.

MICHELAN, RENATO FABIO. Dissertação de Mestrado: Prospecções de Novas Possibilidades de Soldagem com Duplo Eletrodo Não Consumível, Florianópolis 2011.

MORGANTI, M. P. S.Monografia de Pós - Graduação: Estudo da Influência do Espaçamento entre Chapas e do Ataque do Arame no Processo Robotizado de Soldagem MIG/MAG de Junta Sobreposta para Arame de 1,2 mm, São Caetano do Sul 2013.

ROMANO, V. F. Robótica industrial - Aplicação na Indústria de Manufatura e de Processos. 1 ed. Edgard Blucher Ltda, São Paulo, 2002.

ROSÁRIO, J. M. Robótica Industrial I - Modelagem, Utilização e Programação. $1^{\text {a }}$ Ed. São Paulo: Baraúna, 2010. 
SCOTTI, A. PONOMAREV, V. Soldagem MIG/MAG. Melhor entendimento, melhor desempenho. São Paulo: Arliber Editora, 2008. 17 p.

SCHNEE, M. "What to know before choosing a robotic welding system" Vol 72, p $49-51$, Welding Journal, Miami, 1996.

WAINER, E; Soldagem. Associação Brasileira dos Metais. 9ª Ed. São Paulo 1976.

ZAWODNY, J. - Welding with the shielding gás. Welding Journal, pp 49 -50, December, 2001. 


\section{SOBRE O ORGANIZADOR}

JOÃO DALLAMUTA Professor assistente da Universidade Tecnológica Federal do Paraná (UTFPR). Graduação em Engenharia de Telecomunicações pela UFPR. MBA em Gestão pela FAE Business School, Mestre pela UEL. Doutorando em Engenharia Espacial pelo INPE, Instituto Nacional de Pesquisas Espaciais. 
ÍNDICE REMISSIVO

\section{A}

Ácidos Graxos 138, 139, 143, 146, 147

Águas Pluviais 25, 26, 27, 28, 31, 33, 38, 39, 40, 43, 45, 55, 76

Algoritmo de Roteamento 120, 123, 126, 127

Algoritmo de Utilização de Regeneradores 120

Análise de Redes Sociais 93, 95, 96, 97, 98, 99, 101, 103, 104

Arquitetura 55, 123, 128, 129, 130, 131, 133, 134, 135, 136

Aspectos Botânicos 170, 171

\section{B}

Biocombustível 161, 162, 164, 165

Biodiesel 3, 13, 161, 162, 163, 164, 165, 166, 167, 168, 169

Biomassa 3, 8, 13, 161

C

Calibração 46, 48, 49, 50, 52, 53, 54

Caraúbas 36, 37, 38, 39, 40, 41, 42, 43, 44

Cluster Comercial 93, 94, 95, 96, 97, 98, 99, 100, 101, 102, 103

Concatenação 128, 129, 135

Conservação de Energia Elétrica 15, 16, 20, 23, 24

Controle de Posição 106, 110, 112, 113, 117, 118, 119

D

Degradação de Estruturas 68

Demanda Energética 1, 2, 7, 8, 9, 10, 12

Desenvolvimento Urbano Sustentável 55

Destilado de Desodorização 138

Drenagem Urbana 25, 37, 38, 40, 43, 44

E

Economia de Energia 15, 22

Eficiência Luminosa 15, 16, 17, 18

Energia Alternativa 161

Equilíbrio Sólido-Líquido 138, 140, 141, 144

Equipamento de Litografia Óptica 106, 108, 110, 111, 112, 118

Escoamentos 25, 27, 29, 30, 31, 33, 56, 62 
Fator de Atrito 46, 49, 50, 52

Filtro Óptico 128, 129, 130, 132

Fotocatálise $80,81,82,89,149,150,151,160$

G

Gestão de Águas Urbanas 36, 38, 44

$\mathbf{L}$

Lixívia Ácida 80, 82, 83, 84, 86, 87, 88, 89, 90, 91, 150, 151, 152, 153, 155, 156, 157, 158, 159

M

Mesa Cartesiana XY 106

Microgravação 106

MIGHA 46, 47, 48, 49, 50, 51, 52, 53

Moagem de Alta Energia 80, 81, 82, 83, 86, 89, 91, 149, 150, 151, 154, 159, 160

Modelagem Termodinâmica 138

$\mathbf{N}$

Nanopartículas 81, 92, 149, 150, 160

Nanopós 81, 149, 150, 151, 152, 153

O

Óleos Essenciais 170, 171

$\mathbf{P}$

Patologias 68, 69

Penalidade Física 128, 129

Propriedades Medicinais 170

Q

Qualidade de Transmissão 120, 121, 128, 129

$\mathbf{R}$

Rede Óptica Elástica 120, 127, 128, 136

Rede Óptica Elástica Translúcida 120, 127, 136

Remoção de Contaminantes 25, 33

Requalificação Ambiental 55, 57, 61, 65

Resiliência a Inundações 55, 57, 60, 62, 65

Roraima 1, 2, 3, 4, 5, 6, 7, 8, 10, 11, 12, 13, 14 
Saneamento Básico 36, 37, 43, 44

Solubilidade $32,138,140,141,142,143,144,145,147,148$

\section{$\mathbf{T}$}

Teatros Públicos 68

$\mathrm{TiO}_{2}$ 81, 82, 83, 85, 86, 87, 88, 89, 90, 91, 92, 149, 150, 151, 152, 153, 154, 155, 156, 157, $158,159,160$

Tratamento de Efluentes 25, 26, 33, 82, 151

Troca de Informações 93, 96, 98, 101, 103 
Agência Brasileira do ISBN

ISBN 978-85-7247-682-9

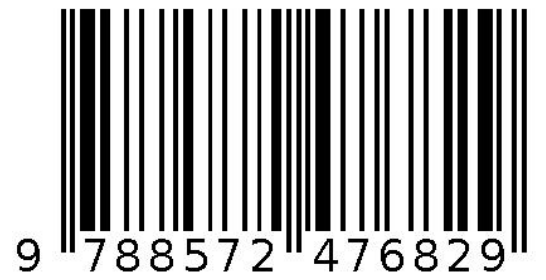

